\title{
In vitro assay systems in the development of therapeutic interventions strategies for neuroprotection and repair
}

Citation for published version (APA):

Gerardo Nava, J. L. (2014). In vitro assay systems in the development of therapeutic interventions strategies for neuroprotection and repair. [Doctoral Thesis, Maastricht University]. Maastricht University. https://doi.org/10.26481/dis.20141209jg

Document status and date:

Published: 01/01/2014

DOI:

10.26481/dis.20141209jg

Document Version:

Publisher's PDF, also known as Version of record

Please check the document version of this publication:

- A submitted manuscript is the version of the article upon submission and before peer-review. There can be important differences between the submitted version and the official published version of record.

People interested in the research are advised to contact the author for the final version of the publication, or visit the DOI to the publisher's website.

- The final author version and the galley proof are versions of the publication after peer review.

- The final published version features the final layout of the paper including the volume, issue and page numbers.

Link to publication

\footnotetext{
General rights rights.

- You may freely distribute the URL identifying the publication in the public portal. please follow below link for the End User Agreement:

www.umlib.nl/taverne-license

Take down policy

If you believe that this document breaches copyright please contact us at:

repository@maastrichtuniversity.nl

providing details and we will investigate your claim.
}

Copyright and moral rights for the publications made accessible in the public portal are retained by the authors and/or other copyright owners and it is a condition of accessing publications that users recognise and abide by the legal requirements associated with these

- Users may download and print one copy of any publication from the public portal for the purpose of private study or research.

- You may not further distribute the material or use it for any profit-making activity or commercial gain

If the publication is distributed under the terms of Article $25 \mathrm{fa}$ of the Dutch Copyright Act, indicated by the "Taverne" license above, 
In vitro assay systems in the development of therapeutic intervention strategies for neuroprotection and repair

\author{
Jose L. Gerardo Nava
}


CJose L. Gerardo Nava, Maastricht 2014

ISBN 978-3-00-048168-0 


\title{
In vitro assay systems in the development of therapeutic intervention strategies for neuroprotection and repair
}

\author{
DISSERTATION \\ To obtain the degree of Doctor at Maastricht University, \\ on the authority of the Rector Magnificus, Prof. dr. L.L.G. Soete \\ In accordance with the decision of the Board of Deans, \\ to be defended in Public on Tuesday $9^{\text {th }}$ of December 2014 \\ by \\ Jose Luis Gerardo Nava \\ Born the $19^{\text {th }}$ of November 1978 in Ciudad Obregón
}




\section{Supervisors}

Univ. Prof. Dr. med. J. Weis, RWTH Aachen

Prof. Dr. H.W.M. Steinbusch

\section{Co-Supervisors}

PD. G.A. Brook, PhD, RWTH Aachen

\section{Assessment Committee}

Prof. Dr. B. Joosten (chairman)

Prof. Dr. M. De Baets

Dr. R. Deumens, Université Catholique de Louvain, Belgium

Dr. A. Des Rieux, Université Catholique de Louvain, Belgium

Prof. Dr. Y. Temel 
«Me, my thoughts are flower strewn, ocean storm, bayberry moon... »

R.E.M. 



\section{Contents}

Chapter $1 \quad 9$

General Introduction

Chapter 23

Tissue Engineering: The central nervous system

Chapter $3 \quad 69$

Human neural cell interactions with orientated electrospun nanofibers in vitro

Chapter $4 \quad 103$

Spinal cord organotypic slice cultures for the study of regenerating motor axon interactions with 3D scaffolds

Chapter $5 \quad 127$

Differential pattern of neuroprotection in lumbar, cervical and thoracic spinal cord in an organotypic rat model of glutamate-induced excitotoxicity.

Chapter $6 \quad 145$

Characterization of the glutamate uptake capacity of the human fetal stem cell line SPC1 and its neuroprotective capacity in a slice culture model for excitotoxicity

Chapter $7 \quad 161$

General Discussion

175

Valorisation

179

Abbreviations

181

Summary/Samenvatting 
183

Acknowledgements

187

Curriculum Vitae

189

List of Publications 


\title{
Chapter 1
}

\author{
General Introduction
}


General Introduction 


\section{General introduction}

Rapid advances in tissue engineering, material sciences and stem cell biology have substantially increased the number of potential therapeutic strategies that may be applied to the field of regenerative medicine for the nervous system, including neuroprotection. The development of novel strategies designed to address problems of neurotrauma and neurodegeneration, require extensive stages of evaluation and characterization to assess their properties as well as suitability of use before testing in experimental animals may take place. First level in vitro studies focus upon establishing the basic properties as well as the characteristics of the designed therapies in the form of drugs, materials or cells, within a highly controlled and reproducible environment. In the context of developing 3D bioengineered scaffolds, purified populations of primary cell cultures or cell lines are confronted with the scaffold in question in an attempt to evaluate the interactions between individual cell types and the designed topography, functionalization, or both. However, while these reductionist paradigms offer valuable information regarding individual cell-substrate interactions, the responses observed, lack the modulatory influence that may be expected from the involvement of other cell types when considering a more realistic tissue response to a particular material or structure. As a result, the use of organotypic slice cultures (OSC) has gained popularity in recent years as a tool to complement single cell type studies. Compared to cell cultures, this tissue, or multi-cell type approach, offers the added advantages of preserved tissue cytoarchtecture and appropriate cell-cell interactions that allow for the characterization of complex tissue responses to either material-based, molecular-based, or cell-based therapeutic strategies within a controlled environment. However, some degree of refinement of such in vitro assay systems is still required if they are to be used for the characterization of the potential role of implantable materials or donor cells in neuroprotection and repair. The use of OSCS is also of major interest because it follows the principles of "replacement, reduction and refinement" in animal experimentation that were established within the European Union directive 2010/63/EU:

\footnotetext{
"When choosing methods, the principles of replacement, reduction and refinement should be implemented through a strict hierarchy of the requirement to use alternative methods. Where no alternative method is recognised by the legislation of the Union, the numbers of animals used may be reduced by resorting to other methods and by implementing testing strategies, such as the use of in vitro and other methods that would reduce and refine the use of animals. "
}

Improving the in vitro models used by scientists in the lab would allow for better identification of the therapies with greater potential, thereby accelerating their further development and reducing the number of animal experiments needed for research. 


\section{Cell-substrate interactions related to axon regeneration}

Severe traumatic injury to the nervous system leads to motor, sensory and autonomic disturbances, which may often be permanent. After trauma, most axons of both the central nervous system (CNS) and the peripheral nervous system (PNS) have the potential to regenerate. However, axonal growth is strongly modulated by its environment, and in the case of the lesioned CNS, axons are confronted by potent growth inhibitory cues, compared with the growth promoting milieu found in the distal nerve stumps of the lesioned PNS. Successful reconnection of the severed axons with their target is the primary objective in nerve regeneration. This is achieved by creating an axon growthpromoting environment that will allow for the restoration of the ascending and descending pathways in the lesioned spinal cord as well as for the reconnection of the proximal and distal stumps of the lesioned PNS, particularly, in large gap-forming lesions. For this purpose, natural and or synthetic scaffolds that contain different materials, topographies, molecules, and cellular components for the repair of both CNS and PNS tissues have been proposed (Schmidt \& Leach 2003). Simple hollow tubes have evolved into complex microstructured conduits, capable of presenting both physical and molecular cues, that are believed to be important for orientated glial cell migration and axonal growth (Deumens et al. 2010; Hodde et al. 2012). In order to develop better materials and bioengineered scaffolds for their use in the field of nerve regeneration, it is of great importance to have a clear understanding of how regenerating axons, and their supporting glial (and non-glial) cells, interact with different topographies and molecular cues.

Simple 2D cultures, in particular, help decipher cell-substrate interactions and how these interactions modulate cell behavior such as growth, morphology and function (Dike et al. 1999; Singhvi et al. 1994). Research on patterned substrates has demonstrated that aligned ECM, as well as micron-scale topography in the form of fibers or grooves, have profound effects on the guidance and orientation of regenerating cells and their processes (Biran et al. 2007; Dubey et al. 2001; Lietz et al. 2006; Murugan \& Ramakrishna 2007; Schmidt \& Leach 2003; Wen \& Tresco 2006). These observations are of relevance for the development of highly aligned biomaterial-based scaffolds capable of promoting the repair of traumatically injured nerves of the PNS and white matter tracts of the CNS (Lietz et al. 2006; Yoshii et al. 2003; Yoshii \& Oka 2001). However, as substrate design moves into the sub-micron range, studying the influence of individual topographical cues on the behavior of cells and their processes has been limited by the difficulty of generating the appropriate test substrates. Therefore, until recently, the evaluation of cell interactions with nanofiber-based materials had to rely on an unsatisfactory approach of employing 
mats or coatings of nanofibers at high densities, making the study of single cell-singe nanofiber interactions difficult. Another important aspect to be considered for the evaluation of topographical cues in 2D bioengineered substrates is the use of the appropriate cell types. In vitro investigations usually rely on the use of cell lines or primary cell suspensions. While protocols for the isolation of neuronal and non-neuronal cells are currently available, much of the reliance on cell lines relates to their ease of use, low maintenance costs, and the ability to generate highly reproducible results. Cell lines have also demonstrated to be of limited relevance as they often undergo senescence, dedifferentiation, and loss of function; effectively misrepresenting the behavior of the cell type of interest (Allen et al. 2005).

The last couple of decades have seen a boom in the development of new manufacturing processes that allow for the production of bioengineered designed 3D structures from biocompatible materials. This has propelled a shift of thinking within the tissue engineering/cell culture field from $2 \mathrm{D}$ to $3 \mathrm{D}$, and has opened the door for the development of new analytical methods that would allow for the in vitro evaluation of 3D constructs. The new challenges presented when evaluating 3D bioengineered constructs go beyond the study of single cell-substrate interactions, commonly assessed with 2D culture systems, and expand upon evaluating the way tissue as a whole responds to the bioengineered constructs. To assess the axon guidance capabilities of bioengineered nerve scaffolds, they are usually co-cultured with neuronal and non-neuronal cells or with tissue explants in vitro (Möllers et al. 2009). To date, the major source of neurons for use in such in vitro investigations has been the dorsal root ganglion (DRG). DRGs have the advantage that they are easy to dissect and can be maintained in culture for extended periods of time (Corey et al. 2007; Schnell et al. 2007). Whole DRG explants or single cell suspensions, allow for tissue and individual sensory neuron interactions with the substrate to be studied. However, motor axon growth is commonly neglected in these studies. Investigations done using the rat femoral nerve have shown that regenerating motor neurons preferentially re-innervate terminal nerve branches connected to muscle as opposed to skin (Brushart 1988). This motor and sensory selectivity is still however poorly understood and is believed to be dependent on cellular and or molecular cues, as described in both in vivo and in vitro models (Allodi et al. 2011; Höke et al. 2006; Madison et al. 2007). These differences highlight the importance of developing assays capable of evaluating the responses of specific adult neuronal sub-populations to novel bioengineered scaffolds. In vivo injury models, such as the spinal cord hemisection model and the sciatic nerve transaction model, are still the standard for the investigation of interactions between regenerating motor axons and bioengineered based substrates (Bozkurt et al. 2012; Deumens et al. 2013). While these models provide reliable information on axonal growth and functional recovery, they present several ethical and practical drawbacks relating to animal experimentation. Injury models are invasive and 
time consuming and require highly technical expertise that, even if performed by skilled personnel, inherently generate significant inter-animal variability requiring large group sizes for statistical validity (Talac et al. 2004). In vitro, the difficulties of culturing motor neurons for extended periods of time have further hindered characterization of motor axon-scaffold interactions. Harvesting primary MN cultures from mouse or rat, commonly obtained from embryonic and adult animals, involve long isolation protocols with minimal yields that are either short lived or require media supplemented with growth factors to achieve long survival times (up to 30 days), thereby increasing their costs (Montoya $\mathrm{G}$ et al. 2009). One of the shortcomings of primary embryonic $M N$ cultures is the intrinsic regenerative capacity of prenatal motor axons which may not reflect that which is exhibited by more mature populations (Bandtlow \& Löschinger 1997; Blackmore \& Letourneau 2006; Shewan et al. 1995). Similar arguments restrict the use of cell lines, where cell differentiation protocols are commonly required to achieve "MN-like" phenotypes but poorly reflect extensive axonal growth as seen in vivo (Maier et al. 2013). In this context, the spinal cord organotypic slice cultures (OSC) is a technique that has proven to be a robust approach for MN-related investigations (Gähwiler et al. 1997). Commonly obtained from mice or rat pups as early as postnatal day 7 , organotypic slices maintain the major cytoarchitectural features observed in the adult spinal cord. At this stage, MN in the slice cultures are capable of further maturation in vitro as demonstrated by the ability of ventral horn acetyl choline esterase positive MN to extend neurites, and the segregation of these neurons into groups similar to those of the Rexed's lamina XI (Delfs et al. 1989). Motor neurons within the OSC extend long axonal processes which grow around the edge of the OSC forming clusters of axons. While these axons have been shown to be redirected to follow the trajectory of explanted peripheral nerve or ventral roots, and grow on growth factor laden hydrogels (Allodi et al. 2011; Vyas et al. 2010), little information has been obtained as to how closely this regenerative process follows that which is observed in the in vivo situation. Further development of the OSC models will allow for the evaluation of axonal regeneration from a tissue perspective by including the response of not only axons, but also glial and non-glial cells, thereby better emulating in vivo conditions. In this regard, the OSC presents a promising model that would allow for the reduction of the number of animals required for similar in vivo studies.

\section{Slice cultures for assaying neuroprotective strategies}

Protecting the integrity of the neurons in the CNS from further degeneration following insult is of great importance. Neuroprotection, in particular that of $\mathrm{MN}$, is a field that extends from $\mathrm{SCl}$ research to motoneuronal diseases (MND), such as amyotrophic lateral sclerosis (ALS), which present a more devastating scenario following the generalized loss 
of upper and lower MN in the chronic stages of the disease (Bäumer et al. 2014; Lau \& Tymianski 2010). While the research field of $M N$ protection is quite vast, there are unifying mechanisms that occur as a consequence of either injury or disease, which contribute to $\mathrm{MN}$ degeneration to a greater or lesser degree. Glutamate induced excitotoxicity is an example of one such mechanism and refers to a pathological state caused by excessive or prolonged exposure to the excitatory neurotransmitter glutamate, resulting in neuronal cell death (Doble 1999). Increased glutamate levels, lead to an over activation of glutamatergic ionotropic receptors (i.e. N-methyl, -D-aspartate [NMDA], aamino-3-hydroxy-5-methyl-4-isoxazole propionate [AMPA], and kainate [KA]) in motor neurons, inducing excessive $\mathrm{Ca} 2+$ influx into the cell, which leads to the death of the MN. Glutamate induced MN death is believed to stem from complex pathways that become activated and prompt the cell to enter into a combined state of apoptosis and necrosis (Emerit et al. 2004; Martin et al. 1998). In spinal cord injury, the initial mechanical events that cause the destruction of grey and white matter at the point of injury are followed by a cascade of secondary degenerative events that include: bleeding, ischemia, free-radical production, edema, excitotoxicity, inflammation, programed cell death, scarring and cyst formation (Schwab \& Bartholdi 1996). From these, glutamate induced excitotoxicity is an important element contributing to $\mathrm{MN}$ cell death. Glutamate concentrations increase acutely to toxic levels minutes after injury and are responsible for the extensive loss of neurons (Liu et al. 1991). Esposito and colleagues showed that, in an in vivo model of SCl, MK-801, a well characterized noncompetitive antagonist of the NMDA receptor, provided increased neuroprotection and reduced damage to the grey matter (Esposito et al. 2011) thereby accentuating the important role excitotoxicity plays as a secondary degenerative event. Similarly, excitotoxicity has been identified as one of the main mechanisms involved in MND (Danbolt 2001). In ALS, chronic accumulation of glutamate in the tissue is believed to stem from alterations to its regulatory mechanisms (Rothstein et al. 1995). The excitatory amino acid transporter 2 (EAAT2; GLT-1 for rodents) is the principal regulator of glutamate levels after synaptic transmission and is primarily expressed in astrocytes. Studies performed in spinal cord tissue from ALS patients as well as rodent models of ALS have shown reduced expression of EAAT2 occurs during disease progression (Anderson \& Swanson 2000; Bendotti et al. 2008; Foran \& Trotti 2009; Rothstein et al. 1995). This reduced expression of the EAAT2 transporter suggests that glial cells are also affected by the disease and are direct contributors to $\mathrm{MN}$ degeneration. Therefore, cell transplantation/replacement therapies using neural stem cells and their astrocytic derivatives have been proposed as a way to re-establish glutamate regulation and prevent motoneuronal loss. The involvement of different cell types in the excitotoxic process mandates that in order to truly evaluate the effects of neuroprotective agents against excitotoxicity, complex multicellular systems are needed, capable of reproducing the intercellular interactions involved in the excitotoxic process. Methods used for the evaluation of new cell-based therapies as MN protective agents, aimed at reducing the 
detrimental effects caused by glutamate induced excitotoxicity, have focused primarily on the use of in vivo models and in vitro slice culture models (Esposito et al. 2011; Maragakis et al. 2005). Selective degeneration of MN in in vivo ALS rodent models has allowed their use as a tool to assess the MN protection afforded by transplantation/replacement therapies using stem cells and their derivatives (e.g. mesenchymal stem cells, neural stem cells and glial progenitors) (Lepore et al. 2008; Zhao et al. 2007). However, the complex scenarios presented by these in vivo models, which involves not only the desired multicellular response, but also includes the multiple mechanisms involved in disease progression, make the interpretation of these results difficult. In vitro slice culture models, on the other hand, part from the premise that the specific mechanism to be studied can be induced in slice culture healthy tissue allowing better observations on the basis of a single input. Long term survival of MN in the spinal cord OSC (up to 3 months) has allowed for the development of in vitro models of acute glutamate induced excitotoxicity and chronic glutamate induced MN degeneration, designed for the evaluation of neuroprotective agents (Guzmán-Lenis et al. 2009; Rothstein et al. 1993). In the OSC model of chronic excitotoxicity, high glutamate levels within the slice culture are achieved by inhibiting the uptake capacity of the glutamate transporters GLT-1 and GLAST, responsible for excess glutamate clearance after synaptic transmission (Rothstein et al. 1993). However, directly tampering with the glutamate uptake machinery of the astrocytic population makes the model unsuitable for the assessment of astrocyte replacement therapies, especially those designed as compensatory glutamate regulators. Acute OSC excitotoxicity models on the other hand, directly introduce high levels of glutamate into the culture medium for short periods of time, producing a toxic environment for the tissue (Guzmán-Lenis et al. 2009). The ability of this model to demonstrate neuroprotective effects by astrocyte replacement/supplementation strategies is, as yet, untested.

\section{Aim and outline of this thesis}

The aim of this thesis was to apply, and to some degree in some aspects, refine in vitro assays systems used for the characterization of cell-substrate interactions as well as for donor cell-tissue interactions. This is of substantial significance in the development of strategies in the field of regenerative medicine and neuroprotection. This included assessing the responses of individual cells to single nanofibers; evaluating the importance of using primary cells for in vitro cell-substrate investigations; as well as the modification of organotypic slice culture technology for the evaluation of emergent therapies for both nerve regeneration and neuroprotection. The questions to be addressed in this thesis are:

- Can deposition of low density nanofibers allow for the evaluation of individual cell - single nanofiber interactions? 
- Do human astrocytoma cell lines respond to topographical and molecular cues? Do these responses reflect those of primary human neural progenitor-derived astrocytes?

- $\quad$ Are the axons from MN present in the slice culture, able to respond to physical cues presented by 3D micropatterned and non-micropatterned substrates?

- Can the MN population in the in vitro organotypic slice culture model of excitotoxicity be further characterized?

- Is the in vitro organotypic slice culture model of excitotoxicity capable of demonstrating the neuroprotective properties of the primary human spinal cord progenitor stem cells (SPC-01)?

Chapter 2 reviews the pathophysiology of $\mathrm{SCl}$ and the development of biomaterials and tissue engineering strategies intended to promote axon regeneration following traumatic injury.

Chapter 3 describes the use of an in vitro assay which takes advantage of the collection of orientated electrospun nanofibers onto glass coverslips at low densities. This permits the study of neural cell-substrate interactions in relatively simple 2D tissue culture systems. In this chapter, the cell line SH-SY5Y underwent differentiation with BDNF and RA into neurite bearing cells and was used to assess neurite interactions with nanofibers. The responses of the U373 astrocytic cell line as well as astrocytes derived from human brain neural progenitors, were compared to determine the extent to which cell lines may reflect behavior of neural progenitor derived astrocytes.

Chapter 4 moves the emphasis from relatively simple 2D in vitro assays to more complex 3D in vitro assays. The particular focus of this chapter is the study of motor axon regeneration from organotypic spinal cord slice preparations into explanted spinal nerve roots as well into 3D scaffolds (in the presence or absence of an engineered microstructure). First, the ability of the nerve root reconstruction model was used to validate the system in the reproduction of events associated with Wallerian degeneration, axon regeneration, and re-myelination in vivo. This was followed by evaluation of axonal growth/infiltration as well as slice culture-biomaterial interactions, and the influence of microstructure on axonal guidance.

Chapter 5 describes the use of the organotypic spinal cord slice preparation to investigate motoneuronal excitotoxicity in complex 3D tissues. For this, a model of MN degeneration through excess glutamate using the spinal cord slice cultures was established. By obtaining slices from different levels of the spinal cord (cervical, thoracic and lumbar) we investigate the effects of glutamate on different sub-populations of motor neurons and their responses to known neuroprotective agents. 
General Introduction

Chapter 6 describes the characterization of an immortalized human fetal spinal cord stem cell line SPC-01 and their astrocytic derivatives and establishes the functional uptake capacity of their glutamate transporters GLT1 and GLAST. This is followed by the assessment of the neuroprotection provided by the SPC-01 cells in the organotypic spinal cord slice model of excitotoxicity.

Chapter 7 summarizes and discusses the findings from the preceding chapters and an overall conclusion of this thesis is presented. 


\section{References}

Allen, D.D., Caviedes, R., Cárdenas, A.M., Shimahara, T., Segura-Aguilar, J. \& Caviedes, P.A., 2005. Cell lines as in vitro models for drug screening and toxicity studies. Drug development and industrial pharmacy, 31(8), pp.757-68.

Allodi, I., Guzmán-Lenis, M.-S., Hernàndez, J., Navarro, X. \& Udina, E., 2011. In vitro comparison of motor and sensory neuron outgrowth in a 3D collagen matrix. Journal of neuroscience methods, 198(1), pp.53-61.

Anderson, C.M. \& Swanson, R.A., 2000. Astrocyte glutamate transport: review of properties, regulation, and physiological functions. Glia, 32(1), pp.1-14.

Bandtlow, C.E. \& Löschinger, J., 1997. Developmental changes in neuronal responsiveness to the CNS myelinassociated neurite growth inhibitor NI-35/250. The European journal of neuroscience, 9(12), pp.2743-52.

Bäumer, D., Talbot, K. \& Turner, M.R., 2014. Advances in motor neurone disease. Journal of the Royal Society of Medicine, 107(1), pp.14-21.

Bendotti, C., Tortarolo, M., Suchak, S.K., Calvaresi, N., Carvelli, L., Bastone, A., Rizzi, M., Rattray, M. \& Mennini, T., 2008. Transgenic SOD1 G93A mice develop reduced GLT-1 in spinal cord without alterations in cerebrospinal fluid glutamate levels. Journal of Neurochemistry, 79(4), pp.737-746.

Biran, R., Martin, D.C. \& Tresco, P.A., 2007. The brain tissue response to implanted silicon microelectrode arrays is increased when the device is tethered to the skull. Journal of biomedical materials research. Part $A$, 82(1), pp.169-78.

Blackmore, M. \& Letourneau, P.C., 2006. L1, beta1 integrin, and cadherins mediate axonal regeneration in the embryonic spinal cord. Journal of neurobiology, 66(14), pp.1564-83.

Bozkurt, A., Lassner, F., O’Dey, D., Deumens, R., Böcker, A., Schwendt, T., Janzen, C., Suschek, C. V, Tolba, R., Kobayashi, E., Sellhaus, B., Tholl, S., Eummelen, L., Schügner, F., Damink, L.O., Weis, J., Brook, G.A. \& Pallua, N., 2012. The role of microstructured and interconnected pore channels in a collagen-based nerve guide on axonal regeneration in peripheral nerves. Biomaterials, 33(5), pp.1363-75.

Brushart, T.M., 1988. Preferential reinnervation of motor nerves by regenerating motor axons. The Journal of neuroscience : the official journal of the Society for Neuroscience, 8(3), pp.1026-31.

Corey, J.M., Lin, D.Y., Mycek, K.B., Chen, Q., Samuel, S., Feldman, E.L. \& Martin, D.C., 2007. Aligned electrospun nanofibers specify the direction of dorsal root ganglia neurite growth. Journal of biomedical materials research. Part A, 83(3), pp.636-45.

Danbolt, N.C., 2001. Glutamate uptake. Progress in neurobiology, 65(1), pp.1-105.

Delfs, J., Friend, J., Ishimoto, S. \& Saroff, D., 1989. Ventral and dorsal horn acetylcholinesterase neurons are maintained in organotypic cultures of postnatal rat spinal cord explants. Brain research, 488(1-2), pp.3142. 


\section{General Introduction}

Deumens, R., Bozkurt, A., Meek, M.F., Marcus, M.A.E., Joosten, E.A.J., Weis, J. \& Brook, G.A., 2010. Repairing injured peripheral nerves: Bridging the gap. Progress in neurobiology, 92(3), pp.245-76.

Deumens, R., Van Gorp, S.F.J., Bozkurt, A., Beckmann, C., Führmann, T., Montzka, K., Tolba, R., Kobayashi, E., Heschel, I., Weis, J. \& Brook, G.A., 2013. Motor outcome and allodynia are largely unaffected by novel olfactory ensheathing cell grafts to repair low-thoracic lesion gaps in the adult rat spinal cord. Behavioural brain research, 237, pp.185-9.

Dike, L.E., Chen, C.S., Mrksich, M., Tien, J., Whitesides, G.M. \& Ingber, D.E., 1999. Geometric control of switching between growth, apoptosis, and differentiation during angiogenesis using micropatterned substrates. In vitro cellular \& developmental biology. Animal, 35(8), pp.441-8.

Doble, A., 1999. The role of excitotoxicity in neurodegenerative disease: implications for therapy. Pharmacology \& therapeutics, 81(3), pp.163-221.

Dubey, N., Letourneau, P.C. \& Tranquillo, R.T., 2001. Neuronal contact guidance in magnetically aligned fibrin gels: effect of variation in gel mechano-structural properties. Biomaterials, 22(10), pp.1065-75.

Emerit, J., Edeas, M. \& Bricaire, F., 2004. Neurodegenerative diseases and oxidative stress. Biomedicine \& pharmacotherapy = Biomédecine \& pharmacothérapie, 58(1), pp.39-46.

Esposito, E., Paterniti, I., Mazzon, E., Genovese, T., Galuppo, M., Meli, R., Bramanti, P. \& Cuzzocrea, S., 2011. MK801 attenuates secondary injury in a mouse experimental compression model of spinal cord trauma. $B M C$ neuroscience, 12, p.31.

Foran, E. \& Trotti, D., 2009. Glutamate transporters and the excitotoxic path to motor neuron degeneration in amyotrophic lateral sclerosis. Antioxidants \& redox signaling, 11(7), pp.1587-602.

Gähwiler, B.H., Capogna, M., Debanne, D., McKinney, R. a \& Thompson, S.M., 1997. Organotypic slice cultures: a technique has come of age. Trends in neurosciences, 20(10), pp.471-7.

Guzmán-Lenis, M.-S., Navarro, X. \& Casas, C., 2009. Drug screening of neuroprotective agents on an organotypicbased model of spinal cord excitotoxic damage. Restorative neurology and neuroscience, 27(4), pp.33549.

Hodde, D., Gerardo-Nava, J.L., Deumens, R., Mey, J. \& Brook, G.A., 2012. Electrospinning of Nanofibres for Repair of the Injured Peripheral Nervous System. In R. J. . Hunter, ed. Nanomedicine and the Nervous System. Science Publishers, pp. 310-346.

Höke, A., Redett, R., Hameed, H., Jari, R., Zhou, C., Li, Z.B., Griffin, J.W. \& Brushart, T.M., 2006. Schwann cells express motor and sensory phenotypes that regulate axon regeneration. The Journal of neuroscience : the official journal of the Society for Neuroscience, 26(38), pp.9646-55.

Lau, A. \& Tymianski, M., 2010. Glutamate receptors, neurotoxicity and neurodegeneration. Pflügers Archiv : European journal of physiology, 460(2), pp.525-42. 
Lepore, A.C., Rauck, B., Dejea, C., Pardo, A.C., Rao, M.S., Rothstein, J.D. \& Maragakis, N.J., 2008. Focal transplantation-based astrocyte replacement is neuroprotective in a model of motor neuron disease. Nature neuroscience, 11(11), pp.1294-301.

Lietz, M., Dreesmann, L., Hoss, M., Oberhoffner, S. \& Schlosshauer, B., 2006. Neuro tissue engineering of glial nerve guides and the impact of different cell types. Biomaterials, 27(8), pp.1425-36.

Liu, D., Thangnipon, W. \& McAdoo, D.J., 1991. Excitatory amino acids rise to toxic levels upon impact injury to the rat spinal cord. Brain research, 547(2), pp.344-8.

Madison, R.D., Robinson, G.A. \& Chadaram, S.R., 2007. The specificity of motor neurone regeneration (preferential reinnervation). Acta physiologica (Oxford, England), 189(2), pp.201-6.

Maier, O., Böhm, J., Dahm, M., Brück, S., Beyer, C. \& Johann, S., 2013. Differentiated NSC-34 motoneuron-like cells as experimental model for cholinergic neurodegeneration. Neurochemistry international, 62(8), pp.1029-38.

Maragakis, N.J., Rao, M.S., Llado, J., Wong, V., Xue, H., Pardo, A., Herring, J., Kerr, D., Coccia, C. \& Rothstein, J.D., 2005. Glial restricted precursors protect against chronic glutamate neurotoxicity of motor neurons in vitro. Glia, 50(2), pp.145-59.

Martin, L.J., Al-Abdulla, N.A., Brambrink, A.M., Kirsch, J.R., Sieber, F.E. \& Portera-Cailliau, C., 1998. Neurodegeneration in excitotoxicity, global cerebral ischemia, and target deprivation: A perspective on the contributions of apoptosis and necrosis. Brain research bulletin, 46(4), pp.281-309.

Möllers, S., Heschel, I., Damink, L.H.H.O., Schügner, F., Deumens, R., Müller, B., Bozkurt, A., Nava, J.G., Noth, J. \& Brook, G.A., 2009. Cytocompatibility of a novel, longitudinally microstructured collagen scaffold intended for nerve tissue repair. Tissue engineering. Part A, 15(3), pp.461-72.

Montoya G, J. V, Sutachan, J.J., Chan, W.S., Sideris, A., Blanck, T.J.J. \& Recio-Pinto, E., 2009. Muscle-conditioned media and cAMP promote survival and neurite outgrowth of adult spinal cord motor neurons. Experimental neurology, 220(2), pp.303-15.

Murugan, R. \& Ramakrishna, S., 2007. Design strategies of tissue engineering scaffolds with controlled fiber orientation. Tissue engineering, 13(8), pp.1845-66.

Rothstein, J.D., Jin, L., Dykes-Hoberg, M. \& Kuncl, R.W., 1993. Chronic inhibition of glutamate uptake produces a model of slow neurotoxicity. Proceedings of the National Academy of Sciences of the United States of America, 90(14), pp.6591-5.

Rothstein, J.D., Van Kammen, M., Levey, A.I., Martin, L.J. \& Kuncl, R.W., 1995. Selective loss of glial glutamate transporter GLT-1 in amyotrophic lateral sclerosis. Annals of neurology, 38(1), pp.73-84.

Schmidt, C.E. \& Leach, J.B., 2003. Neural tissue engineering: strategies for repair and regeneration. Annual review of biomedical engineering, 5, pp.293-347. 


\section{General Introduction}

Schnell, E., Klinkhammer, K., Balzer, S., Brook, G., Klee, D., Dalton, P. \& Mey, J., 2007. Guidance of glial cell migration and axonal growth on electrospun nanofibers of poly-epsilon-caprolactone and a collagen/polyepsilon-caprolactone blend. Biomaterials, 28(19), pp.3012-25.

Schwab, M.E. \& Bartholdi, D., 1996. Degeneration and regeneration of axons in the lesioned spinal cord. Physiological reviews, 76(2), pp.319-70.

Shewan, D., Berry, M. \& Cohen, J., 1995. Extensive regeneration in vitro by early embryonic neurons on immature and adult CNS tissue. The Journal of neuroscience : the official journal of the Society for Neuroscience, 15(3 Pt 1), pp.2057-62.

Singhvi, R., Kumar, A., Lopez, G.P., Stephanopoulos, G.N., Wang, D.I., Whitesides, G.M. \& Ingber, D.E., 1994. Engineering cell shape and function. Science (New York, N.Y.), 264(5159), pp.696-8.

Talac, R., Friedman, J.A., Moore, M.J., Lu, L., Jabbari, E., Windebank, A.J., Currier, B.L. \& Yaszemski, M.J., 2004. Animal models of spinal cord injury for evaluation of tissue engineering treatment strategies. Biomaterials, 25(9), pp.1505-10.

Vyas, A., Li, Z., Aspalter, M., Feiner, J., Hoke, A., Zhou, C., O’Daly, A., Abdullah, M., Rohde, C. \& Brushart, T.M., 2010. An in vitro model of adult mammalian nerve repair. Experimental neurology, 223(1), pp.112-8.

Wen, X. \& Tresco, P.A., 2006. Effect of filament diameter and extracellular matrix molecule precoating on neurite outgrowth and Schwann cell behavior on multifilament entubulation bridging device in vitro. Journal of biomedical materials research. Part A, 76(3), pp.626-37.

Yoshii, S. \& Oka, M., 2001. Peripheral nerve regeneration along collagen filaments. Brain research, 888(1), pp.158-162.

Yoshii, S., Oka, M., Shima, M., Akagi, M. \& Taniguchi, A., 2003. Bridging a spinal cord defect using collagen filament. Spine, 28(20), pp.2346-51.

Zhao, C.-P., Zhang, C., Zhou, S.-N., Xie, Y.-M., Wang, Y.-H., Huang, H., Shang, Y.-C., Li, W.-Y., Zhou, C., Yu, M.-J. \& Feng, S.-W., 2007. Human mesenchymal stromal cells ameliorate the phenotype of SOD1-G93A ALS mice. Cytotherapy, 9(5), pp.414-26. 


\section{Chapter 2}

\section{Tissue Engineering - From Lab to Clinic:}

\section{Central Nervous System}

Tobias Führmann ${ }^{1}$, Jose Gerardo-Nava ${ }^{1}$, and Gary A. Brook ${ }^{1}$

${ }^{1}$ Institute for Neuropathology, Medical Faculty, RWTH Aachen, Aachen, Germany 


\section{Abstract}

This chapter focuses on the development of biomaterials and tissue engineering strategies intended to promote axon regeneration following traumatic injury, in particular, of the CNS following spinal cord injury $(\mathrm{SCl})$. Human $\mathrm{SCl}$ is a condition for which no widely accepted treatment strategies are available apart from the surgical stabilisation of damaged vertebrae followed by intensive rehabilitation. The complexity of the CNS and its response to injury dictates that the latest advances in bioengineering and macromolecular chemistry be implemented in the design of scaffolds intended to promote neuroprotection and functional repair. The reader will be presented with a brief overview of some aspects of the pathophysiology involved in traumatic $\mathrm{SCl}$. The chapter will then highlight some aspects of device design as well as a range of biomaterials, derived from natural and synthetic polymers, which have been developed for applications in traumatic $\mathrm{SCl}$. Issues related to prosthetic devices for electrical stimulation (e.g. cochlear or retinal implants) will not be covered in this chapter. 


\section{Introduction}

This chapter focuses on the development of biomaterials and tissue engineering strategies intended to promote axon regeneration following traumatic injury, in particular, of the CNS following spinal cord injury $(\mathrm{SCl})$. Human $\mathrm{SCl}$ is a condition for which no widely accepted treatment strategies are available apart from the surgical stabilisation of damaged vertebrae followed by intensive rehabilitation. The complexity of the CNS and its response to injury dictates that the latest advances in bioengineering and macromolecular chemistry be implemented in the design of scaffolds intended to promote neuroprotection and functional repair. The reader will be presented with a brief overview of some aspects of the pathophysiology involved in traumatic $\mathrm{SCl}$. The chapter will then highlight some aspects of device design as well as a range of biomaterials, derived from natural and synthetic polymers, which have been developed for applications in traumatic $\mathrm{SCl}$. Issues related to prosthetic devices for electrical stimulation (e.g. cochlear or retinal implants), will not be covered in this chapter.

\section{Aim of the Discipline}

Over recent decades, enormous progress has been made in obtaining a fundamental understanding of the pathophysiology of neurological diseases and disorders, including traumatic $\mathrm{SCl}$. Numerous cellular and molecular mechanisms have been identified as targets for intervention strategies aimed at promoting functional tissue repair and these have shifted the longstanding pessimistic outlook of clinicians and scientists to one of optimism and great hope. Furthermore, recent advances in material sciences have brought closer the notion that biomaterials may contribute to tissue engineering strategies that could compliment future multifactorial approaches in promoting functional tissue repair following $\mathrm{SCl}$. The goal of the use of biomaterials in tissue engineering and regenerative medicine is to replace or restore the anatomic structure and function of damaged or missing tissues following any injury or disease process by combining the topographical cues of biomaterials with cells or bioactive molecules. The development and design of biocompatible polymers for CNS tissue engineering has resulted in the appreciation that ... "This approach requires in-growth and close contact with regenerating neuronal structures and integration of host tissue within and around the implant" (Wu et al. 2001). Providing an axon growth-permissive environment for damaged neural tissue is essential for the regeneration of the injured nervous system. In order to prepare an environment that promotes orientated axon regeneration, the physical, chemical, and biochemical characteristics of the implant must be engineered to ensure the 
presentation of guidance cues that will facilitate axon re-growth across the lesion site and allow the navigation of growth cones back into host tissue, crossing the implant-host interface and extending towards functionally relevant distant targets. Before presenting some of the latest developments in biomaterials and tissue engineering related to CNS repair, the pathophysiology of $\mathrm{SCl}$ will be briefly described to allow an appreciation of the challenges facing the medical and scientific communities aiming to promote the repair of such complex tissues.

\section{State of the Art}

\section{Pathophysiology of Traumatic Spinal Cord Injury}

The devastating consequences, permanent functional loss and a poor prognosis after traumatic $\mathrm{SCl}$ have been well known for thousands of years. The first medical documentation of $\mathrm{SCl}$ was recorded on Egyptian papyrus, dating back to approximately $1500 \mathrm{BC}$ and reported: If you examine a man with a neck injury ..... and find he is without sensation in both arms and legs, and unable to move them, and he is incontinent of urine... it is due to the breaking of the spinal cord by dislocation of a cervical vertebra. This is a condition which cannot be treated (taken from The Edwin Smith Surgical Papyrus, JH Breasted (ed.) The University of Chicago Press, 1930; cited by Raisman (Raisman 2001)). The first indications of the cellular basis for the poor outcome after $\mathrm{SCl}$ were determined by Ramon y Cajal and his students in the early twentieth century using silver impregnated tissue sections of experimental spinal cord lesions. Ramon y Cajal reported that In adult centres the nerve paths are something fixed, ended, immutable. Everything may die, nothing may be regenerated. It is for the science of the future to change, if possible, this harsh decree (Reier et al. 1983).

Traumatic human $\mathrm{SCl}$ is widely acknowledged to be a highly heterogeneous disorder and the characteristics of the lesion site are known to depend on a number of parameters including the type of injury, severity and time after injury. Nonetheless, four main types of injury have been identified (Bunge et al. 1993; Bunge et al. 1997):
1. Compression injury
2. Contusion injury
3. Laceration injury
4. Solid core lesions

This has resulted in the development of a number of experimental models of $\mathrm{SCl}$, which mimic (to a greater or lesser degree) the pathophysiology seen in a range of 26 
different human spinal cord injuries. These models have also been used to investigate the cascade of cellular and molecular events that are initiated by the primary insult, as well as for the development and evaluation of a range of biomaterials designed to promote tissue repair e.g. (Taylor et al. 2004). The permanent motor, sensory and autonomic disturbances caused by severe $\mathrm{SCl}$ are the result of the immediate destruction of numerous descending and ascending nerve fibre pathways and the concomitant disruption of the highly organised cytoarchitecture of the spinal cord white matter. These primary degenerative events also include the mechanical destruction of grey matter at the point of injury and are followed by a cascade of secondary degenerative events including bleeding, ischemia, free-radical production, oedema, excitotoxicity, inflammation, programmed cell death, scarring and cystic cavitation; all of which contribute to the augmentation of tissue loss (Bunge et al. 1993; Kang et al. 2009; Shi \& Borgens 1999) (see Schematic illustration in Fig. 1). The dynamics of the secondary degenerative events may take place over a time scale of hours, days, weeks and even months after the injury. It is now widely acknowledged that the lack of any functionally significant axon regeneration in the lesioned CNS is due to an imbalance of local axon growth promoting and growthinhibitory mechanisms, including the relatively poor expression of neurotrophic factors and guidance cues at the lesion site, as well as the presence of potent molecular and physical barriers to axon growth, for reviews see (Fawcett \& Asher 1999; Houweling et al. 1998; lannotti et al. 2003; Singhvi et al. 1994). Critical experiments of Aguayo and colleagues in the 1980s clearly demonstrated that lesioned CNS axons were capable of mounting a significant regenerative response when presented with the growth permissive environment of a grafted peripheral nerve, many regenerating axons growing for long distances within the graft. However, relatively few axons were able to re-cross the PNSCNS interface to re-enter the CNS (David \& Aguayo 1981; Rocha et al. 2002; Wang et al. 2002a). The biomaterials presented in this chapter have been designed to import growth factors, cells and drugs into the lesion site within a structured framework or scaffold, effectively resetting the balance between growth-promoting and growth-inhibitory cues in favour of tissue repair. Investigations into the mechanisms underpinning the poor sprouting and regenerative growth of CNS axons resulted in the eventual identification of two environmental factors that are widely believed to play major roles in preventing axon regeneration: CNS myelin and the formation of the glial scar.

\section{Myelin-Associated Inhibitors}

The primary and secondary degenerative events caused by traumatic injury release, as debris, a number of potent myelin-associated axon growth-inhibitory molecules into the lesion site and the surrounding tissues. The first of these molecules to be identified was 
NI-35/250 (recently cloned and renamed NOGO-A)(Chen et al. 2000; Grimpe \& Silver 2002; Nomura et al. 2006a). This membrane-bound glycoprotein constitutes only a few percent of the total protein content of mature central myelin, but is an extremely potent inhibitor of axon growth. It induces the rapid, Nogo receptor ( $\mathrm{NgR}$ )-mediated collapse of axonal growth cones by the activation of the small GTP-ase RhoA (Fournier \& Strittmatter 2001; Galtrey \& Fawcett 2007; Nomura et al. 2006a). The development of a monoclonal antibody (IN-1) which blocks the inhibitory activity of NOGO-A has proved to be extremely useful in promoting the regeneration of axotomised corticospinal axons, as well as substantial sprouting and re-organisation of non-lesioned axonal projections (Bareyre et al. 2002; Bregman et al. 1995; Thompson \& Pelto 1982; Zahir et al. 2008). Other potent myelin-associated inhibitors are myelinassociated glycoprotein (MAG) and oligodendrocyte myelin glycoprotein (OMgp), both of which also act via NgR and share the same intracellular signalling pathway (Domeniconi et al. 2002; Wang et al. 2002b; Wang et al. 1998). NOGO-A, MAG and OMgp have also been found to act via a supplementary receptor system, via paired immunoglobin-like receptor B (PirB) (Atwal et al. 2008). Recent investigations have clearly demonstrated that the myelin-associated axon growthinhibitory molecules stabilise the existing connections within the mature CNS and suppress plasticity. In this context, the use of anti-NOGO-A antibodies or blocking peptides has been shown to promote functional recovery by supporting some degree of regeneration by lesioned corticospinal axons as well as compensatory (or collateral) sprouting (Li et al. 2009); see also recent review by (GrandPré et al. 2000).

\section{Astroglial Scarring and Axon Growth-Repulsive Molecules}

The cell types involved in CNS scarring include astroglia, microglia, macrophages and leptomeningeal fibroblasts. Hyperplasia and interdigitation of reactive astrocytic processes during scar formation, combined with the invasion of meningeal fibroblasts and inflammatory cells results in the increased expression of a family of extracellular matrix (ECM) molecules, collectively termed the chondroitin sulphate proteoglycans (CSPG) (Dou \& Levine 1994; Gautier et al. 1998; Murugan \& Ramakrishna 2007). The generation of a tightly packed network of overlapping reactive astrocytic processes and the deposition of new basal lamina form a physical and molecular barrier that is important for the protection of the adjacent, relatively intact nervous tissue from subsequent or ongoing damage (Richardson et al. 1980; Stokols \& Tuszynski 2004). The rapid expression of the highly sulphated proteoglycans in and around the lesion during the early stages of tissue damage and scarring plays a major role in inhibiting axon growth across the scar (Fawcett 2006; Fawcett \& Asher 1999; Gautier et al. 1998; Singhvi et al. 1994). The infusion of the enzyme chondroitinase $A B C$ results in the digestion of the inhibitory sulphated 
glycosaminoglycan side chains of the CSPGs and promotes enhanced axon regeneration and plasticity of long-distance projecting sensory axons and the return of some degree of motor and sensory function (Bradbury et al. 2002; Gautier et al. 1998; Midha et al. 2003).
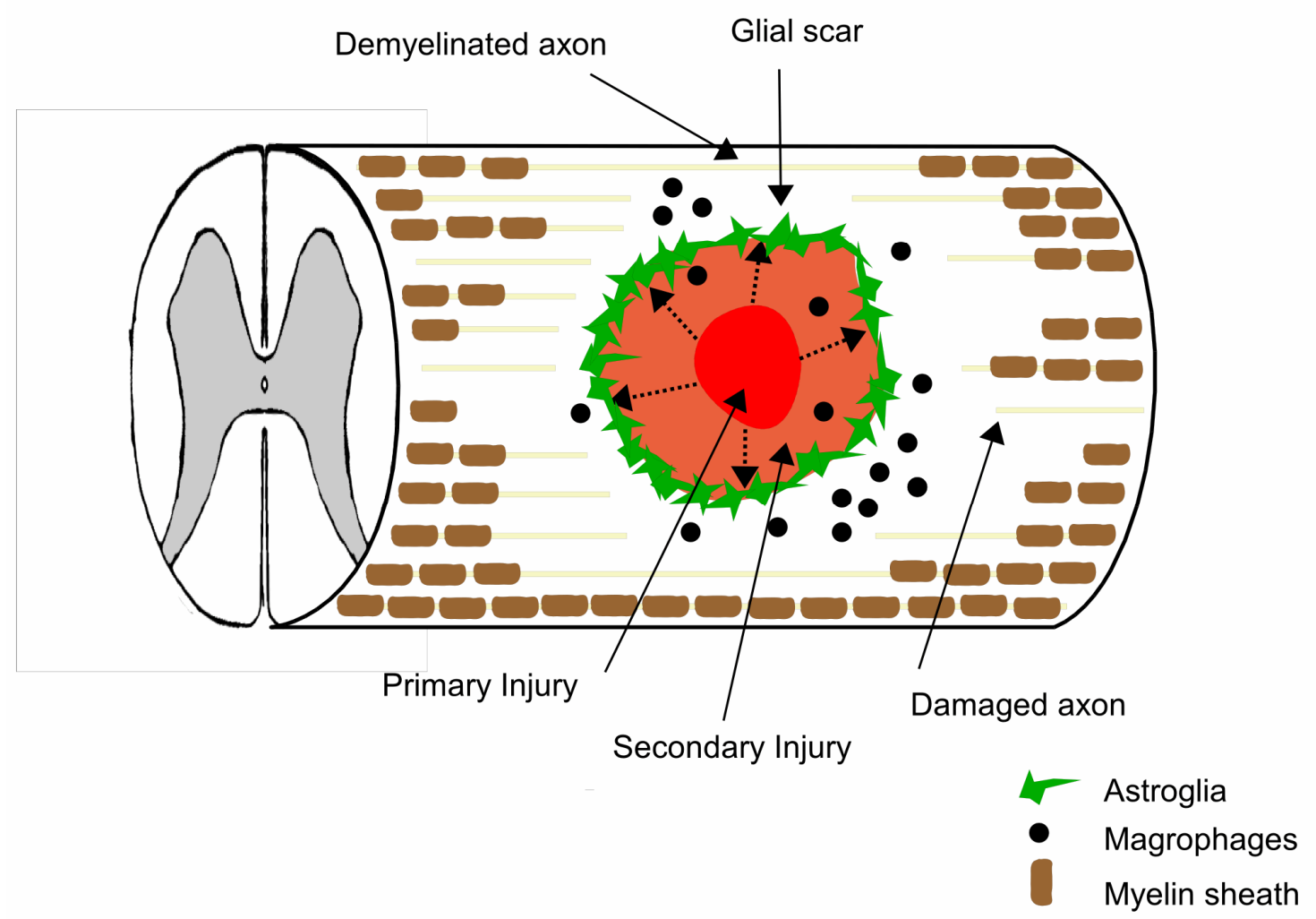

Axons

Fig. 1 Schematic diagram of the pathological events initiated by compression- or contusion-type traumatic injury to the spinal cord. The injury causes rapid degeneration of the neural cell bodies and processes within the spinal cord grey matter at the lesion epicentre, accompanied by local bleeding. The ensuing ischemia, free-radical production, excitotoxicity, inflammation, oedema and programmed cell death all contribute to secondary degeneration which increases the size of the lesion over time. Reactive astrocytes express elevated levels of CSPGs and contribute to scar formation. Oligodendrocytic necrosis and apoptosis result in myelin debris being released at and around the lesion site and some degree of demyelination of spared axons. Mild- and moderate compression and contusion injuries often demonstrate some sparing of axons at the outermost aspect of the white matter.

\section{Other Axon Growth-Inhibitory Molecules}

In addition to the myelin and CSPG-related inhibitory molecules, a number of other extrinsic and intrinsic factors have been shown to exert significant influence over the 
balance between axon growth-inhibitory and promoting mechanisms, including the upregulation of ECM-related molecules such as tenascins, ephrins and semaphorins, (Fawcett 2006; Guo et al. 2007; Patist et al. 2004) as well as the intrinsic neuronal molecules phosphatase and tensin homolog (PTEN), a negative regulator of the mammalian target of rapamycin (mTOR) pathway (Pasterkamp et al. 1999).

\section{Spontaneous Axon Sprouting and Regeneration}

Although no spontaneous functional regeneration of the long-distance projecting axons takes place after $\mathrm{SCl}$, it has become clear that the processes of axonal sprouting and cellular re-organisation that occur after $\mathrm{SCl}$ are more extensive and organised than had previously been appreciated. Experimental models of $\mathrm{SCl}$ (i.e. compression- and lacerating-type injuries) have revealed that the ECM framework deposited during early bleeding in the lesion site supports the migration of different populations of cells, i.e. polymorphonuclear neutrophils, followed by endothelial cells, meningeal fibroblasts, macrophages, activated microglia and Schwann cells (Shi \& Borgens 1999). The presence of migrating Schwann cells appears to tip the balance between growth-promotion vs. growth-inhibition towards the support of axon regeneration, predominantly by populations of local intrinsic spinal cord GABAergic and glycinergic interneurons (Beattie et al. 1997; Brook et al. 1998; Brook et al. 2000; Han et al. 2009). All of the axonal regrowth taking place after compression- and laceration-type injuries is associated with a framework of overlapping Schwann cell bodies and processes which present the important growth-promoting cell adhesion molecule, L1 (Brook et al. 2000) (see schematic illustration in Fig. 2). The framework is remarkable in that, in many places, it demonstrates a high degree of orientation, in parallel with the longitudinal axis of the spinal cord. Similar observations of orientated Schwann cells and axons have been reported to form following human spinal cord lesions (Wen \& Tresco 2006). An even more striking, plasticitymediated, return of function has been demonstrated following partial thoracic (hemisection-type) injuries (Bareyre et al. 2004). Lesioned lumbar projecting corticospinal axons were found to sprout and innervate short- and long-distance projecting propriospinal neurons (PSN). With time, contacts with the short-distance projecting PSN were lost, while those with the long-distance projecting PSN were maintained. The longdistance projecting PSN extended synaptic contacts to include de-afferented lumbar motoneurons. The spontaneously sprouting corticospinal axons thus established contacts which effectively by-passed the lesion site (Bareyre et al. 2004). A better understanding of the regulation and restrictions of these spontaneous events may lead to the identification and manipulation of novel targets which enhance and maintain endogenous tissue repair processes. Clearly, the optimal design of biomaterials for promoting tissue repair across spinal cord lesions will need to support and enhance the endogenous tissue repair 30 
mechanisms. Since many populations of CNS neurons and their local circuits, both rostral and caudal to the lesion site, remain intact following $\mathrm{SCl}$ (e.g. the central pattern generator for stepping movements) (Feraboli-Lohnherr et al. 1997), substantial effort has been spent trying to promote functional repair by re-connecting severed nerve fibres to their original targets. These endeavours have been encouraged by the fact that only a small percentage $(1-10 \%)$ of the original nerve fibre projection is needed for the maintenance of useful motor or sensory function (Fehlings \& Tator 1995; Liang et al. 2004). Over recent years, a range of increasingly sophisticated natural and synthetic polymer nerve guides and hydrogels have been developed in an attempt to bridge spinal cord lesions, supporting optimal graft-host integration to allow axon regeneration across both the interfaces (i.e. rostral and caudal) of the implant-host transitional zone. Such biomaterials have been engineered to present physical or haptotactic guidance cues with key cellular and molecular components.

\section{Design of Implantable Biomaterials for SCI}

\section{Hollow Conduits}

One of the simplest physical guides for nerve repair is the hollow conduit or nerve guide which is intended to span the gap created by experimental $\mathrm{SCl}$. Such cylindrical conduits needed to be flexible, sterile and permeable to gaseous exchange, as well as demonstrating properties that do not lead to irritation or mechanical damage of adjacent spinal cord tissues. The advantage presented by such simple conduits includes the ability to load additional elements into the hollow centre, including axon growth-promoting glia, bioactive molecules, drugs and orientated microstructures (Dalton \& Mey 2009; GerardoNava et al. 2009; Schnell et al. 2007; Xu et al. 1995b; Xu et al. 1997; Yamada \& Olden 1978), Fig. 3, adapted from (Hulsebosch 2002). The choice of the cell types to be loaded into the hollow conduits have included peripheral glia (e.g. Schwann cells, olfactory ensheathing cells) as well as neural progenitor cells (Chen et al. 1996; Phillips et al. 2004; Xu et al. 1995b; Xu et al. 1997; Xu et al. 1999; Zhong et al. 2006) (Ramon y Cajal 1928a). An issue of considerable importance for the use of hollow conduits (or any three-dimensional biomaterial based scaffold) in the repair of $\mathrm{SCl}$ is that most compression- and contusiontype injuries demonstrate some (limited) degree of recovery over the first months post insult, e.g. (Fawcett 2006). Much of this functional recovery is due to the conduction of impulses along spared axons that occupy the outermost rim of the spinal cord white matter. The preservation of these axons and the modalities that they subserve is of utmost importance to the maintenance of any residual function of the $\mathrm{SCl}$ patient. Any intervention strategy (including the implantation of biomaterials) should aim to cause minimal disruption or damage to the survival and function of these spared axons. 

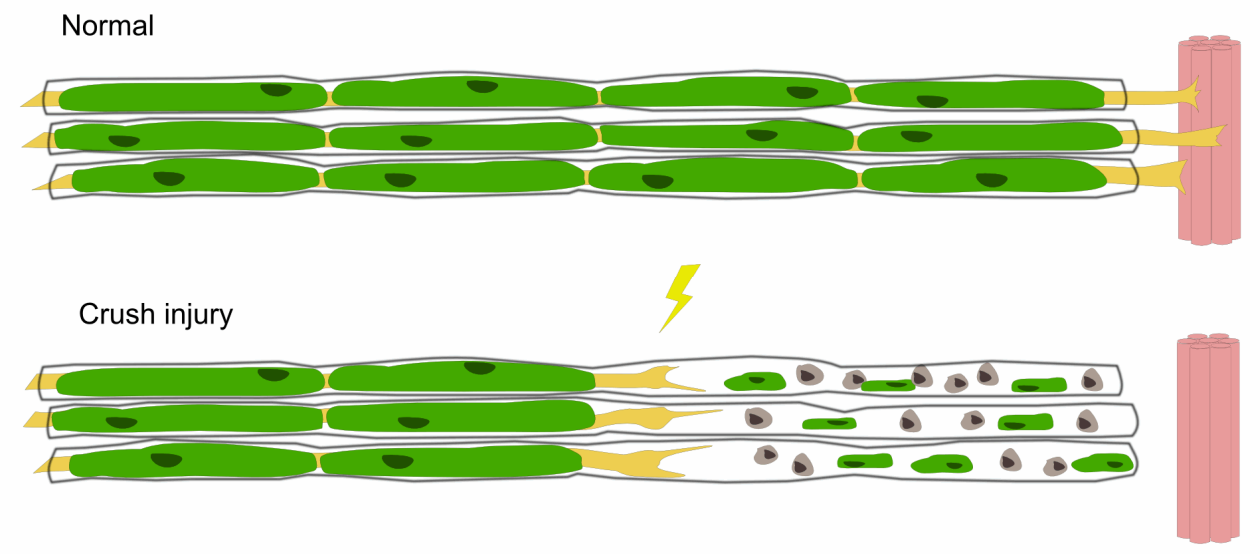

Sucessful regeneration
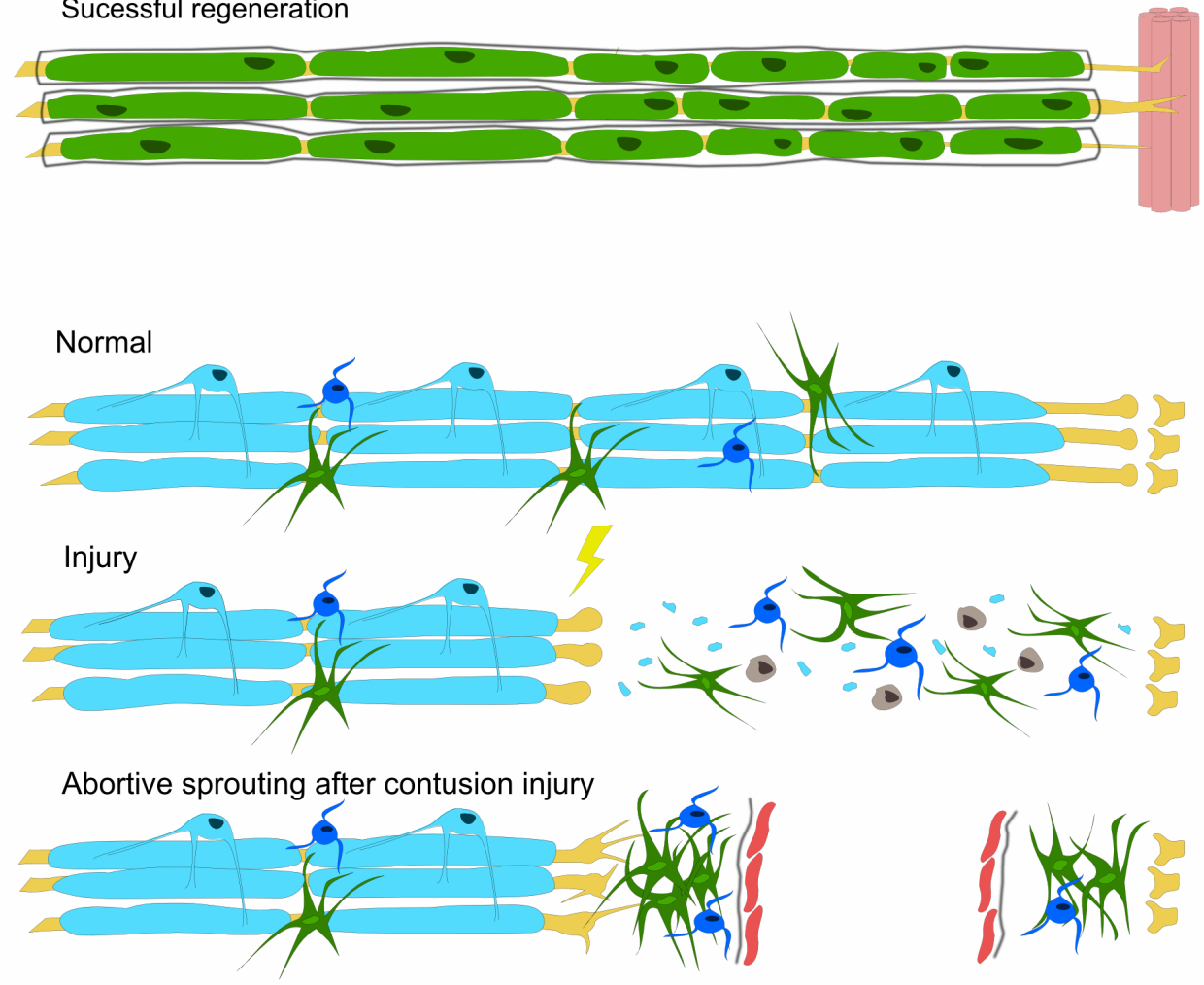

Attempted tissue repair after compression injury

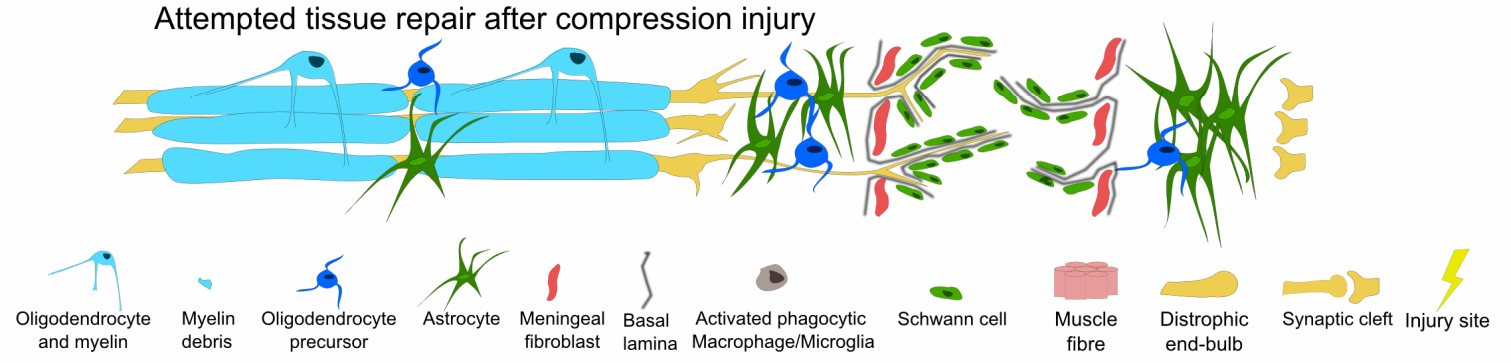


Fig. 2 Schematic diagram illustrating the differences in tissue responses between lesioned nerve fibres in the PNS and those in the CNS white matter tracts. The upper three panels represent PNS injury and the lower four panels represent CNS injury. In the upper top three panels, injury causes local destruction of axons and Schwann cells. Wallerian degeneration of the distal stump involves axon fragmentation and Schwann cell proliferation within the basal lamina tubes. Sprouting axons regenerate along the Schwann cell-filled basal lamina tubes (bands of Büngner), eventually reaching their targets and re-establishing neuromuscular junctions. In the lower four panels, injury also causes the local destruction of axons and glia, followed by a slower Wallerian-type degeneration. In contusion-type injuries, the rapid migration of leptomeningeal fibroblasts into the lesion site and their interactions with reactive astrocytes causes the deposition of basal lamina at the scarring interface, the interior of the lesion usually progressing to cystic cavitation. In compression-type injuries, the migration of Schwann cells (from damaged spinal nerve roots) and leptomeningeal cells causes the establishment of a framework within the lesion that is capable of supporting axon regeneration, largely from local spinal cord interneurons. In all cases of spinal cord injury, the lesioned long-distance projecting axons do not regenerate to their original targets.
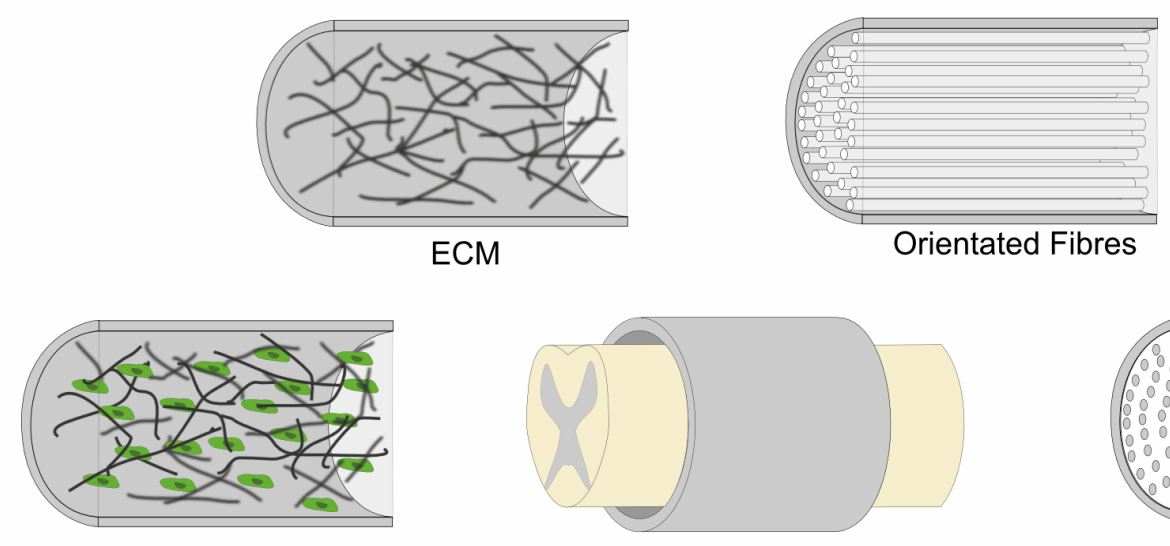

$\mathrm{ECM}+$ Glia
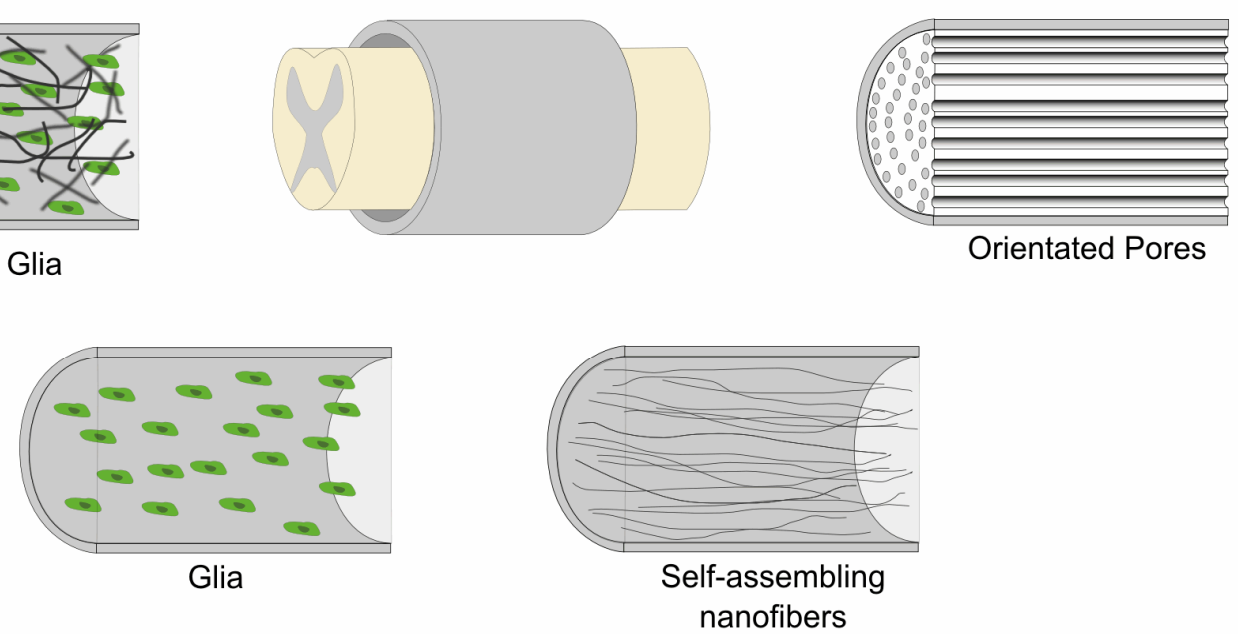

Fig. 3 Schematic representation of the versatility of hollow conduit design for spinal cord injury. The transacted spinal cord can be bridged by the implantation of hollow conduits loaded with a range of axon growth-promoting cells, molecules or drugs including: ECM, peripheral glia, ECM and peripheral glia, selfassembling nanofibers, clusters of orientated electrospun nano- or extruded microfibers as well as scaffolds containing an orientated micro-porous structure. 
Hydrogels

Hydrogels are cross-linked networks of insoluble hydrophilic polymers that swell in aqueous solutions (Tysseling-Mattiace et al. 2008). The elastic modulus of hydrogels may be very similar to the host CNS tissues they will be implanted into and their gel-like consistency affords them the advantage of readily filling the hollow conduits or of being able to adopt to irregular lesion conformations, making them particularly useful for soft tissue repair (Balgude et al. 2001; Tysseling-Mattiace et al. 2008; Woerly et al. 2001a). The high water content and loose 3D network of hydrogels facilitates cell adhesion and proliferation, supported by the ready exchange of nutrients and metabolites between the implant and the host (Hejcl et al. 2008b; Prádný et al. 2005). Hydrogels can also be designed for the encapsulation and timed release of bioactive molecules such as growth factors or DNA (Johnson et al. 2009). The local gelation of hydrogels after injection into the CNS lesions may be induced by mechanisms such as ionic cross-linking (Holmes et al. 2000) or temperature changes (Lietz et al. 2006).

\section{Topographical Cues and Patterning}

Defining the mechanisms by which substrate topography and chemical composition influence the cell form and function has become a subject of increasing interest in the field of biomaterials and tissue engineering (Dike et al. 1999; Smeal et al. 2005). Although the crucial experiments performed by Ingber and colleagues employed non-neural cells, the striking influence of substrate topography on cell shape and function has become clear. Using contact micro-printing to generate "islands" and "tracks" of cell-adhesive ECM surrounded by non-adhesive regions, hepatocyte cell spreading and proliferation could be controlled to the extent that the cells seeded onto small islands underwent programmed cell death. Furthermore, culturing capillary endothelial cells on the tracks of ECM of varying width markedly influenced cell differentiation; cells grown on $20 \mu \mathrm{m}$-wide tracks underwent only a moderate degree of spreading but cooperated with each other, differentiating to form tubular (capillary-like) structures. Such cooperation and differentiation could not be observed when the cells were grown on $30 \mu \mathrm{m}$-wide tracks (Chen et al. 1997; Chen et al. 1998; Dike et al. 1999; Smeal et al. 2005). The principles highlighted by Ingber and colleagues have spurred investigations into the effect of substrate topography on a range of cell types including neural cells of the PNS and CNS. It has become clear that mechanical cues can assist in the guidance of growing axons. A promising aspect to patterned substrate research has been the demonstration that aligned ECM, as well as micron scale topography of fibres or grooves have profound effects on the guidance and orientation of regenerating cells and their processes (Biran et al. 2007; Dubey et al. 2001; Liu et al. 2001; Niederöst et al. 2002). This is of particular 
interest for the development of biomaterial-based scaffolds capable of promoting the functional repair of traumatically injured nerves of the PNS or white matter tracts of the CNS (Liu et al. 2001; Yoshii et al. 2003; Yu \& Bellamkonda 2001). For example, in vitro studies have demonstrated the influence of fibre diameter on the orientation of process outgrowth. The greater surface curvature of small diameter fibres prompted an increasing tendency for neurite outgrowth to follow the longitudinal axis of the fibres; small calibre fibres (5-30 $\mu \mathrm{m}$ diameter) promoted much greater orientated process growth than large calibre fibres (up to $500 \mu \mathrm{m}$ diameter). This phenomenon is due to the topological effect of the fibre on neurite growth (Smeal \& Tresco 2008; Sofroniew 2005). The orientation and microstructure of pores within sponges has also been demonstrated to exert a directional influence on the processes of neurons and glia. Sponges with diameters of approximately $50 \mu \mathrm{m}$ are capable of promoting the orientated migration of a range of glia including Schwann cells, olfactory ensheathing cells and astrocytes. Furthermore, directional axonal growth from dorsal root ganglia (DRG) and neuronally differentiated human SH-SY5Y neuroblastoma has been demonstrated (Bozkurt et al. 2007; Bozkurt et al. 2009).

\section{Nanofibres}

Recent advances in nanotechnology and renewed focus on electrospinning has led to the innovation and potential advantage of engineering biomaterials as orientated fibres with sub-micron diameters, thus presenting directional axon growth-promoting cues with a significantly enhanced surface to mass ratio. Our group has demonstrated a novel method for electrospinning highly orientated fibres (up to several $\mathrm{cm}$ in length) that can be transferred and stabilised at either high or low density on flat surfaces, allowing the interactions between single cells and single fibres to be observed in vitro over a number of days (Schoof et al. 2001). The ability of fibres with diameters in the sub-micron range to affect the behaviour of nonneural cells (Moellers et al. 2004; Suzuki et al. 1999) as well as neural cells of the PNS and CNS has recently been demonstrated using in vitro assays (Corey et al. 2007; Giannetti et al. 2001; Schoof et al. 2001). Cell adhesion, survival and proliferation were well supported, but morphology and alignment were strikingly altered by orientated nanofibres. Orientated fibres promoted longer axonal extension than nonorientated fibres (Corey et al. 2007; Corey et al. 2008), but fibre composition was also found to play a role; functionalisation of polycaprolactone (PCL) fibre surfaces with type I collagen (C/PCL) increased cell adherence, proliferation and process extension of PNSrelated cells (Schoof et al. 2001); however, neural progenitor-derived astroglia showed different interactions with adhesion and process length being unaffected by collagen-I functionalisation of the fibres. Astrocytic migration was the only parameter to be 
enhanced by the presence of collagen on the surface of the nanofibres (Giannetti et al. 2001). Thus, it is clear that nanofibres may play a significant role in future scaffold designs intended to promote CNS axon regeneration.

\section{General Considerations for Implantable Biomaterials for CNS Applications}

A number of general issues need to be borne in mind when considering the choice of biomaterial and the design of scaffolds intended to promote the repair of the traumatically injured spinal cord, including:

1. Biocompatibility, minimising adverse tissue reactions in vivo

2. Topographic cues for orientated tissue integration

3. Cytocompatibility, promoting optimal cell adhesion, migration and axon outgrowth

4. Physical properties (elasticity, strength, deformability) that approach those of the host tissue

5. Biodegradability with the production of non-toxic by-products

Although degradability has been identified as an ideal property for a biomaterial intended for CNS repair, non-degradable materials have also been investigated. The following section describes the use of both degradable and non-degradable natural and synthetic polymers.

\section{Biomaterials Developed for SCI: Natural Polymers}

\section{Collagen}

Collagen is one of the major ECM proteins, accounting for up to $30 \%$ of the total protein in the human body. Collagens are among the most popular materials in bioengineering, being applicable to both soft- and hard tissue (e.g. bone) reconstruction (Rochkind et al. 2002). In comparison to many synthetic polymers, biomaterials made from collagen offer several advantages, including biocompatibility, nontoxic degradation products and the induction of minimal foreign body responses (Ruszczak \& Friess 2003; Schmidt \& Leach 2003). In vitro studies have shown that collagen promotes neural cell attachment as well as neurite outgrowth (Carbonetto et al. 1983; Tian et al. 2005); it is amenable to the controlled manipulation of its shape, microstructure and stability and has already been 36 
fabricated in the form of tubular guidance channels for peripheral nervous system (PNS) repair e.g. (Jain et al. 2006) and CNS repair, e.g. (Loh et al. 2001). Bridging the transected spinal cord with collagen gels has induced vascularisation of the implant and resulted in the regrowth of small numbers of myelinated axons from the host spinal cord, even when combined with neurotrophic factors, such as brain-derived neurotrophic factor (BDNF) or neurotrophin-3 (NT-3) (Houweling et al. 1998; Hung et al. 1981; Kakulas \& Taylor 1992; de la Torre 1982; Massey et al. 2006). However, care must be taken when using collagen in the form of a gel because, if used at too high a concentration, it may act as a physical barrier to axon regeneration (Mo et al. 2004). Furthermore, the use of collagen alone as a matrix-filling for hollow guidance conduits that were implanted into spinal cord transection injuries was found to promote the regeneration of a relatively small number of brain stem neurons (Tsang \& Bhatia 2004). However, the use of thin sheets of polymerised collagen as supports for highly purified Schwann cells that could be rolled into orientated tube-like structures and implanted into dorsal spinal cord resection injuries has resulted in the regeneration of numerous myelinated and non-myelinated host axons (Park et al. 2008).

Apart from the choice of material, the orientation and micro-structuring of the scaffold will have an enormous influence on its suitability as a bridging device. Recently, extruded collagen microfibers (20-30 $\mu \mathrm{m}$ diameter) have been used to promote a partial functional recovery in experimental models of complete spinal cord transection injuries (Yu \& Bellamkonda 2001). Instead of the surface of collagen fibres providing the orientational cue, collagen scaffolds or sponges with parallel oriented micro-pores have been engineered by a patented directional freezing process (Schwab \& Bartholdi 1996). Video microscopy of the synchronous, orientated growth of ice-crystals used to form uniformly orientated pores within a collagen solution can be seen at the following web site: http://www.optimaix.com/html/product.html. The rate of degradation of the freezedried collagen- based scaffolds can be modified by chemical cross-linking, e.g. using 1ethyl-3(3-dimethylaminopropyl) carbodiimide (EDC) (Oudega et al. 2001) and scaffolds can be sterilised with $25 \mathrm{kGy}$ gamma irradiation prior to use. Such orientated microporous collagen scaffolds have been found to be cytocompatible with a range of PNS and CNSrelated cell types. Investigations of the cell-substrate interactions of neuronal and non-neuronal cell types, including dorsal root ganglion neurons, Schwann cells, fibroblasts, olfactory nerve ensheathing cells (OEC) and astrocytes, have demonstrated excellent adhesion and process extension as well as orientated migration following the longitudinal axis of the microporous channels (Bozkurt et al. 2007; Bozkurt et al. 2009; Morgenstern et al. 2002). Implantation of OEC seeded scaffolds into mid-cervical resection injuries of the adult rat spinal cord have resulted in substantial orientated growth by axonal and vascular elements as well as improvements in behavioural tasks (Möllers et al. 2009). 
Recent advances using collagen scaffolds have involved the fusion of growth factors (e.g. BDNF) to orientated collagen fibres via a linker polypeptide (possessing a collagen binding domain). The orientated collagen fibres supported PC12 cell survival and longitudinally directed axon regeneration from DRG in vitro. Implantation of the BDNFlinked collagen fibres into mid-low thoracic spinal cord hemisections promoted host axonal regeneration and improvement of locomotor function (He et al. 2009).

\section{Fibronectin}

Fibronectin (FN) is an ECM glycoprotein involved in a number of cell and tissue events, including blood clotting, cell adhesion and migration (Yoshii \& Oka 2001). Adherence and axon extension by CNS neurons over FN substrates have been shown to be dependent on the interactions with the RGD (arginine, glycine, aspartate) peptide sequences of this ECM molecule (Ruszczak 2003). Mats of fibronectin have demonstrated excellent cytocompatibility with Schwann cells and astrocytes in vitro (Piantino et al. 2006); however, their use to promote repair after $\mathrm{SCl}$ has proved rather disappointing. It was reported that orientated regeneration of some populations of host axons, including calcitonin gene- related peptide (CGRP)-positive and substance P-positive sensory axons, GABAergic, cholinergic and noradrenergic axons, was supported by grafts of naïve (untreated) FN mats (King et al. 2004). However, axons generally failed to re-enter the host tissues, even when combined with a range of neurotrophins, e.g. nerve growth factor (NGF), BDNF or NT-3, or with the coapplication of anti-transforming growth factor-b antibodies that were intended to interfere with the scarring process (King et al. 2006; Klinkhammer et al. 2009).

\section{Fibrin}

Fibrin is a fibrous protein involved in blood clotting, where it is polymerised to form a "mesh" which, in combination with the platelets, acts as a haemostatic clot at the site of blood vessel injury. Fibrin is generated by the action of thrombin on the soluble plasma glycoprotein, fibrinogen, and is cross-linked by factor XIV to form a clot. It has proved possible to manipulate the organisation of the fibrin matrix in a controlled manner by applying high-strength magnetic fields (4.7 and 9.4 T) during fibril polymerisation (Dubey et al. 2001). Fibre diameter and alignment exerted significant effects on neurite outgrowth from dorsal root ganglion explants in vitro: fibrin fibres with diameters of $460 \mathrm{~nm}$ provided better guidance and support for neurites than those with diameters of approximately 150 $\mathrm{nm}$; furthermore, aligned fibres supported longer growth than randomly orientated fibres 
(Dubey et al. 2001). The inclusion of fibrin matrix into hollow synthetic conduits has been particularly successful in promoting the regeneration of axons from reticulospinal neurons with concomitant improvement of locomotor function (BBB open field rating) following implantation into complete spinal cord transections (Tsang \& Bhatia 2004). Although fibrin has been used for the controlled release of the neurotrophin NT-3 into complete spinal cord transections and has been reported to induce a qualitatively stronger regenerative response by neurofilament (NF)-positive axons at 9 days post implantation (Teng et al. 2002), the longer-term effects (8 weeks) on axonal growth were not significantly different from those induced by fibrin alone (Tsang \& Bhatia 2004). Furthermore, the ability of the NT-3 releasing fibrin matrix to support axon regeneration from brain stem neurons was (for reasons unknown) substantially inferior to that supported by fibrin alone (Tsang \& Bhatia 2004). Recently, the implantation of pre-polymerised fibrin scaffolds into T9 dorsal spinal cord hemisections has been performed at the sub-acute stage ( 2 weeks) after injury - reflecting a time scale that would be more realistic for the future treatment of spinal cord-injured patients (Jones et al. 2001). Implanted scaffolds reduced GFAP-positive astrocytic scarring and supported host axon regeneration into the scaffold that was often associated with NG2-positive cellular structures (probably newly formed blood vessels), but no significant improvement of function could be detected (Jones et al. 2001).

\section{Alginate}

Alginate is a polyanionic co-polymer predominantly derived from the cell walls of brown algae (in particular, seaweed). Implantation of alginate into complete spinal cord transection injuries of young and adult rats has been shown to reduce the expression of growth inhibitory CSPGs and to promote the regeneration of descending and ascending populations of host axons with the recovery of some degree of motor-evoked and somatosensory function (Khor \& Lim 2003; Talac et al. 2004; Taylor et al. 2004). Furthermore, anterograde tracing techniques have demonstrated regenerating axons leaving the implant to integrate with de-afferented spinal cord tissue (Talac et al. 2004; Tsai et al. 2004). Alginate has also been reported to act as a cell carrier capable of preventing the rejection of non-autologous fibroblast as well as supporting the survival and eventual migration of neural progenitors into adjacent host spinal tissues (Prinjha et al. 2000; Xu et al. 1995a). The incorporation of unidirectional capillaries (or pores) into alginate hydrogels has demonstrated their ability to promote orientated axonal growth in in vitro organ slice preparations as well as following implantation into defined dorsal column lesions of the adult rat spinal cord (Prinjha et al. 2000). However, it was not possible to determine whether the orientated axon regeneration resulted in improved function, because behavioural studies were not performed in the latter investigation. 
Agarose

Agarose is a polysaccharide extracted from the seaweed that will form gels on cooling. Agarose gels modified with the peptide CDPGYIGSR resulted in improved DRG neurite growth compared to unmodified agarose (Borkenhagen et al. 1998), which were, themselves, capable of supporting some degree of DRG axon growth in vitro (Z'Graggen et al. 1998). The immobilisation of other functional bioactive molecules (e.g. GRGD peptide sequence) into uniformly orientated $200 \mu \mathrm{m}$ diameter channels within agarose hydrogels has been achieved using photolithographic techniques. Such modified agarose hydrogels were observed to support the attachment and growth of DRG axons which preferentially followed the trajectory of the functionalised channels in vitro (Maquet et al. 2001). As an alternative method, freeze-drying has been developed to generate agarose hydrogels with uniaxial linear pores (125 $\mu \mathrm{m}$ diameter) that could be loaded with axon growth-promoting molecules (e.g. growth factors) (Stokols et al. 2006). Implantation of BDNF-loaded (or BDNF/ mesenchymal stromal cells (MSC)-loaded) scaffolds into cervical (level C3) dorsal column lesions resulted in orientated blood vessel and Schwann cell migration into the scaffold as well as directional axon regeneration. However, possible implant-mediated functional recovery has not been assessed using this biomaterial. Such agarose scaffolds elicited only minimal host inflammatory reactions and were not encapsulated by reactive tissues (Stokols \& Tuszynski 2006; Sun et al. 2005). Orientated or non-orientated agarose implants elicited minimal inflammatory response in rat spinal cord, but did not support neurite growth into the scaffold (Johnson et al. 2009; Stokols \& Tuszynski 2006; Sun et al. 2005).

\section{Chitosan}

Chitosan is prepared from chitin, the second most abundant polysaccharide in nature (after cellulose), and is the main component of crustacean- and insect exoskeletons, and of cell walls of some bacteria and fungi (Khoueir et al. 2007; Nomura et al. 2008a). The non-toxicity, biocompatibility and biodegradability of chitosan has resulted in its use as a conduit, the lumen of which could be filled with axon growth-promoting molecules e.g. type I collagen, (Li et al. 1998), segments of peripheral nerve (Nomura et al. 2008b) or neural progenitors (Novikov et al. 2002; Zhong et al. 2006)). Loaded or non-loaded chitosan conduits have been implanted into spinal cord lesions and the beneficial effects of the implants compared. All the loaded conduits supported substantial host axon regeneration, whereas relatively few regenerating axons could be identified in the empty chitosan conduits. Although some improvement of motor function was reported as early as 2 weeks after implantation into partial spinal cord lesions, it is most likely that such rapid recovery be due to implant induced tissue sparing rather than the axon regeneration 40 
that was claimed by the authors (Li et al. 1998). In contrast, implantation of chitosanbased conduits into complete spinal cord transections resulted in no motor improvement (Nomura et al. 2008b; Novikov et al. 2002).

Poly-b-hydroxybutyrate (PHB)

Poly-b-hydroxybutyrate (PHB) can be obtained from micro-organisms in which it exists as energy storage granules (Doyle et al. 1991). Fibres of PHB coated with alginate and fibronectin (with or without Schwann cells seeding) have been implanted in spinal cord lesions. Although the PHB-containing conduits integrated well with the host tissues and supported the survival of axotomised rubrospinal neurons, relatively little axonal regeneration took place (Novikova et al. 2008). More recently, ECM-coated (i.e. fibronectin, laminin and collagen type IV) PHB has been demonstrated to support Schwann cell adhesion, proliferation and survival, and the implantation of such conduits into adult rat cervical spinal cord hemisections promoted the regeneration of populations of descending and ascending axons (e.g. serotonergic and CGRP-positive sensory axons). However, no functional analyses have been performed with such

\section{Hyaluronic Acid}

Hyaluronic acid (HA) is a naturally occurring polysaccharide and has an important role in peripheral nerve repair (Wang et al. 1996). Hyaluronan-based conduits have been reported to be biodegradable, non-cytotoxic, and biocompatible (Avitabile et al. 2001). When used in combination with low-power laser radiation treatment, implanted HA maintained the survival of donor embryonic spinal cord tissue, induced host axon regeneration and a moderate recovery of somatosensory evoked potentials following complete spinal cord transection injuries (Rogers et al. 1987). Similarly, a HA-poly-d-lysine co-polymer hydrogel has been reported to support neural cell growth and differentiation and integrate well with host astroglia after implantation into CNS lesions (Tobias et al. 2005). More recently, a hyaluronan-methylcellulose (HAMC) composite gel has been developed as a biodegradable, non cell-adhesive hydrogel that can be injected locally to CNS injuries for the controlled release of bioactive molecules (Guth et al. 1985). Injection of HAMC into the intrathecal space of normal and compression-injured adult rat spinal cords had no detrimental effects in normal tissues and even caused slight improvements to injured animals, probably due to the anti-oxidant and anti-inflammatory effects of HAMC. Accordingly, lesion volumes were smaller, fewer inflammatory cells were found at the injury site, and locomotion and coordination showed improved trends after HAMC 
injection (Guth et al. 1985). The efficacy of intrathecal injection of HAMC as a delivery mechanism for the neuroprotective agent, erythropoietin (EPO), was compared with direct intrathecal bolus injection- and intraperitoneal injection of EPO (Kataoka et al. 2004). The HAMC hydrogel route of EPO delivery provided the greatest neuroprotective benefit to rats receiving a mild-moderate compression injury, raising the possibility that such a system might form the basis for the efficacious local delivery of neuroprotective agents to patients suffering $\mathrm{SCl}$.

\section{Synthetic Polymers}

Biomaterials made of synthetic polymers have some advantages over natural polymers, in particular, of reduced impurities, pathogens or contaminant and lower batch-to-batch variability, as well as consistent and reproducible mechanical and physical properties. Some of the synthetic polymers that have been applied to $\mathrm{SCl}$ research are presented below.

\section{Poly(-Hydroxy Acids)}

Poly(-hydroxy acids) such as poly-glycolic acid (PGA), poly-l-lactic acid (PLLA), poly-d-lactic acid (PDLA) and PCL are biocompatible polymers that are degrades by hydrolysis and have mechanical characteristics that can be readily controlled. Poly(-hydroxy acids) are already widely used in the medical industry (e.g. for sutures). Guidance conduits made from a range of poly(-hydroxy acids) have proved useful in promoting axon regeneration and functional recovery of the PNS (Dalton \& Mey 2009). Their usefulness in promoting CNS axon regeneration after $\mathrm{SCl}$ has also been demonstrated and the composition of the conduits has been modified to improve their properties. For example, Schwann cell containing PDLA conduits implanted into complete rat spinal cord transection injuries underwent rapid degradative hydrolysis and collapsed or fragmented over a number of months, the ensuing change in conduit geometry having detrimental effects of axon regeneration and tissue repair (Paíno et al. 1994). To modify the degradation rate, other polymers including PCL, poly(d,I-lactic acid-co-glycolic acid) (PLGA), or a mixture of the two have been assessed. Neural stem cell-seeded PLGA conduits have been reported to promote tissue repair and functional recovery after implantation into rat spinal cord hemisection injuries (Thallmair et al. 1998). Attempts to improve conduit microstructure have included copolymers of poly(ethylene oxide)-block poly(d,I-lactic acid) (PELA-PDLLA) which were moulded into rods and bound in groups using acidic fibroblast growth factor (aFGF) containing fibrin glue. The conduit (with or without BDNF supplement) promoted directional host blood vessel, Schwann cell and axon regeneration following implantation 
into complete spinal cord transection injuries, but no functional improvement was reported (Marchand et al. 1993; Pearse et al. 2007). A two-component polymer scaffold composed of PLGA and a block co-polymer of PLGA-poly-lysine has been engineered such that the porous inner portion emulated spinal cord grey matter and its longitudinally orientated porous outer portion emulated the spinal cord white matter. The inner layer of the scaffold was seeded with neural precursor cells prior to implantation into hemisection injuries of the rat spinal cord. Interestingly, the implant reduced astroglial scar formation and promoted substantial host axon regeneration (including descending corticospinal axons) that was associated with a long-term functional improvement (Thallmair et al. 1998). Others have generated parallel channels within PLGA of approximately $500 \mu \mathrm{m}$, which supported Schwann cell and mesenchymal stromal cell attachment and proliferation in vitro, and induced only minor macrophage responses at the implant-host interfaces and no glial responses in the adjacent spinal cord tissue, demonstrating the biocompatibility of such biomaterials (Hejcl et al. 2008a). Such scaffolds have also been developed for combined tissue engineering and gene therapy applications. The non-viral local delivery of DNA to lesioned host tissues has been achieved using lipoplexes bound to fibronectin-coated PLGA implants. The walls between the channels served as a reservoir for the material (DNA) being delivered. It was reported that local transgene expression of a marker protein was detectable for up to 3 weeks following implantation, suggesting that such combined tissue engineering/gene therapy strategies may be of use in the treatment of SCl (De Laporte et al. 2009).

\section{Poly-(Acrylonitrile-Co-Vinylchloride)}

Poly-(acrylonitrile-co-vinylchloride) (PAN/PVC) is a structurally stable, biocompatible and non-toxic copolymer (Silver \& Miller 2004), which has been used to form conduits for the repair of $\mathrm{SCl}$. Empty (or Matrigel ${ }^{\mathrm{TM}}$ containing) PAN/PVC conduits provided little regenerative support, e.g. (Bunge 2002); however, conduits loaded with axon growthpromoting peripheral glia (e.g. Schwann cells or olfactory ensheathing glia) and different combinations of growth factors (e.g. BDNF, NT-3 or glia derived nerve growth factor (GDNF)) have induced significant axon regeneration and remyelination (Bamber et al. 2001; Fouad et al. 2005; Itoh et al. 2002; Joosten et al. 1995; Ramon y Cajal 1928b; Xu et al. 1999; Yamada \& Olden 1978). Increasing the complexity of the combinatorial approach to repair SCl has included the implantation of Schwann cell-seeded PAN/PVC conduits into complete spinal cord transection injuries, accompanied by OEC implantation into the rostral and caudal spinal cord stumps and the infusion of the enzyme, chondroitinase $A B C$, at the implant-host tissue interface where it is capable of digesting and reducing the local axon growth-inhibitory effects of CSPG (Fouad et al. 2005; Fournier et al. 2001). Such 
strategies have promoted axon regeneration from spinal cord PSN as well as from populations of brain stem neurons (including serotonergic fibres from the Raphe nucleus, vestibulospinal and reticulospinal neurons), all of which play a role in stepping and locomotion (Fouad et al. 2005; Vidal-Sanz et al. 1987). Interestingly, this combined strategy has also improved the bladder function of spinal cord-injured rats (Fouad et al. 2009).

\section{Poly(2-Hydroxyethyl Methacrylate)}

Poly(2-hydroxyethyl methacrylate) (PHEMA) is a non-biodegradable, biocompatible and non-toxic polymer. PHEMA-based conduits have a similar elastic modulus to spinal cord tissues and provide long-term stability for tissue regeneration (Dalton et al. 2002; Flynn et al. 2003; Hudson et al. 1999). The implantation of PHEMA scaffolds into the lesion cavity of rat spinal cord contusion injuries promoted an enhanced degree of host axon regeneration (Gonzenbach \& Schwab 2008). Interestingly, the implantation of empty poly (2-hydroxyethyl methacrylate-co-methyl methacrylate) (PHEMA/PHEMA-MMA) conduits into complete spinal cord transection injuries was reported to support significant host axon regeneration from reticulospinal, vestibulospinal and Raphe nuclei in the brain stem, some of which traversed the lesion (at T8) and were reported to extend as far as T13/L1. Although other biomaterial-implantation studies had reported axon regeneration into biomaterial-based scaffolds, this study was significant in that it was the first to demonstrate such extensive axonal growth into unfilled synthetic hydrogel conduits (Tsai et al. 2006). However, partial collapse of the conduits was observed by 2 months after implantation, prompting modifications involving coil-reinforcement. Attempts to enhance the extent of axon regeneration by the inclusion of different combinations of growth factors (e.g. aFGF) and ECM components (e.g. fibrin) proved unsuccessful, because animals developed signs of syringomyelia, suggesting that conduit design required further development (Nomura et al. 2006b). Attempts to systematically assess the regenerative potential of adding ECM (fibrin, collagen, Matrigel ${ }^{\mathrm{TM}}$ or methylcellulose) and/or growth factors (aFGF or NT-3) to the original simple design of the PHEMA/PHEMA-MMA conduits indicated that the inclusion of fibrin into the conduit enhanced the number of brain stem (reticulospinal) neurons growing into and beyond the lesion. However, inclusion of aFGF with fibrin had no apparent effect on the number of regenerating neurons while inclusion of NT-3, in contrast, caused a precipitous drop in the number of regenerating brain stem neurons in comparison to unfilled, control channels. The inclusion of collagen into the PHEMA/PHEMA-MMA conduit induced minor increases in the number of brain stem (reticulospinal and vestibulospinal) neurons above that seen in empty conduits; however, inclusion of aFGF with the collagen markedly increased the number of regenerating 
neurons from both brain stem nuclei, while inclusion of NT-3 (similar to fibrin plus NT-3) caused a massive decrease in numbers. The reason for the detrimental effects of NT-3 remain unclear (Tsang \& Bhatia 2004). Manipulation of the electric charge carried by the HEMA hydrogel by polymerisation with positively or negatively charged co-polymers demonstrated that positively charged co-polymers imparted a beneficial effect by improving cell adhesion (as tested with bone marrow stromal cells)(Li \& Strittmatter 2003; Prang et al. 2006). Furthermore, implantation of positively charged hydrogel was recently reported to promote greater ECM deposition and axonal growth than uncharged hydrogels following implantation into experimental spinal cord lesions (Guth et al. 1985). Although in vitro studies demonstrated that the deposition of collagen and laminin onto the surface of the hydrogels increased the adhesion and growth of mesenchymal stromal cells and astrocytes (Novikova et al. 2008), in vivo implantation studies demonstrated little or no host astrocytic growth into the hydrogels (Guth et al. 1985). The delayed implantation ( 7 days after complete spinal cord transection) of the positively charged hydrogels was also found to induce greater ECM deposition, in-growth of blood vessels, Schwann cells and axons, as well as reducing cystic cavitation in comparison to the acute implantation of such hydrogels, or to the non-implanted controls (Hejcl et al. 2009).

\section{Polyethylene Glycol}

Polyethylene glycol (PEG) is a hydrophilic polymer that has low protein and cell adhesion properties. Application of PEG solution in a number of experimental models of $\mathrm{SCl}$ has resulted in the re-establishment of anatomical continuity, reduced lesion volume and improved functional recovery (Borgens et al. 2002; Lesný et al. 2002; Shi et al. 1999; Shi \& Borgens 2000; Shoichet \& Rein 1996). It has been suggested that the neuroprotective properties of PEG may be due to its ability to re-seal damaged cell plasma membranes, anti-oxidative and anti-apoptotic effects following SCl (Luo et al. 2004; Luo \& Shoichet 2004). PEG has also been used to modify surfaces, making them non-adhesive to cells and protein for a number of weeks, and have thus been used in a number of cell-substrate patterning experiments (Giannetti et al. 2001; Kwon et al. 2009; Schoof et al. 2001). Biodegradable PEG-based hydrogels containing poly(lactic acid)-b-poly(ethylene glycol)-b(poly lactic acid) (PLA-b-PEG-b-PLA) and the growth factor NT-3 have been developed in which gelation was induced via blue light photopolymerization. Such PEG-based gels implanted into spinal cord hemisection injuries promoted axon regeneration and some degree of functional recovery (Prádný et al. 2005). PEG has also been used as a formulation for the targeted delivery of the neuroprotective agent, magnesium sulphate, to both compression-type SCl (Ditor et al. 2007) and more recently to contusion-type SCl (Laverty et al. 2004). Optimising the administration of MgSO4/PEG with a dosing time 
window starting up to $2 \mathrm{~h}$ after injury followed by up to 6 separate infusions provided the optimal neuroprotection with the lesion volume reduced by approximately $50 \%$ in comparison to saline-injected control animals (Laverty et al. 2004).

\section{Poly[N-(2-Hydroxypropyl) Methacrylamide}

Poly[N-(2-hydroxypropyl)methacrylamide] (PHPMA or Neurogel ${ }^{\mathrm{TM}}$ ) is a synthetic polymer that forms a hydrogel that has proven useful for spinal cord repair as well as PHEMA (Woerly et al. 1999). Implantation of NeuroGel ${ }^{\mathrm{TM}}$ (with or without growth factors) into the transected cat spinal cord promoted neo-vascularisation, infiltration by glial cells and axonal regeneration and myelination of the descending and ascending populations of axons. The axon growth traversed the implant-host interfaces which demonstrated reduced astroglial scarring. The tissue repair supported by such implants was associated with some degree of functional improvement (Luo et al. 2002; Woerly et al. 2001c; Woerly et al. 2004; Wong et al. 2007). Furthermore, implantation into chronic rat SCl (3 months after the initial insult) also reduced lesion cavity size, promoted host blood vessel and Schwann cell migration and axon regeneration, and improved functional recovery (Woerly et al. 2001b).

\section{Self-Assembling Nanofiber Scaffolds}

A recent development in the field of biomaterials is the molecular self-assembly of structures for use in biomedicine, in particular for the repair of the injured CNS. The capacity of nanofiber scaffolds to self-assemble into a framework capable of supporting functional tissue repair following implantation has been investigated following experimental brain- and $\mathrm{SCl}$. The constituents of these biomaterial scaffolds are selfcomplementary amphiphilic oligopeptides that have regular repeating units of positively charged residues (lysine or arginine) and negatively charged residues (aspartate or glutamate) separated by hydrophobic residues (alanine or leucine). The assembly of ionic self-complementary synthetic peptides from the alternating positive and negative l-amino acids is initiated by the presence of physiologically relevant concentrations of salt solutions, as in the extracellular or cerebrospinal fluid (Horner \& Gage 2000). Threedimensional, self-assembling peptide nanofiber scaffolds have already proven successful in reducing local astrocytic scarring and inflammation, as well as effectively "knitting" the two edges of a lesion together following relatively thin, penetrating injuries of the CNS. When introduced into living animals, these self-assembling scaffolds did not induce a measurable immune or inflammatory response by the host tissues (Holmes 2002) and 
generated an axon growth permissive environment that was capable of supporting some degree of functional tissue repair following lesions of the optic tract or cerebral cortex (Ellis-Behnke et al. 2006; Gupta et al. 2006). Furthermore, self-assembling nanofiber scaffolds have been demonstrated to reduce apoptosis and astrocytosis, as well as supporting axon regeneration and a moderate degree of functional recovery in models of SCl (Guo et al. 2009; Vavrek et al. 2007). It is possible that the future use of orientated nanofibers may be able to improve the efficacy of the axon regeneration across large lesions. The design of such self-assembling nanofiber scaffolds presents a number of characteristics that are advantageous for CNS repair:

1. The peptides can be injected into- and fill the cavitating, irregular-shaped lesion sites that typically form following $\mathrm{SCl}$.

2. This approach causes minimal damage to the surrounding rim of intact spinal cord tissue that is usually present in most contusion or compression-type cases of $\mathrm{SCl}$.

3. The nanofiber scaffold forms a hydrogel with physical properties that are unlikely to provoke any additional damage to the host tissues.

4. The scaffold is biodegradable, breaking down to natural amino acids.

5. The scaffold is also immunologically inert, avoiding potentially damaging issues of enhanced inflammation and rejection. These characteristics make the selfassembling nanofiber scaffolds very promising biomaterials for bridging $\mathrm{SCl}$.

\section{Clinical Application}

The application of biomaterials to promote functional axon regeneration in clinical cases of $\mathrm{SCl}$ still remains a goal for the future development of the discipline. Current clinical tests for biomaterials related to $\mathrm{SCl}$ tend to be limited to the use of materials or devices intended for spinal column stabilisation (King et al. 2003). The discipline is not at a point where a material has been tested and its interactions with the lesioned host tissues sufficiently understood and controlled to be able to contemplate the clinical trials. Furthermore, any beneficial effect brought about by a particular biomaterial in small laboratory animals (with well-defined and highly reproducible spinal cord lesions) does not guarantee that a similar effect would be seen in humans. An unavoidable concern in the issue of translating advances in "bridging" spinal cord lesions in the laboratory to similar applications in the clinic is that of size. Most experimental spinal cord lesions used for bridging experiments induce gaps of several $\mathrm{mm}$ in length. Severe $\mathrm{SCl}$ in humans could, however, result in lesions of up to several $\mathrm{cm}$ in length. It would be a major advance in the 
field if regenerating axons were able to grow such distances and reach the distal, partially de-afferented spinal cord tissue. Currently, the implantation of relatively simple "first generation" bioengineered scaffolds has resulted in the support to some degree, albeit limited, of the functional repair in experimental animals. Any functional improvement that can be promoted in patients with $\mathrm{SCl}$ would be a welcome development. Even small improvements, such as lowering the apparent segmental level of the functional deficit by a single spinal cord level could lead to the acquisition of the control of finger movements in patients with cervical injuries, potentially bringing about a substantial increase in the quality of life. An issue of considerable clinical importance is that most compression- and contusion-type spinal cord injuries are followed by some (limited) degree of recovery over the first months post-injury. As mentioned earlier, much of this recovery of function is due to the conduction of impulses along spared axons that occupy the outermost rim of the white matter. The preservation of these axons and the modalities that they serve is of utmost importance to the maintenance of residual function in the $\mathrm{SCl}$ patient. Any intervention strategy (including the implantation of biomaterials) should aim to cause minimal disruption or damage to the survival and function of these spared axons. It is therefore likely that certain biomaterial designs will be of particular interest in the repair of different types of spinal cord injuries; for example, the minimally traumatic approach of injecting hydrogels may be more appropriate for contusion- or compression-type injuries, while the implantation of pre-formed, orientated, scaffolds may be more appropriate in resection or laceration-type injuries.

\section{Expert Opinion}

Investigations into the use of biomaterials for the repair of the lesioned PNS have the advantage of the widely accepted "gold standard" autograft for the repair of peripheral nerves. Numerous clinical studies have demonstrated that the best degree of functional peripheral nerve axon regeneration is promoted by similarly sized segments of "donor" peripheral nerve, harvested from the patient themselves e.g. (Bhandari et al. 2007). This has provided the investigators with a benchmark, facilitating the development of implantable biomaterials that could mimic the properties of the autograft. The performance of the bioengineered scaffolds could be compared with that of the autograft. No such gold standard exists for $\mathrm{SCl}$ research, resulting in the need to assess the regenerative properties of a wide range of natural and synthetic polymers. As has already been seen with "first generation" biomaterials, future generations of biomaterials will probably result in similar degrees of functional improvement. However, it will be difficult to draw any detailed conclusions about the relative merits of the different materials because of the disparate investigative techniques employed by different researchers. Only direct comparisons of different materials within the same group or alternatively, two 48 
research groups adopting identical investigative procedures would provide accurate comparative data. Such approaches for the identification of the most promising biomaterial for further development have, so far, only rarely been adopted. Although current in vivo investigations often assess the consequences of biomaterial implantation on motor (and sometimes sensory) function, relatively few groups include studies into the development of pathological pain e.g. allodynia. It is possible that implanted biomaterials may modify the connectivity or function of sensory neurons. Future investigations of potentially interesting biomaterials would clearly benefit from the inclusion of studies aimed at addressing this issue.

\section{Five-Year Perspective}

The striking reparative effects of injecting self-assembling nanofiber hydrogels into experimental CNS lesions suggests that modification of the composition of such gels will lead to even more interesting observations. Future investigations which promote the effective tailoring of functional peptide sequences to control specific cell-substrate interactions will represent a major step forward in the discipline. However, it is unlikely that such modifications will be restricted to self-assembling nanofibers; the coupling of a range of functional molecules (e.g. growth factors, functional peptide sequences from cell adhesion molecules or ECM, or enzymes capable of degrading the inhibitory influences in and around the lesion site) to both natural and synthetic polymer scaffolds will provide valuable information about the implant-mediated consequences of modifying the environment of the lesion site. It is encouraging to see that the in vivo assessment of biomaterials (alone or as part of a combination strategy) is being conducted more frequently following delayed implantation. The identification of the effective window of opportunity for any particular intervention strategy represents the adoption of an experimental approach that more realistically reflects the likely delays that would take place before any $\mathrm{SCl}$ patient would be in a position to be treated with biomaterials. It is anticipated that the next few years will bring even more systematic studies into the effects of both acute and delayed implantation of biomaterials with interest focussing on, as yet, poorly understood host responses including the effects on the inflammatory response and neo-vascularisation. Although the beneficial effects of biomaterials should ideally be determined in small rodents, larger animals and eventually non-human primates before entering clinical trials, it would not be surprising to witness the initiation of limited clinical safety trials for promising strategies involving hydrogels within the next 5 years. 


\section{Limitations/Critical View}

As indicated earlier, $\mathrm{SCl}$ affects both the ascending and descending populations of axons. These nerve fibre tracts within the spinal cord have their own particular stereotypical distribution within the white matter and their own growth requirements, being preferentially responsive to certain growth factors, cell adhesion molecules and ECM molecules. Optimal tissue repair would ideally involve the successful regeneration of a number of these different nerve fibre populations, requiring that the biomaterial (or scaffold) be able to present compartmentalised growth-promoting substrates (each of which being specifically tailored to a particular population of axons). The design of "intelligent" biomaterials that are capable of the controlled release of growth factors (or other axon growth modulating molecules) requires a clear definition of the timing of such a release. Bearing this in mind, the current state of the art for the design of biomaterials with axon growth-promoting properties is still rather crude. However, this will no doubt change in the near future. The ultimate goal of promoting some degree of functional recovery by axon regeneration remains a medium- to-long-term goal for research in the field of neurotraumatology; however, improved function by enhancing tissue sparing and compensatory plasticity is more likely to be achieved in the short- to-medium term.

\section{Conclusion/Summary}

The development of effective bioengineering strategies for the repair of $\mathrm{SCl}$ has presented a number of complex challenges. Nonetheless, it has become clear that numerous synthetic and natural biomaterials are capable of integrating with the lesioned host spinal cord and promoting some degree of axon regeneration. However, the properties of implantable biomaterials that influence the biomaterials' ability to interact with the lesioned host tissues in a controlled and specific manner are, at this time, rather limited. The future development of implantable devices that will be able to target and modify a number of the key pathophysiological events that arise after $\mathrm{SCl}$ will require increasingly intense collaborations between the clinicians and scientists from a wide range of disciplines. Although no single biomaterial has yet been identified as the ideal substrate for prompting functional axonal regeneration, the application of self-assembling nanofibers has presented itself as a particularly interesting and versatile development. The field of biomaterials research for CNS applications has clearly grown beyond its infancy and is developing into an area of multi-disciplinary research. This is likely, in the future, to deliver real benefits for regenerative medicine. 


\section{Suggested Readings with Abstracts}

Dike LE, Chen CS, Mrksich M, Tien J, Whitesides GM, Ingber DE. Geometric control of switching between growth, apoptosis, and differentiation during angiogenesis using micropatterned substrates. In vitro Cell Dev Biol Anim. 1999; 35:441-48.

Past studies using micropatterned substrates coated with adhesive islands of ECM revealed that capillary endothelial cells can be geometrically switched between growth and apoptosis. Endothelial cells cultured on single islands larger than 1,500 $\mathrm{mm} 2$ spread and progressed through the cell cycle, whereas cells restricted to areas less than $500 \mathrm{~mm} 2$ failed to extend and underwent apoptosis. The present study addressed whether island geometries that constrained cell spreading to intermediate degrees, neither supporting cell growth nor inducing apoptosis, cause cells to differentiate. Endothelial cells cultured on substrates micropatterned with 10-mm-wide lines of fibronectin formed extensive cellcell contacts and spread to approximately $1,000 \mathrm{~mm} 2$. Within $72 \mathrm{~h}$, cells shut off both growth and apoptosis programmes and underwent differentiation, resulting in the formation of capillary tube-like structures containing a central lumen. Accumulation of ECM tendrils containing fibronectin and laminin beneath cells and the reorganisation of the platelet endothelial cell adhesion molecule-positive cell-cell junctions along the lengths of the tubes preceded the formation of these structures. Cells cultured on wider $(30 \mathrm{~mm})$ lines also formed cell- cell contacts and aligned their actin cytoskeleton, but these cells spread to larger areas $(2,200 \mathrm{~mm} 2)$, proliferated, and did not form tubes. The use of micropatterned substrates revealed that altering the geometry of cell spreading can switch endothelial cells among the three major genetic programmes that govern angiogenesis growth, apoptosis and differentiation. The system presented here provides a well-defined adhesive environment to further investigate the steps involved in angiogenesis.

Xu XM, Guenard V, Kleitman N, Aebischer P, Bunge MB. A combination of BDNF and NT-3 promotes supraspinal axonal regeneration into Schwann cell grafts in adult rat thoracic spinal cord. Exp Neurol. 1995;134:261-72.

We previously demonstrated that Schwann cells (SCs) in semipermeable guidance channels promote axonal regeneration in adult rat spinal cord transected at the midthoracic level. Propriospinal but not supraspinal axons grew into these channels. Here, we tested the ability of the exogenous brain-derived neurotrophic factor (BDNF) and neurotrophin-3 (NT-3) to promote axonal regeneration in this novel model. The two neurotrophins were delivered simultaneously into the channel by an Alzet minipump at a rate of $12 \mathrm{mg} /$ day for each neurotrophin for 14 of 30 days tested; phosphate- buffered 
saline, the vehicle solution, was used as a control. Significantly, more myelinated nerve fibres were present in SC/neurotrophin grafts than in SC/ vehicle grafts (1523 \pm 292 vs. $882 \pm 287$ ). In the graft, at least $5 \mathrm{~mm}$ from the rostral cord-graft interface, some nerve fibres were immunoreactive for serotonin, a neurotransmitter specific to raphe-derived axons in rat spinal cord. Fast blue retrograde tracing from $\mathrm{SC} /$ neurotrophin grafts revealed labelled neurons in ten nuclei of the brain stem, $67 \%$ of these being in the lateral and spinal vestibular nuclei. The mean number of labelled brain stem neurons in the $\mathrm{SC} /$ neurotrophin group $(92 ; n=3)$ contrasted with the mean in the SC/ vehicle group $(6 ; n$ $=4$ ). Our results clearly demonstrate that BDNF and NT-3 infusion enhanced propriospinal axonal regeneration and, more significantly, promoted the axonal regeneration of specific distant populations of brain stem neurons into grafts at the mid-thoracic level in adult rat spinal cord.

Teng YD, Lavik EB, Qu X, Park KI, Ourednik J, Zurakowski D, Langer R, Snyder EY. Functional recovery following traumatic spinal cord injury mediated by a unique polymer scaffold seeded with neural stem cells. PNAS. 2002;99:3024-29.

For better direct repair following spinal cord injury $(\mathrm{SCl})$, we designed an implant modelled after the intact spinal cord consisting of a multi-component polymer scaffold seeded with neural stem cells. Implantation of the scaffold-neural stem cells unit into an adult rat hemisection model of $\mathrm{SCl}$ promoted long-term improvement in function (persistent for 1 year in some animals) relative to a lesion-control group. At 70 days post-injury, animals implanted with scaffold-plus cells exhibited coordinated, weight-bearing hind limb stepping. Histology and immunocytochemical analysis suggested that this recovery might be attributable partly to a reduction in tissue loss from secondary injury processes as well as in diminished glial scarring. Tract tracing demonstrated corticospinal tract fibres passing through the injury epicentre to the caudal cord, a phenomenon not present in untreated groups. Together with the evidence of enhanced local GAP-43 expression not seen in controls, these findings suggest a possible regeneration component. These results may suggest a new approach to $\mathrm{SCl}$ and, more broadly, may serve as a prototype for multidisciplinary strategies against complex neurological problems.

Tysseling-Mattiace VM, Sahni V, Niece KL, Birch D, Czeisler C, Fehlings MG, Stupp SI, Kessler JA. Self-assembling nanofibres inhibit glial scar formation and promote axon elongation after spinal cord injury. J Neurosci. 2008;28: 3814-23. 
Peptide amphiphile (PA) molecules that self-assemble in vivo into supramolecular nanofibers were used as a therapy in a mouse model of spinal cord injury $(\mathrm{SCl})$. Because self-assembly of these molecules is triggered by the ionic strength of the in vivo environment, nanoscale structures can be created within the extracellular spaces of the spinal cord by simply injecting a liquid. The molecules are designed to form cylindrical nanofibers that display to the cells in the spinal cord the laminin epitope IKVAV at nearly van der Waals density. IKVAV PA nanofibers are known to inhibit glial differentiation of cultured neural stem cells and to promote neurite outgrowth from cultured neurons. In this work, in vivo treatment with the PA after $\mathrm{SCl}$ reduced astrogliosis, reduced cell death, and increased the number of oligodendroglia at the site of injury. Furthermore, the nanofibers promoted the regeneration of both the descending motor fibres and ascending sensory fibres through the lesion site. Treatment with the PA also resulted in significant behavioural improvement. These observations demonstrate that it is possible to inhibit glial scar formation and to facilitate regeneration after $\mathrm{SCl}$ using bioactive threedimensional nanostructures displaying high densities of neuroactive epitopes on their surfaces.

\section{Acknowledgements}

T. Führmann is supported by a grant from the European Community's Sixth Framework Programme (Rescue project, Contract N LSHB-CT-2005-518233). We would like to thank Elaine Brook for her assistance in the preparation of the manuscript. 


\section{References}

Atwal, J.K., Pinkston-Gosse, J., Syken, J., Stawicki, S., Wu, Y., Shatz, C. \& Tessier-Lavigne, M., 2008. PirB is a functional receptor for myelin inhibitors of axonal regeneration. Science (New York, N.Y.), 322(5903), pp.967-70.

Avitabile, T., Marano, F., Castiglione, F., Bucolo, C., Cro, M., Ambrosio, L., Ferrauto, C. \& Reibaldi, A., 2001. Biocompatibility and biodegradation of intravitreal hyaluronan implants in rabbits. Biomaterials, 22(3), pp.195-200.

Balgude, A.P., Yu, X., Szymanski, A. \& Bellamkonda, R. V, 2001. Agarose gel stiffness determines rate of DRG neurite extension in 3D cultures. Biomaterials, 22(10), pp.1077-84.

Bamber, N.I., Li, H., Lu, X., Oudega, M., Aebischer, P. \& Xu, X.M., 2001. Neurotrophins BDNF and NT-3 promote axonal re-entry into the distal host spinal cord through Schwann cell-seeded mini-channels. The European journal of neuroscience, 13(2), pp.257-68.

Bareyre, F.M., Haudenschild, B. \& Schwab, M.E., 2002. Long-lasting sprouting and gene expression changes induced by the monoclonal antibody IN-1 in the adult spinal cord. The Journal of neuroscience : the official journal of the Society for Neuroscience, 22(16), pp.7097-110.

Bareyre, F.M., Kerschensteiner, M., Raineteau, O., Mettenleiter, T.C., Weinmann, O. \& Schwab, M.E., 2004. The injured spinal cord spontaneously forms a new intraspinal circuit in adult rats. Nature neuroscience, 7(3), pp.269-77.

Beattie, M.S., Bresnahan, J.C., Komon, J., Tovar, C.A., Van Meter, M., Anderson, D.K., Faden, A.I., Hsu, C.Y., Noble, L.J., Salzman, S. \& Young, W., 1997. Endogenous repair after spinal cord contusion injuries in the rat. Experimental neurology, 148(2), pp.453-63.

Bhandari, P., Sadhotra, L., Bhargava, P., Bath, A., Mukherjee, M. \& Bavdekar, R., 2007. What is new in peripheral nerve repair? The Indian Journal of Neurotrauma, 4(1), pp.21-23.

Biran, R., Martin, D.C. \& Tresco, P.A., 2007. The brain tissue response to implanted silicon microelectrode arrays is increased when the device is tethered to the skull. Journal of biomedical materials research. Part $A$, 82(1), pp.169-78.

Borgens, R.B., Shi, R. \& Bohnert, D., 2002. Behavioral recovery from spinal cord injury following delayed application of polyethylene glycol. The Journal of experimental biology, 205(Pt 1), pp.1-12.

Borkenhagen, M., Clémence, J.F., Sigrist, H. \& Aebischer, P., 1998. Three-dimensional extracellular matrix engineering in the nervous system. Journal of biomedical materials research, 40(3), pp.392-400.

Bozkurt, A., Brook, G.A., Moellers, S., Lassner, F., Sellhaus, B., Weis, J., Woeltje, M., Tank, J., Beckmann, C., Fuchs, P., Damink, L.O., Schügner, F., Heschel, I. \& Pallua, N., 2007. In vitro assessment of axonal growth using dorsal root ganglia explants in a novel three-dimensional collagen matrix. Tissue engineering, 13(12), pp.2971-9. 
Bozkurt, A., Deumens, R., Beckmann, C., Olde Damink, L., Schügner, F., Heschel, I., Sellhaus, B., Weis, J., JahnenDechent, W., Brook, G.A. \& Pallua, N., 2009. In vitro cell alignment obtained with a Schwann cell enriched microstructured nerve guide with longitudinal guidance channels. Biomaterials, 30(2), pp.169-79.

Bradbury, E.J., Moon, L.D.F., Popat, R.J., King, V.R., Bennett, G.S., Patel, P.N., Fawcett, J.W. \& McMahon, S.B., 2002. Chondroitinase $A B C$ promotes functional recovery after spinal cord injury. Nature, 416(6881), pp.636-40.

Bregman, B.S., Kunkel-Bagden, E., Schnell, L., Dai, H.N., Gao, D. \& Schwab, M.E., 1995. Recovery from spinal cord injury mediated by antibodies to neurite growth inhibitors. Nature, 378(6556), pp.498-501.

Brook, G.A., Houweling, D.A., Gieling, R.G., Hermanns, T., Joosten, E.A., Bär, D.P., Gispen, W.H., Schmitt, A.B., Leprince, P., Noth, J. \& Nacimiento, W., 2000. Attempted endogenous tissue repair following experimental spinal cord injury in the rat: involvement of cell adhesion molecules L1 and NCAM? The European journal of neuroscience, 12(9), pp.3224-38.

Brook, G.A., Plate, D., Franzen, R., Martin, D., Moonen, G., Schoenen, J., Schmitt, A.B., Noth, J. \& Nacimiento, W., 1998. Spontaneous longitudinally orientated axonal regeneration is associated with the Schwann cell framework within the lesion site following spinal cord compression injury of the rat. Journal of neuroscience research, 53(1), pp.51-65.

Bunge, M.B., 2002. Bridging the transected or contused adult rat spinal cord with Schwann cell and olfactory ensheathing glia transplants. Progress in brain research, 137, pp.275-82.

Bunge, R.P., Puckett, W.R., Becerra, J.L., Marcillo, A. \& Quencer, R.M., 1993. Observations on the pathology of human spinal cord injury. A review and classification of 22 new cases with details from a case of chronic cord compression with extensive focal demyelination. Advances in neurology, 59, pp.75-89.

Bunge, R.P., Puckett, W.R. \& Hiester, E.D., 1997. Observations on the pathology of several types of human spinal cord injury, with emphasis on the astrocyte response to penetrating injuries. Advances in neurology, 72, pp.305-15.

Carbonetto, S., Gruver, M.M. \& Turner, D.C., 1983. Nerve fiber growth in culture on fibronectin, collagen, and glycosaminoglycan substrates. The Journal of neuroscience : the official journal of the Society for Neuroscience, 3(11), pp.2324-35.

Chen, A., Xu, X.M., Kleitman, N. \& Bunge, M.B., 1996. Methylprednisolone administration improves axonal regeneration into Schwann cell grafts in transected adult rat thoracic spinal cord. Experimental neurology, 138(2), pp.261-76.

Chen, C.S., Mrksich, M., Huang, S., Whitesides, G.M. \& Ingber, D.E., 1997. Geometric control of cell life and death. Science (New York, N.Y.), 276(5317), pp.1425-8.

Chen, C.S., Mrksich, M., Huang, S., Whitesides, G.M. \& Ingber, D.E., 1998. Micropatterned surfaces for control of cell shape, position, and function. Biotechnology progress, 14(3), pp.356-63. 


\section{Tissue Engineering - Central Nervous System}

Chen, M.S., Huber, A.B., van der Haar, M.E., Frank, M., Schnell, L., Spillmann, A.A., Christ, F. \& Schwab, M.E., 2000. Nogo-A is a myelin-associated neurite outgrowth inhibitor and an antigen for monoclonal antibody IN-1. Nature, 403(6768), pp.434-9.

Corey, J.M., Gertz, C.C., Wang, B.-S., Birrell, L.K., Johnson, S.L., Martin, D.C. \& Feldman, E.L., 2008. The design of electrospun PLLA nanofiber scaffolds compatible with serum-free growth of primary motor and sensory neurons. Acta biomaterialia, 4(4), pp.863-75.

Corey, J.M., Lin, D.Y., Mycek, K.B., Chen, Q., Samuel, S., Feldman, E.L. \& Martin, D.C., 2007. Aligned electrospun nanofibers specify the direction of dorsal root ganglia neurite growth. Journal of biomedical materials research. Part A, 83(3), pp.636-45.

Dalton, P.D., Flynn, L. \& Shoichet, M.S., 2002. Manufacture of poly(2-hydroxyethyl methacrylate-co-methyl methacrylate) hydrogel tubes for use as nerve guidance channels. Biomaterials, 23(18), pp.3843-51.

Dalton, P.D. \& Mey, J., 2009. Neural interactions with materials. Frontiers in bioscience (Landmark edition), 14, pp.769-95.

David, S. \& Aguayo, A.J., 1981. Axonal elongation into peripheral nervous system "bridges" after central nervous system injury in adult rats. Science (New York, N.Y.), 214(4523), pp.931-3.

Dike, L.E., Chen, C.S., Mrksich, M., Tien, J., Whitesides, G.M. \& Ingber, D.E., 1999. Geometric control of switching between growth, apoptosis, and differentiation during angiogenesis using micropatterned substrates. In vitro cellular \& developmental biology. Animal, 35(8), pp.441-8.

Ditor, D.S., John, S.M., Roy, J., Marx, J.C., Kittmer, C. \& Weaver, L.C., 2007. Effects of polyethylene glycol and magnesium sulfate administration on clinically relevant neurological outcomes after spinal cord injury in the rat. Journal of neuroscience research, 85(7), pp.1458-67.

Domeniconi, M., Cao, Z., Spencer, T., Sivasankaran, R., Wang, K., Nikulina, E., Kimura, N., Cai, H., Deng, K., Gao, Y., $\mathrm{He}, \mathrm{Z}$. \& Filbin, M., 2002. Myelin-associated glycoprotein interacts with the Nogo66 receptor to inhibit neurite outgrowth. Neuron, 35(2), pp.283-90.

Dou, C.L. \& Levine, J.M., 1994. Inhibition of neurite growth by the NG2 chondroitin sulfate proteoglycan. The Journal of neuroscience : the official journal of the Society for Neuroscience, 14(12), pp.7616-28.

Doyle, C., Tanner, E.T. \& Bonfield, W., 1991. In vitro and in vivo evaluation of polyhydroxybutyrate and of polyhydroxybutyrate reinforced with hydroxyapatite. Biomaterials, 12(9), pp.841-7.

Dubey, N., Letourneau, P.C. \& Tranquillo, R.T., 2001. Neuronal contact guidance in magnetically aligned fibrin gels: effect of variation in gel mechano-structural properties. Biomaterials, 22(10), pp.1065-75.

Ellis-Behnke, R.G., Liang, Y.-X., You, S.-W., Tay, D.K.C., Zhang, S., So, K.-F. \& Schneider, G.E., 2006. Nano neuro knitting: peptide nanofiber scaffold for brain repair and axon regeneration with functional return of vision. Proceedings of the National Academy of Sciences of the United States of America, 103(13), pp.5054-9. 
Fawcett, J.W., 2006. Overcoming inhibition in the damaged spinal cord. Journal of neurotrauma, 23(3-4), pp.37183.

Fawcett, J.W. \& Asher, R.A., 1999. The glial scar and central nervous system repair. Brain research bulletin, 49(6), pp.377-91.

Fehlings, M.G. \& Tator, C.H., 1995. The relationships among the severity of spinal cord injury, residual neurological function, axon counts, and counts of retrogradely labeled neurons after experimental spinal cord injury. Experimental neurology, 132(2), pp.220-8.

Feraboli-Lohnherr, D., Orsal, D., Yakovleff, A., Giménez y Ribotta, M. \& Privat, A., 1997. Recovery of locomotor activity in the adult chronic spinal rat after sublesional transplantation of embryonic nervous cells: specific role of serotonergic neurons. Experimental brain research, 113(3), pp.443-54.

Flynn, L., Dalton, P.D. \& Shoichet, M.S., 2003. Fiber templating of poly(2-hydroxyethyl methacrylate) for neural tissue engineering. Biomaterials, 24(23), pp.4265-72.

Fouad, K., Pearse, D.D., Tetzlaff, W. \& Vavrek, R., 2009. Transplantation and repair: combined cell implantation and chondroitinase delivery prevents deterioration of bladder function in rats with complete spinal cord injury. Spinal cord, 47(10), pp.727-32.

Fouad, K., Schnell, L., Bunge, M.B., Schwab, M.E., Liebscher, T. \& Pearse, D.D., 2005. Combining Schwann cell bridges and olfactory-ensheathing glia grafts with chondroitinase promotes locomotor recovery after complete transection of the spinal cord. The Journal of neuroscience : the official journal of the Society for Neuroscience, 25(5), pp.1169-78.

Fournier, A.E., GrandPre, T. \& Strittmatter, S.M., 2001. Identification of a receptor mediating Nogo-66 inhibition of axonal regeneration. Nature, 409(6818), pp.341-6.

Fournier, A.E. \& Strittmatter, S.M., 2001. Repulsive factors and axon regeneration in the CNS. Current opinion in neurobiology, 11(1), pp.89-94.

Galtrey, C.M. \& Fawcett, J.W., 2007. The role of chondroitin sulfate proteoglycans in regeneration and plasticity in the central nervous system. Brain research reviews, 54(1), pp.1-18.

Gautier, S.E., Oudega, M., Fragoso, M., Chapon, P., Plant, G.W., Bunge, M.B. \& Parel, J.M., 1998. Poly(alphahydroxyacids) for application in the spinal cord: resorbability and biocompatibility with adult rat Schwann cells and spinal cord. Journal of biomedical materials research, 42(4), pp.642-54.

Gerardo-Nava, J., Führmann, T., Klinkhammer, K., Seiler, N., Mey, J., Klee, D., Möller, M., Dalton, P.D. \& Brook, G.A., 2009. Human neural cell interactions with orientated electrospun nanofibers in vitro. Nanomedicine (London, England), 4(1), pp.11-30.

Giannetti, S., Lauretti, L., Fernandez, E., Salvinelli, F., Tamburrini, G. \& Pallini, R., 2001. Acrylic hydrogel implants after spinal cord lesion in the adult rat. Neurological research, 23(4), pp.405-9. 


\section{Tissue Engineering - Central Nervous System}

Gonzenbach, R.R. \& Schwab, M.E., 2008. Disinhibition of neurite growth to repair the injured adult CNS: focusing on Nogo. Cellular and molecular life sciences : CMLS, 65(1), pp.161-76.

GrandPré, T., Nakamura, F., Vartanian, T. \& Strittmatter, S.M., 2000. Identification of the Nogo inhibitor of axon regeneration as a Reticulon protein. Nature, 403(6768), pp.439-44.

Grimpe, B. \& Silver, J., 2002. The extracellular matrix in axon regeneration. Progress in brain research, 137, pp.333-49.

Guo, J., Leung, K.K.G., Su, H., Yuan, Q., Wang, L., Chu, T.-H., Zhang, W., Pu, J.K.S., Ng, G.K.P., Wong, W.M., Dai, X. \& Wu, W., 2009. Self-assembling peptide nanofiber scaffold promotes the reconstruction of acutely injured brain. Nanomedicine : nanotechnology, biology, and medicine, 5(3), pp.345-51.

Guo, J., Su, H., Zeng, Y., Liang, Y.-X., Wong, W.M., Ellis-Behnke, R.G., So, K.-F. \& Wu, W., 2007. Reknitting the injured spinal cord by self-assembling peptide nanofiber scaffold. Nanomedicine : nanotechnology, biology, and medicine, 3(4), pp.311-21.

Gupta, D., Tator, C.H. \& Shoichet, M.S., 2006. Fast-gelling injectable blend of hyaluronan and methylcellulose for intrathecal, localized delivery to the injured spinal cord. Biomaterials, 27(11), pp.2370-9.

Guth, L., Barrett, C.P., Donati, E.J., Anderson, F.D., Smith, M. V \& Lifson, M., 1985. Essentiality of a specific cellular terrain for growth of axons into a spinal cord lesion. Experimental neurology, 88(1), pp.1-12.

Han, Q., Sun, W., Lin, H. \& Zhao, W., 2009. Linear ordered collagen scaffolds loaded with collagen-binding brainderived neurotrophic factor improve the recovery of spinal cord injury in rats. Engineering Part $A$.

He, L., Zhang, Y., Zeng, C., Ngiam, M., Liao, S., Quan, D., Zeng, Y., Lu, J. \& Ramakrishna, S., 2009. Manufacture of PLGA multiple-channel conduits with precise hierarchical pore architectures and in vitro/vivo evaluation for spinal cord injury. Tissue engineering. Part C, Methods, 15(2), pp.243-55.

Hejcl, A., Lesný, P., Prádný, M., Michálek, J., Jendelová, P., Stulík, J. \& Syková, E., 2008a. Biocompatible hydrogels in spinal cord injury repair. Physiological research / Academia Scientiarum Bohemoslovaca, 57 Suppl 3, pp.S121-32.

Hejcl, A., Lesný, P., Prádný, M., Sedý, J., Zámecník, J., Jendelová, P., Michálek, J. \& Syková, E., 2009. Macroporous hydrogels based on 2-hydroxyethyl methacrylate. Part 6: 3D hydrogels with positive and negative surface charges and polyelectrolyte complexes in spinal cord injury repair. Journal of materials science. Materials in medicine, 20(7), pp.1571-7.

Hejcl, A., Urdzikova, L., Sedy, J., Lesny, P., Pradny, M., Michalek, J., Burian, M., Hajek, M., Zamecnik, J., Jendelova, P. \& Sykova, E., 2008b. Acute and delayed implantation of positively charged 2-hydroxyethyl methacrylate scaffolds in spinal cord injury in the rat. Journal of neurosurgery. Spine, 8(1), pp.67-73.

Holmes, T.C., 2002. Novel peptide-based biomaterial scaffolds for tissue engineering. Trends in biotechnology, 20(1), pp.16-21. 
Holmes, T.C., de Lacalle, S., Su, X., Liu, G., Rich, A. \& Zhang, S., 2000. Extensive neurite outgrowth and active synapse formation on self-assembling peptide scaffolds. Proceedings of the National Academy of Sciences of the United States of America, 97(12), pp.6728-33.

Horner, P.J. \& Gage, F.H., 2000. Regenerating the damaged central nervous system. Nature, 407(6807), pp.96370.

Houweling, D.A., van Asseldonk, J.T., Lankhorst, A.J., Hamers, F.P., Martin, D., Bär, P.R. \& Joosten, E.A., 1998. Local application of collagen containing brain-derived neurotrophic factor decreases the loss of function after spinal cord injury in the adult rat. Neuroscience letters, 251(3), pp.193-6.

Hudson, T.W., Evans, G.R. \& Schmidt, C.E., 1999. Engineering strategies for peripheral nerve repair. Clinics in plastic surgery, 26(4), pp.617-28, ix.

Hulsebosch, C.E., 2002. Recent advances in pathophysiology and treatment of spinal cord injury. Advances in physiology education, 26(1-4), pp.238-55.

Hung, T.K., Chang, G.L., Lin, H.S., Walter, F.R. \& Bunegin, L., 1981. Stress-strain relationship of the spinal cord of anesthetized cats. Journal of biomechanics, 14(4), pp.269-76.

Iannotti, C., Li, H., Yan, P., Lu, X., Wirthlin, L. \& Xu, X.M., 2003. Glial cell line-derived neurotrophic factor-enriched bridging transplants promote propriospinal axonal regeneration and enhance myelination after spinal cord injury. Experimental neurology, 183(2), pp.379-93.

Itoh, S., Takakuda, K., Kawabata, S., Aso, Y., Kasai, K., Itoh, H. \& Shinomiya, K., 2002. Evaluation of cross-linking procedures of collagen tubes used in peripheral nerve repair. Biomaterials, 23(23), pp.4475-81.

Jain, A., Kim, Y.-T., McKeon, R.J. \& Bellamkonda, R. V, 2006. In situ gelling hydrogels for conformal repair of spinal cord defects, and local delivery of BDNF after spinal cord injury. Biomaterials, 27(3), pp.497-504.

Johnson, P.J., Parker, S.R. \& Sakiyama-elbert, S.E., 2009. Fibrin-based tissue engineering scaffolds enhance neural fiber sprouting and delay the accumulation of reactive astrocytes at the lesion in a subacute model of spinal cord injury Wiley InterScience :: Article Full Text HTML In vivo studies : Dorsal hemise. , (September 2008), pp.1-10.

Jones, L.L., Oudega, M., Bunge, M.B. \& Tuszynski, M.H., 2001. Neurotrophic factors, cellular bridges and gene therapy for spinal cord injury. The Journal of physiology, 533(Pt 1), pp.83-9.

Joosten, E.A., Bär, P.R. \& Gispen, W.H., 1995. Collagen implants and cortico-spinal axonal growth after midthoracic spinal cord lesion in the adult rat. Journal of neuroscience research, 41(4), pp.481-90.

Kakulas, B. \& Taylor, J., 1992. Pathology of injuries in the vertebral column and spinal cord. In P. Vinken, B. Bruyn, H. Klauwens, \& H. Frankel, eds. Handbook of clinical neurology. Elsevier Science Publishers.

Kang, C.E., Poon, P.C., Tator, C.H. \& Shoichet, M.S., 2009. A new paradigm for local and sustained release of therapeutic molecules to the injured spinal cord for neuroprotection and tissue repair. Tissue engineering. Part $A, 15(3)$, pp.595-604. 


\section{Tissue Engineering - Central Nervous System}

Kataoka, K., Suzuki, Y., Kitada, M., Hashimoto, T., Chou, H., Bai, H., Ohta, M., Wu, S., Suzuki, K. \& Ide, C., 2004. Alginate enhances elongation of early regenerating axons in spinal cord of young rats. Tissue engineering, 10(3-4), pp.493-504.

Khor, E. \& Lim, L.Y., 2003. Implantable applications of chitin and chitosan. Biomaterials, 24(13), pp.2339-49.

Khoueir, P., Oh, B.C., DiRisio, D.J. \& Wang, M.Y., 2007. Multilevel anterior cervical fusion using a collagenhydroxyapatite matrix with iliac crest bone marrow aspirate: an 18-month follow-up study. Neurosurgery, 61(5), pp.963-70; discussion 970-1.

King, V.R., Henseler, M., Brown, R.A. \& Priestley, J. V, 2003. Mats made from fibronectin support oriented growth of axons in the damaged spinal cord of the adult rat. Experimental neurology, 182(2), pp.383-98.

King, V.R., Phillips, J.B., Brown, R.A. \& Priestley, J. V, 2004. The effects of treatment with antibodies to transforming growth factor beta1 and beta2 following spinal cord damage in the adult rat. Neuroscience, 126(1), pp.173-83.

King, V.R., Phillips, J.B., Hunt-Grubbe, H., Brown, R. \& Priestley, J. V, 2006. Characterization of non-neuronal elements within fibronectin mats implanted into the damaged adult rat spinal cord. Biomaterials, 27(3), pp.485-96.

Klinkhammer, K., Seiler, N., Grafahrend, D., Gerardo-Nava, J., Mey, J., Brook, G.A., Möller, M., Dalton, P.D. \& Klee, D., 2009. Deposition of electrospun fibers on reactive substrates for in vitro investigations. Tissue engineering. Part C, Methods, 15(1), pp.77-85.

Kwon, B.K., Roy, J., Lee, J.H.T., Okon, E., Zhang, H., Marx, J.C. \& Kindy, M.S., 2009. Magnesium chloride in a polyethylene glycol formulation as a neuroprotective therapy for acute spinal cord injury: preclinical refinement and optimization. Journal of neurotrauma, 26(8), pp.1379-93.

De la Torre, J.C., 1982. Catecholamine fiber regeneration across a collagen bioimplant after spinal cord transection. Brain research bulletin, 9(1-6), pp.545-52.

De Laporte, L., Yan, A.L. \& Shea, L.D., 2009. Local gene delivery from ECM-coated poly(lactide-co-glycolide) multiple channel bridges after spinal cord injury. Biomaterials, 30(12), pp.2361-8.

Laverty, P.H., Leskovar, A., Breur, G.J., Coates, J.R., Bergman, R.L., Widmer, W.R., Toombs, J.P., Shapiro, S. \& Borgens, R.B., 2004. A preliminary study of intravenous surfactants in paraplegic dogs: polymer therapy in canine clinical SCI. Journal of neurotrauma, 21(12), pp.1767-77.

Lesný, P., De Croos, J., Prádný, M., Vacík, J., Michálek, J., Woerly, S. \& Syková, E., 2002. Polymer hydrogels usable for nervous tissue repair. Journal of chemical neuroanatomy, 23(4), pp.243-7.

Li, S. \& Strittmatter, S.M., 2003. Delayed systemic Nogo-66 receptor antagonist promotes recovery from spinal cord injury. The Journal of neuroscience : the official journal of the Society for Neuroscience, 23(10), pp.4219-27. 
Li, X., Yang, Z., Zhang, A., Wang, T. \& Chen, W., 2009. Repair of thoracic spinal cord injury by chitosan tube implantation in adult rats. Biomaterials, 30(6), pp.1121-32.

Li, Y., Field, P.M. \& Raisman, G., 1998. Regeneration of adult rat corticospinal axons induced by transplanted olfactory ensheathing cells. The Journal of neuroscience : the official journal of the Society for Neuroscience, 18(24), pp.10514-24.

Liang, H.-F., Hong, M.-H., Ho, R.-M., Chung, C.-K., Lin, Y.-H., Chen, C.-H. \& Sung, H.-W., 2004. Novel method using a temperature-sensitive polymer (methylcellulose) to thermally gel aqueous alginate as a $\mathrm{pH}$-sensitive hydrogel. Biomacromolecules, 5(5), pp.1917-25.

Lietz, M., Dreesmann, L., Hoss, M., Oberhoffner, S. \& Schlosshauer, B., 2006. Neuro tissue engineering of glial nerve guides and the impact of different cell types. Biomaterials, 27(8), pp.1425-36.

Liu, S., Said, G. \& Tadie, M., 2001. Regrowth of the rostral spinal axons into the caudal ventral roots through a collagen tube implanted into hemisected adult rat spinal cord. Neurosurgery, 49(1), pp.143-50; discussion 150-1.

Loh, N.K., Woerly, S., Bunt, S.M., Wilton, S.D. \& Harvey, A.R., 2001. The regrowth of axons within tissue defects in the CNS is promoted by implanted hydrogel matrices that contain BDNF and CNTF producing fibroblasts. Experimental neurology, 170(1), pp.72-84.

Luo, J., Borgens, R. \& Shi, R., 2002. Polyethylene glycol immediately repairs neuronal membranes and inhibits free radical production after acute spinal cord injury. Journal of neurochemistry, 83(2), pp.471-80.

Luo, J., Borgens, R. \& Shi, R., 2004. Polyethylene glycol improves function and reduces oxidative stress in synaptosomal preparations following spinal cord injury. Journal of neurotrauma, 21(8), pp.994-1007.

Luo, Y. \& Shoichet, M.S., 2004. A photolabile hydrogel for guided three-dimensional cell growth and migration. Nature materials, 3(4), pp.249-53.

Maquet, V., Martin, D., Scholtes, F., Franzen, R., Schoenen, J., Moonen, G. \& Jér me, R., 2001. Poly(D,L-lactide) foams modified by poly(ethylene oxide)-block-poly(D,L-lactide) copolymers and a-FGF: in vitro and in vivo evaluation for spinal cord regeneration. Biomaterials, 22(10), pp.1137-46.

Marchand, R., Woerly, S., Bertrand, L. \& Valdes, N., 1993. Evaluation of two cross-linked collagen gels implanted in the transected spinal cord. Brain research bulletin, 30(3-4), pp.415-22.

Massey, J.M., Hubscher, C.H., Wagoner, M.R., Decker, J.A., Amps, J., Silver, J. \& Onifer, S.M., 2006. Chondroitinase $A B C$ digestion of the perineuronal net promotes functional collateral sprouting in the cuneate nucleus after cervical spinal cord injury. The Journal of neuroscience : the official journal of the Society for Neuroscience, 26(16), pp.4406-14.

Midha, R., Munro, C.A., Dalton, P.D., Tator, C.H. \& Shoichet, M.S., 2003. Growth factor enhancement of peripheral nerve regeneration through a novel synthetic hydrogel tube. Journal of neurosurgery, 99(3), pp.555-65. 


\section{Tissue Engineering - Central Nervous System}

Mo, X.M., Xu, C.Y., Kotaki, M. \& Ramakrishna, S., 2004. Electrospun P(LLA-CL) nanofiber: a biomimetic extracellular matrix for smooth muscle cell and endothelial cell proliferation. Biomaterials, 25(10), pp.1883-90.

Moellers, S., Heschel, I. \& Noth, J., 2004. A newly developed orientated collagen type I scaffold for use in acute spinal cord injury - cytocompatibility and orientated nerve regeneration. Restorative neurology and neuroscience, 23, p.156.

Möllers, S., Heschel, I., Damink, L.H.H.O., Schügner, F., Deumens, R., Müller, B., Bozkurt, A., Nava, J.G., Noth, J. \& Brook, G.A., 2009. Cytocompatibility of a novel, longitudinally microstructured collagen scaffold intended for nerve tissue repair. Tissue engineering. Part A, 15(3), pp.461-72.

Morgenstern, D.A., Asher, R.A. \& Fawcett, J.W., 2002. Chondroitin sulphate proteoglycans in the CNS injury response. Progress in brain research, 137, pp.313-32.

Murugan, R. \& Ramakrishna, S., 2007. Design strategies of tissue engineering scaffolds with controlled fiber orientation. Tissue engineering, 13(8), pp.1845-66.

Niederöst, B., Oertle, T., Fritsche, J., McKinney, R.A. \& Bandtlow, C.E., 2002. Nogo-A and myelin-associated glycoprotein mediate neurite growth inhibition by antagonistic regulation of RhoA and Rac1. The Journal of neuroscience : the official journal of the Society for Neuroscience, 22(23), pp.10368-76.

Nomura, H., Baladie, B., Katayama, Y., Morshead, C.M., Shoichet, M.S. \& Tator, C.H., 2008a. Delayed implantation of intramedullary chitosan channels containing nerve grafts promotes extensive axonal regeneration after spinal cord injury. Neurosurgery, 63(1), pp.127-41; discussion 141-3.

Nomura, H., Katayama, Y., Shoichet, M.S. \& Tator, C.H., 2006a. Complete spinal cord transection treated by implantation of a reinforced synthetic hydrogel channel results in syringomyelia and caudal migration of the rostral stump. Neurosurgery, 59(1), pp.183-92; discussion 183-92.

Nomura, H., Tator, C.H. \& Shoichet, M.S., 2006b. Bioengineered strategies for spinal cord repair. Journal of neurotrauma, 23(3-4), pp.496-507.

Nomura, H., Zahir, T., Kim, H., Katayama, Y., Kulbatski, I., Morshead, C.M., Shoichet, M.S. \& Tator, C.H., 2008 b. Extramedullary chitosan channels promote survival of transplanted neural stem and progenitor cells and create a tissue bridge after complete spinal cord transection. Tissue engineering. Part A, 14(5), pp.64965.

Novikov, L.N., Novikova, L.N., Mosahebi, A., Wiberg, M., Terenghi, G. \& Kellerth, J.-O., 2002. A novel biodegradable implant for neuronal rescue and regeneration after spinal cord injury. Biomaterials, 23(16), pp.3369-76.

Novikova, L.N., Pettersson, J., Brohlin, M., Wiberg, M. \& Novikov, L.N., 2008. Biodegradable poly-betahydroxybutyrate scaffold seeded with Schwann cells to promote spinal cord repair. Biomaterials, 29(9), pp.1198-206. 
Oudega, M., Gautier, S.E., Chapon, P., Fragoso, M., Bates, M.L., Parel, J.M. \& Bunge, M.B., 2001. Axonal regeneration into Schwann cell grafts within resorbable poly(alpha-hydroxyacid) guidance channels in the adult rat spinal cord. Biomaterials, 22(10), pp.1125-36.

Paíno, C.L., Fernandez-Valle, C., Bates, M.L. \& Bunge, M.B., 1994. Regrowth of axons in lesioned adult rat spinal cord: promotion by implants of cultured Schwann cells. Journal of neurocytology, 23(7), pp.433-52.

Park, K.K., Liu, K., Hu, Y., Smith, P.D., Wang, C., Cai, B., Xu, B., Connolly, L., Kramvis, I., Sahin, M. \& He, Z., 2008. Promoting axon regeneration in the adult CNS by modulation of the PTEN/mTOR pathway. Science (New York, N.Y.), 322(5903), pp.963-6.

Pasterkamp, R.J., Giger, R.J., Ruitenberg, M.J., Holtmaat, A.J., De Wit, J., De Winter, F. \& Verhaagen, J., 1999. Expression of the gene encoding the chemorepellent semaphorin III is induced in the fibroblast component of neural scar tissue formed following injuries of adult but not neonatal CNS. Molecular and cellular neurosciences, 13(2), pp.143-66.

Patist, C.M., Mulder, M.B., Gautier, S.E., Maquet, V., Jérôme, R. \& Oudega, M., 2004. Freeze-dried poly(D,L-lactic acid) macroporous guidance scaffolds impregnated with brain-derived neurotrophic factor in the transected adult rat thoracic spinal cord. Biomaterials, 25(9), pp.1569-82.

Pearse, D.D., Sanchez, A.R., Pereira, F.C., Andrade, C.M., Puzis, R., Pressman, Y., Golden, K., Kitay, B.M., Blits, B., Wood, P.M. \& Bunge, M.B., 2007. Transplantation of Schwann cells and/or olfactory ensheathing glia into the contused spinal cord: Survival, migration, axon association, and functional recovery. Glia, 55(9), pp.976-1000.

Phillips, J.B., King, V.R., Ward, Z., Porter, R.A., Priestley, J. V \& Brown, R.A., 2004. Fluid shear in viscous fibronectin gels allows aggregation of fibrous materials for CNS tissue engineering. Biomaterials, 25(14), pp.2769-79.

Piantino, J., Burdick, J.A., Goldberg, D., Langer, R. \& Benowitz, L.I., 2006. An injectable, biodegradable hydrogel for trophic factor delivery enhances axonal rewiring and improves performance after spinal cord injury. Experimental neurology, 201(2), pp.359-67.

Prádný, M., Lesný, P., Smetana, K., Vacík, J., Slouf, M., Michálek, J. \& Syková, E., 2005. Macroporous hydrogels based on 2-hydroxyethyl methacrylate. Part II. Copolymers with positive and negative charges, polyelectrolyte complexes. Journal of materials science. Materials in medicine, 16(8), pp.767-73.

Prang, P., Müller, R., Eljaouhari, A., Heckmann, K., Kunz, W., Weber, T., Faber, C., Vroemen, M., Bogdahn, U. \& Weidner, N., 2006. The promotion of oriented axonal regrowth in the injured spinal cord by alginatebased anisotropic capillary hydrogels. Biomaterials, 27(19), pp.3560-9.

Prinjha, R., Moore, S.E., Vinson, M., Blake, S., Morrow, R., Christie, G., Michalovich, D., Simmons, D.L. \& Walsh, F.S., 2000. Inhibitor of neurite outgrowth in humans. Nature, 403(6768), pp.383-4.

Raisman, G., 2001. Olfactory ensheathing cells - another miracle cure for spinal cord injury? Nature reviews. Neuroscience, 2(5), pp.369-75.

Ramon y Cajal, S., 1928a. Degeneration and regeneration of the nervous system, Oxford: Oxford University Press. 


\section{Tissue Engineering - Central Nervous System}

Ramon y Cajal, S., 1928b. Degeneration and regeneration of the nervous system, Oxford: Oxford University Press.

Reier, P., Stensaas, L. \& Guth, L., 1983. The astrocytic scar s an impediment to regeneration in the central nervous system. In C. Kao, P. Bunge, \& P. Reir, eds. Spinal cord reconstruction. New York: Raven Press, pp. 151-162.

Richardson, P.M., McGuinness, U.M. \& Aguayo, A.J., 1980. Axons from CNS neurons regenerate into PNS grafts. Nature, 284(5753), pp.264-5.

Rocha, L.B., Goissis, G. \& Rossi, M.A., 2002. Biocompatibility of anionic collagen matrix as scaffold for bone healing. Biomaterials, 23(2), pp.449-56.

Rochkind, S., Shahar, A., Amon, M. \& Nevo, Z., 2002. Transplantation of embryonal spinal cord nerve cells cultured on biodegradable microcarriers followed by low power laser irradiation for the treatment of traumatic paraplegia in rats. Neurological research, 24(4), pp.355-60.

Rogers, S.L., Letourneau, P.C., Peterson, B.A., Furcht, L.T. \& McCarthy, J.B., 1987. Selective interaction of peripheral and central nervous system cells with two distinct cell-binding domains of fibronectin. The Journal of cell biology, 105(3), pp.1435-42.

Ruszczak, Z., 2003. Effect of collagen matrices on dermal wound healing. Advanced drug delivery reviews, 55(12), pp.1595-611.

Ruszczak, Z. \& Friess, W., 2003. Collagen as a carrier for on-site delivery of antibacterial drugs. Advanced drug delivery reviews, 55(12), pp.1679-98.

Schmidt, C.E. \& Leach, J.B., 2003. Neural tissue engineering: strategies for repair and regeneration. Annual review of biomedical engineering, 5, pp.293-347.

Schnell, E., Klinkhammer, K., Balzer, S., Brook, G., Klee, D., Dalton, P. \& Mey, J., 2007. Guidance of glial cell migration and axonal growth on electrospun nanofibers of poly-epsilon-caprolactone and a collagen/polyepsilon-caprolactone blend. Biomaterials, 28(19), pp.3012-25.

Schoof, H., Apel, J., Heschel, I. \& Rau, G., 2001. Control of pore structure and size in freeze-dried collagen sponges. Journal of biomedical materials research, 58(4), pp.352-7.

Schwab, M.E. \& Bartholdi, D., 1996. Degeneration and regeneration of axons in the lesioned spinal cord. Physiological reviews, 76(2), pp.319-70.

Shi, R. \& Borgens, R.B., 1999. Acute repair of crushed guinea pig spinal cord by polyethylene glycol. Journal of neurophysiology, 81(5), pp.2406-14.

Shi, R. \& Borgens, R.B., 2000. Anatomical repair of nerve membranes in crushed mammalian spinal cord with polyethylene glycol. Journal of neurocytology, 29(9), pp.633-43. 
Shi, R., Borgens, R.B. \& Blight, A.R., 1999. Functional reconnection of severed mammalian spinal cord axons with polyethylene glycol. Journal of neurotrauma, 16(8), pp.727-38.

Shoichet, M.S. \& Rein, D.H., 1996. In vivo biostability of a polymeric hollow fibre membrane for cell encapsulation. Biomaterials, 17(3), pp.285-90.

Silver, J. \& Miller, J.H., 2004. Regeneration beyond the glial scar. Nature reviews. Neuroscience, 5(2), pp.146-56.

Singhvi, R., Kumar, A., Lopez, G.P., Stephanopoulos, G.N., Wang, D.I., Whitesides, G.M. \& Ingber, D.E., 1994. Engineering cell shape and function. Science (New York, N.Y.), 264(5159), pp.696-8.

Smeal, R.M., Rabbitt, R., Biran, R. \& Tresco, P.A., 2005. Substrate curvature influences the direction of nerve outgrowth. Annals of biomedical engineering, 33(3), pp.376-82.

Smeal, R.M. \& Tresco, P.A., 2008. The influence of substrate curvature on neurite outgrowth is cell type dependent. Experimental neurology, 213(2), pp.281-92.

Sofroniew, M. V, 2005. Reactive astrocytes in neural repair and protection. The Neuroscientist : a review journal bringing neurobiology, neurology and psychiatry, 11(5), pp.400-7.

Stokols, S., Sakamoto, J., Breckon, C., Holt, T., Weiss, J. \& Tuszynski, M.H., 2006. Templated agarose scaffolds support linear axonal regeneration. Tissue engineering, 12(10), pp.2777-87.

Stokols, S. \& Tuszynski, M.H., 2006. Freeze-dried agarose scaffolds with uniaxial channels stimulate and guide linear axonal growth following spinal cord injury. Biomaterials, 27(3), pp.443-51.

Stokols, S. \& Tuszynski, M.H., 2004. The fabrication and characterization of linearly oriented nerve guidance scaffolds for spinal cord injury. Biomaterials, 25(27), pp.5839-46.

Sun, T., Mai, S., Norton, D., Haycock, J.W., Ryan, A.J. \& MacNeil, S., 2005. Self-organization of skin cells in threedimensional electrospun polystyrene scaffolds. Tissue engineering, 11(7-8), pp.1023-33.

Suzuki, K., Suzuki, Y., Ohnishi, K., Endo, K., Tanihara, M. \& Nishimura, Y., 1999. Regeneration of transected spinal cord in young adult rats using freeze-dried alginate gel. Neuroreport, 10(14), pp.2891-4.

Talac, R., Friedman, J.A., Moore, M.J., Lu, L., Jabbari, E., Windebank, A.J., Currier, B.L. \& Yaszemski, M.J., 2004. Animal models of spinal cord injury for evaluation of tissue engineering treatment strategies. Biomaterials, 25(9), pp.1505-10.

Taylor, S.J., McDonald, J.W. \& Sakiyama-Elbert, S.E., 2004. Controlled release of neurotrophin-3 from fibrin gels for spinal cord injury. Journal of controlled release : official journal of the Controlled Release Society, 98(2), pp.281-94.

Teng, Y.D., Lavik, E.B., Qu, X., Park, K.I., Ourednik, J., Zurakowski, D., Langer, R. \& Snyder, E.Y., 2002. Functional recovery following traumatic spinal cord injury mediated by a unique polymer scaffold seeded with neural 


\section{Tissue Engineering - Central Nervous System}

stem cells. Proceedings of the National Academy of Sciences of the United States of America, 99(5), pp.3024-9.

Thallmair, M., Metz, G.A., Z'Graggen, W.J., Raineteau, O., Kartje, G.L. \& Schwab, M.E., 1998. Neurite growth inhibitors restrict plasticity and functional recovery following corticospinal tract lesions. Nature neuroscience, $1(2)$, pp.124-31.

Thompson, J.M. \& Pelto, D.J., 1982. Attachment, survival and neurite extension of chick embryo retinal neurons on various culture substrates. Developmental neuroscience, 5(5-6), pp.447-57.

Tian, W.M., Hou, S.P., Ma, J., Zhang, C.L., Xu, Q.Y., Lee, I.S., Li, H.D., Spector, M. \& Cui, F.Z., 2005. Hyaluronic acidpoly-D-lysine-based three-dimensional hydrogel for traumatic brain injury. Tissue engineering, 11(3-4), pp.513-25.

Tobias, C.A., Han, S.S.W., Shumsky, J.S., Kim, D., Tumolo, M., Dhoot, N.O., Wheatley, M.A., Fischer, I., Tessler, A. \& Murray, M., 2005. Alginate encapsulated BDNF-producing fibroblast grafts permit recovery of function after spinal cord injury in the absence of immune suppression. Journal of neurotrauma, 22(1), pp.138-56

Tsai, E.C., Dalton, P.D., Shoichet, M.S. \& Tator, C.H., 2006. Matrix inclusion within synthetic hydrogel guidance channels improves specific supraspinal and local axonal regeneration after complete spinal cord transection. Biomaterials, 27(3), pp.519-33.

Tsai, E.C., Dalton, P.D., Shoichet, M.S. \& Tator, C.H., 2004. Synthetic hydrogel guidance channels facilitate regeneration of adult rat brainstem motor axons after complete spinal cord transection. Journal of neurotrauma, 21(6), pp.789-804.

Tsang, V.L. \& Bhatia, S.N., 2004. Three-dimensional tissue fabrication. Advanced drug delivery reviews, 56(11), pp.1635-47.

Tysseling-Mattiace, V.M., Sahni, V., Niece, K.L., Birch, D., Czeisler, C., Fehlings, M.G., Stupp, S.I. \& Kessler, J.A., 2008. Self-assembling nanofibers inhibit glial scar formation and promote axon elongation after spinal cord injury. The Journal of neuroscience : the official journal of the Society for Neuroscience, 28(14), pp.3814-23.

Vavrek, R., Pearse, D.D. \& Fouad, K., 2007. Neuronal populations capable of regeneration following a combined treatment in rats with spinal cord transection. Journal of neurotrauma, 24(10), pp.1667-73.

Vidal-Sanz, M., Bray, G.M., Villegas-Pérez, M.P., Thanos, S. \& Aguayo, A.J., 1987. Axonal regeneration and synapse formation in the superior colliculus by retinal ganglion cells in the adult rat. The Journal of neuroscience : the official journal of the Society for Neuroscience, 7(9), pp.2894-909.

Wang, K.C., Kim, J.A., Sivasankaran, R., Segal, R. \& He, Z., 2002a. P75 interacts with the Nogo receptor as a coreceptor for Nogo, MAG and OMgp. Nature, 420(6911), pp.74-8.

Wang, K.C., Koprivica, V., Kim, J.A., Sivasankaran, R., Guo, Y., Neve, R.L. \& He, Z., 2002b. Oligodendrocyte-myelin glycoprotein is a Nogo receptor ligand that inhibits neurite outgrowth. Nature, 417(6892), pp.941-4. 
Wang, K.K., Nemeth, I.R., Seckel, B.R., Chakalis-Haley, D.P., Swann, D.A., Kuo, J.W., Bryan, D.J. \& Cetrulo, C.L., 1998. Hyaluronic acid enhances peripheral nerve regeneration in vivo. Microsurgery, 18(4), pp.270-5.

Wang, Z.H., Walter, G.F. \& Gerhard, L., 1996. The expression of nerve growth factor receptor on Schwann cells and the effect of these cells on the regeneration of axons in traumatically injured human spinal cord. Acta neuropathologica, 91(2), pp.180-4.

Wen, X. \& Tresco, P.A., 2006. Effect of filament diameter and extracellular matrix molecule precoating on neurite outgrowth and Schwann cell behavior on multifilament entubulation bridging device in vitro. Journal of biomedical materials research. Part A, 76(3), pp.626-37.

Woerly, S., Doan, V.D., Evans-Martin, F., Paramore, C.G. \& Peduzzi, J.D., 2001a. Spinal cord reconstruction using NeuroGel implants and functional recovery after chronic injury. Journal of neuroscience research, 66(6), pp.1187-97.

Woerly, S., Doan, V.D., Sosa, N., de Vellis, J. \& Espinosa, A., 2001b. Reconstruction of the transected cat spinal cord following NeuroGel implantation: axonal tracing, immunohistochemical and ultrastructural studies. International journal of developmental neuroscience : the official journal of the International Society for Developmental Neuroscience, 19(1), pp.63-83.

Woerly, S., Doan, V.D., Sosa, N., de Vellis, J. \& Espinosa-Jeffrey, A., 2004. Prevention of gliotic scar formation by NeuroGel allows partial endogenous repair of transected cat spinal cord. Journal of neuroscience research, 75(2), pp.262-72.

Woerly, S., Petrov, P., Syková, E., Roitbak, T., Simonová, Z. \& Harvey, A.R., 1999. Neural tissue formation within porous hydrogels implanted in brain and spinal cord lesions: ultrastructural, immunohistochemical, and diffusion studies. Tissue engineering, 5(5), pp.467-88.

Woerly, S., Pinet, E., de Robertis, L., Van Diep, D. \& Bousmina, M., 2001c. Spinal cord repair with PHPMA hydrogel containing RGD peptides (NeuroGel). Biomaterials, 22(10), pp.1095-111.

Wong, D.Y., Hollister, S.J., Krebsbach, P.H. \& Nosrat, C., 2007. Poly(epsilon-caprolactone) and poly (L-lactic-coglycolic acid) degradable polymer sponges attenuate astrocyte response and lesion growth in acute traumatic brain injury. Tissue engineering, 13(10), pp.2515-23.

Wu, S., Suzuki, Y., Kitada, M., Kitaura, M., Kataoka, K., Takahashi, J., Ide, C. \& Nishimura, Y., 2001. Migration, integration, and differentiation of hippocampus-derived neurosphere cells after transplantation into injured rat spinal cord. Neuroscience letters, 312(3), pp.173-6.

Xu, X.M., Chen, A., Guénard, V., Kleitman, N. \& Bunge, M.B., 1997. Bridging Schwann cell transplants promote axonal regeneration from both the rostral and caudal stumps of transected adult rat spinal cord. Journal of neurocytology, 26(1), pp.1-16.

Xu, X.M., Guénard, V., Kleitman, N., Aebischer, P. \& Bunge, M.B., 1995a. A combination of BDNF and NT-3 promotes supraspinal axonal regeneration into Schwann cell grafts in adult rat thoracic spinal cord. Experimental neurology, 134(2), pp.261-72. 


\section{Tissue Engineering - Central Nervous System}

Xu, X.M., Guénard, V., Kleitman, N. \& Bunge, M.B., 1995b. Axonal regeneration into Schwann cell-seeded guidance channels grafted into transected adult rat spinal cord. The Journal of comparative neurology, 351(1), pp.145-60.

Xu, X.M., Zhang, S.X., Li, H., Aebischer, P. \& Bunge, M.B., 1999. Regrowth of axons into the distal spinal cord through a Schwann-cell-seeded mini-channel implanted into hemisected adult rat spinal cord. The European journal of neuroscience, 11(5), pp.1723-40.

Yamada, K.M. \& Olden, K., 1978. Fibronectins--adhesive glycoproteins of cell surface and blood. Nature, 275(5677), pp.179-84.

Yoshii, S. \& Oka, M., 2001. Peripheral nerve regeneration along collagen filaments. Brain research, 888(1), pp.158-162.

Yoshii, S., Oka, M., Shima, M., Akagi, M. \& Taniguchi, A., 2003. Bridging a spinal cord defect using collagen filament. Spine, 28(20), pp.2346-51.

Yu, X. \& Bellamkonda, R. V, 2001. Dorsal root ganglia neurite extension is inhibited by mechanical and chondroitin sulfate-rich interfaces. Journal of neuroscience research, 66(2), pp.303-10.

Z'Graggen, W.J., Metz, G.A., Kartje, G.L., Thallmair, M. \& Schwab, M.E., 1998. Functional recovery and enhanced corticofugal plasticity after unilateral pyramidal tract lesion and blockade of myelin-associated neurite growth inhibitors in adult rats. The Journal of neuroscience : the official journal of the Society for Neuroscience, 18(12), pp.4744-57.

Zahir, T., Nomura, H., Guo, X.D., Kim, H., Tator, C., Morshead, C. \& Shoichet, M., 2008. Bioengineering neural stem/progenitor cell-coated tubes for spinal cord injury repair. Cell transplantation, 17(3), pp.245-54.

Zhong, S., Teo, W.E., Zhu, X., Beuerman, R.W., Ramakrishna, S. \& Yung, L.Y.L., 2006. An aligned nanofibrous collagen scaffold by electrospinning and its effects on in vitro fibroblast culture. Journal of biomedical materials research. Part A, 79(3), pp.456-63. 


\section{Chapter 3}

\section{Human neural cell interactions with orientated electrospun nanofibers in vitro}

Jose Gerardo-Nava ${ }^{1}$, Tobias Führmann ${ }^{2}$, Kristina Klinkhammer ${ }^{3}$, Nadine Seiler ${ }^{4}$, Jörg Mey $^{4}$, Doris Klee ${ }^{3}$, Martin Möller ${ }^{3}$, Paul D Dalton ${ }^{5}$ \& Gary A Brook ${ }^{1,2}$

${ }^{1}$ Institute for Neuropathology, Medical Faculty, RWTHAachen University, Germany

${ }^{2}$ Department of Neurology, Medical Faculty, RWTH Aachen University, Germany

${ }^{3}$ Institute for Technical \& Macromolecular Chemistry and DWI e.V., RWTH Aachen University, Germany

${ }^{4}$ Institute for Biology II, RWTHAachen University, Germany

${ }^{5}$ School of Biological Sciences, RWTH Aachen University 


\begin{abstract}
Aim: Electrospun nanofibers represent potent guidance substrates for nervous tissue repair. Development of nanofiber-based scaffolds for CNS repair requires, as a first step, an understanding of appropriate neural cell type-substrate interactions. Materials \& methods: Astrocyte-nanofiber interactions (e.g., adhesion, proliferation, process extension and migration) were studied by comparing human neural progenitor-derived astrocytes (hNP-ACS) and a human astrocytoma cell line (U373) with aligned polycaprolactone $(\mathrm{PCL})$ nanofibers or blended (25\% type I collagen/75\% $\mathrm{PCL}$ ) nanofibers. Neuron-nanofiber interactions were assessed using a differentiated human neuroblastoma cell line (SH-SY5Y). Results \& discussion: U373 cells and hNP-AC showed similar process alignment and length when associated with $\mathrm{PCL}$ or Type I collagen/PCL nanofibers. Cell adhesion and migration by hNP-AC were clearly improved by functionalization of nanofiber surfaces with type I collagen. Functionalized nanofibers had no such effect on U373 cells. Another clear difference between the U373 cells and hNP-AC interactions with the nanofiber substrate was proliferation; the cell line demonstrating strong proliferation, whereas the hNP-AC line showed no proliferation on either type of nanofiber. Long axonal growth (up to $600 \mu \mathrm{m}$ in length) of SH-SY5Y neurons followed the orientation of both types of nanofibers even though adhesion of the processes to the fibers was poor. Conclusion: The use of cell lines is of only limited predictive value when studying cell-substrate interactions but both morphology and alignment of human astrocytes were affected profoundly by nanofibers. Nanofiber surface functionalization with collagen significantly improved hNP-AC adhesion and migration. Alternative forms of functionalization may be required for optimal axon-nanofiber interactions.
\end{abstract}

KEYWORDS: astrocyte, collagen, electrospinning, human cell lines, human fetal neural progenitors, nanofibers, NHNP, polycaprolactone, SH-SY5Y, U373 


\section{Introduction}

Traumatic injury to the spinal cord induces permanent functional deficits through axonal damage, disruption of the well-organized cytoarchitecture of the lesioned white-matter tracts and the presence of an environment that is hostile to axonal regrowth and tissue repair (Schwab \& Bartholdi 1996). In particular, the formation of a disorganized reactive astrocytic scar and the deposition of axon growth repulsive extracellular matrix (ECM) molecules in and around the lesion present a potent physical and molecular barrier to axon regeneration (Fawcett 2006; Fawcett \& Asher 1999; Reier \& Houle 1988). The lesioninduced increase of expression of a number of molecules known to influence axonal guidance during development is believed to have similar effects on axonal sprouts following injury (Fawcett 2006; Tessier-Lavigne \& Goodman 1996). Attempts to bridge the inhibitory environment of the lesion have included the implantation of oriented growthpromoting tissues (e.g., peripheral nerve) and, more recently, oriented biomaterials that are capable of supporting directional axon regeneration and tissue repair (reviewed in (Dalton \& Mey 2009; Schmidt \& Leach 2003)). Attempts to design the ideal scaffold for such bridging strategies have prompted numerous investigations of cell-substrate interactions. The influence of substrate topography and chemical composition on cell form and function has thus become a subject of increasing interest in the field of tissue engineering research (Dike et al. 1999; Singhvi et al. 1994). A promising aspect to patterned substrate research has been the demonstration that aligned ECM, as well as micron-scale topography of fibers or grooves, has profound effects on the guidance and orientation of regenerating cells and their processes (Biran et al. 2007; Dubey et al. 2001; Lietz et al. 2006; Murugan \& Ramakrishna 2007; Schmidt \& Leach 2003; Wen \& Tresco 2006). This is of particular interest for the development of biomaterial-based scaffolds capable of promoting the repair of traumatically injured nerves of the peripheral nervous system (PNS) or white matter tracts of the CNS (Lietz et al. 2006; Yoshii et al. 2003a; Yoshii \& Oka 2001). In vitro studies have demonstrated the influence of fiber diameter on the orientation of process outgrowth. The greater surface curvature of small-diameter fibers prompted an increasing tendency for neurite outgrowth to follow the longitudinal axis of the fibers. Small-caliber fibers (5-30 $\mu \mathrm{m}$ diameters) promoted much greater oriented process growth than large-caliber fibers (up to $500 \mu \mathrm{m}$ diameter). This phenomenon is not owing to chemotropism but rather to the topograpraphical effect of the fiber on neurite growth (Smeal et al. 2005; Smeal \& Tresco 2008). Recent advances in nanotechnology and a renewed focus on electrospinning has led to an interest in cell interactions with substrates in the sub-micron range. Recently, we have demonstrated a novel method for electrospinning highly oriented fibers (up to several $\mathrm{cm}$ in length) that can be transferred and stabilized at either high or low density on flat surfaces, enabling 
the interactions between single cells and single fibers to be observed in vitro over a number of days (Schnell et al. 2007). The ability of fibers with diameters in the sub-micron range to affect the behavior of non-neural cells (Mo et al. 2004; Sun et al. 2005; Zhong et al. 2006) as well as neural cells of the PNS has been demonstrated recently in in vitro assays (Corey et al. 2007; Schnell et al. 2007). Cell adhesion, survival and proliferation were well supported, whereas morphology and alignment were strikingly altered by oriented nanofibers. Oriented fibers promoted longer axonal extension than non-oriented fibers (Corey et al. 2007; Corey et al. 2008) but fiber composition also has a role; functionalization of polycaprolactone ( $P C L$ ) fiber surfaces with type I collagen (C/PCL) increased cell adherence, proliferation and process extension (Schnell et al. 2007). It is clear that oriented nanofibers have a significant role in scaffold designs intended to promote axon regeneration in the PNS but their potential for supporting bridging CNS lesions remains uncertain. As a first step in assessing this potential, the present investigation was performed to study astroglial interactions (i.e., adhesion, morphological appearance, proliferation and migration) with electrospun $\mathrm{PCL}$ and $\mathrm{C} / \mathrm{PCL}$ in vitro. The in vitro testing of neural cell-biomaterial interactions has often relied on the use of cell lines (Corey et al. 2007; Cui et al. 2001; Dumont \& Born 2005; Kullenberg et al. 2008; Li et al. 2007; Unger et al. 2004; Yang et al. 2004; Yang et al. 2005; Zhu et al. 2005) or, less frequently, on freshly dissociated primary cells grown in serum-supplemented (Corey et al. 2007; Goldner et al. 2006; Schnell et al. 2007; Winter et al. 2007) or serum-free (Corey et al. 2008) media. The use of popular cell lines to predict the behavior of primary cells may be limited but the extent of this limitation is uncertain. Here, we have investigated the astrocyte-nanofiber interactions using the human U373 astrocytoma cell line as well as fetal normal human neural progenitor-derived astrocytes. Furthermore, neuronnanofiber interactions were investigated using neuronally differentiated human SH-SY5Y neuroblastoma cells. Earlier investigations had demonstrated the relative superiority of $\mathrm{C} / \mathrm{PCL}$ nanofibers over PCL-only nanofibers using a range of primary PNS-related neural and non-neural cell types from experimental animals, including embryonic chicks and adult rats (Schnell et al. 2007). The collagen-containing nanofibers supported improved glial attachment, migration, process extension and axonal growth. However, the ability of such nanofibers to support similar behavior of human neural cells remained untested. The present study shows that the use of an astrocytic cell line has relatively little predictive value of the responses of human neural progenitor-derived astrocytes (hNP-ACs) substrate interactions. Furthermore, although cell morphology and alignment of human astrocytes are clearly influenced by their interactions with fibers, the functionalization of the surface of the nanofibers by incorporation of type I collagen significantly improves the extent of cell migration by the hNP-ACs. The relatively poor adhesion of neuronally differentiated $\mathrm{SH}-\mathrm{SY} 5 \mathrm{Y}$ cells limited the investigations with the neuronal cell line but a clear influence of the direction of neurite growth could be demonstrated. 


\section{Materials \& methods}

\section{Glass-coverslip preparation}

The glass coverslips (12 mm diameter; Steinheim, Germany, Marienfeld) were surfacefunctionalized (Marienfeld Lauda-Königshofen, Germany), dried with toluene and placed in a glove box prior to nanofiber collection, as described previously (Groll et al. 2005). Within the glove box, $20 \mathrm{mg}$ of star-shaped polyethylene glycol (sPEG, MW $12000 \mathrm{Da}$ ) was dissolved in $0.2 \mathrm{ml}$ tetrahydrofurane. Before use, $1.8 \mathrm{ml}$ de-ionized water was added and the mixture was allowed to partially crosslink for $5 \mathrm{~min}$. The SPEG solution was sterilefiltered $(0.2 \mu \mathrm{m})$ and applied to cover-slips by spin-coating, undergoing $5 \mathrm{~s}$ of acceleration to $4000 \mathrm{rpm}$ and then maintaining this speed for $40 \mathrm{~s}$. Approximately $30 \mathrm{~min}$ was allowed for cross linking between the SPEG and the activated cover-slips prior to binding with the nanofibers. Some glass cover-slips were coated with poly-l-lysine (PLL) to provide a positive- control substrate. For this, cover-slips were washed in distilled water, soaked in $70 \%$ ethanol for $15 \mathrm{~min}$, and then rinsed again in distilled water before immersion in PLL (100 ng/ml, $1 \mathrm{~h})$.

\section{Electrospinning of oriented nanofibers}

Pure PCL (Sigma-Aldrich [MA, USA] MW 65000 Da), dissolved in chloroform/methanol (75:25 vol\%) or a blend of PCL and calf skin type I collagen (Sigma-Aldrich, 75:25 wt\%), then dissolved in 1,1,1,3,3,3-hexafluoro-2-propanol (Sigma-Aldrich) was prepared as a 9 wt\% solution and electrospun as described previously (Schnell et al. 2007). Electrospun nanofibers were deposited between parallel metal bars $(4 \mathrm{~cm}$ apart), which were positioned $20 \mathrm{~cm}$ from the spinneret and acted as grounded nanofiber collectors. The nanofibers were then collected by passing the sPEG-coated glass cover-slips through the array (Schnell et al. 2007). Fiber diameter was measured from high-resolution scanningelectron microscopy (SEM) images of the electrospun fibers ( $n=50$ for each fiber type). To quantify the number of low density PCL and C/PCL fibers used in the present assays, five randomly chosen fields were photographed from each of three $P C L$ and $C / P C L$ samples. $A$ line, of defined length $(345 \mu \mathrm{m})$, perpendicular to the axis of the nanofibers was drawn and the number of fibers crossing this line was counted.

\section{Tissue culture}

Normal human neural progenitor cells were purchased through Lonza Sprl. (Verviers, Belgium) from anonymous donors, according to all state and federal guidelines. Cells were 
cultured as neurospheres in neural progenitor proliferation medium consisting of Dulbecco's Modified Eagle's Medium (DMEM)/F12 (1:1, high glucose) containing Glutamax $^{\mathrm{TM}}$ (Invitrogen, Karlsruhe, Germany), human recombinant EGF $(20 \mathrm{ng} / \mathrm{ml}$, Cell Concepts, Umkrich, Germany), human recombinant basic FGF (20 ng/ml, Invitrogen), neuronal stem cell supplement (PAA Laboratories $\mathrm{GmbH}$, Cölbe, Germany) and penicillin/streptomycin (PAA). Medium was changed every 2-3 days. Spheres were passaged using accutase (undiluted solution, PAA) as described by others (Wachs 2003). At passage 4 , the medium was changed to neural progenitor differentiation medium (NPDM), as described previously (Weible \& Chan-Ling 2007), leading to the generation of a pure population of progenitor-derived type I astrocytes after eight passages (Weible \& ChanLing 2007). Cells from passage 8-16 were used in the present experiments. Human SHSY5Y neuroblastoma cells were cultivated in (Sigma-Aldrich) supplemented with $10 \%$ fetal bovine serum (FBS). The human U373 astrocytoma cell line was cultured in DMEM/F12 $(1: 1$, GIBCO) with $10 \% \mathrm{FBS}, 1000 \mathrm{U}$ penicillin/streptomycin and $1 \%$ Glutamax (GIBCO). All cells were handled in sterile conditions and maintained in incubators at $37^{\circ} \mathrm{C}$ and $5 \% \mathrm{CO} 2$. For the in vitro assays, nanofiber-coated coverslips were placed in four-well plates, sterilized with $70 \%$ ethanol (30 $\mathrm{min}$ ) and washed twice with sterile phosphate-buffered saline before cell seeding. hNP-ACs, U373 cells and SH?SY5Y cell suspensions were applied by pipetting $500 \mu \mathrm{l}$ of a $2 \times 104 \mathrm{cell} / \mathrm{ml}$ suspension (10,000 cells/ well) onto the cover-slips. In addition, after $24 \mathrm{~h}$ in culture, the human SH-SY5Y cells were neuronally differentiated by sequential treatment with $10 \mu \mathrm{M}$ retinoic acid (RA; Sigma-Aldrich) for 5 days followed by brain-derived neurotrophic factor (BDNF; Amgen) at a concentration of $50 \mathrm{ng} / \mathrm{ml}$ in serum-free medium, as described previously (Encinas et al. 2000). This was considered day 0 and samples were cultured for 1, 4 and 7 days. Culture medium was replaced every third to fourth day. At 1, 4 and 7 days in culture, the preparations were fixed in cold $4 \%$ paraformaldehyde (PFA) at room temperature (RT) for $30 \mathrm{~min}$ for fluorescence microscopy or in $2.5 \%$ glutaraldehyde for $2 \mathrm{~h}$ for SEM.

\section{Immunocytochemistry \& F-actin staining}

After fixation, samples were processed for immunocytochemical staining, as described previously (Schnell et al. 2007). For double immunofluorescence of hNP-AC and U373 cells, a mixture of polyclonal rabbit anti-glial fibrillary acidic protein (GFAP; 1:2500, Dako) and monoclonal anti-vimentin (clone V9, 1:5000, Sigma-Aldrich) was used. The differentiated SH-SY5Y neuronal cell bodies and neuritis were detected by immunocytochemistry using rabbit anti-neurofilament 200 kDa (NF200, 1:1000, SigmaAldrich) primary antibody. The primary antibodies were detected by the use of single or combined secondary antibodies: Alexa Fluor ${ }^{\circledast}$ 488goat anti-rabbit IgG (1:500, Molecular 
Probes, Leiden, The Netherlands) and Alexa Fluor 594 goat anti-mouse IgG (1:500, Molecular Probes) for $2 \mathrm{~h}$ at RT. Cell nuclei were counterstained with 4,6-diamidino-2phenylindole dihydrochloride (DAPI, Sigma-Aldrich; $1 \mu \mathrm{g} / \mathrm{ml}$ ). Coverslips were then mounted onto microscopic slides using Fluoroprep (BioMerieux S.A., Nüttingen, Germany). Preparations were visualized with a Zeiss Axioplan fluorescence microscope coupled to an online digital camera (Axiovision software). Confocal micrographs were obtained using Leica confocal laser microscope (20x objective, using 405, 488 and $543 \mathrm{~nm}$ excitation and filter settings for DAPI, fluorescein and Cy3, sampling rate $200 \mathrm{~Hz}$, Leica 2004 software).

\section{Cell-adhesion assay \& cell-number counting}

The cell-adhesion assay, based on crystal-violet staining 90 min after cell seeding, was performed as described previously (Schnell et al. 2007). Cell proliferation/ survival was determined by counting the number of DAPI-stained cell nuclei that were associated with the PCL or C/PCL nanofiber preparations after 1,4 and 7 days in vitro (DIV). The cell counts were performed in five rectangular fields of $345 \times 435 \mu \mathrm{m}(0.15 \mathrm{~mm} 2)$ that were selected randomly for each sample.

\section{Process \& neurite length}

Process lengths of hNP-ACs and U373 cells were measured from the edge of the DAPIlabeled cell nucleus to the tip of the cell's longest process. Owing to the high proliferation rate of the U373 cell line, process length was only estimated at 1 DIV to avoid overlapping of cells and processes. The lengths of the longest $10 \%$ of at least 50 randomly chosen processes were measured for each sample. Owing to the fragility and poor attachment of the fixed, SH-SY5Y-derived axons (see results section), the processes of living cells were measured following labeling with the fluorescent lipophilic marker Di-I $(2.5 \mathrm{mg} / \mathrm{ml}$ stock solution in absolute ethanol, Molecular Probes). After the 5 day treatment with RA, the differentiating SH-SY5Y cells were incubated for $1 \mathrm{~h}$ in DMEM containing 5\% (v/v) Di-I stock solution. The nanofiber/cell combinations were then washed once in DMEM and incubated in $50 \mathrm{ng} / \mathrm{ml}$ BDNF-containing serum free medium. The fluorescent neurites of individual SH-SY5Y neuronal cell bodies (or small cell clusters) could then be visualized and measured at 1 and 7 DIV using the fluorescent microscope. 


\section{Cell-migration assay}

Cell aggregates or astrospheres of hNP-ACs and U373 cells were used for the migration assay. U373 astrospheres were generated by cultivating the cells in NPDM. Migration away from the spheres was assayed on three different substrates: orientated $\mathrm{C} / \mathrm{PCL}$ nanofibers, (orientated PCL nanofibers and PLL-coated tissue culture plastic as a nonoriented adhesion/migration-promoting substrate. Each assay was performed in triplicate, with a total of 12-15 spheres of uniform diameter $(272 \pm 10 \mu \mathrm{m})$ being plated in wells containing the different substrates. After 2 days, the spheres were fixed with $4 \%$ PFA and processed for immunocytochemistry as described earlier. Samples were observed and photographed with an inverse microscope (Leica, 10x objective) coupled to an online digital camera (Leica, Diskus software). For quantification, nine spheres from each condition were evaluated. The distance of the $10 \%$ farthest migrating DAPI nuclei along the axis of the oriented nanofibers was measured using ImageJ software. Similarly, the $10 \%$ farthest migrating cells, perpendicular to the axis of the nanofibers, were measured. For estimation of cell migration on the nonoriented PLL substrate, a line was drawn at random through the center of the sphere as well as a second line, perpendicular to the first. The farthest $10 \%$ migrating cells along these axes were then measured.

\section{Scanning-electron microscopy}

SEM was used to analyze the fine structure of cell-seeded and nonseeded nanofibers. The glutaraldehyde-fixed samples were dehydrated in acetone using a Polaron E3000 criticalpoint dryer. The specimens were then mounted on stubs and sputter coated with gold, loaded into an ESEM XL30 FEG scanning-electron microscope (Philips EO, Eindhoven, NL, USA) and viewed under an accelerating voltage of $5 \mathrm{kV}$.

\section{Statistical analysis}

All experiments were performed in triplicate unless otherwise mentioned. All data are presented as means \pm standard error of the mean. Data were subjected to a Student's ttest or analysis of variance (ANOVA) followed by a Tukey-Kramer test for multiple comparisons between pairs of means ( $p<0.05$ was regarded as significant). All of these tests were performed using statistical software GraphPad Prism version 4.0. 


\section{Results}

\section{SEM of oriented PCL \& C/PCL nanofibers}

Highly oriented nanofibers made of either PCL or the blended $C / P C L$ were prepared by electrospinning and collected onto the SPEG-coated coverslips. Similar to previous reports (Schnell et al. 2007), the diameter of both types of nanofiber was in the sub-micron range (PCL nanofiber mean diameter \pm standard deviation: $564.4 \pm 208.8 \mathrm{~nm}$; C/PCL nanofibers: $601.4 \pm 151.2 \mathrm{~nm}$ ). These fibers were uniform in diameter, were highly oriented and could be collected at both high and low density (Fig. 1A \& B). An estimation of the density of nanofibers collected under low density conditions (i.e., short electrospinning times) was obtained by counting the number of fibers crossing a sample (345 $\mu \mathrm{m}$ ) line drawn perpendicular to the axis of the fibers. Under these conditions, the density of oriented $\mathrm{PCL}$ nanofibers was $60 \pm 14$ fibers/mm (average interfiber distance $16.6 \mu \mathrm{m}$ ) and, for $\mathrm{C} / \mathrm{PCL}$ fibers, was $57 \pm 7$ fibers/mm (average interfiber distance of $17.4 \mu \mathrm{m}$ ). High-density fibers were spun to generate a dense mat of oriented fibers that covered the glass coverslips completely.
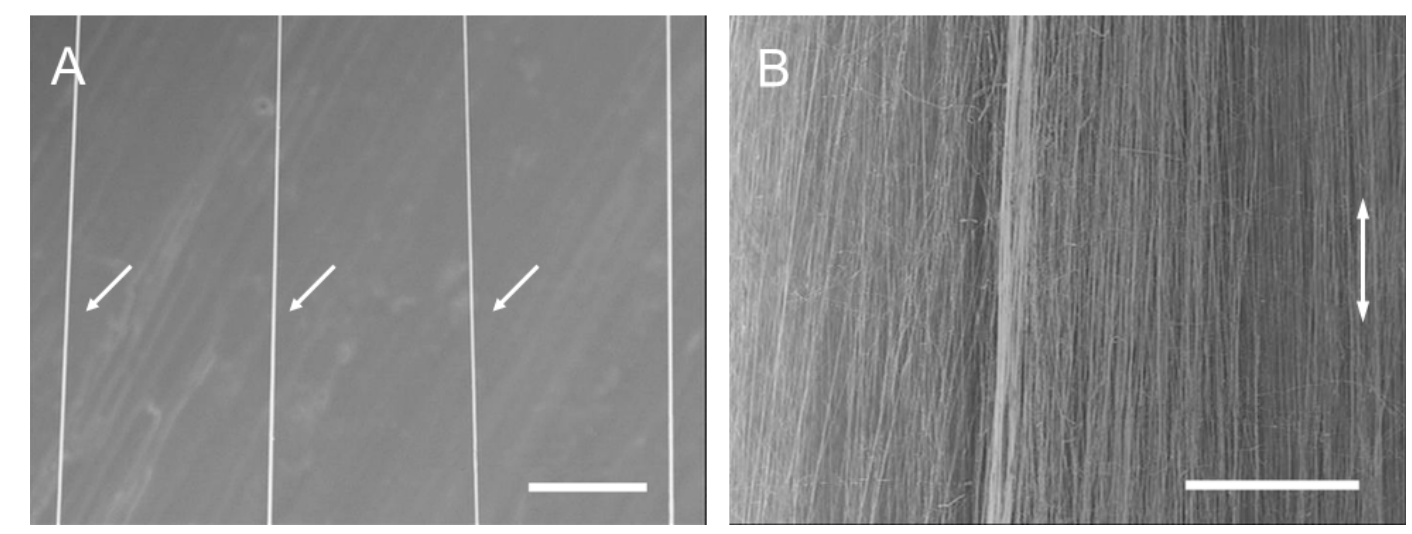

Fig. 1. Example of scanning-electron micrograph of oriented polycaprolactone nanofibers. Electrospun type I collagen polycaprolactone $(C / P C L)$ nanofibers were similar and therefore are not shown. (A) Low density, oriented nanofibers (arrows). (B) High density, oriented nanofibers. Electrospun nanofibers of either polycaprolactone or C/PCL were largely uniform in diameter and unbranched. Scale bars: (A) $30 \mu \mathrm{m}$ and (B) 200 $\mu \mathrm{m}$.

Adhesion \& proliferation/survival of cells

To establish the cytocompatibility of the PCL and C/PCL nanofibers with human CNSrelated neurons and glia, adhesion and proliferation/survival assays were carried out using the hNP-ACs, the U373 astoglioma cells and the nondifferentiated neuroblastoma SHSY5Y. Comparison of hNP-ACs and U373 cells demonstrated that very few cells bound to the poorly adhesive SPEG substrate (which served as a negative-control substrate). The U373 cells bound equally well to both PCL nanofibers and the PLL-coated surface (which 
acted as a positive control; $p>0.05$ ) but slightly less to $C / P C L$ nanofibers that showed a small but statistically significant reduction when compared with the PLL-positive control ( $p$ $<0.05$; PLL compared with C/PCL fibers; Fig. 2A). Adhesion of hNP-ACs to the different substrates was rather different. Adhesion to PCL nanofibers and PLL substrate was much lower that observed with the $\mathrm{U} 373$ cell line. The functionalized C/PCL nanofibers, however, demonstrated a significant improvement in adhesion when compared with the PCL nanofibers or PLL substrates ( $p<0.05$; Fig. 2A). The adhesion assay for the nondifferentiated SH-SY5Y was unsuccessful and, even after 90 min incubation, no cells were found on the nanofiber-carrying cover-slips, whereas cells attached to the PLL control (data not shown). As a second measure of the suitability of the nanofibers for CNSrelated cell interactions, the survival and proliferation of the cells that were bound to the nanofibers were assessed by comparing the number of bound cells detected at 1 DIV to the number of cells that were seeded initially. This approach demonstrated that the longer incubation time enabled the attachment of all seeded SY5Y cells to the three different substrates (Fig. 2B).
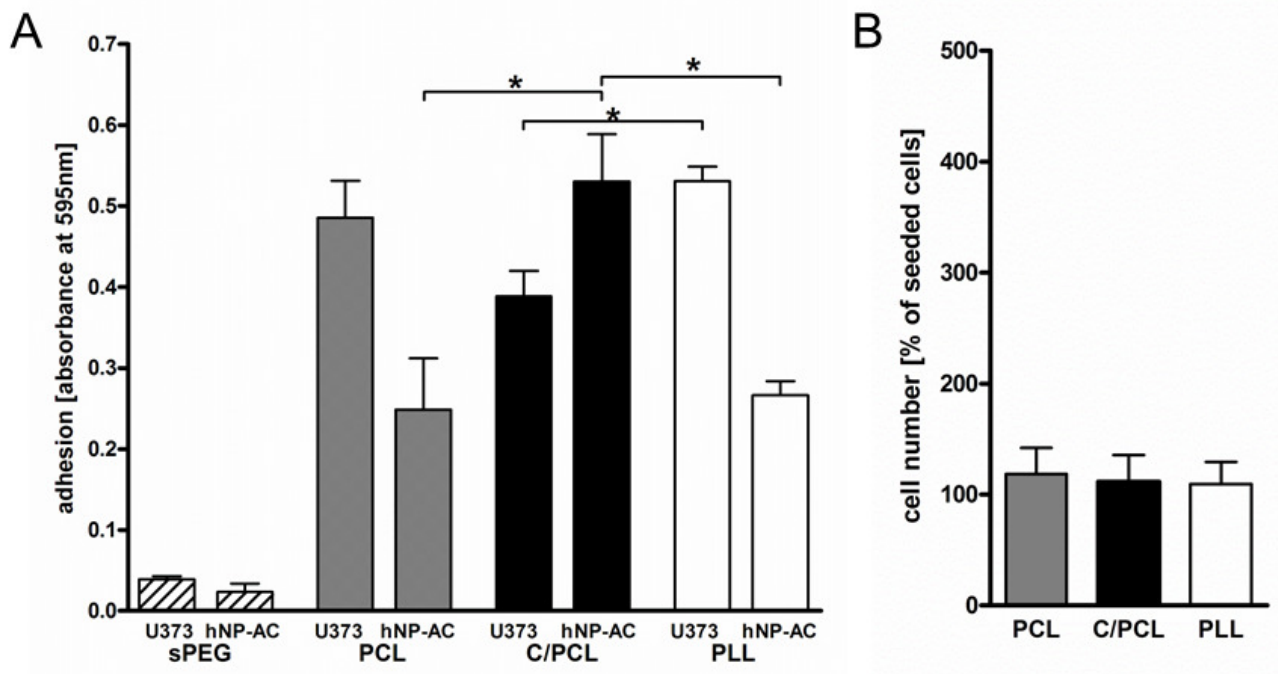

Fig. 2. Quantification of cell adhesion to polycaprolactone and type I collagen polycaprolactone nanofibers. (A) U373 cell line and hNP-AC were incubated for 90 min on SPEG (negative control), PCL fibers, C/PCL fibers and PLL (positive control) substrate. Colorimetric analysis was then used to determine cell adherence. Few U373 or hNP-AC adhered to the sPEG substrate. U373 cells adhered equally well onto PCL fibers and PLL substrate ( $p>$ $0.05)$. However, fewer cells adhered to the $C / P C L$ fibers $(p<0.05)$. hNP-AC also adhered equally well to $P C L$ fibers and PLL substrate $(p>0.05)$ but adhesion was significantly lower than that demonstrated by U373 cells ( $p$ $<0.05)$. hNP-AC adhesion to C/PCL fibers was significantly greater than that on PCL or PLL $(p<0.05)$. SH-SY5Y cell adhesion was not detectable following the 90 min incubation. (B) SH-SY5Y cells adhered equally to PCL fibers, $\mathrm{C} / \mathrm{PCL}$ fibers and PLL (positive control) substrate after a much longer $(24 \mathrm{~h}$ ) incubation. Cell counts were made from images taken using a $\times 20$ objective ( $n=5$ sample fields per substrate). C/PCL: Type I collagen polycaprolactone; hNP-AC: Human neural progenitor derived astrocytes; PCL: Polycaprolactone; PLL: Poly-Ilysine; sPEG: Star-shaped polyethylene glycol. 
The U373 astrocytoma cell line demonstrated a progressive increase in the number of cells on all substrates over 1, 4 and 7 days post-seeding (proliferation on the PLL positive control substrate being significantly greater than on PCL or C/PCL nanofibers at 4 and 7 DIV; $p<0.05)$. However, no differences in proliferation were observed between U373 cells on PCL and C/PCL nanofibers during this time (Fig. $3 \mathrm{~A}$ ). The strong proliferative capacity of the U373 cells on all substrates was in stark contrast to behavior of the hNP-AC cells. No proliferation of hNP-ACs could be detected over 1, 4 and 7 DIV on either PCL or functionalized C/PCL nanofibers. This effect was not brought about by nanofiber-induced cytotoxicity to hNP-ACs because both immunocytochemistry and DAPI staining failed to reveal necrotic cells, cellular debris or fragmented nuclei. The only statistically significant increase of hNP-AC numbers was observed on the PLL-substrate between 4 and 7 days post-seeding ( $<<0.05$; Fig. 3B). The nondifferentiated SH-SY5Y cells also showed a high degree of proliferation by 4 and 7 DIV, although no reliable quantification could be obtained by counting DAPI-labeled nuclei because of the tendency of the cell line to form dense clusters.
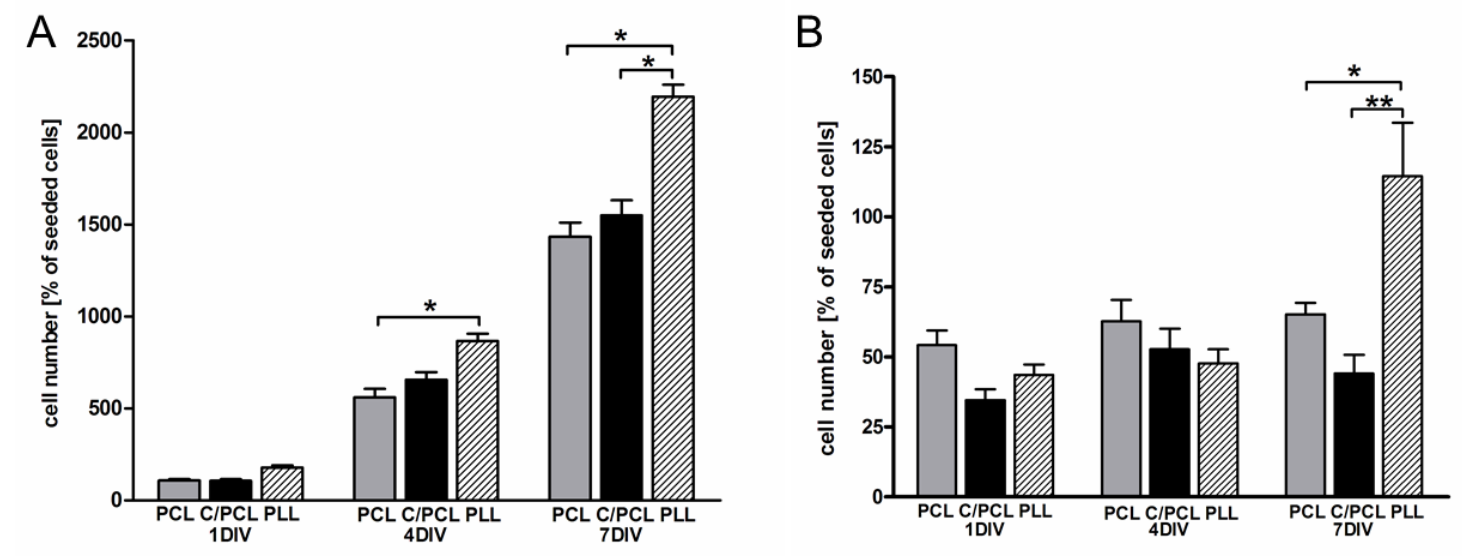

Fig. 3. Survival and proliferation of cells on polycaprolactone and type I collagen polycaprolactone fibers after 1, 4 and 7 days. (A) U373 cell numbers increase over time; however, there was no significant difference in proliferation on $\mathrm{PCL}$ or $\mathrm{C} / \mathrm{PCL}$ at any particular time point $(\mathrm{p}>0.05)$. Proliferation tended to be greater on the PLL (positive control) substrate, being significantly greater than that on $\mathrm{PCL}$ or $\mathrm{C} / \mathrm{PCL}$ at 7 days. (B) Human neural progenitor-derived astrocytes demonstrate no proliferation over 7 days on either PCL or C/PCL fibers $(p>0.05)$. Cell proliferation was, however, apparent on the PLL (positive control) substrate, being significantly greater than that on PCL or C/PCL at 7 days $(p<0.05)$. Clustering of neuronally differentiated SH-SY5Y cells on the nanofiber substrates made the counting of neurons unreliable and is therefore not shown. C/PCL: Type I collagen polycaprolactone; PCL: Polycaprolactone; PLL: Poly-I-lysine. 


\section{Morphology \& process length of cells}

The morphology of the hNP-ACs and U373 cells on all substrates was investigated by double immunofluorescence (for the cytoskeletal proteins GFAP [green] and vimentin [red]) (Fig. 4A-D \& Fig. 5A-D) and by SEM (Fig. 6A-D \& Fig. 7A-D). Both hNP-ACs and U373 cells grown on the PLL surface adopted a pleiomorphic, 'fried-egg'-type morphology with only a small proportion of cells showing a clear process-forming morphology (arrows, Fig. 4A). All hNP-ACs were vimentin- and GFAP-immunoreactive, whereas U373 cells demonstrated variable degrees of double immunoreactivity. By 1 and 4 DIV, most nanofiber-bound hNP-ACs and U373 cells had adopted either a unipolar or bipolar morphology (arrows, Fig. 4B). The high proliferation rate of the U373 cells on the nanofiber substrates prevented the unambiguous measurement of nonoverlapping processes beyond 1 DIV. The length of the processes of both cell types had already reached well over $100 \mu \mathrm{m}$ by 1 DIV (Fig. 8). Although there was a trend for U373 cells to have longer processes than the hNP-ACs on either PCL or C/PCL, the difference never reached statistical significance (U373 on PCL: $142.1 \pm 31.1$; U373 on C/PCL: $143 \pm 26.7$; hNP-ACS on PCL: $124 \pm 25.9$; hNP-ACs on C/PCL: $125.3 \pm 27.2$; Fig. 8 ; $p>0.05$ for all comparisons). The SEM clearly revealed the close interaction between the hNP-ACs or U373 cells and the nanofibers. Single cells that adhered to single fibers demonstrated a strong tendency to align their processes in parallel with the orientation of the nanofibers, the slender processes growing directly over the surface of the nanofibers (arrows, Fig. 6A \& C \& Fig. 7A) and extending simple, 'bullet-shaped' growth cone-like structures when viewed at high magnification (Fig. 6C \& D). Following the seeding of hNP-ACs or U373 suspensions onto nanofibers, occasional cells managed to span the gap between adjacent fibers, spreading their cell bodies in a flattened, sheet-like manner (e.g., arrow heads Fig. $6 \mathrm{C}$, maximal distance spanned was $20 \mu \mathrm{m}$ ). This behavior was even more pronounced in the area of cell migration immediately adjacent to the zones of astrosphere placement (Fig. 5A-C \& Fig. 7A \& B). By 7 DIV, the rapidly proliferating U373 cells demonstrated the capacity to form bundles of multiple processes that followed the orientation of single nanofibers (arrows, Fig. 6B). Where the cell density was high enough, even the areas between nanofibers became populated with oriented U373 cell bodies and processes (Fig. $4 C$ ). This behavior was also observed in areas where hNP-AC suspensions settled, by chance, in higher numbers (Fig. 4D). 

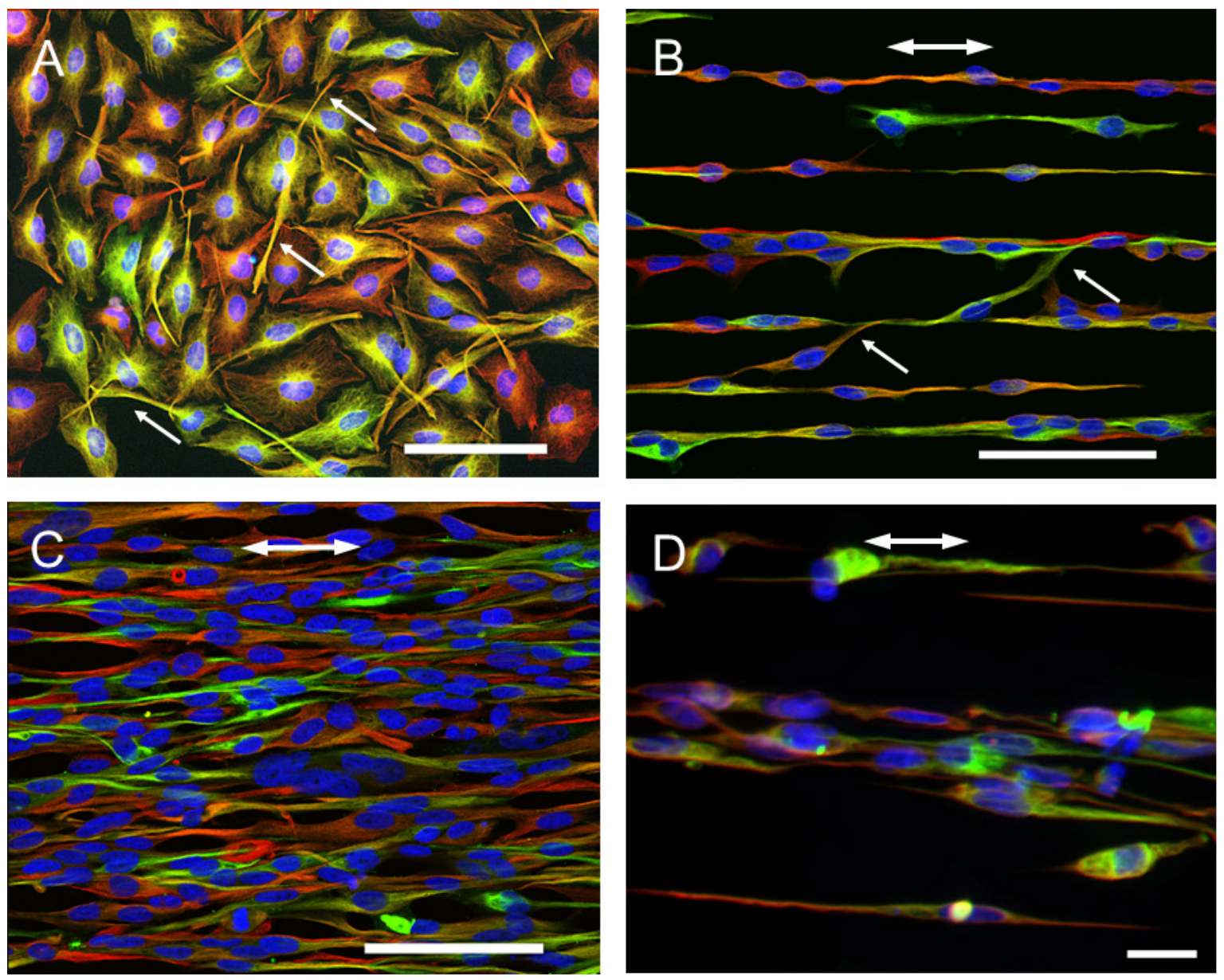

Fig. 4. Morphology and aligned-process extension of U373 cell and human neural progenitor-derived astrocytes on polycaprolactone nanofibers. Immunofluorescence for GFAP (green) and vimentin (red). (A) A nonoriented pleiomorphic appearance was adopted by most U373 cells when allowed to spread freely on the nonoriented poly-I-lysine (PLL) substrate at 4 DIV. Occasional cells demonstrated a process bearing morphology (arrows). Human neural progenitor derived astrocyte (hNP-AC) adopted a similar morphology on PLL (not shown); (B) association of U373 cells with oriented polycaprolactone (PCL) nanofibers at 4 DIV and (C) 7 DIV. Orientation of nanofibers is indicated by the double-headed arrow. Most cells remained strictly aligned and associated with individual nanofibers. However, occasional cells traversed the gap between adjacent fibers (arrows in B). Continued proliferation of cells does not appear to alter the general orientation of the densely packed U373 cells as seen in (C); (D) alignment of hNP-AC processes on PCL nanofibers. Areas of densely packed, oriented cells were attached to and also between the orientated nanofibers. (A-C) Confocal microscopy; (D) epifluorescence. The morphology and alignment of U373 cells and hNP-AC was similar on type I collagen polycaprolactone nanofibers (therefore not shown). Scale bars $=100 \mu \mathrm{m}$. 


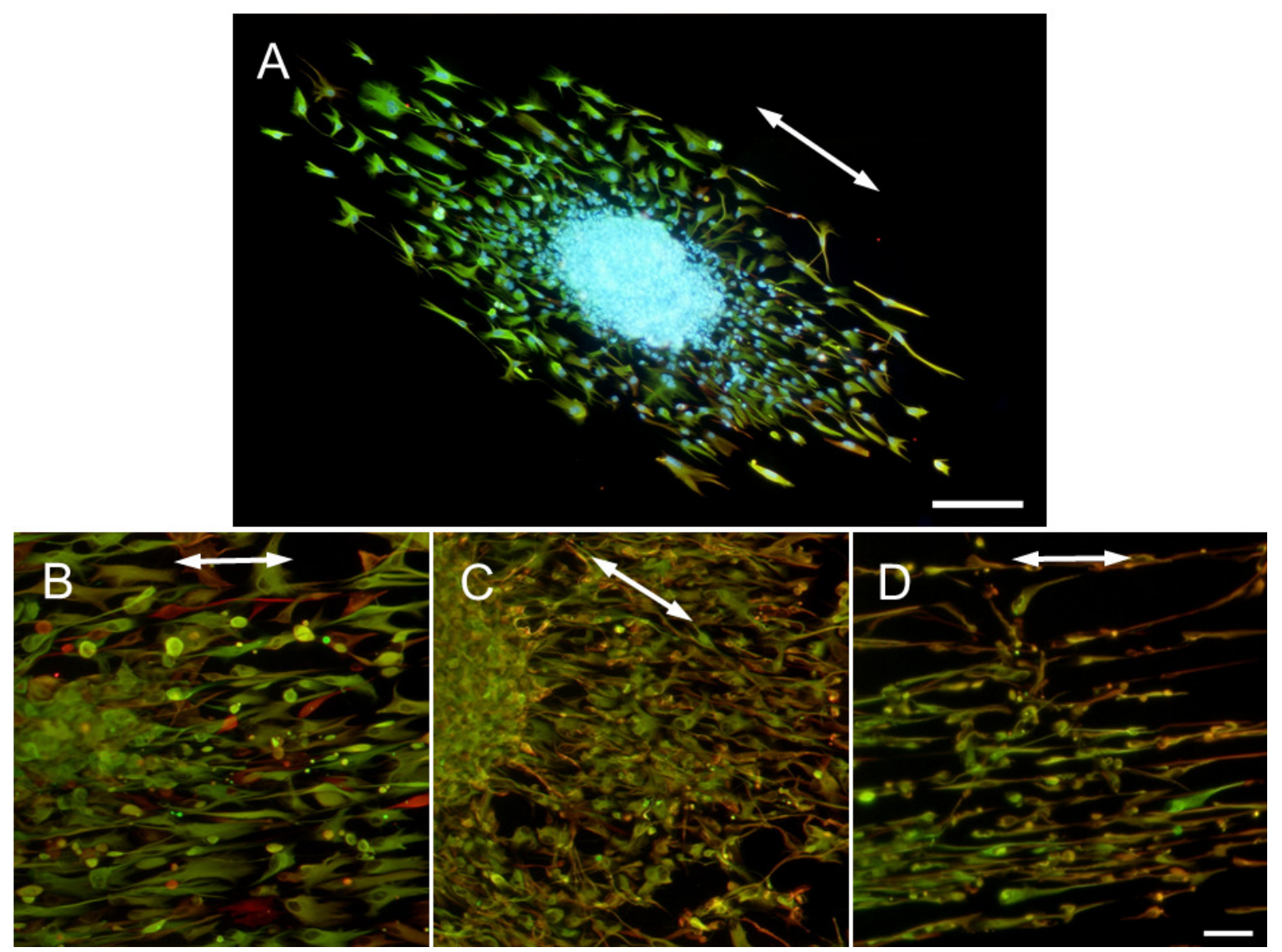

Fig. 5. Immunocytochemistry of migrating U373 cells and human neural progenitor-derived astrocytes from astrosphere preparations 2 days after seeding onto polycaprolactone and type I collagen polycaprolactone nanofibers. Immunofluorescence for GFAP (green) and vimentin (red). (A) Overview of U373 cell astrosphere on polycaprolactone (PCL) nanofibers. The cluster of densely packed cells was demonstrated clearly by the DAPI nuclear stain (blue). Migration of cells away from the astrosphere was influenced strongly by the nanofiber substrate; cells following the orientation of the fibers migrated for significantly greater distances than those that attempted to migrate perpendicular to the main axis of nanofiber orientation. This resulted in an ovoid distribution of cells around the astrosphere. (B) U373 cells having just exited the astrosphere appear as sheets of densely packed cells with spindle and flattened morphologies on type I collagen polycaprolactone (C/PCL) nanofibers. (C) Human neural progenitor-derived astrocytes (hNP-ACs), having just exited the astrosphere, showed similar packing densities and morphologies on PCL nanofibers as demonstrated by the U373 cells. (D) hNP-ACs, having migrated further away from the astrosphere along C/PCL nanofibers, adopted an elongated, spindle-shaped morphology. Orientation of nanofibers is indicated by the double headed arrow. Scale bars: $(A)=$ $200 \mu \mathrm{m}$ and $(B-D)=50 \mu \mathrm{m}$. 

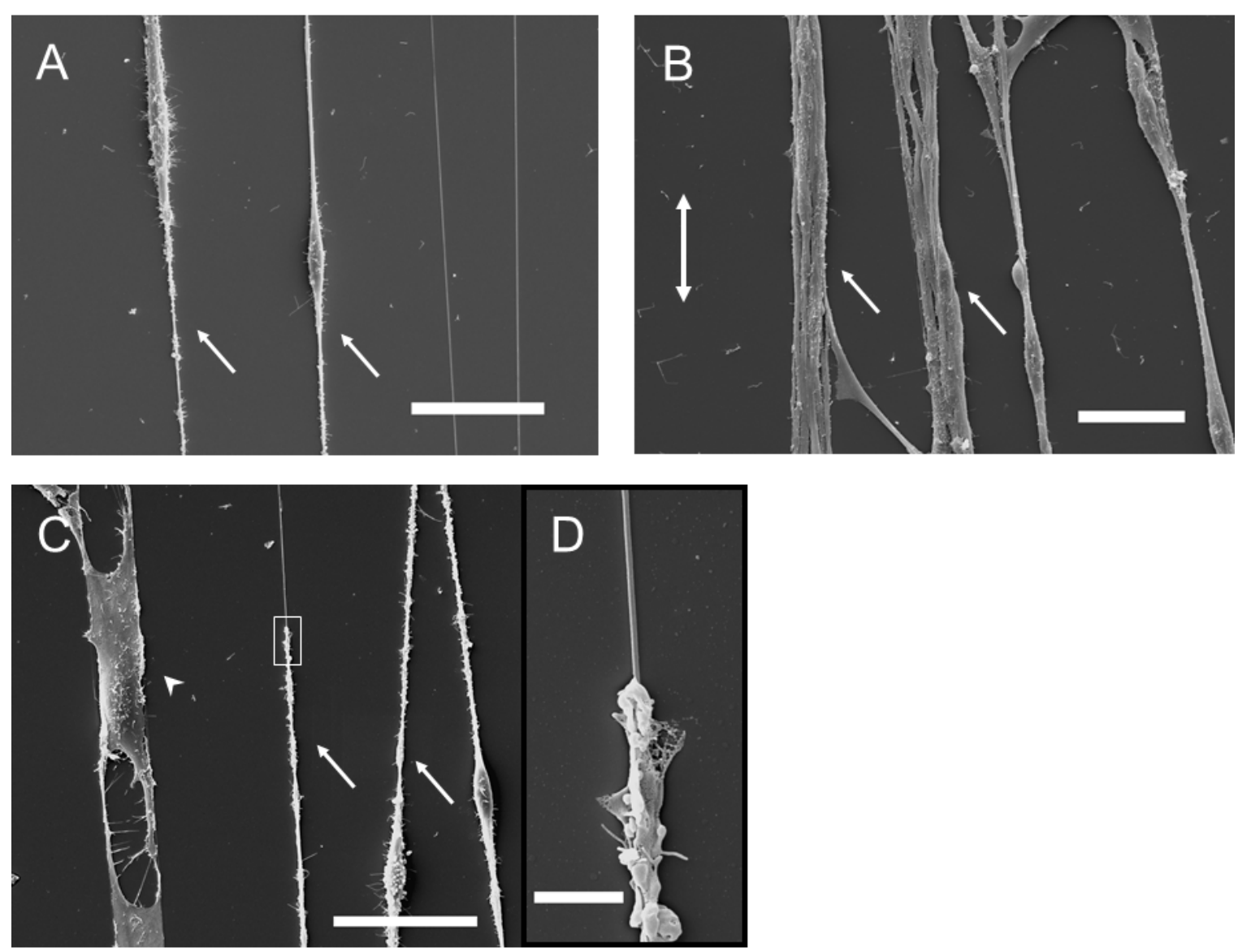

Fig. 6. Scanning-electron micrograph of dissociated U373 cells seeded onto polycaprolactone nanofibers. (A) Individual cells and their elongated, oval-shaped cell bodies and elongated process (arrows) can be seen associated closely with the oriented nanofibers at 4 DIV; (B) bundles (arrows) of closely packed and aligned cell bodies and processes follow orientation of the nanofibers at 7 DIV. Orientation of fibers is indicated by the double-headed arrow; (C) range of cell morphologies seen at 4 DIV; individual spindle-shaped cells (arrows) and flattened cells (arrowhead) arranged along the nanofibers. Boxed area in (C) shown at higher magnification in (D) demonstrates the simple, ruffled growth cone-like structure of the leading astrocytic processes. The morphology of U373 cells on type I collagen polycaprolactone (C/PCL) and of dissociated human neural progenitor-derived astrocytes on both polycaprolactone and C/PCL nanofibers was similar (therefore not shown). Scale bars: $(A-C)=$ $40 \mu \mathrm{m}$ and $(D)=3 \mu \mathrm{m}$. 

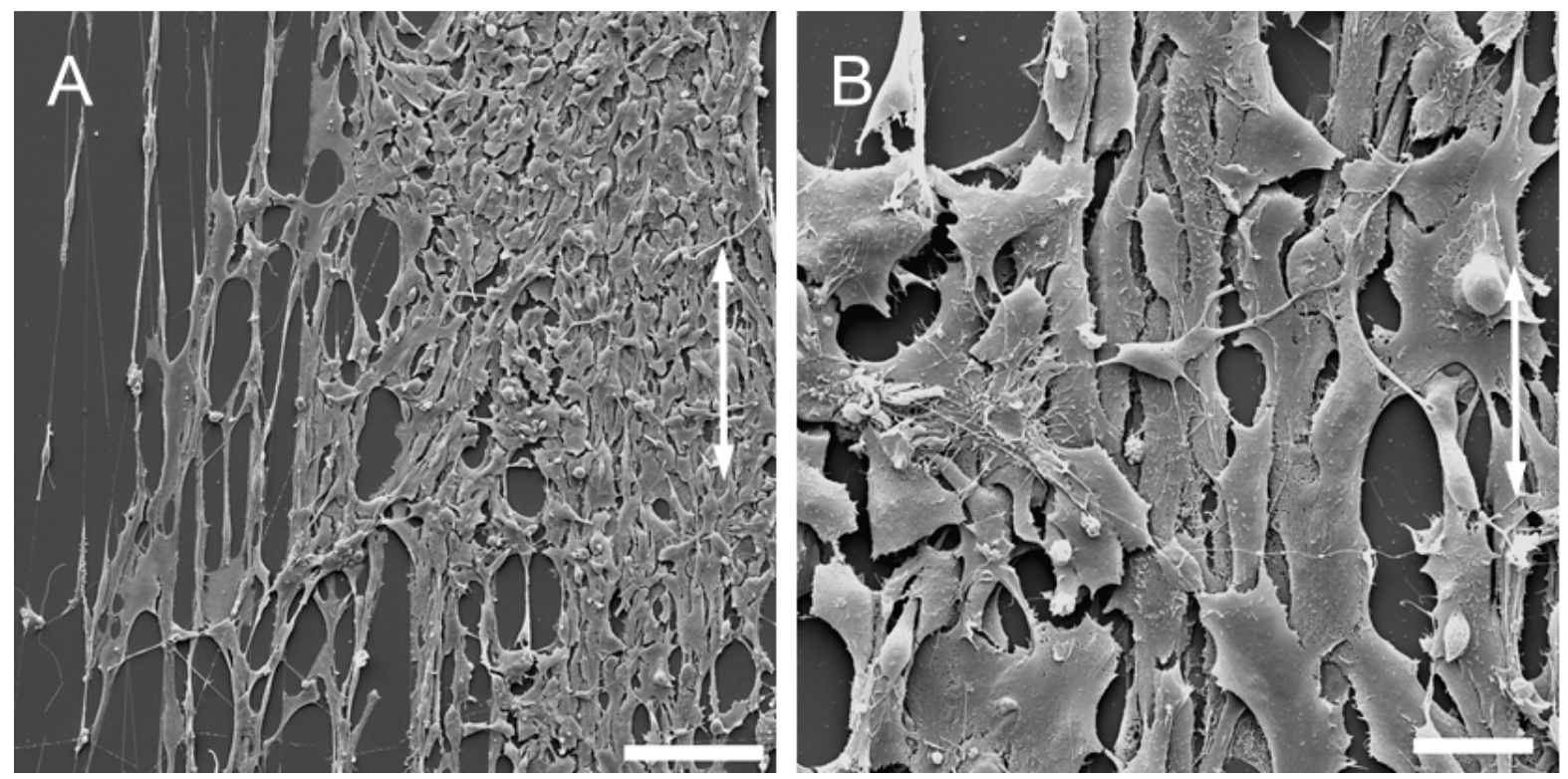

Fig. 7. Scanning electron microscope of migrating human neural progenitor-derived astrocytes from astrosphere preparations 4 days after seeding onto nanofibers. (A) Low magnification of the sheet of densely packed cells, having just migrated away from the astrosphere. To the left of the image, individual cells associated with single fibers have adopted an elongated, spindle-shaped morphology (demonstrated at higher magnification in Fig. 6). (B) Higher magnification of human neural progenitor derived astrocytes that had migrated a short distance away from the astrosphere. Sheets of overlapping, flattened cells could be seen that still adopted a longitudinal orientation. Other more rounded and process bearing cells could be seen growing over the surface of the flattened cells. Orientation of nanofibers is indicated by the double-headed arrow. Scale bars: $(A)=100$ $\mu \mathrm{m}$ and $(\mathbf{B})=20 \mu \mathrm{m}$.

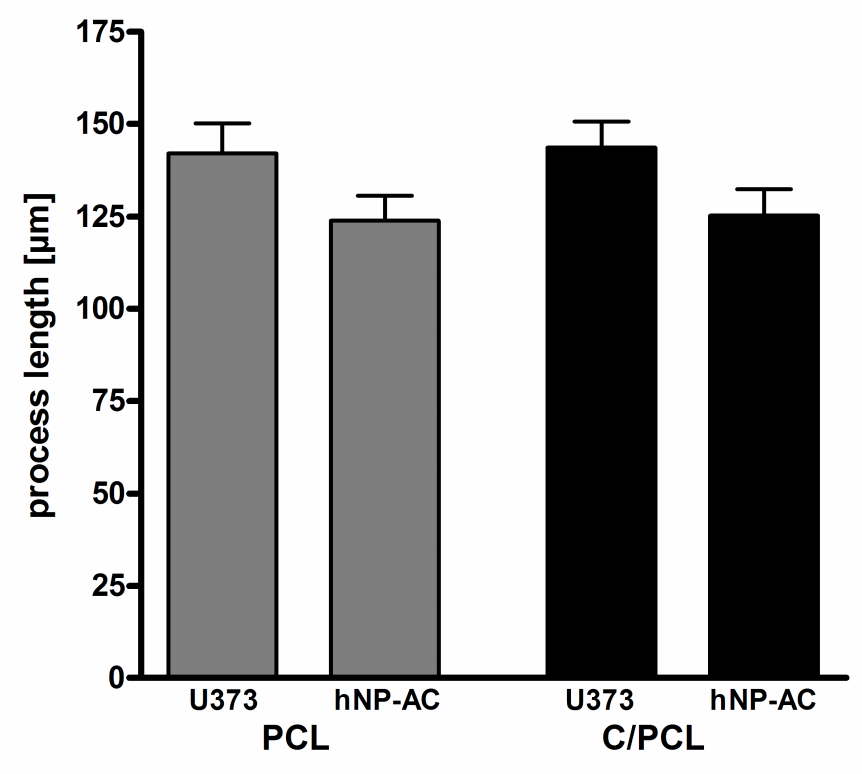

Fig. 8. Quantification of U373 and human neural progenitor-derived astrocytes process length, measured at 1 DIV after seeding onto polycaprolactone and type I collagen polycaprolactone nanofibers. U373 cells extended processes of similar length on $\mathrm{PCL}$ and $C / P C L(p>0.05)$. hNP-AC also extended processes of similar length on $\mathrm{PCL}$ and $\mathrm{C} / \mathrm{PCL}$ nanofibers ( $p>0.05$ ), which tended to be slightly shorter than the U373 processes, but differences did not reach statistical significance ( $p>0.05)$. C/PCL: Type I collagen polycaprolactone; hNP-AC: Human neural progenitor derived astrocyte; PCL: Polycaprolactone. 
Migration of cells along nanofibers

The migration of hNP-ACs and U373 cells on PCL and C/PCL nanofibers was investigated at 2 DIV after adhering astrospheres of both types of cells to the fibers. Migration away from the astrospheres resulted in an elliptical distribution of cells around the astrosphere, with the greatest migration following the orientation of the nanofibers (Fig. 5A). Cellular migration away from astrospheres plated onto the PLL-coated substrate was uniform in all directions (data not shown). The PLL-coated substrate acted as a nonoriented positive control for cell migration. The U373 cells migrated for similarly long distances on both PCL and $\mathrm{C} / \mathrm{PCL}$ nanofibers. Migration by hNP-ACs on both nanofiber substrates was significantly less than that demonstrated by the U373 cells $(p<0.01)$ but was clearly enhanced on the functionalized, C/PCL nanofibers ( $p<0.01$; Fig. 9).

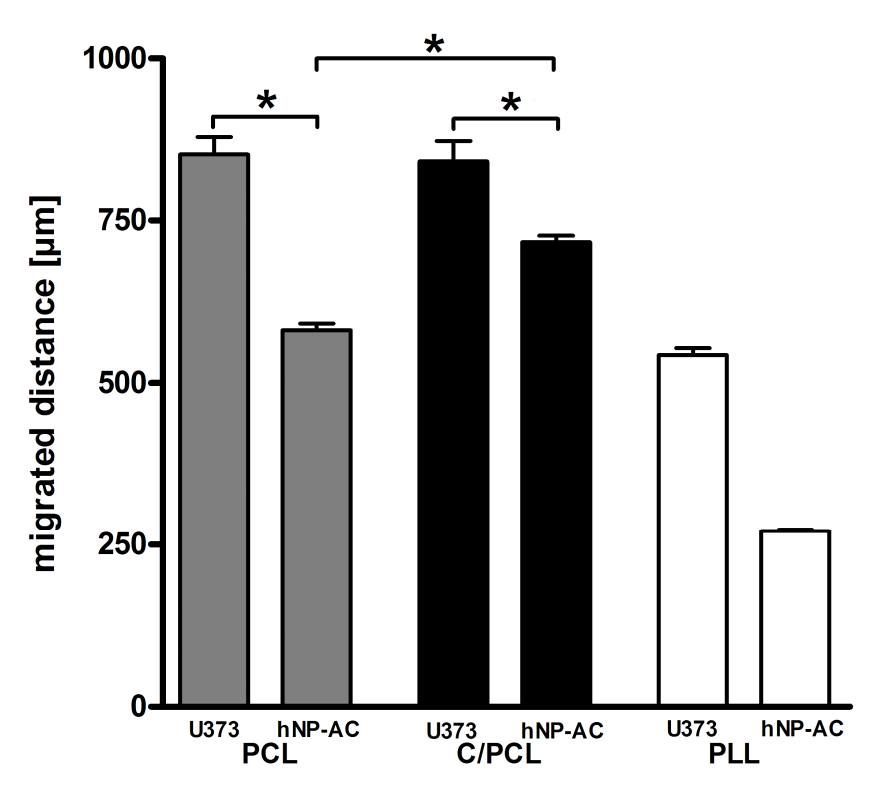

Fig. 9. Quantification of migration of U373 cells and human neural progenitor-derived astrocytes along polycaprolactone and type I collagen polycaprolactone nanofibers. U373 migration was similar on both types of nanofiber but significantly greater than on that observed on the nonoriented PLL (positive control) substrate $(p<0.01)$. U373 cell migration was also significantly greater than that demonstrated by the hNP-ACs ( $p<$ 0.01). hNP-AC migration was improved by functionalization of the nanofibers, being significantly greater on the $C / P C L$ than on the PCL nanofibers $(p<0.01)$. C/PCL: Type I collagen polycaprolactone; hNP-AC: Human neural progenitor derived astrocyte; $\mathrm{PCL}$ : Polycaprolactone; PLL: Poly-I-lysine.

\section{Neurite extension on nanofibers}

Differentiated human SH-SY5Y cells were used to assess the ability of the newly developing neuritis to bind to and interact with the PCL and C/PCL nanofibers. The extent of these interactions was investigated using fluorescence microscopy and SEM (Fig. 10A-C \& Fig. $11 \mathrm{~A}-\mathrm{C}$ ). For this purpose, nondifferentiated SH-SY5Y cells were seeded onto the nanofibers and underwent differentiation to a full neuronal phenotype by sequential treatment with RA (5 days) and BDNF (up to 7 days). Neurofilament immunoreactivity (NF200) revealed that differentiated SH-SY5Y cells that were grown on the PLL substrate developed multiple neurites that grew in a random, nonoriented manner, effectively 
establishing a network of processes that connected adjacent and near-adjacent neurons (Fig. 10A). Neurites of cells grown on the nanofiber-coated cover-slips extended in a highly oriented manner, following the direction of the aligned nanofibers (Fig. 10B). Highmagnification immunofluorescence demonstrated that growing neurites used the nanofibers as guides but the attachment of the cells and processes to $P C L$ and $C / P C L$ nanofibers was rather weak. Similar poor adhesion behavior was observed on neurites of differentiated cells grown on plastic and PLL, substrates that are good for supporting nondifferentiated SH-SY5Y cells (data not published). This poor adhesion profile provoked the loss of neuritic processes during fixation and the continuous washing cycles required by immunofluorescence, therefore, Dil staining and visualization of viable neurites was used. Growing neuritis often revealed areas of loose connection with both types of nanofibers, resulting in lengths of neurite that had apparently looped away from the nanofibers, only to rejoin them some distance later (e.g., arrows in Fig. 10C). SEM demonstrated numerous fine branches that extended away from the axis of the main neurite towards other, nearby neurites and nanofibers and even appeared to explore the poorly adhesive surrounding substrate (e.g., arrow in Fig. 11A). The axons of differentiated SH-SY5Y cells often demonstrated a clear beaded morphology (e.g., arrows in Fig. 11C) and appeared to switch from one nanofiber to another and formed bundles of axons (Fig. 11A $\&$ B). Quantification of neurite lengths of Dil labeled cells was performed to identify the effect of the nanofiber composition on the extent of axonal growth. These results established that neuritis growing along PCL nanofibers were capable of longer growth than those growing along $C / P C L$ nanofibers (neurite lengths at 7 DIV: PCL $380.1 \pm 12.2$ $\mu \mathrm{m} ; \mathrm{C} / \mathrm{PCL} 319.3 \pm 16.6 \mu \mathrm{m}$; Fig. $12 \mathrm{~A} \& \mathrm{~B} ; \mathrm{p}<0.01$ ). The cumulative distribution of lengths at 7 DIV revealed that, although neurites on both types of nanofibers achieved maximal lengths of approximately $600 \mu \mathrm{m}$, only $56 \%$ of the neurites measured on C/PCL were longer than $200 \mu \mathrm{m}$, compared with the $74.2 \%$ that were found on the PCL nanofibers (Fig. 12B). 


\section{Chapter 3}
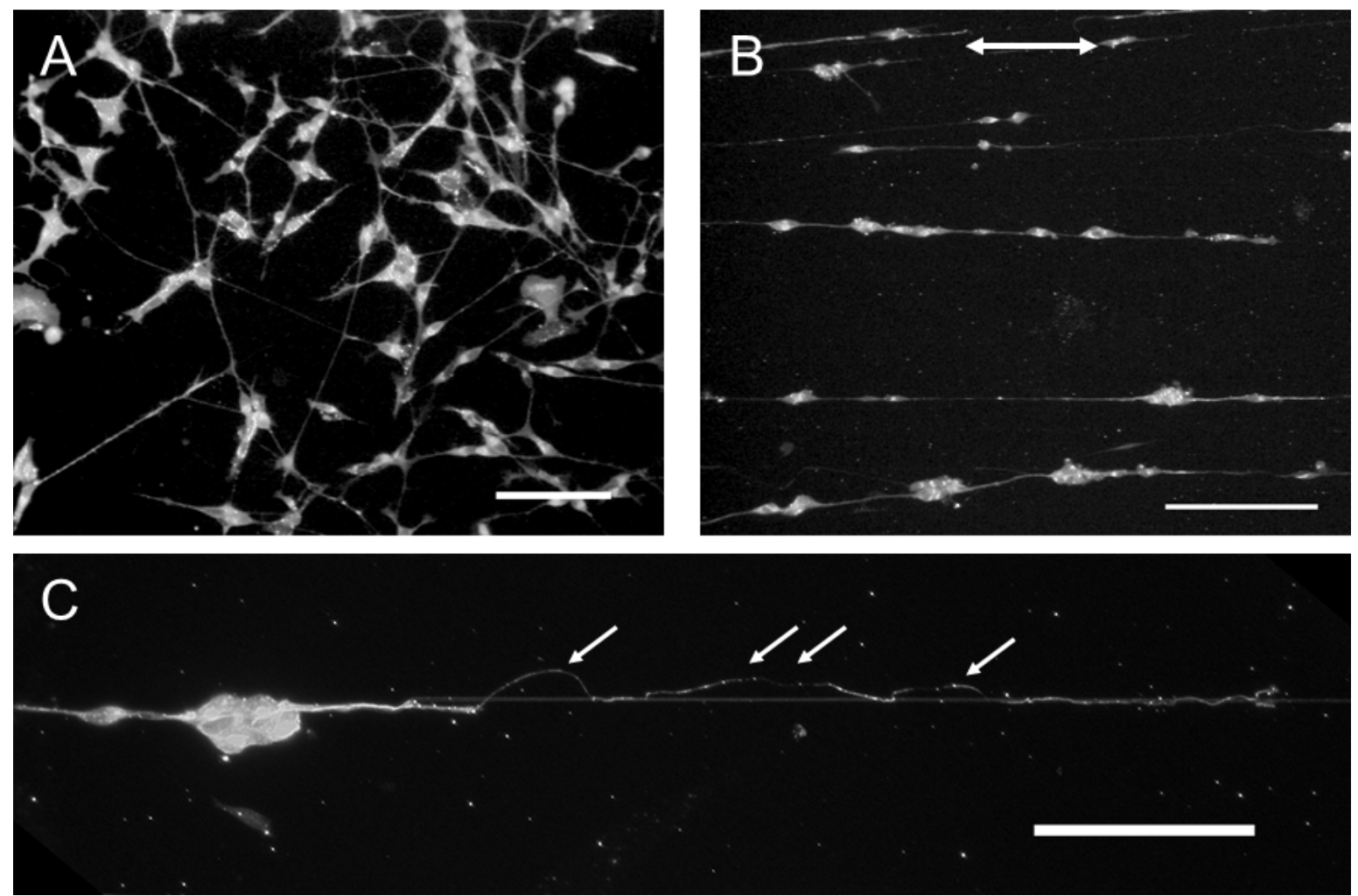

Fig. 10. Morphology of differentiated SH-SY5Y neurons on nanofibers. (A) NF200-positive neurons growing on the nonoriented poly-I-lysine (PLL) (positive control) substrate and on (B \& C) type I collagen polycaprolactone $(C / P C L)$ nanofibers after 7 DIV. (A) Neurites grow in a random manner forming networks on the PLL covered surfaces; (B) oriented neuritic outgrowth along the C/PCL nanofibers; (C) growth of a single neurite along a C/PCL nanofiber showing low fiber-neurite adhesion-forming loops (arrows) of processes. Neurites extending on polycaprolactone nanofibers were morphologically similar (therefore not shown). Scale bars: (A-C) = $100 \mu \mathrm{m}$. 

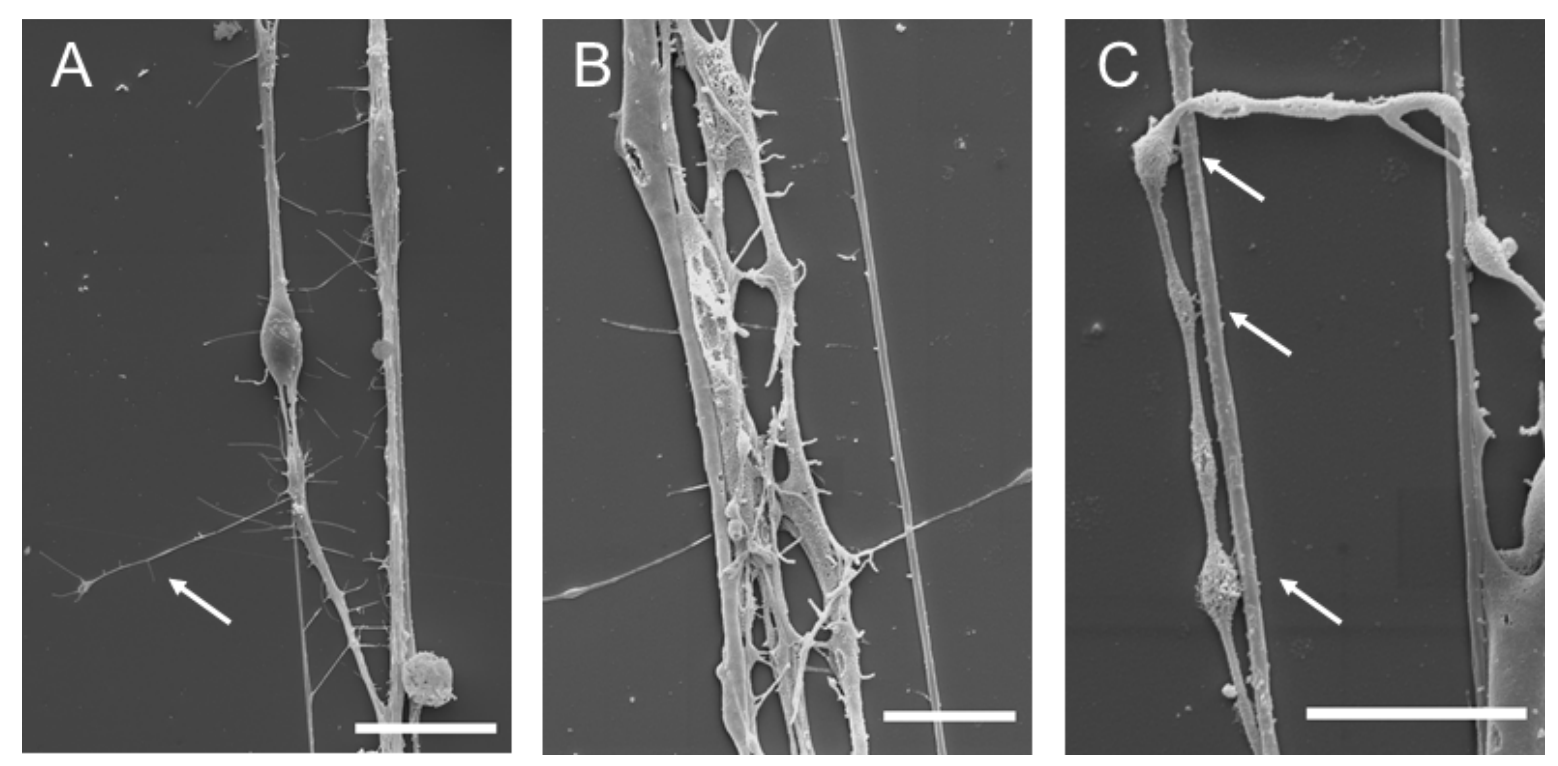

Fig. 11. Scanning-electron micrograph of SH-SY5Y-derived neurons on polycaprolactone nanofibers at 7 days. (A \& B) Main neurites followed the orientation of the nanofibers. Numerous small, perpendicular branches and sprouts (e.g., arrow) appeared to branch off towards electrospun fibers or extend on the underlying substrate. Some sprouts demonstrated growth cone-like extension at their tips. (C) High magnification of regular varicosities that characterized some neuritic processes. Limited contact between the nanofiber surface and the plasma membrane of the neurites can also be seen (arrows). Axonal growth on type I collagen polycaprolactone was similar and therefore is not shown. Scale bars: $(A)=20 \mu \mathrm{m}$ and $(\mathbf{B} \& \mathbf{C})=5 \mu \mathrm{m}$.
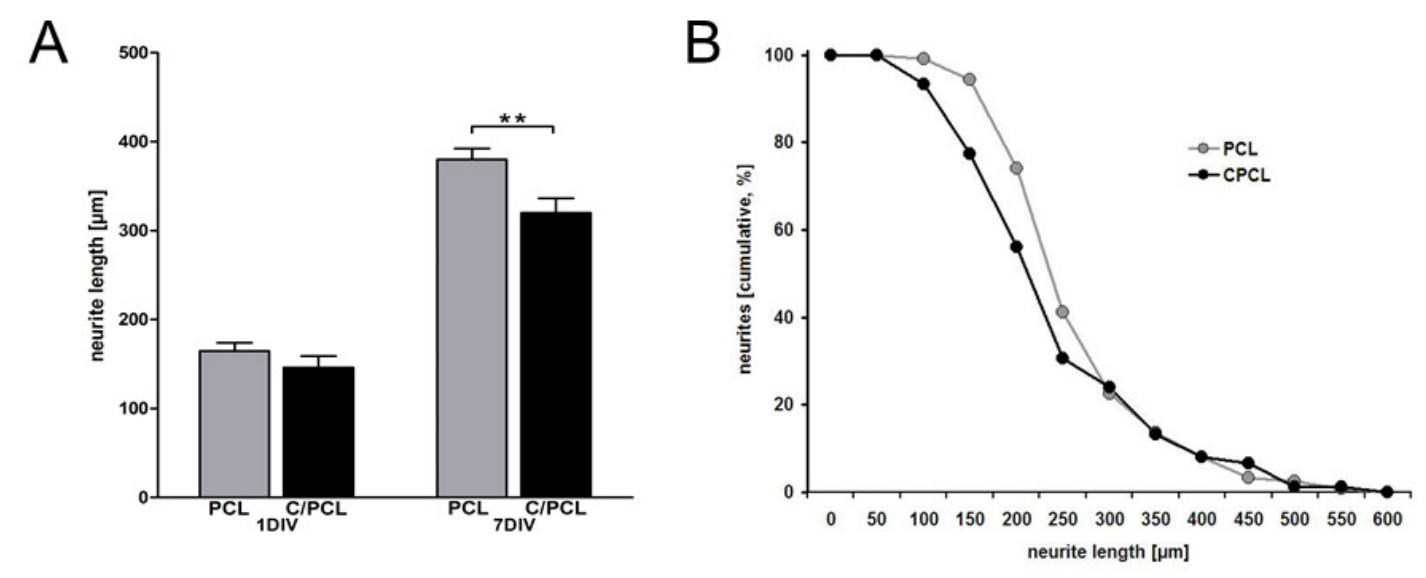

Fig. 12. Quantification of SH-SY5Y-derived neuronal process outgrowth. Quantification of differentiated Di-Ilabeled SH-SY5Y neuritic outgrowth on PCL and C/PCL nanofibers at 1 DIV and 7 DIV. (A) Longer neuritic growth could be detected at 7 DIV on the PCL compared with C/PCL nanofibers $(p<0.01)$. (B) Cumulative percentage of neuritic growth over PCL and C/PCL nanofibers at 7 DIV reveal that maximal neuritic outgrowth was the same on both PCL and C/PCL nanofibers, yet the greater mean neuritic length on PCL nanofibers could be explained by the fact that only $56 \%$ of the neurites measured on $\mathrm{C} / \mathrm{PCL}$ were longer than $200 \mu \mathrm{m}$, compared with the $74.2 \%$ that had achieved at least this length on the PCL nanofibers. C/PCL: Type I collagen polycaprolactone; PCL: Polycaprolactone. 


\section{Discussion}

Multidisciplinary research into biomaterials and their potential contribution to regenerative medicine is a rapidly expanding area of interest. Traumatic injury to peripheral nerve or the CNS white-matter tracts results in axonal degeneration, infiltration by inflammatory cells and fibroblasts, deposition of scar-related molecules and the disruption of the cytoarchitecture (Evans 2001; Fawcett 2006; Pettigrew et al. 2001; Schwab \& Bartholdi 1996). Although a number of increasingly sophisticated strategies have been developed for bridging lesions to nervous tissue, the optimal design of such scaffolds is yet to be identified (Schmidt \& Leach 2003). The improvement of scaffold concept and design requires a fundamental understanding of the influence that engineered substrates exert on cell morphology and function. The size, orientation and topography of adhesive substrates profoundly affect cell shape, growth and function (Dike et al. 1999; Singhvi et al. 1994). In the mid- to late 1990s, contact micro printing was used to generate 'islands' and 'tracks' of cell adhesive ECM surrounded by non-adhesive regions. Large islands promoted hepatocyte cell spreading and proliferation, whereas small islands prevented cell spreading and induced programmed cell death. Culturing capillary endothelial cells on tracks of ECM of varying width markedly influenced cell differentiation; cells grown on $20 \mu \mathrm{m}$-wide tracks only underwent a moderate degree of spreading but cooperated with each other, differentiating to form tubular (capillary-like) structures. Such cooperation and differentiation was not observed when the cells were grown on $30 \mu \mathrm{m}$ wide tracks (Chen et al. 1997; Chen et al. 1998; Dike et al. 1999; Singhvi et al. 1994).

A promising aspect of patterned-substrate research has been the demonstration that aligned ECM, as well as the micron-scale topography of fibers or grooves, has profound effects on the guidance and orientation of regenerating cells and their processes (Dubey et al. 2001; Lietz et al. 2006; Murugan \& Ramakrishna 2007; Schmidt \& Leach 2003; Wen \& Tresco 2006). This is of particular interest for the development of biomaterial- based scaffolds intended to promote repair of traumatically injured PNS or CNS; systems that would benefit substantially from directed axonal regeneration. In vitro studies have demonstrated the influence of fiber diameter on the orientation of process outgrowth. The greater surface curvature of small-diameter fibers prompted an increasing tendency for neurite outgrowth to follow the longitudinal axis of the fibers; small-caliber fibers (5-30 $\mu \mathrm{m}$ diameter) promoting much greater oriented process growth than largecaliber fibers (up to $500 \mu \mathrm{m}$ diameter). This phenomenon is not due to chemotropism but rather to the topographical effect of the fiber curvature on neurite growth (Smeal et al. 2005; Smeal \& Tresco 2008). The interest in cellular guidance by fibers is based on the premise that fibers can be readily suspended within a gel or housed in a nerve guide and that transformations to a $3 D$ device are more readily possible than for patterned 
substrates (Ngo et al. 2003; Yoshii et al. 2003a; Yoshii et al. 2003b). Advances in nanotechnology have led to an interest in cell interactions with substrates in the submicron range. Electrospun nanofibers have been used to generate oriented and nonoriented structures that, to some extent, can mimic the properties of the extracellular environment (Boudriot et al. 2006; Zhang et al. 2005). The ability of nanostructured surfaces or nanofibers to affect the behavior of non-neural cells (Mo et al. 2004; Sun et al. 2005; Walsh et al. 2005; Zhong et al. 2006) as well as neural cells of the PNS has been demonstrated recently in vitro (Corey et al. 2007; Schnell et al. 2007). Cell adhesion, survival and proliferation were well supported but morphology and alignment were altered strikingly by oriented nanofibers, promoting longer axonal growth than nonoriented fibers (Corey et al. 2007; Corey et al. 2008). It has therefore become clear that oriented nanofibers may have a significant role in the design of scaffolds intended to promote axon regeneration in the PNS. However, their potential role in bridging CNS lesions remains uncertain. As a first step in assessing this potential, the present investigation was performed to study nanofiber-astroglial interactions in vitro. Astrocytes were chosen for the study because activated/reactive astroglia are known to have a pivotal role in determining the growth-inhibitory characteristics of the glial environment surrounding a lesion (Fawcett 2006; Reier \& Houle 1988). The properties of activated/reactive host astroglia also strongly influence the integration and extent of axonal regeneration supported by implants or grafts into the CNS (Brook et al. 2001; Fishman et al. 1983). Furthermore, neural stem cell-derived astrocytes may be of benefit in future therapeutic implantation strategies (Davies et al. 2008). The present experimental design was developed to enable the cell-substrate interactions of single cells with single nanofibers to be observed in a relatively simple $2 \mathrm{D}$ in vitro system.

The in vitro testing of neural cell-biomaterial interactions relies commonly on the use of cell lines from animal or human sources (Corey et al. 2007; Cui et al. 2001; Dumont \& Born 2005; Kullenberg et al. 2008; Li et al. 2007; Unger et al. 2004; Yang et al. 2004; Yang et al. 2005; Zhu et al. 2005) or, less frequently, on freshly dissociated primary cells grown in serum-supplemented (Corey et al. 2007; Goldner et al. 2006; Schnell et al. 2007; Winter et al. 2007) or serum free (Corey et al. 2008) media. However, the extent to which cell lines are able to predict the responses of primary cells in such investigations remains uncertain. In an attempt to address this issue, we have compared astrocyte-nanofiber interactions using both the human U373 astrocytoma cell line and human neural progenitor-derived astrocytes. The results showed that U373 cells adhered strongly to both nonfunctionalized $(\mathrm{PCL})$ and functionalized $(\mathrm{C} / \mathrm{PCL})$ nanofibers. The adherent cells proliferated well, extended aligned processes and migrated to similar extents along both types of fiber. Cell adhesion and migration by hNP-ACs were, by contrast, significantly affected by nanofiber functionalization, both parameters being enhanced on $\mathrm{C} / \mathrm{PCL}$ nanofibers. Another difference between U373 cells and hNP-ACs was that the progenitor- 
derived astrocytes showed no tendency to proliferate on the nanofibers, whereas the astrocytoma cells maintained a strong rate of proliferation, albeit it at a lower rate (but still significantly different) than that observed on the PLL-positive-control substrate. The lack of an effect of type I collagen on hNP-AC proliferation supports previous in vitro investigations that demonstrated increased proliferation of rat astrocytes when grown on laminin and fibronectin, although no such effect could be seen when the cells were grown on type I collagen (Nagano et al. 1993). It is possible that the restriction of cell spreading imposed on U373 cells by their adhesion to the nanofibers may have resulted in reduced proliferation. Cells grown on the unpatterned PLL substrate spread freely and adopted a pleiomorphic appearance, whereas most of the cells that were seeded onto nanofibers had small cell bodies and long, thin unipolar or bipolar morphologies. A clear relationship between cell spreading and proliferation has been demonstrated by Ingber and colleagues. Cells growing on uniform, unpatterned surfaces demonstrated the greatest degree of proliferation, whereas cells grown on progressively smaller islands of adhesive substrate showed progressively restricted spreading and lower proliferation rates, the smallest adhesive islands inducing apoptosis (Chen et al. 1997; Singhvi et al. 1994). Although the present investigation compared cell-substrate interactions on two types of electrospun fibers, it would have been of interest to include observations of the behavior of cells seeded onto smooth surfaces coated with either PCL or C/PCL. Such comparisons, enabling the demonstration of the roles played by substrate nanofeatures, were unfortunately not included in the present study. Migration by U373 astrocytoma and hNPACs on functionalized and nonfunctionalized nanofibers was another clear example in which the cell line behaved differently from the progenitor-derived astrocytes. Migration ofU373 cells were equally extensive on both PCL and C/PCL nanofibers. Migration of hNPACs on PCL nanofibers was similar to that on the PLL-positive-control substrate. The presence of type I collagen, however, promoted a significant increase in migration by the hNP-ACs (although this still remained inferior to the migration demonstrated by the U373 cells). Cell migration requires the formation of focal-adhesion points between the cell and the extracellular substrate. Focal adhesions are macromolecular complexes that physically link the ECM to the contractile actin cytoskeleton (Wang et al. 1993); the most important molecular receptors for ECM binding are integrins. Because integrins bind directly to collagen (Leitinger \& Hohenester 2007), the improved cell migration of hNP-ACs on C/PCL nanofibers may have been anticipated. In addition, an indirect binding between collagen and integrin receptors may be mediated by fibronectin (Geiger et al. 2001). This may also have occurred in our cell cultures because fibronectin may have been present in the serum-containing medium or may have been secreted by the cells themselves. ECMintegrin interactions are known to activate a variety of intracellular signal cascades. This may result in potential synergistic effects between growth factor and integrin signaling (Geiger et al. 2001). It might thus be possible to further increase the migratory behavior of cells on electrospun fibers by a number of mechanisms: incorporation of other ECM 
molecules, for example, fibronectin or laminin into the blend for electrospinning; chemical modification of PCL fibers to present specific integrin-activating peptides, such as GRGDS, IKVAV and YIGSR; and combining ECM molecules with soluble factors that may act synergistically on integrin-activated pathways (e.g., FGF-2, TGF- $\beta$ or PDGF) (Dalton \& Mey 2009; French-Constant \& Colognato 2004). The optimal design of future aligned scaffolds demands that the efficacy of a number of parameters must be investigated, including the choices of polymer, its degree of functionalization, diameter and packing density. Our initial concept for the choice of nanofibers, rather than microfibers, as the orienting substrate for a nerve guide was based on the notion that the nanofibers would present a much greater surface area to volume ratio and many more fibers could be packed into the limited space of future scaffolds. There is a general notion that the presentation of a large surface area is useful for strategies applicable to regenerative medicine, particularly for those related to the repair of the nervous system. Accordingly, the effect of packing increasingly greater numbers of microfibers ( $50 \mu \mathrm{m}$ diameter) into nerve guides has been studied on peripheral nerve-fiber regeneration in vivo. Surprisingly, the greatest number of regenerating axons was observed in nerve guides that had been packed with the least number of microfibers (Ngo et al. 2003). The present observation that the orientation of large numbers of astroglia may be controlled by relatively small numbers of nanofibers is in keeping with the notion that only small numbers of guidance cues (e.g., fibers) may be required to support oriented tissue repair in a 3D scaffold, however, this hypothesis still remains to be tested because cell-nanofiber interactions in 3D may be somewhat different to those seen in the present 2D system. 3D, self-assembling peptide nanofiber scaffolds have already proven successful in reducing local astrocytic scarring and inflammation, as well as effectively 'knitting' the two edges of a lesion together following relatively thin, penetrating injuries of the CNS. When introduced into living animals, these self-assembling scaffolds did not induce a measurable immune or inflammatory response by the host tissues (Holmes et al. 2000) and generated an axon growth-permissive environment that was capable of supporting some degree of functional tissue repair following lesions of the optic tract (Ellis-Behnke et al. 2006). Furthermore, self-assembling nanofiber scaffolds reduce apoptosis and astrocytosis and also support axon regeneration and a moderate degree of functional recovery in a mouse model of spinal cord injury (Tysseling-Mattiace et al. 2008). It is possible that the future use of oriented nanofibers may be able to improve the efficacy of axon regeneration across large lesions. It has been reported recently that sheets of oriented, nonfunctionalized nanofibers stacked into a nerve guide are capable of supporting significant axon regeneration through topographical cues within the lesioned PNS (Kim et al. 2008). Functionalization of the scaffold, as seen in the present investigation, by the incorporation of ECM components (i.e., type I collagen) or even the by incorporation of growth factors (or other growth-promoting molecules) has the potential of improving the performance of such scaffolds (Jain et al. 2006). The ECM molecule, type I collagen, was chosen for surface functionalization of the PCL nanofibers 
because it is a natural polymer that can be mixed and electrospun with PCL and is known to activate axonal and glial integrin receptors capable of supporting cell adhesion and migration (Tawil et al. 1990; Turner et al. 1989). However, it has been reported recently that electrospinning results in the denaturation of up to $99 \%$ of the collagen to gelatin, especially when fluoralcohols are used as a solvent (Zeugolis et al. 2008). The extent to which collagen was denatured to gelatin in the present investigation remains uncertain, however, the effect of surface functionalization of the interactions of hNP-ACs are clear. The ability of nanofibers to influence the behavior of astrocytes, shifting their shape from a pleiomorphic appearance to a highly oriented one, may be of particular interest for CNS repair strategies. Lesions to the CNS induce a reactive astroglial response that includes scarring and the deposition new basal lamina and chondroitin sulfate proteoglycans. Such reactive astrocytic responses are important for protecting adjacent intact nervous tissue from further damage but also contribute to the axon-growth inhibitory environment at and around the lesion site (Fawcett 2006; Shearer \& Fawcett 2001; Sofroniew 2005). However, axon growth-promoting properties of reactive astrocytes have also been described (Liberto et al. 2004). Furthermore, the processes of activated/reactive astrocytes can be encouraged to support CNS axon regeneration, effectively chaperoning re-growing axons across a host graft interface (Brook et al. 2001; Kawaja \& Gage 1991). It is possible that the ability of nanofibers to modify astrocytic morphology at graft-host interfaces may be useful in supporting improved graft-host integration; promoting astroglial attachment and aligned migration into the scaffold rather than astroglial scarring, so effectively isolating the graft. Both $\mathrm{PCL}$ and collagen reduce astrocytic activation (Wong et al. 2007). Thus, implantation of a collagen-PCL nanofiber scaffold might be anticipated to reduce astrocytic scarring at the graft-host interface and thereby improve oriented cell and tissue integration. The real extent of scaffold-host tissue interactions may, however, be somewhat different in the vastly more complicated setting of in vivo implantation and is yet to be tested.

\section{Neuronal-nanofiber interactions}

The poor attachment of nondifferentiated SH-SY5Y cells during the 90 min incubation time used in the attachment assay was overcome by the longer incubation times used for the survival assays, indicating that the nondifferentiated cells require more time for binding to the nanofiber substrates. The neuronally differentiated SH-SY5Y cells demonstrated direct interactions with $\mathrm{PCL}$ and $\mathrm{C} / \mathrm{PCL}$ fibers, resulting in the aligned growth of neurites along the axis of the nanofibers. Although the neurites adhered rather weakly to both $\mathrm{PCL}$ and $\mathrm{C} / \mathrm{PCL}$ nanofibers, substantial growth could still be observed. Some of the branches that extended away from the main axis of the neurite appeared to end in growth cone-like 
terminations that explored the poorly adhesive surrounding substrate. However, many of the fine branches extended towards adjacent neurites and nanofibers, resembling the stress-related filopodia generated by the cell as it attempts to anchor itself to the surrounding environment (Karuri et al. 2004). The clustering and poor adhesion of the differentiated SH-SY5Y neurons probably reflects the neuronal ( $\mathrm{N}$ type) phenotype of neuroblastoma-derived cells that show a propensity to self-aggregation and relatively poor substrate adhesion (Ross et al. 2003). Differentiated SH-SY5Y-derived neurons extended processes that reached up to $600 \mu \mathrm{m}$ over 7 days on both types of nanofibers. However, overall neurite length was slightly greater on $\mathrm{PCL}$ than $\mathrm{C} / \mathrm{PCL}$ nanofibers. In comparison, explanted embryonic DRG axonal growth over PCL or C/PCL nanofibers over 4 days achieves distances of $1250 \mu \mathrm{m}$ or greater, with the longest growth occurring over PCL nanofibers (Schnell et al. 2007). The fact that neuritic growth was slightly better on PCL than C/PCL nanofibers in the present investigation suggests that the main guiding property of the fibers was through topographical cues rather than collagen-mediated biochemical cues as suggested for glial cells and primary neurons (Schnell et al. 2007). Others have also demonstrated the extension of processes by neuroblastoma cells and stem cell-derived neurons along polymer surfaces in the absence of functionalizing adhesion molecules (Corey et al. 2007; Yang et al. 2005).

\section{Conclusion}

The sPEG-mediated attachment of low density, oriented nanofibers to glass cover-slips enables interactions between single cells and single nanofibers to be studied in relatively simple 2D cultures. The potential value of using nanofibers for CNS-based regenerative strategies was addressed by studying a range of astroglia-nanofiber interactions in vitro. The limited predictive value of using cell lines for studying cell-substrate interactions became apparent when comparing the responses of human U373 astrocytoma cells and human neural progenitor-derived astrocytes. Although the morphology and alignment of processes of both cell types were strikingly influenced by orientated nanofibers, only hNPACs showed enhanced cell adhesion and cell migration in response to fiber functionalization. However, hNP-ACs revealed no proliferative activity on either PCL or $\mathrm{C} / \mathrm{PCL}$ nanofibers, whereas U373 cell proliferation occurred and was only reduced moderately by association with the nanofibers. Although functionalized (C/PCL) and nonfunctionalized (PCL) fibers proved to be poor substrates for SH-SY5Y cell adhesion, differentiated neurons extended long axonal growth, the alignment of which was controlled by the oriented nanofibers. Surprisingly, C/ PCL nanofibers did not induce longer axonal growth by the differentiated SH-SY5Y neurons. By contrast, axonal length over C/PCL nanofibers showed a small but significant reduction when compared with the 
nonfunctionalized PCL nanofibers. Both types of nanofibers present strong topographical cues for the oriented growth and migration of both neuronal and glial profiles. In this context, even small numbers of nanofibers were able to control the orientation of large numbers of cells, suggesting that fewer nanofibers than anticipated may be required to promote directed tissue repair in a 3D scaffold. However, this hypothesis can only be tested by in vivo implantation of 3D scaffolds into experimental models of spinal cord injury.

\section{Future perspective}

Electrospinning and functionalization of fiber surfaces provides a highly versatile means of obtaining fibers with well-defined topography and controlled surface properties. The present, relatively simple, 2D tissue culture systems enable specific aspects of cellsubstrate interactions to be investigated in a strictly controlled environment. This enables investigators to optimize cell- substrate interactions for tissue-repair purposes. In the context of attempting to promote functional tissue repair following traumatic injury to the spinal cord, an implantable scaffold would ideally be able to reduce host astroglial scarring, support graft-host integration and promote axon regeneration by both ascending (e.g., sensory) and descending (e.g., motor) axons. Significant challenges for the future will be the specific functionalization of nanofibers to support axonal regeneration by either ascending or descending populations of projections neurons, as well as the controlled incorporation of such nanofibers into a 3D scaffold. The achievement of such a challenge would represent a major step forward for nanofiber-based oriented growth-promoting scaffolds.

\section{Acknowledgments}

We thank A Kruttgen for the SH-SY5Y cell line. We would like to thank M Bovi (Department of Pathology, UK Aachen) for the excellent technical support with the scanning-electron micrographs. 


\section{Human neural cells and electrospun nanofibers}

\section{References}

Biran, R., Martin, D.C. \& Tresco, P.A., 2007. The brain tissue response to implanted silicon microelectrode arrays is increased when the device is tethered to the skull. Journal of biomedical materials research. Part $A$, 82(1), pp.169-78.

Boudriot, U., Dersch, R., Greiner, A. \& Wendorff, J.H., 2006. Electrospinning approaches toward scaffold engineering--a brief overview. Artificial organs, 30(10), pp.785-92.

Brook, G.A., Lawrence, J.M. \& Raisman, G., 2001. Columns of Schwann cells extruded into the CNS induce ingrowth of astrocytes to form organized new glial pathways. Glia, 33(2), pp.118-30.

Chen, C.S., Mrksich, M., Huang, S., Whitesides, G.M. \& Ingber, D.E., 1997. Geometric control of cell life and death. Science (New York, N.Y.), 276(5317), pp.1425-8.

Chen, C.S., Mrksich, M., Huang, S., Whitesides, G.M. \& Ingber, D.E., 1998. Micropatterned surfaces for control of cell shape, position, and function. Biotechnology progress, 14(3), pp.356-63.

Corey, J.M., Gertz, C.C., Wang, B.-S., Birrell, L.K., Johnson, S.L., Martin, D.C. \& Feldman, E.L., 2008. The design of electrospun PLLA nanofiber scaffolds compatible with serum-free growth of primary motor and sensory neurons. Acta biomaterialia, 4(4), pp.863-75.

Corey, J.M., Lin, D.Y., Mycek, K.B., Chen, Q., Samuel, S., Feldman, E.L. \& Martin, D.C., 2007. Aligned electrospun nanofibers specify the direction of dorsal root ganglia neurite growth. Journal of biomedical materials research. Part A, 83(3), pp.636-45.

Cui, X., Lee, V.A., Raphael, Y., Wiler, J.A., Hetke, J.F., Anderson, D.J. \& Martin, D.C., 2001. Surface modification of neural recording electrodes with conducting polymer/biomolecule blends. Journal of biomedical materials research, 56(2), pp.261-72.

Dalton, P.D. \& Mey, J., 2009. Neural interactions with materials. Frontiers in bioscience (Landmark edition), 14, pp.769-95.

Davies, J.E., Pröschel, C., Zhang, N., Noble, M., Mayer-Pröschel, M. \& Davies, S.J. a, 2008. Transplanted astrocytes derived from BMP- or CNTF-treated glial-restricted precursors have opposite effects on recovery and allodynia after spinal cord injury. Journal of biology, 7(7), p.24.

Dike, L.E., Chen, C.S., Mrksich, M., Tien, J., Whitesides, G.M. \& Ingber, D.E., 1999. Geometric control of switching between growth, apoptosis, and differentiation during angiogenesis using micropatterned substrates. In vitro cellular \& developmental biology. Animal, 35(8), pp.441-8.

Dubey, N., Letourneau, P.C. \& Tranquillo, R.T., 2001. Neuronal contact guidance in magnetically aligned fibrin gels: effect of variation in gel mechano-structural properties. Biomaterials, 22(10), pp.1065-75. 
Dumont, C.E. \& Born, W., 2005. Stimulation of neurite outgrowth in a human nerve scaffold designed for peripheral nerve reconstruction. Journal of biomedical materials research. Part B, Applied biomaterials, 73(1), pp.194-202.

Ellis-Behnke, R.G., Liang, Y.-X., You, S.-W., Tay, D.K.C., Zhang, S., So, K.-F. \& Schneider, G.E., 2006. Nano neuro knitting: peptide nanofiber scaffold for brain repair and axon regeneration with functional return of vision. Proceedings of the National Academy of Sciences of the United States of America, 103(13), pp.5054-9.

Encinas, M., Iglesias, M., Liu, Y., Wang, H., Muhaisen, a, Ceña, V., Gallego, C. \& Comella, J.X., 2000. Sequential treatment of SH-SY5Y cells with retinoic acid and brain-derived neurotrophic factor gives rise to fully differentiated, neurotrophic factor-dependent, human neuron-like cells. Journal of neurochemistry, 75(3), pp.991-1003.

Evans, G.R., 2001. Peripheral nerve injury: a review and approach to tissue engineered constructs. The Anatomical record, 263(4), pp.396-404.

Fawcett, J.W., 2006. Overcoming inhibition in the damaged spinal cord. Journal of neurotrauma, 23(3-4), pp.37183.

Fawcett, J.W. \& Asher, R.A., 1999. The glial scar and central nervous system repair. Brain research bulletin, 49(6), pp.377-91.

Fishman, P.S., Nilaver, G. \& Kelly, J.P., 1983. Astrogliosis limits the integration of peripheral nerve grafts into the spinal cord. Brain research, 277(1), pp.175-80.

French-Constant, C. \& Colognato, H., 2004. Integrins: versatile integrators of extracellular signals. Trends in cell biology, 14(12), pp.678-86.

Geiger, B., Bershadsky, A., Pankov, R. \& Yamada, K.M., 2001. Transmembrane crosstalk between the extracellular matrix--cytoskeleton crosstalk. Nature reviews. Molecular cell biology, 2(11), pp.793-805.

Goldner, J.S., Bruder, J.M., Li, G., Gazzola, D. \& Hoffman-Kim, D., 2006. Neurite bridging across micropatterned grooves. Biomaterials, 27(3), pp.460-72.

Groll, J., Fiedler, J., Engelhard, E., Ameringer, T., Tugulu, S., Klok, H.-A., Brenner, R.E. \& Moeller, M., 2005. A novel star PEG-derived surface coating for specific cell adhesion. Journal of biomedical materials research. Part A, 74(4), pp.607-17.

Holmes, T.C., de Lacalle, S., Su, X., Liu, G., Rich, A. \& Zhang, S., 2000. Extensive neurite outgrowth and active synapse formation on self-assembling peptide scaffolds. Proceedings of the National Academy of Sciences of the United States of America, 97(12), pp.6728-33.

Jain, A., Kim, Y.-T., McKeon, R.J. \& Bellamkonda, R. V, 2006. In situ gelling hydrogels for conformal repair of spinal cord defects, and local delivery of BDNF after spinal cord injury. Biomaterials, 27(3), pp.497-504. 


\section{Human neural cells and electrospun nanofibers}

Karuri, N.W., Liliensiek, S., Teixeira, A.I., Abrams, G., Campbell, S., Nealey, P.F. \& Murphy, C.J., 2004. Biological length scale topography enhances cell-substratum adhesion of human corneal epithelial cells. Journal of cell science, 117(Pt 15), pp.3153-64.

Kawaja, M.D. \& Gage, F.H., 1991. Reactive astrocytes are substrates for the growth of adult CNS axons in the presence of elevated levels of nerve growth factor. Neuron, 7(6), pp.1019-30.

Kim, Y.-T., Haftel, V.K., Kumar, S. \& Bellamkonda, R. V, 2008. The role of aligned polymer fiber-based constructs in the bridging of long peripheral nerve gaps. Biomaterials, 29(21), pp.3117-27.

Kullenberg, J., Rosatini, F., Vozzi, G., Bianchi, F., Ahluwalia, A. \& Domenici, C., 2008. Optimization of PAM scaffolds for neural tissue engineering: preliminary study on an SH-SY5Y cell line. Tissue engineering. Part A, 14(6), pp.1017-23.

Leitinger, B. \& Hohenester, E., 2007. Mammalian collagen receptors. Matrix biology : journal of the International Society for Matrix Biology, 26(3), pp.146-55.

Li, G.N., Livi, L.L., Gourd, C.M., Deweerd, E.S. \& Hoffman-Kim, D., 2007. Genomic and morphological changes of neuroblastoma cells in response to three-dimensional matrices. Tissue engineering, 13(5), pp.1035-47.

Liberto, C.M., Albrecht, P.J., Herx, L.M., Yong, V.W. \& Levison, S.W., 2004. Pro-regenerative properties of cytokine-activated astrocytes. Journal of neurochemistry, 89(5), pp.1092-100.

Lietz, M., Dreesmann, L., Hoss, M., Oberhoffner, S. \& Schlosshauer, B., 2006. Neuro tissue engineering of glial nerve guides and the impact of different cell types. Biomaterials, 27(8), pp.1425-36.

Mo, X.M., Xu, C.Y., Kotaki, M. \& Ramakrishna, S., 2004. Electrospun P(LLA-CL) nanofiber: a biomimetic extracellular matrix for smooth muscle cell and endothelial cell proliferation. Biomaterials, 25(10), pp.1883-90.

Murugan, R. \& Ramakrishna, S., 2007. Design strategies of tissue engineering scaffolds with controlled fiber orientation. Tissue engineering, 13(8), pp.1845-66.

Nagano, N., Aoyagi, M. \& Hirakawa, K., 1993. Extracellular matrix modulates the proliferation of rat astrocytes in serum-free culture. Glia, 8(2), pp.71-6.

Ngo, T.-T.B., Waggoner, P.J., Romero, A.A., Nelson, K.D., Eberhart, R.C. \& Smith, G.M., 2003. Poly(L-Lactide) microfilaments enhance peripheral nerve regeneration across extended nerve lesions. Journal of neuroscience research, 72(2), pp.227-38.

Pettigrew, D.B., Shockley, K.P. \& Crutcher, K.A., 2001. Disruption of spinal cord white matter and sciatic nerve geometry inhibits axonal growth in vitro in the absence of glial scarring. BMC neuroscience, 2, p.8.

Reier, P.J. \& Houle, J.D., 1988. The glial scar: its bearing on axonal elongation and transplantation approaches to CNS repair. Advances in neurology, 47, pp.87-138. 
Ross, R.A., Biedler, J.L. \& Spengler, B.A., 2003. A role for distinct cell types in determining malignancy in human neuroblastoma cell lines and tumors. Cancer letters, 197(1-2), pp.35-9.

Schmidt, C.E. \& Leach, J.B., 2003. Neural tissue engineering: strategies for repair and regeneration. Annual review of biomedical engineering, 5, pp.293-347.

Schnell, E., Klinkhammer, K., Balzer, S., Brook, G., Klee, D., Dalton, P. \& Mey, J., 2007. Guidance of glial cell migration and axonal growth on electrospun nanofibers of poly-epsilon-caprolactone and a collagen/polyepsilon-caprolactone blend. Biomaterials, 28(19), pp.3012-25.

Schwab, M.E. \& Bartholdi, D., 1996. Degeneration and regeneration of axons in the lesioned spinal cord. Physiological reviews, 76(2), pp.319-70.

Shearer, M. \& Fawcett, J., 2001. The astrocyte/meningeal cell interface - a barrier to successful nerve regeneration? Cell and Tissue Research, 305(2), pp.267-273.

Singhvi, R., Kumar, A., Lopez, G.P., Stephanopoulos, G.N., Wang, D.I., Whitesides, G.M. \& Ingber, D.E., 1994. Engineering cell shape and function. Science (New York, N.Y.), 264(5159), pp.696-8.

Smeal, R.M., Rabbitt, R., Biran, R. \& Tresco, P.A., 2005. Substrate curvature influences the direction of nerve outgrowth. Annals of biomedical engineering, 33(3), pp.376-82.

Smeal, R.M. \& Tresco, P.A., 2008. The influence of substrate curvature on neurite outgrowth is cell type dependent. Experimental neurology, 213(2), pp.281-92.

Sofroniew, M. V, 2005. Reactive astrocytes in neural repair and protection. The Neuroscientist : a review journal bringing neurobiology, neurology and psychiatry, 11(5), pp.400-7.

Sun, T., Mai, S., Norton, D., Haycock, J.W., Ryan, A.J. \& MacNeil, S., 2005. Self-organization of skin cells in threedimensional electrospun polystyrene scaffolds. Tissue engineering, 11(7-8), pp.1023-33.

Tawil, N.J., Houde, M., Blacher, R., Esch, F., Reichardt, L.F., Turner, D.C. \& Carbonetto, S., 1990. Alpha 1 beta 1 integrin heterodimer functions as a dual laminin/collagen receptor in neural cells. Biochemistry, 29(27), pp.6540-4.

Tessier-Lavigne, M. \& Goodman, C.S., 1996. The molecular biology of axon guidance. Science (New York, N.Y.), 274(5290), pp.1123-33.

Turner, D.C., Flier, L.A. \& Carbonetto, S., 1989. Identification of a cell-surface protein involved in PC12 cellsubstratum adhesion and neurite outgrowth on laminin and collagen. The Journal of neuroscience : the official journal of the Society for Neuroscience, 9(9), pp.3287-96.

Tysseling-Mattiace, V.M., Sahni, V., Niece, K.L., Birch, D., Czeisler, C., Fehlings, M.G., Stupp, S.I. \& Kessler, J.A., 2008. Self-assembling nanofibers inhibit glial scar formation and promote axon elongation after spinal cord injury. The Journal of neuroscience : the official journal of the Society for Neuroscience, 28(14), pp.3814-23. 


\section{Human neural cells and electrospun nanofibers}

Unger, R.E., Wolf, M., Peters, K., Motta, A., Migliaresi, C. \& James Kirkpatrick, C., 2004. Growth of human cells on a non-woven silk fibroin net: a potential for use in tissue engineering. Biomaterials, 25(6), pp.1069-75.

Wachs, F.-P., 2003. High Efficacy of Clonal Growth and Expansion of Adult Neural Stem Cells. Laboratory Investigation, 83(7), pp.949-962.

Walsh, J.F., Manwaring, M.E. \& Tresco, P.A., 2005. Directional neurite outgrowth is enhanced by engineered meningeal cell-coated substrates. Tissue engineering, 11(7-8), pp.1085-94.

Wang, N., Butler, J.P. \& Ingber, D.E., 1993. Mechanotransduction across the cell surface and through the cytoskeleton. Science (New York, N.Y.), 260(5111), pp.1124-7.

Weible, M.W. \& Chan-Ling, T., 2007. Phenotypic characterization of neural stem cells from human fetal spinal cord: synergistic effect of LIF and BMP4 to generate astrocytes. Glia, 55(11), pp.1156-68.

Wen, X. \& Tresco, P.A., 2006. Effect of filament diameter and extracellular matrix molecule precoating on neurite outgrowth and Schwann cell behavior on multifilament entubulation bridging device in vitro. Journal of biomedical materials research. Part A, 76(3), pp.626-37.

Winter, J.O., Cogan, S.F. \& Rizzo, J.F., 2007. Neurotrophin-eluting hydrogel coatings for neural stimulating electrodes. Journal of biomedical materials research. Part B, Applied biomaterials, 81(2), pp.551-63.

Wong, D.Y., Hollister, S.J., Krebsbach, P.H. \& Nosrat, C., 2007. Poly(epsilon-caprolactone) and poly (L-lactic-coglycolic acid) degradable polymer sponges attenuate astrocyte response and lesion growth in acute traumatic brain injury. Tissue engineering, 13(10), pp.2515-23.

Yang, F., Murugan, R., Ramakrishna, S., Wang, X., Ma, Y.-X. \& Wang, S., 2004. Fabrication of nano-structured porous PLLA scaffold intended for nerve tissue engineering. Biomaterials, 25(10), pp.1891-900.

Yang, I.H., Co, C.C. \& Ho, C.-C., 2005. Alteration of human neuroblastoma cell morphology and neurite extension with micropatterns. Biomaterials, 26(33), pp.6599-609.

Yoshii, S. \& Oka, M., 2001. Peripheral nerve regeneration along collagen filaments. Brain research, 888(1), pp.158-162.

Yoshii, S., Oka, M., Shima, M., Akagi, M. \& Taniguchi, A., 2003a. Bridging a spinal cord defect using collagen filament. Spine, 28(20), pp.2346-51.

Yoshii, S., Oka, M., Shima, M., Taniguchi, A. \& Akagi, M., 2003b. Bridging a 30-mm nerve defect using collagen filaments. Journal of biomedical materials research. Part A, 67(2), pp.467-74.

Zeugolis, D.I., Khew, S.T., Yew, E.S.Y., Ekaputra, A.K., Tong, Y.W., Yung, L.-Y.L., Hutmacher, D.W., Sheppard, C. \& Raghunath, M., 2008. Electro-spinning of pure collagen nano-fibres - just an expensive way to make gelatin? Biomaterials, 29(15), pp.2293-305. 


\section{Chapter 3}

Zhang, N., Yan, H. \& Wen, X., 2005. Tissue-engineering approaches for axonal guidance. Brain research. Brain research reviews, 49(1), pp.48-64.

Zhong, S., Teo, W.E., Zhu, X., Beuerman, R.W., Ramakrishna, S. \& Yung, L.Y.L., 2006. An aligned nanofibrous collagen scaffold by electrospinning and its effects on in vitro fibroblast culture. Journal of biomedical materials research. Part A, 79(3), pp.456-63.

Zhu, X., Mills, K.L., Peters, P.R., Bahng, J.H., Liu, E.H., Shim, J., Naruse, K., Csete, M.E., Thouless, M.D. \& Takayama, S., 2005. Fabrication of reconfigurable protein matrices by cracking. Nature materials, 4(5), pp.403-6. 
Human neural cells and electrospun nanofibers 


\section{Chapter 4}

\section{Spinal cord organotypic slice cultures for the study of regenerating motor axon interactions with 3D scaffolds}

Jose Gerardo-Nava ${ }^{1,2,3}$ Dorothee Hodde ${ }^{1}$,Istvan Katona ${ }^{1}$, Ahmet Bozkurt ${ }^{4}$, Torsten Grehl $^{5}$, Harry W.M. Steinbusch ${ }^{2,3}$, Joachim Weis ${ }^{1,3}$, Gary A. Brook ${ }^{1,3}$

${ }^{1}$ Institute of Neuropathology, Uniklinik RWTH Aachen, Aachen 52074, Germany

${ }^{2}$ Department of Translational Neuroscience, Maastricht University Medical Center, Maastricht 6229 ER, The Netherlands

${ }^{3}$ European Graduate School of Neuroscience (EURON), Maastricht 6229 ER, The Netherlands

${ }^{4}$ Department of Plastic, Hand and Burns Surgery, Uniklinik RWTH Aachen University, Aachen 52074, Germany

${ }^{5}$ Department of Neurology, Ruhr-University Bochum, BG-Kliniken Bergmannsheil GmbH, Bochum 44789, Germany 


\begin{abstract}
Numerous in-vitro techniques exist for investigating the influence of 3D substrate topography on sensory axon growth. However, simple and cost-effective methods for studying post-natal motor axon interactions with such substrates are lacking. Here, spinal cord organotypic slice cultures (OSC) from post-natal day 7-9 rat pups were presented with spinal nerve roots, or blocks of fibrin hydrogel or 3D microporous collagen scaffolds to investigate motor axon--substrate interactions. By 7-14 days, axons from motor neuronal pools extended into the explanted nerve roots, growing along Schwann cell processes and demonstrating a full range of axon-Schwann cell interactions, from simple ensheathment to concentric wrapping by Schwann cell processes and the formation of compact myelin within a basal lamina sheath. Extensive motor axon regeneration and all stages of axon-Schwann interactions were also supported within the longitudinally orientated microporous framework of the 3D collagen scaffold. In stark contrast, the simple fibrin hydrogel only supported axon growth and cell migration over its surface. The relative ease of demonstrating such motor axon regeneration through the microporous 3D framework by immunofluorescence, two photon microscopy and transmission electron microscopy strongly supports the adoption of this technique for assaying the influence of substrate topography and functionalization in regenerative bioengineering.
\end{abstract}

Keywords: Nerve regeneration; Collagen; Fibrin; In vitro test; Scaffold. 


\section{Introduction}

Scaffolds designed to bridge peripheral nerve defects have evolved from simple hollow tubes, to complex microstructured conduits, presenting both physical and chemical cues that are important for orientated glial cell migration and axonal growth (Deumens et al. 2010; Hodde et al. 2012). The first step in evaluating the axon guidance capabilities in such constructs is usually by in vitro co-culturing with neuronal cell suspensions or with tissue explants (Möllers et al. 2009). Dorsal root ganglia (DRG) have been a major source of neurons for use in such in vitro investigations because they are easy to dissect and can be maintained in culture for extended periods of time (Corey et al. 2007; Schnell et al. 2007). Preparations of whole adult or embryonic DRG explants or single cell cultures allow for tissue- and individual cell interactions with the substrate to be studied. However, patterns of DRG axonal growth do not necessarily reflect the patterns that would be expected by motor axons: differences in axonal growth between the motor and sensory neurons (in both in vivo and in vitro models) have been observed in response to specific cellular and molecular cues, including differences when presented with a 3D hydrogel environment containing a number of growth factors (Allodi et al. 2011; Höke et al. 2006). Such differences highlight the value of assays capable of evaluating neuron subtype-specific responses to scaffolds. The investigation of the behavior and interactions of regenerating motor axons with topographically engineered scaffold surfaces largely relies on the use of relatively expensive in vivo animal models. To date, in vitro investigations of such motor axon-3D scaffold interactions remain poorly characterized, largely due to the difficulties of culturing motor neurons ( $\mathrm{MN}$ ) for extended periods in vitro. Primary MN cultures are commonly obtained from embryonic sources and tend to be short lived. Furthermore, the intrinsic regenerative capacity of prenatal motor axons (or motor neuronal cell lines) may not reflect that exhibited by more mature populations (Shewan et al. 1995). Spinal cord organotypic slice cultures (OSC) obtained from rat pups as early as 7 days have proven to be a robust approach for $\mathrm{MN}$-related investigations (Gähwiler et al. 1997). At this early post-natal age, the main cytoarchitectural features of the spinal cord have already been established and further development and maturation of $\mathrm{MN}$ can take place in vitro (Delfs et al. 1989). The well-established long term survival of MN in OSC has allowed the development of in vitro models of slow $\mathrm{MN}$ degeneration and of excitotoxicity (Rothstein et al. 1993). Motor neurons within OSC also have been demonstrated to extend long axonal processes which grew as clusters of axons around the peripheral edge of the OSC and have also been shown to follow the trajectory of explanted peripheral nerve or ventral roots(Allodi et al. 2011; Vyas et al. 2010). Although the in vitro support of motor axon regeneration by peripheral nerve explants has been impressively revealed by using yellow fluorescent protein (YFP)-expressing $\mathrm{MN}$ in transgenic mouse spinal cord OSC, the 
cells and substrate surfaces employed by the regenerating motor axons have only inferred rather than demonstrated to be within the nerve tissue (Vyas et al. 2010).

A clear understanding of how regenerating motor axons interact with the microstructure and surface topography of 3D growth-promoting substrates (natural or synthetic) is important for the future development of scaffolds in regenerative medicine. The OSC presents a promising model for the investigation of motor axon behavior in a controlled but readily modifiable environment, while significantly reducing the number of animals that would be required for similar in vivo studies. The present work investigates the use of spinal cord OSC for the evaluation of motor axon regeneration with arrange of scaffolds by presenting the ventral aspect of the slices with ventral nerve roots, fibrin hydrogel or longitudinal microstructured collagen scaffolds.

\section{Materials and methods}

\section{Spinal cord organotypic slice culture preparation}

The spinal cord OSC were prepared from post-natal day 7-9 (P7-P9) Sprague Dawley (Charles River) rat pups as previously described (Gerardo-Nava et al. 2013). Efforts were made to minimize the number of animals used and their suffering. Rapid decapitation was performed in accordance with the regulations of our institution's animal ethics committee and the European Communities Council Directive 86/609/EEC. The spinal cord was rapidly isolated and immediately placed in ice-cold explant media (sterile Gey's balanced salt solution [GBSS, Sigma-Aldrich] supplemented with $6.2 \mathrm{mg} / \mathrm{ml} \mathrm{d}$-glucose [Merck]). At this point, ventral nerve roots from the lumbar expansion were removed and collected in explant media for later use (or were immediately fixed for histological processing, see below). The dura mater was carefully removed and the lumbar spinal cord sliced transversely with a Mcllwain tissue chopper (350 $\mu \mathrm{m}$ thick, Mickle Laboratory Engineering). Four slices were carefully transferred to each low-protein-binding, hydrophilic polytetrafluoroethylene (PTFE) culture plate Millicell membrane insert (Millipore). The inserts were then placed in $35 \mathrm{~mm}$ culture plates (Falcon, Becton Dickinson) containing $1 \mathrm{ml}$ medium. Cultures were maintained in a modified serum-based organotypic medium as described by Vyas and colleagues (Vyas et al. 2010), and was composed of 50\% Eagle's Modified Essential Medium with Hank's salts (Lonza) containing 25 mM HEPES (Sigma-Aldrich), 25\% heat-inactivated horse serum (PAA), 25\% Hanks' balanced salt solution (Life Technologies), $6.2 \mathrm{mg} / \mathrm{ml}$ d-glucose, $2 \mathrm{mM}$ GlutaMAX (Life Technologies), glia derived neurotrophic factor (GDNF, Peprotech, $10 \mathrm{ng} / \mathrm{ml}$ ) supplement at $\mathrm{pH}$ 7.2-7.4 with an antibiotic/antimycotic solution (1:100 vol/vol, Sigma--Aldrich). Medium was also supplemented with $160 \mu \mathrm{g} / \mathrm{ml}$ tranexamic acid (Pfizer) to avoid 
excessively rapid proteolytic degradation of fibrin hydrogels. The OSCs were incubated at $37{ }^{\circ} \mathrm{C}$ in a fully humidified atmosphere enriched with 5\% CO2 and culture medium was changed after $24 \mathrm{~h}$, followed by twice weekly changes for the duration of the experiments.

\section{Biomaterial preparation}

Fibrin (5 mg/ml, Merck) hydrogel blocks were generated using $3 \mathrm{U} / \mathrm{ml}$ thrombin (SigmaAldrich) and $3.75 \mathrm{mM} \mathrm{CaCl}_{2}$ (Merck) in organotypic media. The components were quickly mixed and $250 \mu$ l of the mixture was poured into a plastic mold (10 $\mathrm{mm} \times 10 \mathrm{~mm} \times 5 \mathrm{~mm}$ ). Fibrin was left to gel for $5 \mathrm{~min}$ at room temperature followed by a further $30 \mathrm{~min}$ gelling period at $37^{\circ} \mathrm{C}$ in a humidified incubator. Gels were removed from the molds and cut into rectangular blocks of approximately $4.5 \mathrm{~mm} \times 2 \mathrm{~mm} \times 2 \mathrm{~mm}$. Longitudinally orientated collagen type I scaffolds (Optimaix 3D, Matricel $\mathrm{GmbH}$ ) (Bozkurt et al. 2007) were also cut into rectangular blocks of approximately $3 \mathrm{~mm} \times 1.5 \mathrm{~mm} \times 0.8 \mathrm{~mm}$.

\section{Preparation of organotypic slice-biomaterial co-cultures}

Twenty-four hours after generating the OSC, the ventral nerve roots, collagen scaffolds or fibrin hydrogels were carefully positioned in contact with ventral surface using a dissection microscope, ensuring that no gaps were present (Fig. $1 \mathrm{~A}-\mathrm{C}$ ). As controls, ventral nerve roots were cultured on membranes in the absence of OSCs to determine the extent of nerve degeneration in isolation.

\section{Cryosectioning}

After 14 days incubation, OSC-biomaterial/ventral nerve root co-cultures were fixed by immersion in 4\% paraformaldehyde (PFA, Applichem) for $1 \mathrm{~h}$. The fibrin hydrogel and ventral nerve root preparations were cryoprotected in 30\% sucrose for $24 \mathrm{~h}$ followed by embedding in Tissue-Tek OCT Compound (Sakura). To ensure section adhesion to glass slides, collagen scaffold samples were embedded in $10 \%$ gelatin (Merck) containing $5 \%$ sucrose in phosphate buffered saline (PBS, Life Technologies). Longitudinal and transverse cryostat sections (50 $\mu \mathrm{m}$ thick) were prepared using a Leica CM3600 (Leica), cryostat and mounted on slides (Superfrost gold, Menzler Gläse). 


\section{Electron microscopy}

For transmission electron microscopy (TEM), 3.9\% glutaldehyde-fixed tissue specimens were post-fixed with $1 \%$ OsO4 in $0.1 \mathrm{M}$ cacodylate buffer containing $50 \mathrm{mM} \mathrm{K3Fe(CN)6}$ and embedded in epoxy resin. Semi-thin sections were stained with toluidine blue and paraphenylendiamine. Ultrathin sections were contrasted with $0.5 \%$ uranyl acetate and 3\% lead citrate (Laurylab) and examined with a Philips CM10 electron microscope. Images were obtained from freshly dissected (control) ventral nerve roots, 7-day degenerated ventral nerve root, 7-day regenerating OSC-ventral nerve root co-culture, as well as 14-day OSC-collagen scaffold model. Micrographs were generated at 3 different positions along the OSC-collagen scaffold/ventral nerve root axis (i.e. in regions close to- and far from the coaptation point, as well as intermediate regions in the middle of the sample).

\section{Immunohistochemistry}

Immunohistochemistry was performed on whole free-floating OSC-biomaterial/ventral nerve root co-cultures as well as on cryosections that had been mounted onto glass slides. Cryosections were post-fixed with 4\% PFA for $10 \mathrm{~min}$. All samples were blocked with $5 \%$ normal goat serum and $0.5 \%$ triton X-100 (Sigma-Aldrich) in PBS for $1 \mathrm{~h}$ at room temperature (RT). Single- or double immunofluorescence was performed using combinations of the following primary antibodies: mouse monoclonal antibodies to neurofilament 200 (1:5000, SMI-32, Covance), beta III tubulin (TUBB3, 1:1000, SigmaAldrich), low affinity nerve growth factor receptor/p75 (1:250, Millipore) and ED1 (1:500, Serotec), as well as polyclonal rabbit antibodies to glial fibrillary acidic protein (GFAP, 1:1000, DAKO), S100 (1:1000, DAKO) and Iba1 (1:1000, WAKO). Primary antibodies were incubated at room temperature overnight, and in the case of the whole mounts, a shaker was used. Secondary antibodies used were goat anti-mouse Alexa 594 and goat anti-rabbit Alexa 488 (Life Technologies). A 4',6-diamidino-2-phenylindole dihydrochloride (DAPI, Invitrogen) nuclear counter stain $(1 \mu \mathrm{g} / \mathrm{ml})$ was used as required. Slides were coverslipped with Fluoprep (Biomerieux), whereas whole mounts were imaged by placing them in a drop of PBS.

\section{Tissue imaging}

Images of whole mounts and cryosections were made with the automatic Mosaix system from the AxioVision software, using an AxioPlan microscope (Carl Zeiss Microscopy $\mathrm{GmbH}$ ). Areas of interest were further imaged for 3D reconstruction using either an 
Olympus FV1000 multi-photon microscope or a Zeiss ApoTome Imaging system (Carl Zeiss Microscopy $\mathrm{GmbH}$ ). For both systems a z-stack step of $1 \mu \mathrm{m}$ was used. Video sequences and $3 \mathrm{D}$ reconstructions were generated using the software Imaris Ver 7.4 (Bitplane Scientific).

\section{Axonal growth and penetration}

The longest distance of axonal growth in the OSC-biomaterial preparations was measured for each sample from whole mount images. Duplicate co-cultures from at least three donor animals per condition were evaluated. The extent of scaffold penetration by regenerating axons was assessed by measuring the total length of immunostained axonal profiles present within the biomaterial up to a distance of $450 \mu \mathrm{m}$ from the OSC-scaffold interface. Images of longitudinally orientated SMI-32+/TUBB3+ profiles were traced using GNU Image Manipulator Program (GIMP, GNU General Public License), and subsequently skeletonized into single pixel lines using ImageJ (U. S. National Institutes of Health). Axon penetration was quantified by calculating total pixel counts within the defined area of interest. For quantitative analysis duplicate co-cultures from at least three donor animals per condition were evaluated.

\section{Statistical analysis}

Data are plotted as mean \pm standard error of the mean (SEM). Data was subjected to $t$ test. All tests were performed using GraphPad Prism statistical software ver. 4.0 (GraphPad Software).

\section{Results}

Immunohistochemistry of motor axon growth through reconstructed ventral nerve roots

The in vitro ventral nerve root reconstruction model was achieved by pairing freshly explanted ventral root tissue with spinal cord OSC (Fig. 1A). The same approach was adopted for the pairing of the OSC with the fibrin hydrogel blocks and the collagen scaffold (e.g. Fig. 1B and C). After only 7 days of OSC-ventral nerve root co-culture, SMI32/TUBB3 immunostaining of whole slice preparations revealed axons extending from both ventral horn motor neuron pools, beyond the coaptation site and along the nerve 
root (Fig. 2A). Cross-sections of the mid-point of the nerve roots confirmed that axonal growth occurred within the nerve root rather than over its surface (Fig. 2B). Lateral view reconstruction of a central, $15 \mu \mathrm{m}$ thick region of the cryostat section revealed axons growing unidirectionally, following the longitudinal axis of the explanted nerve root (Fig. 2C). Sections taken from a position close to the coaptation site showed extensive, orientated axonal growth into the tissue, as indicated by the 3D reconstruction image (Fig. $2 \mathrm{D}$ and supplementary video 1 ). Longitudinal cryosections also revealed the elongated, spindle-shaped morphology of S100 + Schwann cells which were orientated along the long axis of the explanted nerve root (small arrows, Fig. 2E). Fine, regenerating NF200 + axonal processes followed the trajectory of the Schwann cells within the roots (small arrows, Fig $2 \mathrm{~F}$ ), while larger diameter regenerating axons could be seen on the surface of the tissue (large arrows, Fig. 2F).

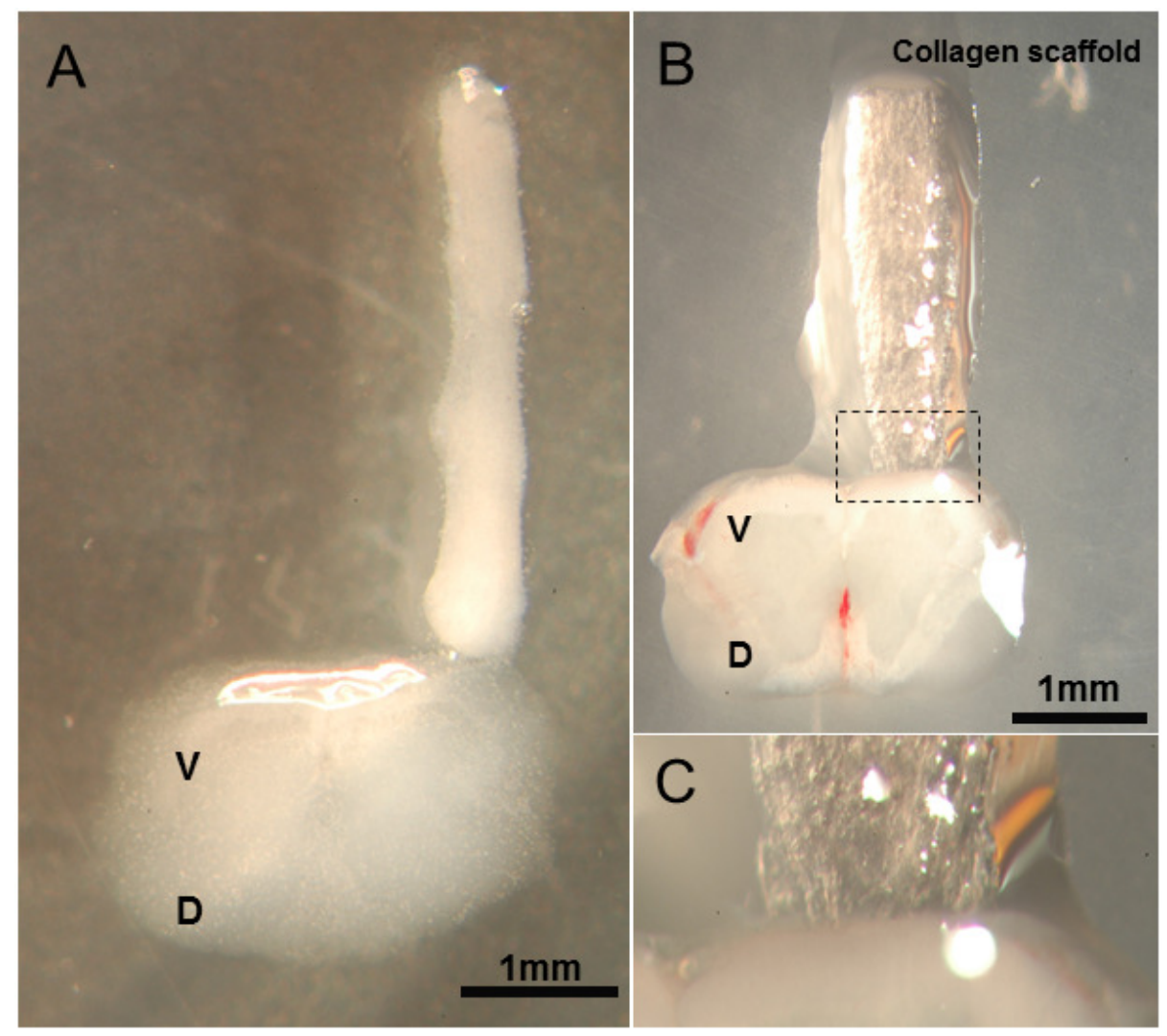

Fig. 1 Co-culture system. A: A ventral nerve root has been positioned in contact with the ventral surface of the spinal cord OSC (already 7 days in culture). B: longitudinally orientated 3D collagen scaffold placed in close 
contact with the ventral surface of a freshly prepared OSC. C: Close contact between the spinal cord slice and the scaffold can be observed. $v=$ ventral, $d=$ dorsal.

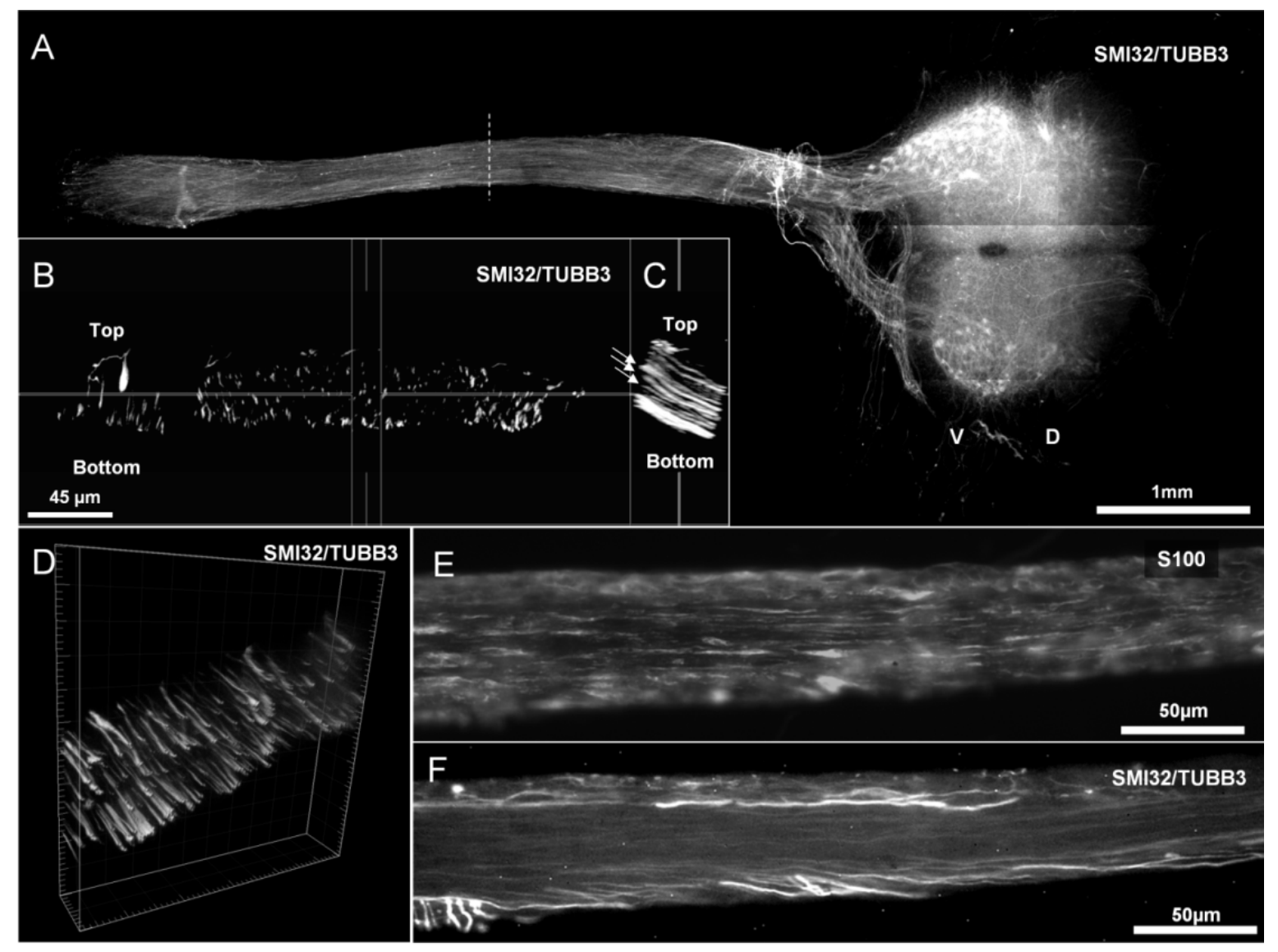

Fig. 2 Ventral root reconstruction model. The lumbar spinal cord OSC cultures were paired with ventral nerve roots from littermates and maintained in culture for 7 days. A: Regenerating axons from ventral horn motoneuronal pools extended through the reconstructed root. B: Distribution of regenerated axons within the spinal root (at dotted line in A). C: Lateral 2D Reconstruction of a central, $15 \mu \mathrm{m}$ thick region, highlighted in B, showed axons orientated within the nerve tissue. D: 3D reconstruction of a section close to the coaptation site showing orientated axonal growth in the nerve tissue. E: S100 + cells present elongated patterns inside the nerve. F: Axonal growth can be observed along the tissue with large caliber axons growing in the outermost part of the tissue and fine, smaller caliber axons inside. $v=$ ventral, $d=$ dorsal.

\section{Electron microscopy of ventral nerve root degeneration and motor axonal growth}

Transmission electron microscopy of control, unlesioned ventral nerve roots displayed characteristic myelinated axonal profiles of different diameters (Fig. 3A). In contrast, isolated ventral nerve roots that had been allowed to degenerate for 7 days in vitro, revealed many degenerating myelin profiles (arrowheads, Fig. 3B) with collapsed axons and vacuolar structures filled with lipids (asterisks, Fig. 3B). No healthy axons could be 
found in such samples. The ventral nerve root reconstruction models that were allowed to regenerate for 7 days were studied at 3 different positions along the OSC-nerve root axis: at the coaptation site, at $1 \mathrm{~mm}$ and at $2 \mathrm{~mm}$ distal to the coaptation site. At the coaptation site, bundles of Schwann cell processes and axons surrounded by a single basal lamina could be observed, sometimes surrounded by circumferential profiles reminiscent of astrocytic processes normally found at the CNS-PNS interface (Fraher 2000) (double arrowheads, Fig. $3 \mathrm{C}$ ). In some cases, individual regenerating axons were wrapped by single Schwann cell process (arrowheads, Fig. 3D), but most axons could be found in close apposition to Schwann cells. Some scattered myelin degeneration could still be observed but the majority of the samples appeared to have been cleared of the debris close to the coaptation site. At $1 \mathrm{~mm}$ distal to the coaptation point, fewer Schwann cell-axon combinations could be detected amongst the debris. Even at this early stage of coculturing, occasional healthy-looking axons in the early stages of myelination were present already (Fig. 3E and F). Further distally ( $2 \mathrm{~mm}$ from the coaptation point), relatively fewer axonal profiles could be found amongst bundled Schwann cell processes. Two main layers of cells were seen in all samples: an inner core composed of small diameter cells and longitudinally oriented processes, and an outer layer composed of larger diameter, loosely packed cells (lower and upper regions of Fig. $3 G$ respectively).

Motor axon growth through a microstructured collagen scaffold and fibrin hydrogels

Immunohistochemistry of whole mount preparations for SMI-32 and TUBB3 revealed axons that, by 14 days, had regenerated up to and even beyond the distal ends of the scaffolds (i.e. a minimal distance of $3 \mathrm{~mm}$, Fig. 4A and B). Two-photon 3D reconstructions of the immunostained whole mounts revealed that axons could only be detected on the outer surface of the fibrin hydrogel (Supplementary video 2), while the collagen scaffold supported axonal growth through its internal microporous framework. However, the depth to which reliable two-photon imaging could be achieved in such samples was limited by the high degree of light scattering properties of the collagen matrix. Longitudinal cryosectioning of the whole mount preparations that had already been processed for NF200 and $\beta$-III tubulin immunohistochemistry, confirmed the presence of regenerating motor neuron axons within the depth of the collagen scaffold while all axonal growth took place over the surface of the fibrin hydrogel (Fig. $4 \mathrm{C}$ and D). 


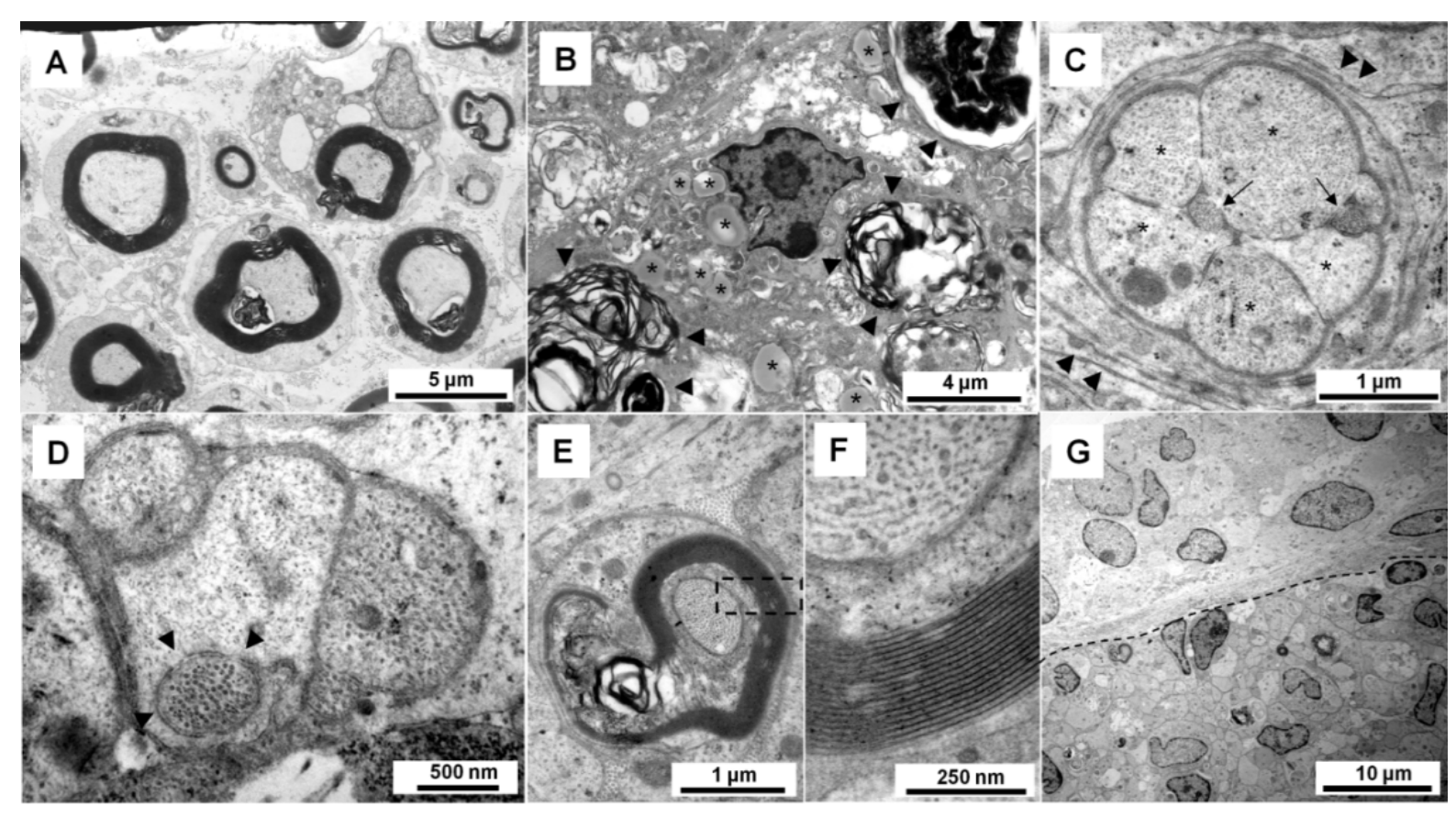

Fig. 3 TEM of nerve root reconstruction model. A: Myelinated axons of different calibers can be observed in control ventral root tissue (P7). B: Nerve root was allowed to degenerate in vitro for 7 days, showing much myelin debris (arrowheads) and lipid filled vacuolar structures (asterisk). C: At 7 days in culture, in the nerve reconstruction model, close to the coaptation site, bundles of Schwann cell processes (asterisk) and axons (arrows) are surrounded by astrocytic processes (arrowheads). D: Some axons can be observed surrounded by a single Schwann cell processes (arrowheads) or in close contact with Schwann cell processes. E: At $1 \mathrm{~mm}$ from the coaptation site a myelinated axon can be observed, boxed area shown at higher magnification in F. F: The myelin sheath shows a typical periodicity of compact myelin. G: Two tissue layers can be observed in the sample: an inner core of cell processes mainly composed of Schwann cells (bottom) and an outer layer of fibroblast-like cells (top).

Semi-thin sections prepared from tissue approximately $1 \mathrm{~mm}$ from the coaptation site of 14-day OSC-collagen scaffold co-cultures revealed clusters of myelinated axonal profiles, macrophages and fibroblast-like cells within the scaffold's microporous framework (Supplementary Fig. 1A-D). Ultra-thin sections demonstrated the fine structure of the cell-cell and cell-scaffold interactions (Fig. 5). A range of Schwann cellaxon interactions, from early association, to ensheathment and myelination could be observed (Fig. 5A-D). First stages of ensheathment could be observed with individual axons and Schwann cells, with the formation of mesaxons (Fig. 5A-B). Although most myelinated bundles were found in close association with the collagenous walls of the scaffold micropores (e.g. Fig. 5C and D), some bundles could be found at the center of the micropores, presumably suspended between nearby walls. No axons were found in isolation, but were always associated with cell processes. As expected, a thick layer of tissue, containing multiple myelinated and unmyelinated axons was prominent at the interface between culture insert membrane and collagen scaffold (Fig. 5E), whereas phagocytic macrophages and fibroblasts were commonly observed throughout the porous 
microframework (Fig. 5E-G). Some of the macrophages could be seen engulfing components of the collagen scaffold wall (e.g. Fig. $5 \mathrm{G}$ and $\mathrm{H}$ )

Quantitative analysis indicated that by 7 days, the fibrin hydrogel and collagen scaffolds had supported regeneration of SMI-32+/TUBB3+ axons to distances of $1456 \pm$ $70.76 \mu \mathrm{m}$ and $1229 \pm 80.09 \mu \mathrm{m}$ respectively ( $P>0.05$, Fig. $6 \mathrm{~A}$ ), and that by 14 days, axonal processes had reached the distal end of the collagen scaffold $(3 \mathrm{~mm})$ and the fibrin hydrogel $(4.5 \mathrm{~mm})$. Quantification of axonal profiles within the biomaterials revealed no penetration into the fibrin hydrogel while significant penetration was supported by the collagen scaffold ( $p<0.001$, Fig. 6B). Qualitatively, GFAP + astrocytic and p75 + Schwann cell migration appeared to be limited to the first $1-2 \mathrm{~mm}$ of the collagen scaffold (Fig. $7 \mathrm{~A}$ and B) while in strong contrast, extensive migration by ED1+/lba1+ macrophages/microglia could be observed (Fig. 7C and D). Cellular migration supported by the fibrin hydrogel appeared to be limited to the substrate surface, showing a similar pattern to that already observed for axonal growth (Supplementary Fig. 2).
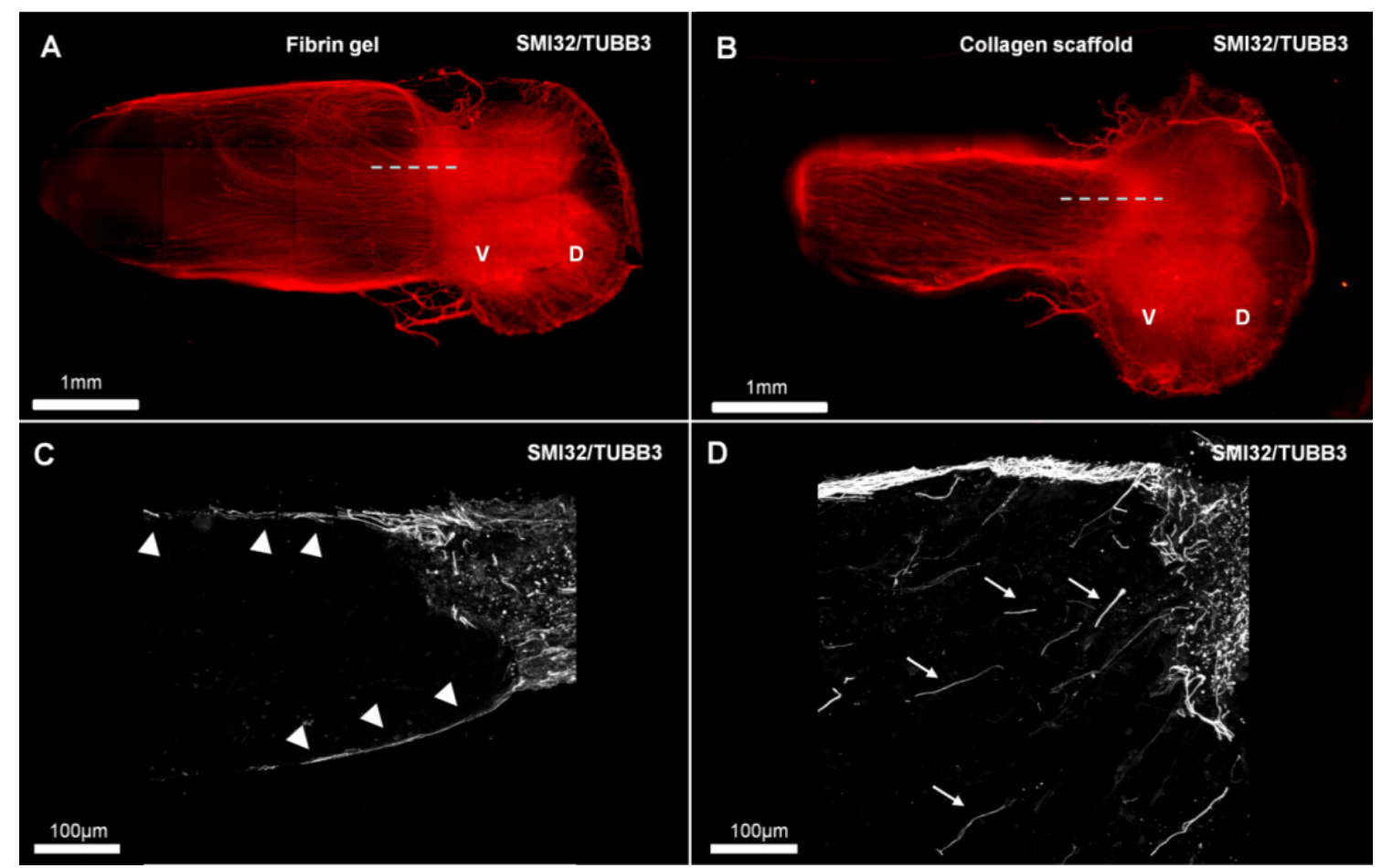

. Fig. 4 Axonal growth supported by fibrin hydrogel blocks and collagen scaffolds. A,B: Whole mounts of fibrin hydrogel block (A) and collagen scaffold (B) stained for SMI32 and TUBB3 revealing the supported growth of large numbers of axons by both substrates. C,D: Close inspection of cryosections of fibrin hydrogels (C) revealed that axonal growth was limited to the outer surface of the construct (arrowheads). In contrast, collagen scaffolds permitted orientated axonal growth through its longitudinal orientated micro channels (arrows, D). $v=$ ventral, $d$ $=$ dorsal 

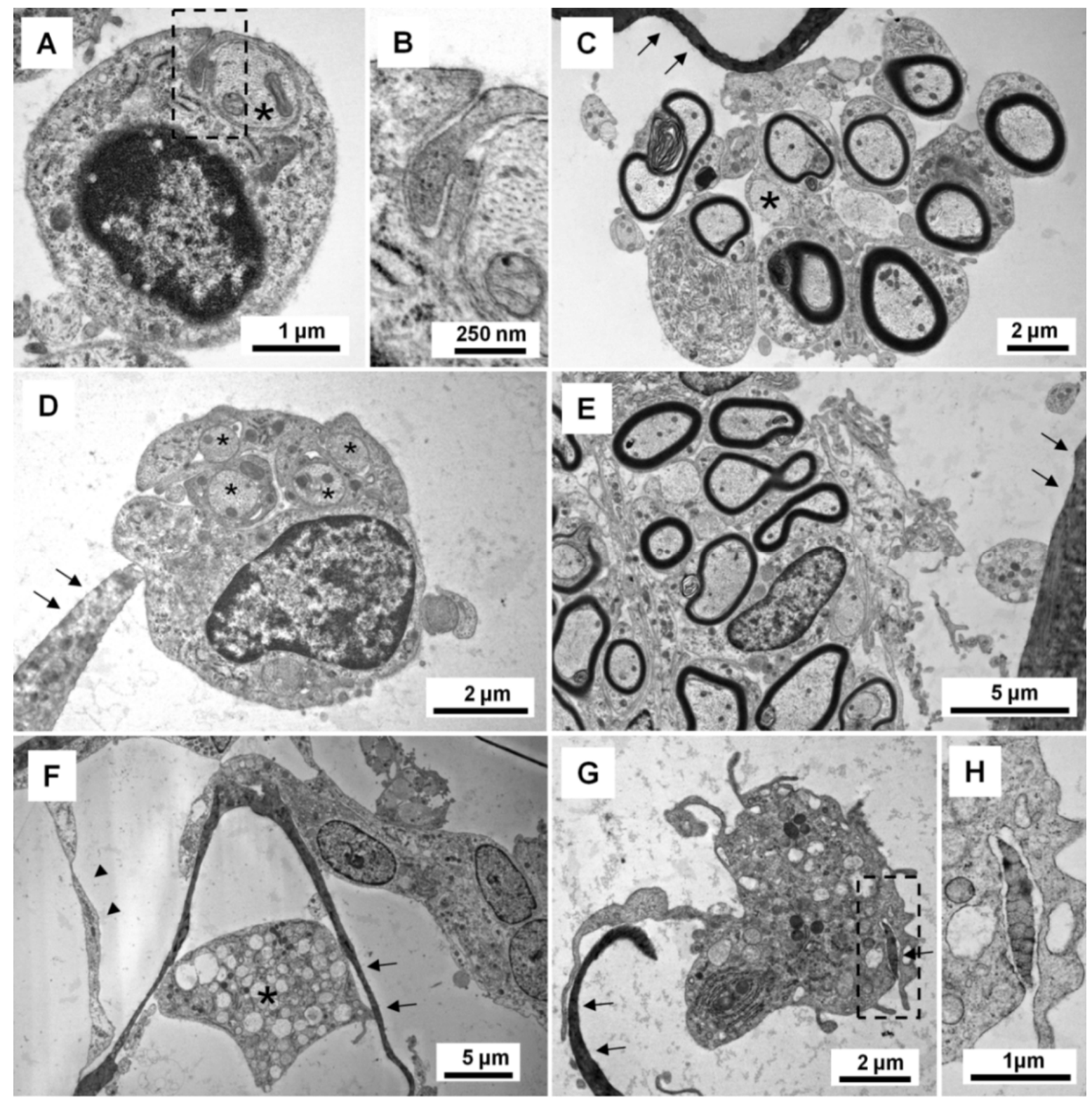

Fig. 5 TEM from the OSC-collagen scaffold co-culture system at 14 DIV. A: Schwann cell-axon (asterisk) interaction at an early stage of ensheathment. B: Magnification of boxed area in A showing the overlapping Schwann cell process $C$ : Clusters of myelinated axons were observed in close contact with the collagen walls of the scaffold (arrows). D: Some clusters only contained unmyelinated axonal processes (asterisk). Axons were always found in close contact with other cellular structures. A spur of the collagen scaffold is indicated by the arrows. E: The majority of the cellular and axonal growth was observed close to the cell culture-membranescaffold interface. Scaffold wall indicated by arrows. F: Other cellular components observed in contact with the collagen walls of the scaffold (arrows) were macrophages (asterisk), fibroblasts and their processes spanning from wall to wall (arrow heads) G: A macrophage in close contact with the collagen wall (arrows) of the scaffold. $\mathrm{H}$ : Higher magnification of boxed area in G. Cell processes apparently engulfing a fragment of the collagen wall, suggesting active degradation processes. 

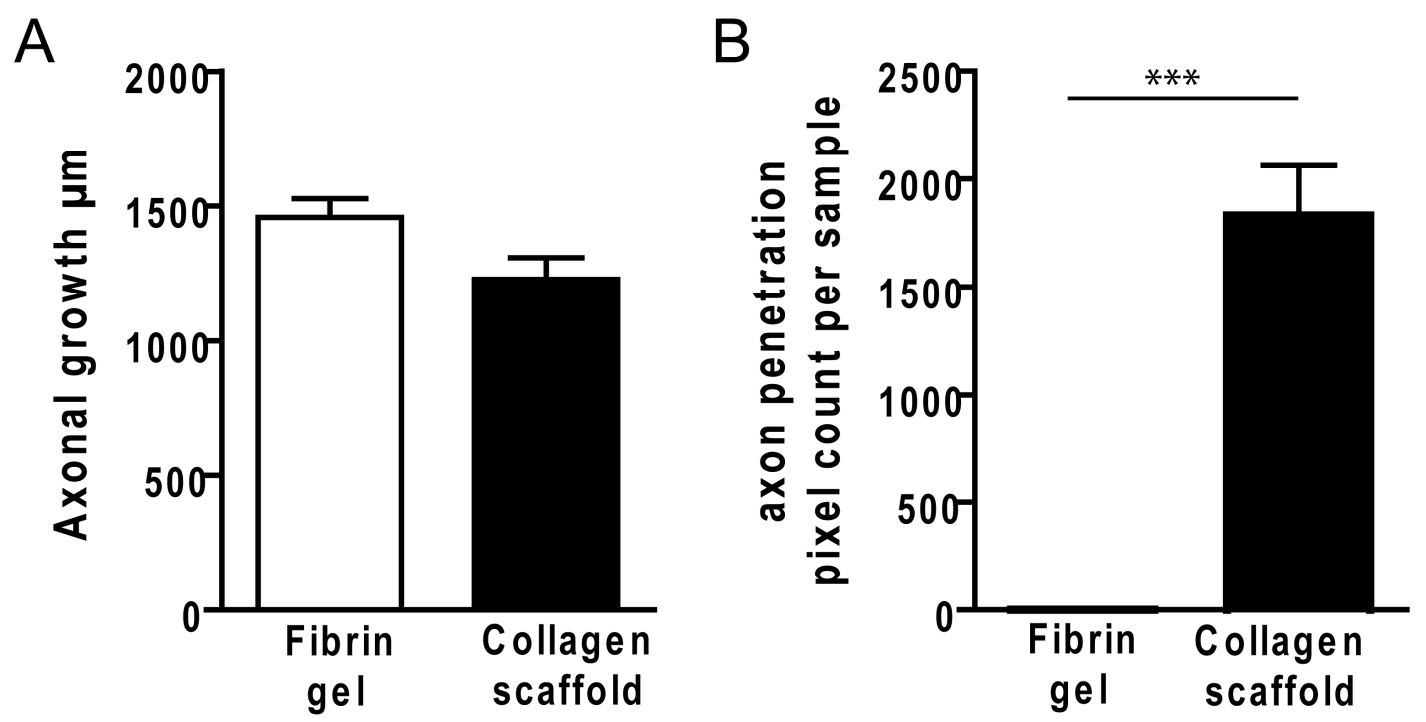

Fig. 6 Quantification of axonal growth and axonal infiltration. A: Axonal growth along the fibrin hydrogels and collagen scaffolds was not significantly different, reaching distances of over $1 \mathrm{~mm}$ within the first 7 days. B: After 14 days, no axons were found within the fibrin hydrogels, while much axonal growth in the collagen scaffold was located within the pores $(* * *<0.001)$.

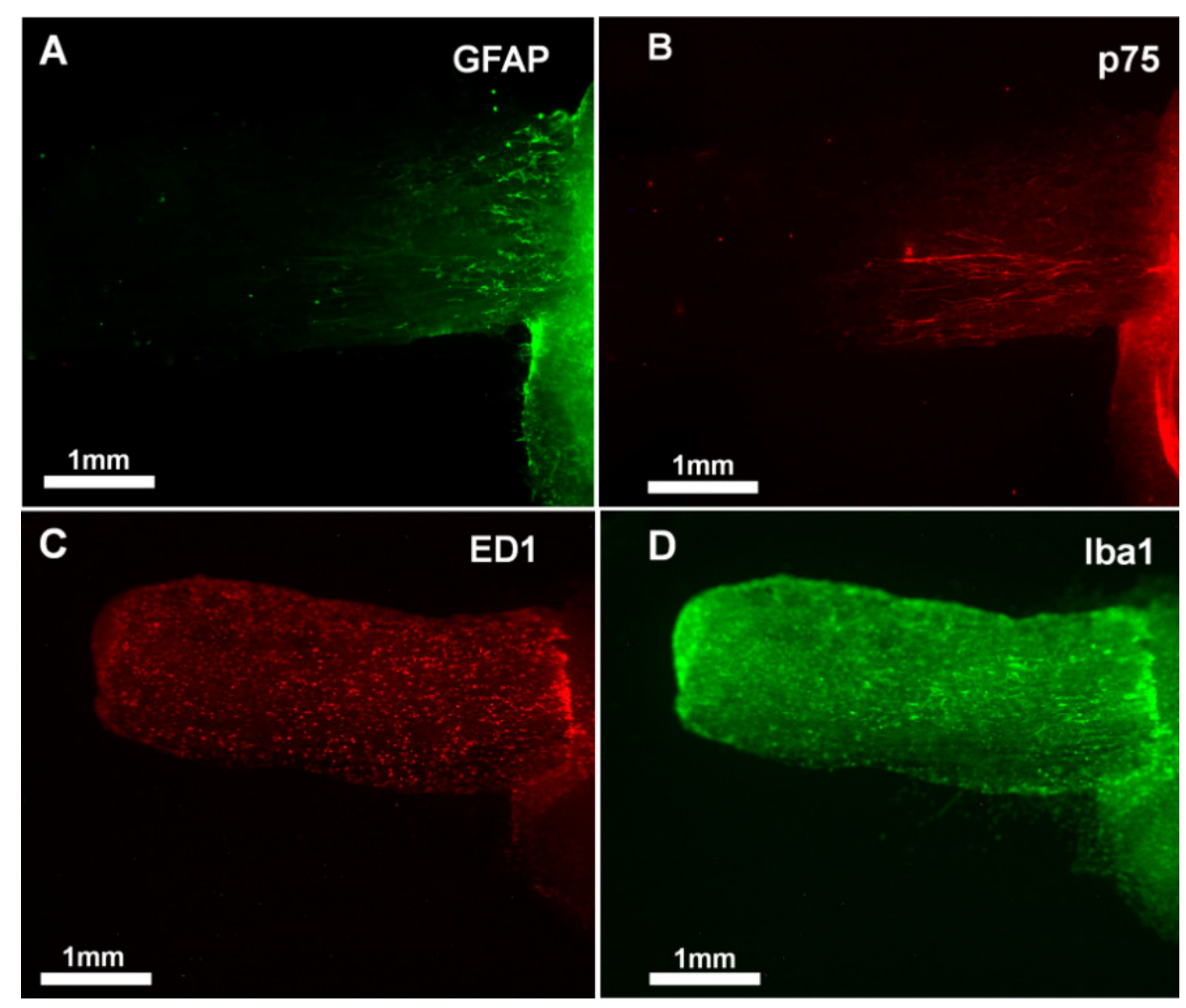

Fig. 7 OSC-collagen scaffold interactions. A: GFAP + astrocytes showed only limited integration beyond the scaffold - OSC interface. B: p75 + immunostaining revealed that some of the migrating cells were Schwann cells derived from the residual spinal nerve roots. C,D: Substantial microglia/macrophage infiltration could also be detected through the whole scaffold as indicated by ED1+ and Iba1+ expressing cells. 


\section{Discussion}

The progressive expansion of tissue engineering for nerve repair has generated the need for highly reproducible in vitro models for screening the regeneration promoting properties of newly developed scaffolds. The organotypic slice preparation represents an excellent candidate for large scale in vitro screening of scaffold properties, because it presents several advantages, including ease of preparation, cost reduction and the preservation of the motoneuronal microenvironment within the OSC- ventral horn grey matter. This supports the maintenance and survival of MN within the OSC for extended periods of time (e.g. for several months if required) (Gerardo-Nava et al. 2013; Rothstein et al. 1994). Numerous investigations have already demonstrated the extensive growth of motor axons around the circumference of spinal cord OSC or, as mentioned earlier, along explants of peripheral nerve and spinal nerve roots as well as through hydrogels (Allodi et al. 2011; Vyas et al. 2010). The present investigation has demonstrated the value of adapting OSC for investigating motor axon interactions with the surfaces of scaffolds, either in the form of complex microstructured porous frameworks or as a simple hydrogel block. Migrating OSC-derived Schwann cells supported motor axon regeneration throughout the longitudinally orientated microporous framework of the collagen scaffold, whereas cell migration and axonal growth could only be demonstrated over the surface of the fibrin hydrogel block. This highlights the preference of cell migration and axonal growth along the multiple surfaces presented by the microstructured collagen scaffold. The potential of employing such an approach for large scale in vitro assays of substrate topography modification (and/or functionalization) on motor axon regeneration is striking.

The study of any potential influence of substrate topography (or functionalization) on Schwann cell-motor axon interactions requires the prior characterization of such cell--cell interactions under the present well defined tissue culture conditions and within the most appropriate substrate for fostering ensheathment and myelination by Schwann cells (i.e. in the explanted ventral nerve roots). The support of OSC-derived motor axon regeneration by explanted ventral nerve roots has already been demonstrated, but only partially characterized (Rothstein et al. 1993). A number of potential routes for axon regeneration are possible when spinal cord OSC have been presented with explanted spinal nerve roots (i.e. over the explant's superficial surface, along the interface between the explant and the supporting membrane or within the explant itself). The present use of TEM and 3D reconstruction of immunostained whole mount preparations and sections has confirmed that motor axon regeneration followed the Bands of Büngner within the Wallerian degenerated nerve. Surprisingly, the speed or efficiency of myelin degeneration and clearance within the explanted nerve appeared to be greater following coaptation of the nerve to the OSC, than was observed if the nerve was cultured in isolation. Although these events followed a similar pattern to that already 
described during Wallerian degeneration in vivo (Beirowski et al. 2004; Hu et al. 2009), it is tempting to speculate that the accelerated clearing of myelin debris within the explanted nerve may have been assisted by the extensive migration of OSC-derived phagocytic macrophages/microglia. Such behavior could not be demonstrated directly in the present investigation, but is strongly suggested by the migration of these cells into the collagen scaffold. As anticipated, the interactions between regenerating motor axons and Schwann cells within the nerve explants demonstrated a range of different stages of maturity; from simple, initial axon-Schwann cell contacts, to the ensheathment of individual axons, the formation of compact myelin, and the grouping of cellular and axonal bundles within a single basal lamina sheet, reproducing, to some extent, the sequence of events taking place during axon regeneration in vivo (Cabaud et al. 1982). This full range of Schwann cell-motor axon interactions was also supported by the longitudinally orientated micropores of the collagen scaffold.

To date, relatively few organotypic slice culture models have been adapted for the evaluation of axonal growth (Allodi et al. 2011; Ishihara et al. 2011; Prang et al. 2006; Vyas et al. 2010; Zhang et al. 2010). Prang and colleagues successfully used an entorhinohippocampal slice culture model to demonstrate directed CNS axon regeneration through a bioengineered construct (Prang et al. 2006). Ishihara on the other hand, proposed cocultures of cerebral cortex to evaluate axonal interactions with Matrigel hydrogels, where cerebral cortex-derived axons were reported to influence Schwann cell orientation, and the most extensive axonal growth taking place over orientated Schwann cells at, or close to the surface of the Matrigel block (Ishihara et al. 2011). In contrast to the present study, Matrigel blocks that had no prior seeding with Schwann cells supported some degree of axon growth throughout the gel. In the present investigation, the fibrin hydrogel only supported axonal growth over its surface and this trajectory was also followed by migrating OSC-derived astrocytes and macrophages. Other studies focusing on hydrogelmediated axonal growth, using DRG explants, have shown similarly poor neurite penetration into the hydrogel in vitro (Kofron et al. 2009; Lampe et al. 2013). In vivo experiments using hollow conduits filled with fibrin hydrogels have demonstrated a slightly better performance, with some studies reporting axon regeneration and myelination beyond the coaptation site as early as 1 -week after transplantation (Nakayama et al. 2007; Williams 1987). Such in vivo axonal penetration into fibrin hydrogels has been suggested to be due to the extensive migration of host cells into the fibrin hydrogel where they degraded and reshaped the matrix, rather than to direct penetration of axons into the hydrogel (Nakayama et al. 2007). It is possible that the reason why our in vitro model fails to reproduce this reshaping process is the use of antiproteolytic agents, needed to stabilize the fibrin hydrogel matrix for periods of time longer than $24 \mathrm{~h}$. 
Topographical cues in the form of fibers or pores have long been appreciated for their usefulness in nerve repair strategies (e.g. Ref. (Deumens et al. 2010)). The orientated growth of sensory axons and Schwann cells from DRG explants into the orientated collagen scaffolds has also been demonstrated in vitro (Bozkurt et al. 2007; Führmann et al. 2010). However, no indication of myelination of the regenerating sensory fibers in such in vitro studies has been documented. Relatively expensive and time consuming in vivo studies ( 6 weeks survival times) have, on the other hand, been able to demonstrate axon regeneration into 3D collagen scaffolds that were implanted into $20 \mathrm{~mm}$ resection injuries of the adult rat sciatic nerve, including myelination of regenerated axons (Bozkurt et al. 2012). TEM and light microscopy images obtained from the OSC-collagen scaffold preparations also showed clusters of myelinated axons within the microporous framework. These were certainly fewer in number than seen in the in vivo experiments, but this would likely be due to the fact that a relatively small number of viable MN was present in each OSC in comparison to those present in the whole sciatic nerve in the animal (in vivo) experiments. The degree of axonal growth and myelination achieved in this in vitro-model, nonetheless, provides an invaluable indication of the behavior of regenerating $\mathrm{MN}$-axons when presented with a suitable scaffold.

Similar observations can be made in regards to the cellular interactions between the OSC and the collagen scaffold. Immunofluorescence revealed the extent of OSCexplant integration by the migration of OSC-derived cells into the collagen scaffolds. GFAPimmunoreactive astroglial processes could be seen extending throughout the porous collagen scaffold for distances of up to $1 \mathrm{~mm}$, whereas the p75-immunoreactive Schwann cell processes were found up to $2 \mathrm{~mm}$ into the scaffolds. The qualitative observations of the extent of OSC-derived astroglial migration into the collagen scaffolds is similar to that observed following the application of freshly prepared astroglial cell suspensions to similarly orientated scaffolds in vitro, where distances of just above $1 \mathrm{~mm}$ were reported after 14 days incubation (Möllers et al. 2009). Astroglia are well known for their role in barrier and scar formation after injury (Fawcett et al. 2012; Reier \& Houle 1988), and the slow rate of migration into the collagen scaffold may reflect a degree of incompatibility between the reactive astrocytes and the scaffold or alternatively, an excessively strong adhesion between the astroglia and the collagenous substrate, effectively slowing cell migration. Indeed, recent studies describing the implantation of a similar orientated microporous collagen scaffold into experimental transaction injuries and hemiresection injuries of the adult rat spinal cord have indicated little or no integration of spinal cord tissues by histological and immunohistochemical criteria (Cholas et al. 2012a; Cholas et al. 2012b). The observation of the p75-immunoreactive Schwann cells likely reflects the orientated migration of dedifferentiated Schwann cells along the most proximal parts of the collagen scaffold. The association with numerous regenerating motor axons, followed by ensheathment and myelin formation would result in a shift of Schwann cell phenotype 
from the dedifferentiated, non-myelinating (p75-positive) form to a more mature, myelin protein expressing phenotype (Mirsky \& Jessen 1999).

In contrast to the modest migration of OSC-derived astrocytes and Schwann cells, there was a remarkably extensive migration of ED1-positive/IBA1-positive macrophages/microglia into the collagen scaffolds. Some of these cells were even observed by TEM to be taking part in the phagocytosis of scaffold break-down products. Although macrophages are known to be important in the rapid clearance of axonal and myelin debris during Wallerian degeneration and for the production of growth factors and cytokines involved in Schwann cell activation (Dubový et al. 2013), the role of the extensive ED1-positive/IBA1-positive macrophages/microglia migration in the Schwann cell and motor axon penetration of the scaffold remains to be elucidated. Others have described the moderate infiltration of implanted collagen conduits by ED1/ED2-positive macrophages following peripheral nerve injury, indicating the lack of an extreme host inflammatory response being beneficial or at least permissive to nerve regeneration in vivo (Keilhoff et al. 2003). Clearly, the macrophage/microglia observed in the present investigation are derived from a CNS (organotypic slice) source and might not reflect the optimal cellular model for macrophage involvement in scaffold-based support of motor axon regeneration in the PNS. Nonetheless, recent reports of the implantation of microstructured collagen scaffolds into spinal cord injured animals (Cholas et al. 2012a; Cholas et al. 2012b) suggest that the present in vitro model may also have applications in determining tissue-biomaterial interactions relevant for regenerative medicine in the CNS.

Although this in vitro organotypic slice has been able model reproduced many of the events taking place in PNS Wallerian degeneration with subsequent axonal regeneration, clear limitations exist, including the lack of any functioning vasculature, an incomplete immune system and the absence of appropriate end organ targets for the regenerating motor axons. Despite these limitations, the OSC model affords a number of significant advantages over assays attempting to employ cultures of freshly isolated embryonic motor neurons (or cells lines), or involving in vivo studies with animal models. Such advantages include the relative simplicity and ease of preparation, the length of time such co-cultures can be maintained (Gähwiler et al. 1997) and the financial and ethical benefits of reducing the number of animals required to perform the investigations. The spinal cord OSC, thus, represents an excellent platform for investigating how regenerating motor axons interact with 3D growth-promoting substrates (natural or synthetic) and can be used as a cost-effective means of screening newly developed scaffolds intended to promote repair of the lesioned PNS. 


\section{Conclusions}

The inclusion of topographical cues for the orientation of axonal growth is an important aspect of modern bioengineering that needs to be considered when designing scaffolds for peripheral nerve repair. The present investigation has demonstrated the potential of the OSC-model as a tool for the evaluation of 3D microstructured scaffolds on motor axon regeneration. By extension of the rationale behind using this model, it is clear that it would also be amenable to investigations of scaffold surface functionalization (cellular or molecular) on motor axon regeneration and the maturation of Schwann cell-axon interactions.

\section{Acknowledgements}

This work has been supported by the RWTH Aachen-Maastricht-University Exchange Program. This work was supported by the facility "Two-Photon Imaging", a core facility of the Interdisciplinary Center of Clinical Research (IZKF) Aachen within the Faculty of Medicine at RWTH Aachen University". D. H. was supported by a grant from the Deutsche Forschungsgemeinschaft to G.A.B. (DFG \#BR2299/4-1). 


\section{Supplementary data}

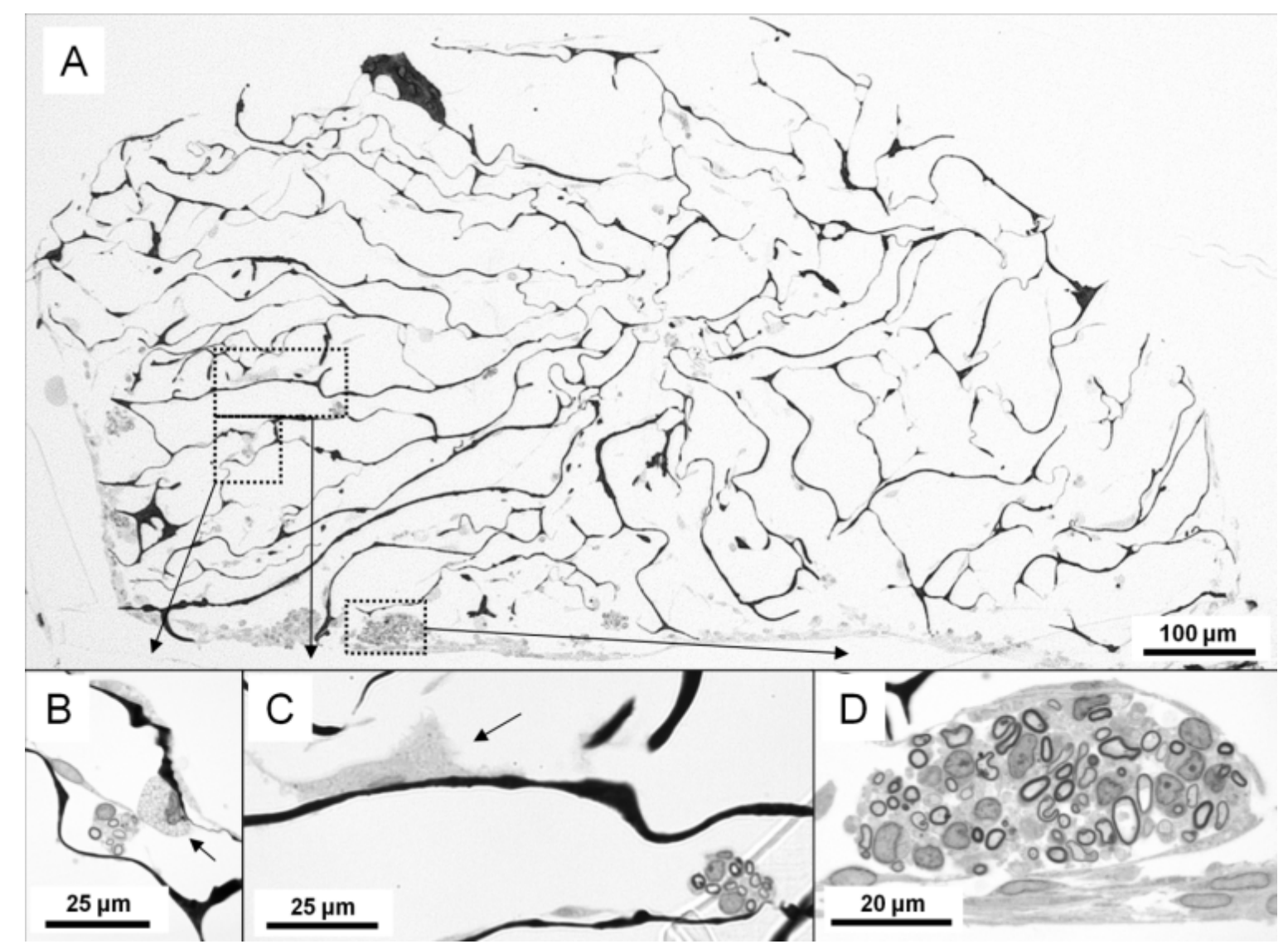

Supplementary Fig. 1 Toluidine blue stained semi-thin sections of the OSC-collagen scaffold at 14 DIV. A) Cross sections of the OSC-collagen scaffold co-cultures, $1 \mathrm{~mm}$ from the coaptation site, showing cellular elements present within the pores of the collagen scaffold. B) A small cluster of myelinated axons close to a macrophage (arrow). C) A large cell, most likely a fibroblast (arrow) growing in close contact to the collagen walls of the scaffold. In the lower right corner another cluster of myelinated axons is clearly visible. D) Cluster of myelinated axons (mini-fascicles) covered by a developing perineurium were commonly found the cell culture-membrane - collagen scaffold interface. A layer of fibroblast-like cells is present right at the interface with the supporting membrane. 

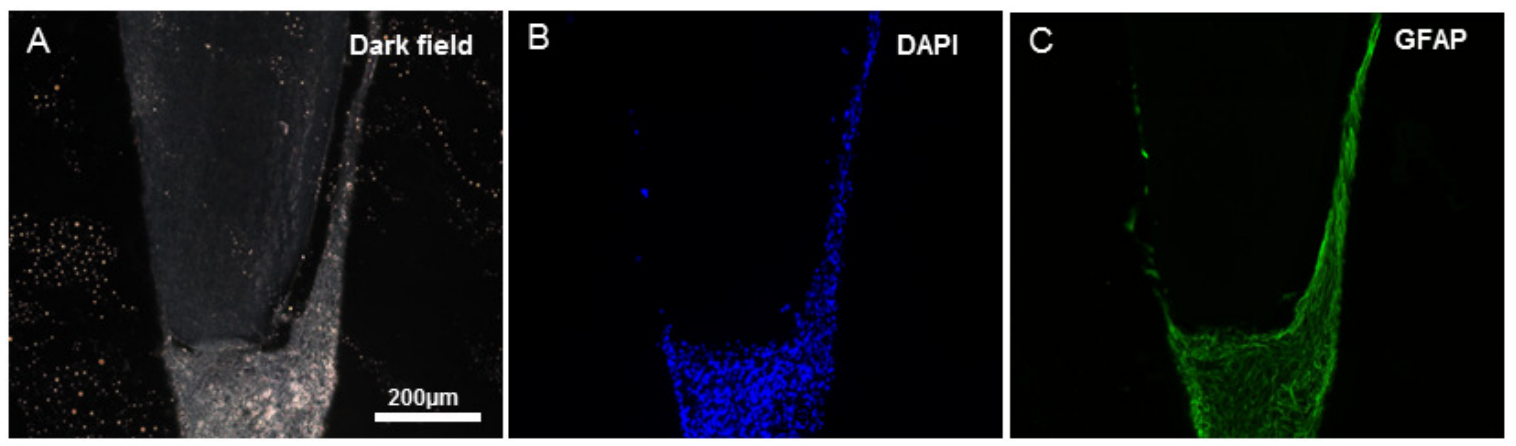

Supplementary Fig. 2 Cellular growth around the fibrin hydrogels. A: Tissue growth on the surface of the fibrin hydrogel as seen by dark field microscopy. B: DAPI nuclear counterstain confirms cell migration is limited to the hydrogel surface. C: GFAP + cells are found amongst the cellular population of the tissue surrounding the fibrin hydrogel.

Supplementary videos related to this article can be found at http://dx.doi.org/10.1016/j.biomaterials.2014.02.007. 


\section{Organotypic Slice Cultures and 3D Scaffolds}

\section{References}

Allodi, I., Guzmán-Lenis, M.-S., Hernàndez, J., Navarro, X. \& Udina, E., 2011. In vitro comparison of motor and sensory neuron outgrowth in a 3D collagen matrix. Journal of neuroscience methods, 198(1), pp.53-61.

Beirowski, B., Berek, L., Adalbert, R., Wagner, D., Grumme, D.S., Addicks, K., Ribchester, R.R. \& Coleman, M.P., 2004. Quantitative and qualitative analysis of Wallerian degeneration using restricted axonal labelling in YFP-H mice. Journal of neuroscience methods, 134(1), pp.23-35.

Bozkurt, A., Brook, G.A., Moellers, S., Lassner, F., Sellhaus, B., Weis, J., Woeltje, M., Tank, J., Beckmann, C., Fuchs, P., Damink, L.O., Schügner, F., Heschel, I. \& Pallua, N., 2007. In vitro assessment of axonal growth using dorsal root ganglia explants in a novel three-dimensional collagen matrix. Tissue engineering, 13(12), pp.2971-9.

Bozkurt, A., Lassner, F., O’Dey, D., Deumens, R., Böcker, A., Schwendt, T., Janzen, C., Suschek, C. V, Tolba, R., Kobayashi, E., Sellhaus, B., Tholl, S., Eummelen, L., Schügner, F., Damink, L.O., Weis, J., Brook, G.A. \& Pallua, N., 2012. The role of microstructured and interconnected pore channels in a collagen-based nerve guide on axonal regeneration in peripheral nerves. Biomaterials, 33(5), pp.1363-75.

Cabaud, H.E., Rodkey, W.G. \& Nemeth, T.J., 1982. Progressive ultrastructural changes after peripheral nerve transection and repair. The Journal of hand surgery, 7(4), pp.353-65.

Cholas, R., Hsu, H.-P. \& Spector, M., 2012a. Collagen scaffolds incorporating select therapeutic agents to facilitate a reparative response in a standardized hemiresection defect in the rat spinal cord. Tissue engineering. Part A, 18(19-20), pp.2158-72.

Cholas, R.H., Hsu, H.-P. \& Spector, M., 2012b. The reparative response to cross-linked collagen-based scaffolds in a rat spinal cord gap model. Biomaterials, 33(7), pp.2050-9.

Corey, J.M., Lin, D.Y., Mycek, K.B., Chen, Q., Samuel, S., Feldman, E.L. \& Martin, D.C., 2007. Aligned electrospun nanofibers specify the direction of dorsal root ganglia neurite growth. Journal of biomedical materials research. Part A, 83(3), pp.636-45.

Delfs, J., Friend, J., Ishimoto, S. \& Saroff, D., 1989. Ventral and dorsal horn acetylcholinesterase neurons are maintained in organotypic cultures of postnatal rat spinal cord explants. Brain research, 488(1-2), pp.3142.

Deumens, R., Bozkurt, A., Meek, M.F., Marcus, M.A.E., Joosten, E.A.J., Weis, J. \& Brook, G.A., 2010. Repairing injured peripheral nerves: Bridging the gap. Progress in neurobiology, 92(3), pp.245-76.

Dubový, P., Jančálek, R. \& Kubek, T., 2013. Role of inflammation and cytokines in peripheral nerve regeneration. International review of neurobiology, 108, pp.173-206.

Fawcett, J.W., Schwab, M.E., Montani, L., Brazda, N. \& Müller, H.W., 2012. Defeating inhibition of regeneration by scar and myelin components. Handbook of clinical neurology, 109, pp.503-22. 
Fraher, J.P., 2000. The transitional zone and CNS regeneration. Journal of anatomy, 196, pp.137-58.

Führmann, T., Hillen, L.M., Montzka, K., Wöltje, M. \& Brook, G.A., 2010. Cell-cell interactions of human neural progenitor-derived astrocytes within a microstructured 3D-scaffold. Biomaterials, 31(30), pp.7705-15.

Gähwiler, B.H., Capogna, M., Debanne, D., McKinney, R. a \& Thompson, S.M., 1997. Organotypic slice cultures: a technique has come of age. Trends in neurosciences, 20(10), pp.471-7.

Gerardo-Nava, J., Mayorenko, I.I., Grehl, T., Steinbusch, H.W.M., Weis, J. \& Brook, G.A., 2013. Differential pattern of neuroprotection in lumbar, cervical and thoracic spinal cord segments in an organotypic rat model of glutamate-induced excitotoxicity. Journal of chemical neuroanatomy, 53, pp.11-17.

Hodde, D., Gerardo-Nava, J.L., Deumens, R., Mey, J. \& Brook, G.A., 2012. Electrospinning of Nanofibres for Repair of the Injured Peripheral Nervous System. In R. J. . Hunter, ed. Nanomedicine and the Nervous System. Science Publishers, pp. 310-346.

Höke, A., Redett, R., Hameed, H., Jari, R., Zhou, C., Li, Z.B., Griffin, J.W. \& Brushart, T.M., 2006. Schwann cells express motor and sensory phenotypes that regulate axon regeneration. The Journal of neuroscience : the official journal of the Society for Neuroscience, 26(38), pp.9646-55.

Hu, M.-E., Tyan, Y.-S., Hsu, P.-W., Hsu, J.-C., Chang, H.-M., Ling, E.-A. \& Lan, C.-T., 2009. Ultrastructural observations on the progress of nerve degeneration and regeneration at the suture site following vagalhypoglossal nerve coaptation in cats. Cells, tissues, organs, 190(4), pp.230-45.

Ishihara, M., Mochizuki-Oda, N., Iwatsuki, K., Kishima, H., Iwamoto, Y., Ohnishi, Y., Umegaki, M. \& Yoshimine, T., 2011. A new three-dimensional axonal outgrowth assay for central nervous system regeneration. Journal of neuroscience methods, 198(2), pp.181-6.

Keilhoff, G., Stang, F., Wolf, G. \& Fansa, H., 2003. Bio-compatibility of type I/III collagen matrix for peripheral nerve reconstruction. Biomaterials, 24(16), pp.2779-87.

Kofron, C.M., Fong, V.J. \& Hoffman-Kim, D., 2009. Neurite outgrowth at the interface of 2D and 3D growth environments. Journal of neural engineering, 6(1), p.016002.

Lampe, K.J., Antaris, A.L. \& Heilshorn, S.C., 2013. Design of three-dimensional engineered protein hydrogels for tailored control of neurite growth. Acta biomaterialia, 9(3), pp.5590-9.

Mirsky, R. \& Jessen, K.R., 1999. The neurobiology of Schwann cells. Brain pathology (Zurich, Switzerland), 9(2), pp.293-311.

Möllers, S., Heschel, I., Damink, L.H.H.O., Schügner, F., Deumens, R., Müller, B., Bozkurt, A., Nava, J.G., Noth, J. \& Brook, G.A., 2009. Cytocompatibility of a novel, longitudinally microstructured collagen scaffold intended for nerve tissue repair. Tissue engineering. Part A, 15(3), pp.461-72.

Nakayama, K., Takakuda, K., Koyama, Y., Itoh, S., Wang, W., Mukai, T. \& Shirahama, N., 2007. Enhancement of peripheral nerve regeneration using bioabsorbable polymer tubes packed with fibrin gel. Artificial organs, 31(7), pp.500-8. 


\section{Organotypic Slice Cultures and 3D Scaffolds}

Prang, P., Müller, R., Eljaouhari, A., Heckmann, K., Kunz, W., Weber, T., Faber, C., Vroemen, M., Bogdahn, U. \& Weidner, N., 2006. The promotion of oriented axonal regrowth in the injured spinal cord by alginatebased anisotropic capillary hydrogels. Biomaterials, 27(19), pp.3560-9.

Reier, P.J. \& Houle, J.D., 1988. The glial scar: its bearing on axonal elongation and transplantation approaches to CNS repair. Advances in neurology, 47, pp.87-138.

Rothstein, J.D., Bristol, L.A., Hosler, B., Brown, R.H. \& Kuncl, R.W., 1994. Chronic inhibition of superoxide dismutase produces apoptotic death of spinal neurons. Proceedings of the National Academy of Sciences of the United States of America, 91(10), pp.4155-9.

Rothstein, J.D., Jin, L., Dykes-Hoberg, M. \& Kuncl, R.W., 1993. Chronic inhibition of glutamate uptake produces a model of slow neurotoxicity. Proceedings of the National Academy of Sciences of the United States of America, 90(14), pp.6591-5.

Schnell, E., Klinkhammer, K., Balzer, S., Brook, G., Klee, D., Dalton, P. \& Mey, J., 2007. Guidance of glial cell migration and axonal growth on electrospun nanofibers of poly-epsilon-caprolactone and a collagen/polyepsilon-caprolactone blend. Biomaterials, 28(19), pp.3012-25.

Shewan, D., Berry, M. \& Cohen, J., 1995. Extensive regeneration in vitro by early embryonic neurons on immature and adult CNS tissue. The Journal of neuroscience : the official journal of the Society for Neuroscience, 15(3 Pt 1), pp.2057-62.

Vyas, A., Li, Z., Aspalter, M., Feiner, J., Hoke, A., Zhou, C., O’Daly, A., Abdullah, M., Rohde, C. \& Brushart, T.M., 2010. An in vitro model of adult mammalian nerve repair. Experimental neurology, 223(1), pp.112-8.

Williams, L.R., 1987. Exogenous fibrin matrix precursors stimulate the temporal progress of nerve regeneration within a silicone chamber. Neurochemical research, 12(10), pp.851-60.

Zhang, J., O'Carroll, S.J., Wu, A., Nicholson, L.F.B. \& Green, C.R., 2010. A model for ex vivo spinal cord segment culture--a tool for analysis of injury repair strategies. Journal of neuroscience methods, 192(1), pp.49-57. 


\section{Chapter 5}

\section{Differential pattern of neuroprotection in lumbar, cervical and thoracic spinal cord segments in an organotypic rat model of glutamate-induced excitotoxicity}

\footnotetext{
Jose Gerardo-Nava ${ }^{1,2,3}$, Ivanna I. Mayorenko ${ }^{1,3}$, Torsten Grehl ${ }^{4}$, Harry W.M. Steinbusch ${ }^{2,3}$, Joachim Weis $^{1,3}$ \& Gary A. Brook ${ }^{1,3}$

${ }^{1}$ Institute of Neuropathology, Medical Faculty, RWTH Aachen University, Pauwel Strasse 30, 52074 Aachen, Germany

${ }^{2}$ Department of Translational Neuroscience, Maastricht University Medical Center, Universiteitsingel 40, 6229 ER Maastricht, The Netherlands

${ }^{3}$ European Graduate School of Neuroscience (EURON), Universiteitsingel 40, 6229 ER Maastricht, The Netherlands

${ }^{4}$ Department of Neurology, Ruhr-University Bochum, BG-Kliniken Bergmannsheil GmbH, Bürkle-de-la-Camp-Platz 1, 44789 Bochum, Germany
} 


\begin{abstract}
Glutamate-induced excitotoxicity is a major contributor to motor neuron (MN) degeneration in disorders such as amyotrophic lateral sclerosis (ALS), stroke and spinal cord injury. Numerous in vitro and in vivo models have been developed to evaluate the efficacy and mode of action of neuroprotective agents. However, the dominance of glutamate receptor-subtype in the different regions of the spinal cord in these models has generally been overlooked. This study first compared the neuroprotective effect of administering glutamate receptor antagonists, (+)-5-methyl-10,11-dihydro-5Hdibenzo[a,d]cyclohepten-5,10-imine (MK-801) and 6-cyano-7-nitroquinoxaline-2,3-dione (CNQX), into a serum-free excitotoxic organotypic in vitro system, on the survival of MNs located in the lumbar area of spinal cord. The poor neuroprotection provided by MK-801 (NMDA (N-methyl-d-aspartate) antagonist) in comparison to CNQX (AMPA/KA (a-amino-3hydroxy-5-methyl-4-isoxazole propionate/kainate) antagonist), raised the hypothesis that the extent of engagement by glutamate receptor sub-types in the mechanism of excitotoxicity may differ within different populations of MNs. The consequent examination of MN susceptibility to glutamate-induced excitotoxicity in relation to the rostro-caudal level from which $\mathrm{MN}$ originated revealed a differential glutamate receptor sub-type dominance at different spinal cord regions (i.e. cervical, thoracic and lumbar). In the cervical and lumbar regions, the AMPA receptor was the main contributor to MN excitotoxicity, whereas in thoracic regions, the NMDA receptor was the main contributor. This study provides a new way of looking at mechanisms leading to glutamate-induced excitotoxicity in $\mathrm{MN}$ and may therefore be important for the development of treatment strategies in protection of spinal MNs in neurodegenerative disease and traumatic injury.
\end{abstract}

KEYWORDS: NMDA; AMPA; MK-801; CQNX; Spinal cord; Organotypic slice culture 


\section{Introduction}

Excitotoxicity has been regarded as a significant contributor to the neurodegeneration in a wide range of conditions including ALS, Huntington's disease, Parkinson's disease, Alzheimer's disease and epilepsy, as well as in more-acute neuropathologic disorders such as traumatic spinal cord injury, stroke and ischemia (Mehta et al. 2013). Imbalanced and de-regulated overactivation of glutamate ionotropic receptors (i.e. NMDA, AMPA, KA) in motor neurons (MN) can lead to the induction of excessive $\mathrm{Ca} 2+$ influx into the cell, resulting in excitotoxicity (Emerit et al. 2004). This marked vulnerability of MN to glutamate-induced excitotoxicity (Van Den Bosch et al. 2000) has led to the study of agents designed to reduce or inhibit glutamate receptor activation. Agents targeting the ionotropic glutamate receptors NMDA, AMPA and KA have been shown to prevent excitotoxicity in several in vitro models (Foran \& Trotti 2009), thus demonstrating their potential for the treatment of a variety of CNS disorders. However, the heterogeneity in the target MN population (and their expression of glutamate receptor sub-types) in the context of their rostro-caudal localization within the spinal cord has commonly been overlooked. This leaves a gap in studies focusing to evaluate agents targeted to protect specific MN populations from excitotoxicity. While a substantial amount of information has been generated over the years regarding the density, distribution and dominance of NMDA/AMPA/KA glutamate receptor sub-types in regions of the brain, relatively little is known about such receptor distributions on spinal cord MNs. In the present investigation, glutamate receptor dominance in the different segmental levels of the spinal cord was studied. For this an organotypic slice culture (OSC) excitotoxic model of early post natal rat spinal cord was used. This approach offered the advantage of preservation of the basic cyto-architecture and dorsal-ventral orientation of the spinal cord slices as well as maintained neuronal-glial interactions, while substantially minimizing the number of animals and reducing the associated costs for such in vivo studies. The present data clearly shows a differential, spinal cord level-dependent, sensitivity in glutamate receptor subtype involvement in the MN population.

\section{Materials and methods}

Organotypic spinal cord slice culture

Spinal cord OSC were prepared from post-natal day 7-9 (P7-P9) Sprague-Dawley donor rat pups as previously described (Guzmán-Lenis et al. 2009). Rat pups were decapitated in accordance with the local animal ethics regulations and with the European Communities 
Council Directive 86/609/EEC. The spinal cord was rapidly isolated and the desired regions: cervical enlargement (cervical), mid-thoracic region (thoracic) or lumbar enlargement (lumbar) sectioned transversely (thickness, $350 \mu \mathrm{m}$ ) with a Mcllwain tissue chopper (Mickle Laboratory Engineering), after which five slices from the same spinal cord level were transferred to a PTFE culture plate membrane inserts (Millipore Millicell CM) and cultured in $35 \mathrm{~mm}$ culture wells (Falcon, Becton Dickinson Labware). The OSC were maintained in serum-free medium [Neurobasal-A medium (Gibco) supplemented with B27 (Gibco), $6.4 \mathrm{mg} / \mathrm{ml}$ d-glucose, $2 \mathrm{mM}$ GlutaMAX (Invitrogen)] with an antibiotic/antimycotic solution (penicillin $G 10,000 \mathrm{U} / \mathrm{ml}$ streptomycin sulfate $10 \mathrm{mg} / \mathrm{ml}$ and amphotericin B $25 \mu \mathrm{g} / \mathrm{ml}$; 1:100 vol/vol, Sigma Aldrich) and incubated at $37^{\circ} \mathrm{C} / 5 \% \mathrm{CO} 2$. Culture medium was refreshed after 1 day in vitro (DIV), then changed twice weekly for the first 14 DIV.

\section{Induction of excitotoxicity}

Glutamate-mediated excitotoxicity was induced in the OSCs as described previously (Guzmán-Lenis et al. 2009) with the only modification that treatment with neuroprotective factor started $15 \mathrm{~min}$ before and lasted until the end of glutamate treatment. Briefly, at 15 DIV, preparations were placed in modified Locke's buffer (137 $\mathrm{mM} \mathrm{NaCl}, 2.5 \mathrm{mM} \mathrm{CaCl}$, $5 \mathrm{mM} \mathrm{KCl}, 5.6 \mathrm{mM}$ d-glucose, $0.3 \mathrm{mM} \mathrm{KH2PO} 4,4 \mathrm{mM}$ NaHCO3, $0.3 \mathrm{mM} \mathrm{Na} 2 \mathrm{HPO} 4,0.01 \mathrm{mM}$ glycine, $10 \mathrm{mM}$ Hepes) in the presence of added glutamate (at concentrations of $50 \mu \mathrm{M}, 100 \mu \mathrm{M}$ or $500 \mu \mathrm{M}$ ) and incubated for $30 \mathrm{~min}$ at $37^{\circ} \mathrm{C}$ in $5 \%$ CO2. OSC were then washed in glutamate-free Locke's buffer for $5 \mathrm{~min}$, transferred to fresh medium and cultured for an additional $48 \mathrm{~h}$. Control samples were placed in Locke's buffer without the addition of glutamate. To investigate glutamate receptor sub-type influence on excitotoxicity, OSC from the different spinal cord regions were incubated with 6-cyano-7-nitroquinoxaline-2,3-dione (CNQX, $30 \mu \mathrm{M})$ or (+)-5-methyl-10,11-dihydro$5 \mathrm{H}$-dibenzo[a,d]cyclohepten-5,10-imine (MK-801, $10 \mu \mathrm{M})$ starting $15 \mathrm{~min}$ prior to exposure and further together with $50 \mu \mathrm{M}$ glutamate (for thoracic samples) or $100 \mu \mathrm{M}$ glutamate (for cervical and lumbar samples).

\section{Evaluation of glutamate-induced cell death}

OSCs were incubated in medium containing $1 \mu \mathrm{g} / \mathrm{ml}$ propidium iodide (PI, Sigma Aldrich) for $30 \mathrm{~min}$ at $37^{\circ} \mathrm{C}$ prior to glutamate exposure and at $48 \mathrm{~h}$ after exposure. Digital images of the OSCs were taken immediately after PI incubations using a digital camera attached to an inverted epifluorescence microscope (Leica), maintaining the same camera settings, 
exposure time, and background corrections for all samples. The calculation of the percentage of $\mathrm{PI}$ incorporation into OSC was based on a method described previously (Loetscher et al. 2009). The percentage of PI incorporation was obtained by counting the number of pixels above the previously defined background threshold value of the area of each slice. Pixel counts before treatment were used to adjust for basal levels of cell death. The overall PI incorporation was calculated as follows: \%PI = ((\#Pixels post - \#Pixels pre)/\#Pixels total slice area) $\times 100$. Image processing was carried out using the GIMP program (GNU Image Manipulation program). Cultures from at least 3 donor animals were used, for the quantitative analysis 2-3 slices per culture were used.

\section{Immunohistochemistry}

Slices were fixed with $4 \%$ paraformaldehyde (PFA) for $1 \mathrm{~h}$ at RT followed by 20 min incubation in ice-cold acetic alcohol (95\% ethanol and 5\% acetic acid) and rinsed in $0.1 \mathrm{M}$ Tris buffered saline (TBS; $0.1 \mathrm{M}$ Tris $-\mathrm{HCl}, 0.15 \mathrm{M} \mathrm{NaCl}$; $\mathrm{pH} 7.4$ ). Within the first days, slice cultures thin down to a thickness of about 90-110 $\mu \mathrm{m}$ and allow for good PI penetration, as well as antibody penetration using the free-floating technique. Free-floating immunohistochemistry was performed as follows: Samples were blocked in $0.1 \mathrm{M}$ TBS containing 5\% normal goat serum (Sigma Aldrich) and 0.2\% Triton X-100 (Sigma Aldrich) at RT for $1 \mathrm{~h}$. Primary antibodies for non-phosphorylated 200 kDa neurofilament (mouse anti-SMI-32, 1:1000; Covance), choline-acetyl transferase (goat anti-ChAT, 1:1000; Millipore), neuronal nuclei antigen (rabbit anti-NeuN, 1:500; Chemicon) and glial fibrillary acidic protein (rabbit anti-GFAP, 1:1000; Dako) were applied to OSCs overnight at $4{ }^{\circ} \mathrm{C}$ on a shaker. Secondary antibodies, raised either in goat or donkey and conjugated to either Alexa 594 or Alexa 488 (both Molecular Probes) were applied at a dilution of 1:500 and incubated at RT for $2 \mathrm{~h}$ in the dark. For some samples, a nuclear counterstain was performed by adding $1 \mu \mathrm{g} / \mathrm{ml}$ diamidino-2-phenylindole (DAPI) to the secondary antibody solutions prior to mounting on glass slides and cover slipping using Fluoroprep mounting medium (BioMerieux). Samples were visualized by epifluorescence using a Zeiss Axiovert coupled to a digital camera Axiocam (Axiovision software) or by 2-photon confocal microscopy (Olympus Fluoview, FV1000MPE).

\section{Analysis and quantification of motor neuronal cell survival}

Entire OSC were photographed (20x objective lens) using the automatic image acquisition and mosaic reconstruction feature of the Zeiss AxioVision software. MN counts were performed on OSC whole mount epifluorescence mosaic reconstructions using the 20x objective, from this images, MN quantification was performed by counting SMI-32positive profiles per slice that were defined by the following criteria: localization to the ventral gray matter and a soma diameter of greater than $20 \mu \mathrm{m}$ (Guzmán-Lenis et al. 
Neuroprotection patterns in the spinal cord

2009). Cultures from at least 3 donor animals were used, for the quantitative analysis 4-5 slices per culture were used.

Statistical analysis

All data was obtained from experiments performed in triplicates, unless otherwise mentioned. Using GraphPad Prism Software version 4.0, multiple group comparisons were performed by one-way analysis of variance (ANOVA) followed by the Bonferroni post hoc test. Differences were considered significant if $p<0.05$ unless stated otherwise.

\section{Results}

Morphological characterization of the rat organotypic spinal cord slice cultures

Cellular integrity of the spinal cord OSCs was assessed using immunohistochemistry at 14 DIV. The baseline status of the spinal cord cultures was assessed through DAPI staining (Fig. 1A). A high concentration of cell nuclei was observed at the ventral rim of the slice cultures, surrounding the ventral horns (arrows, Fig. 1A), and most likely corresponded to the presence of residual cells of the ventral white matter (e.g. oligodendrocytes, microglia) (Guzmán-Lenis et al. 2009; Stavridis et al. 2005). A well-defined central canal was also a major landmark in the OSC preparations (arrowhead, Fig. 1A). GFAP+ astrocytes could be observed throughout the slice cultures, with some areas presenting reduced immunoreactivity, primarily in the ventral rim of the slice cultures (Fig. 1B). These cells demonstrated a characteristic stellate morphology with long processes extending in all directions (Fig. 1C, arrows). Populations of NeuN+ neurons were present in both dorsal(densely packed, even distribution) and ventral horns (scattered clusters of neurons) but were absent from the rim of residual ventral white matter and central canal (Fig. 1D). The SMI-32+ MN populations were readily detectable in the ventral gray matter of the OSCS (arrows Fig. 1E) with individual MNs showing intense immunoreactivity throughout the cell soma (arrows, Fig. 1F), and extending into the tapering dendrite-like profiles as well as into the more uniform diameter axonal profiles (arrowheads, Fig. 1F). Although SMI-32 immunoreactivity is typically referred to as a specific marker for MNs in rat spinal cord (Avossa et al., 2003), intense staining could also be detected in neurons in the dorsal horn (Fig. 1E, G). In order to confirm the phenotype of the MN pool in the ventral horn, colocalization of double immunofluorescence SMI32/ChAT was performed (Fig. 1G-I). 


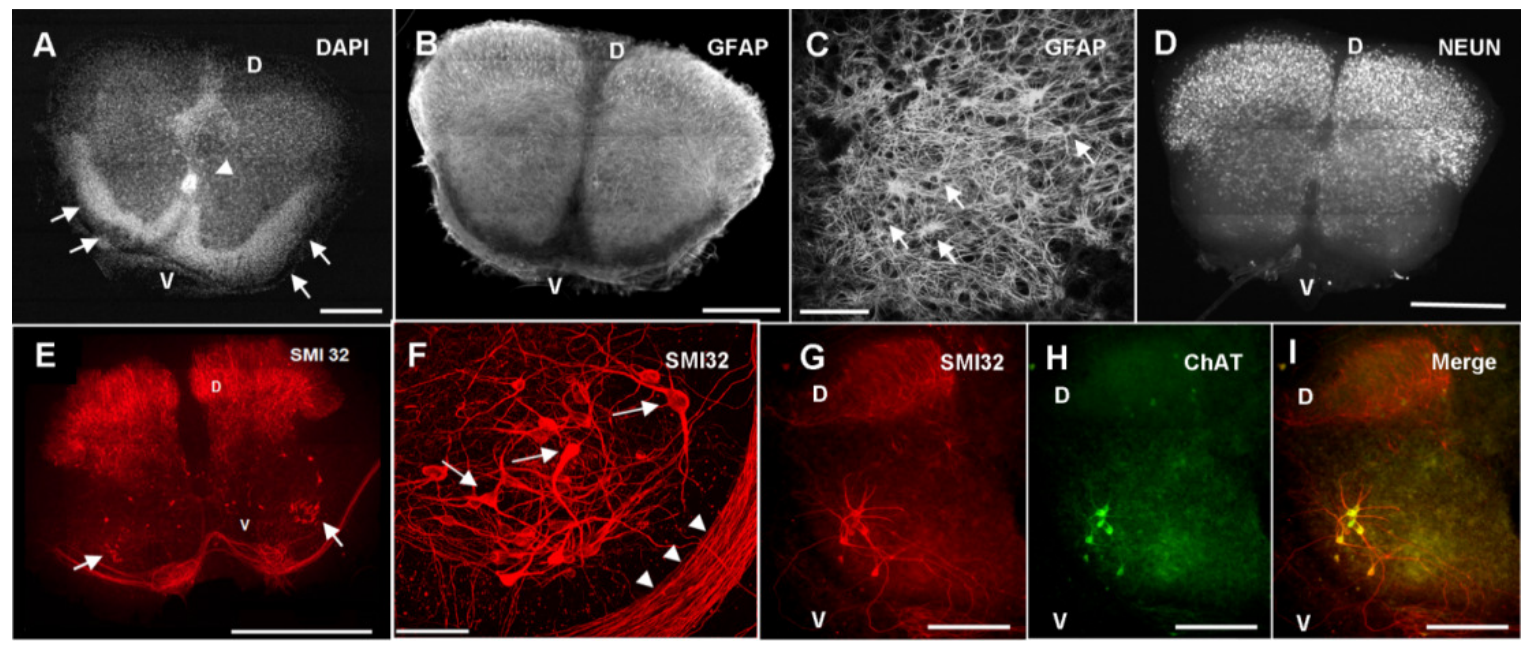

Fig. 1 Characterization of lumbar organotypic slice cultures at day 14. (A) Dense DAPI nuclear stain is observed in the ventral white matter and central canal in comparison to the gray mater. (B) Strong GFAP+ immunoreactive cells spread mainly throughout the gray matter in the slice cultures. (C) Closer inspection reveals GPAF+ cells present stellate morphology. (D) The distribution of neuronal population in the slice culture as indicated through NeuN immunoreactivity shows a densely populated dorsal horn. (E) SMI32 immunoreactivity can be observed not only on MN cell bodies and their processes but also in the dorsal horn neurons. (F) High power image of the ventral horn of a slice culture, large bodied MNs (arrows) are easily detectable and extend long axons that regularly circumscribe the tissue slice (arrowheads). (G and H) SMI32+ large bodied cells in the ventral horn coexpress ChAT while cells in the dorsal horn only express SMI32 (scale bars: A, B, D = 500 $\mu \mathrm{m} ; \mathrm{C}, \mathrm{F}=100 \mu \mathrm{m} ; \mathrm{E}=1$ $\mathrm{mm} ; \mathrm{G}, \mathrm{H}, \mathrm{I}=250 \mu \mathrm{m} ; \mathrm{D}=$ Dorsal; V = Ventral).

Establishment of the glutamate-induced excitotoxicity model in lumbar rat spinal cord OSC

Overall glutamate-induced excitotoxicity in lumbar spinal OSCs was assessed by quantification of PI staining. Control, non-treated OSC that had been maintained for 14 DIV in serum-free conditions demonstrated little or no staining with $\mathrm{PI}$, supporting the notion that the samples were in a generally good condition. Exposure of OSCs to increasing concentrations of glutamate caused an increase in the PI signal (Fig. 2A). Exposure to $50 \mu \mathrm{M}$ glutamate had no quantitative effect on PI staining of the slices, whereas a trend for increased staining was observed following exposure to $100 \mu \mathrm{M}$ glutamate. However, clear and statistically significant evidence of cellular damage as indicated by increased PI labeling could be detected after exposure to $500 \mu \mathrm{M}$ glutamate (38.8\% increase in PI fluorescence from the original PI signal; $p<0.05$; Fig. 2A). Spinal cord OSC treated with elevated glutamate levels (up to $2 \mathrm{mM}$ ) in serum-containing medium had no such effect (data not shown). These results indicate that the toxic effect of excessive levels of glutamate is not only limited to ventral horn MNs, but at higher concentrations can also hinder the overall survival of the spinal cord OSC. Quantification of SMI-32positive ventral horn MNs demonstrated a clear dose-dependent reduction of cell survival 
in response to increasing glutamate concentrations (Fig. 2B). In the lumbar OSC, $50 \mu \mathrm{M}$ glutamate induced a reduction in the number of detectable SMI-32-positive MNs to about $60 \%$ of the control values ( $p>0.05$ ). This was further reduced to about $30 \%$ of control values following exposure to $500 \mu \mathrm{M}$ glutamate ( $<0$. 01; Fig. 2B). Pre-incubation of lumbar spinal cord samples with MK-801 provided only a small (statistically not significant relative to glutamate only treated controls; $p>0.05$ ) increase in the number of surviving $\mathrm{MN}$. For subsequent experiments, samples were exposed to $50 \mu \mathrm{M}$ glutamate (for thoracic OSC) and $100 \mu \mathrm{M}$ glutamate (for cervical and lumbar OSC) since preliminary PI data had suggested that these concentrations induced minimal generalized toxicity in the corresponding OSCs but induced significant ventral MN loss as indicated by SMI-32+ soma counts.

A

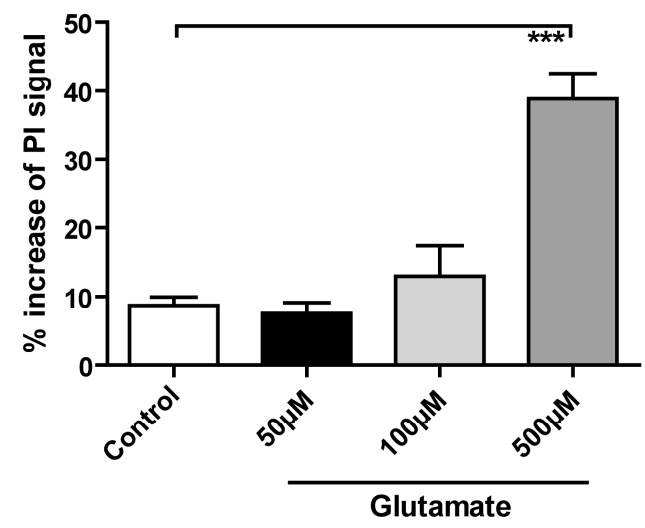

B

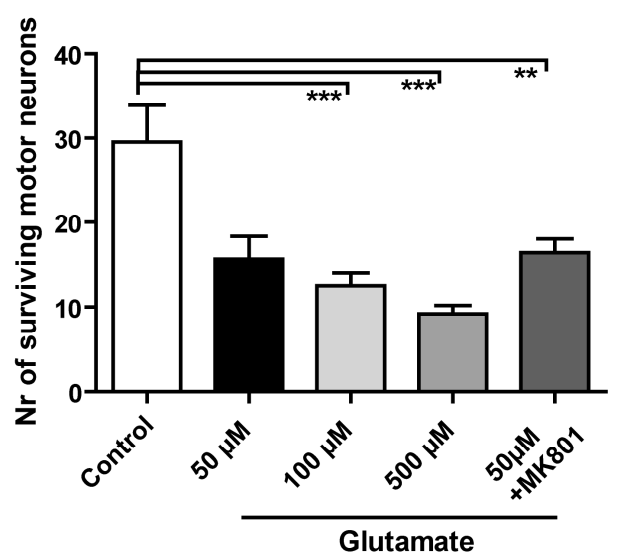

Fig. 2. Detrimental effects of direct application of glutamate to slice cultures. (A) Overall glutamate-induced cell death in lumbar OSCs in terms of percentage increase in intensity of PI fluorescence signal. Application of glutamate at concentrations greater than $100 \mu \mathrm{M}$ induces strong tissue damage. (B) MN death reveals also a strong dose dependent effect with concentrations of $50 \mu \mathrm{M}$ already reducing the $\mathrm{MN}$ population to half; note the inability of MK-801 to protect the MN population from the excitotoxic damage (data shows mean values \pm SEM; $\left.{ }^{* *} p<0.01, * * * p<0.001\right)$.

Influence of spinal cord segmental levels on $\mathrm{MN}$ death and neuroprotection patterns in response to glutamate insult

Acute exposure of cervical and lumbar spinal cord OSC to $100 \mu \mathrm{M}$ glutamate resulted in a significant extent of $\mathrm{MN}$ death with a reduction of $\mathrm{MN}$ numbers to approximately $50 \%$ of the control values (from $34.4 \pm 2.29$ to $16.3 \pm 1.4$ and $30.1 \pm 1.2$ to $15.1 \pm 0.6$ respectively; both $p<0.001$ compared to control; Fig. 3A, B, I, J; Fig. 4A, C). The pre-incubation of cervical and lumbar OSC with MK-801 induced no MN neuroprotection (18.3 \pm 1.2 and $17.6 \pm 1.0$ respectively; both $\mathrm{p}>0.05$ compared to $100 \mu \mathrm{M}$ glutamate; Fig. $3 \mathrm{C}, \mathrm{K}$ ), whereas pre-incubation with CNQX caused the greatest protection for both cervical and lumbar 
MNs (31.8 \pm 1.3 and $29.5 \pm 1.4$; both $p<0.001$ compared to $100 \mu \mathrm{M}$ glutamate; Fig. 3D, L; Fig. $4 \mathrm{~A}, \mathrm{C})$. These results strongly suggest that cervical and lumbar spinal cord $M N$ underwent glutamate-induced excitotoxicity that was mediated through the AMPA/KA glutamate receptor sub-type.

In thoracic OSC (Fig. 4B), glutamate was more effective in reducing the $\mathrm{MN}$ population count at a concentration of $50 \mu \mathrm{M}$ (from 19.6 \pm 2.1 to $7.2 \pm 1.1 ; \mathrm{p}<0.001$, Fig. $3 E, F)$. Pre-incubation with MK-801 improved the MN survival $(20.2 \pm 1.4 ; p<0.001$ compare to $50 \mu \mathrm{M}$ glutamate; Fig. 3G) whereas CNQX pre-incubation had negligible effects ( $9.38 \pm 1.24 ; p>0.05$ compare to $50 \mu \mathrm{M}$ glutamate; Fig. $3 \mathrm{H}$ ), strongly suggesting that thoracic spinal cord $\mathrm{MN}$ underwent glutamate-induced excitotoxicity via NMDA glutamate receptor sub-types.

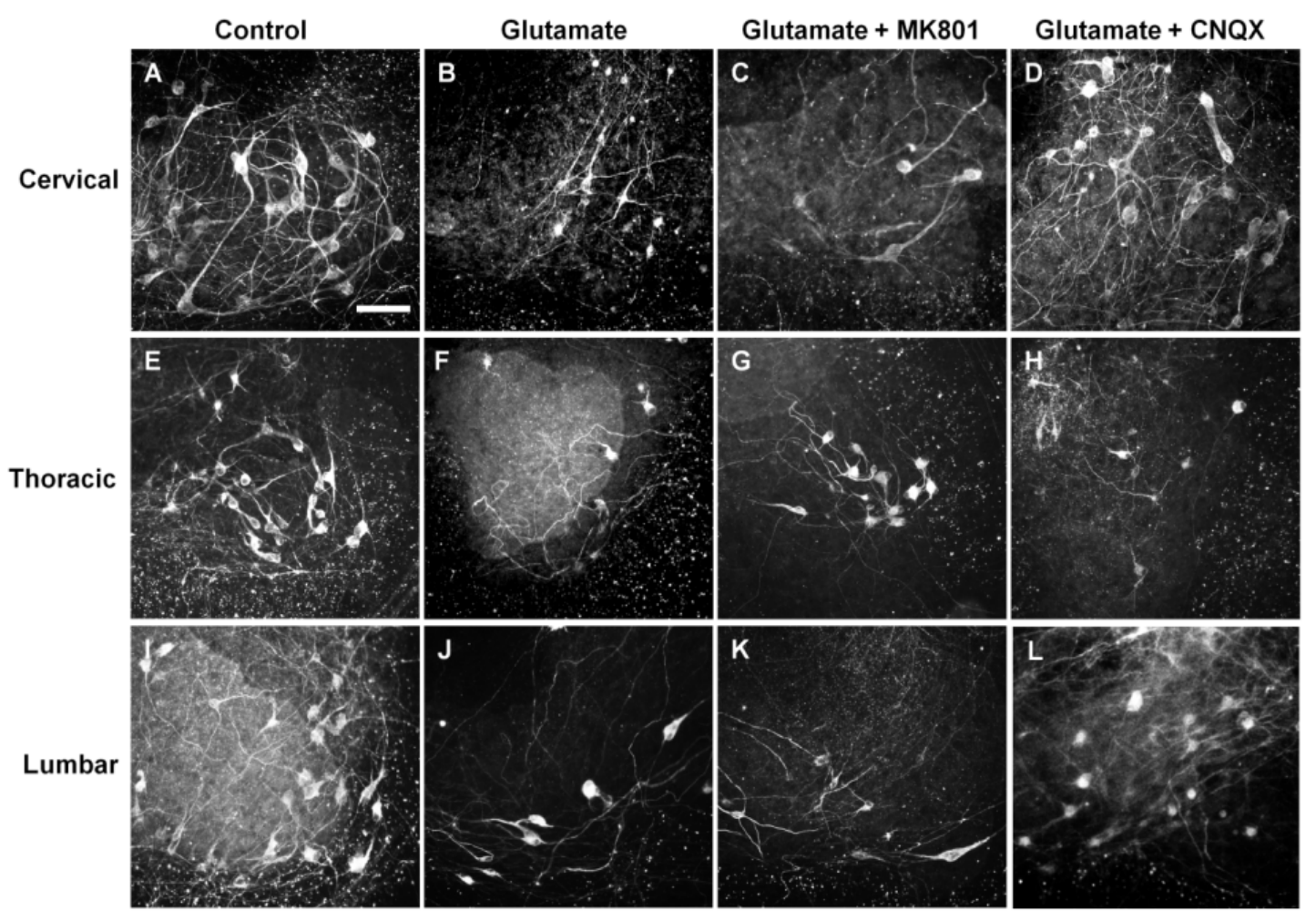

Fig. 3. Micrographs of $S M I+M N$ in the ventral horn illustrating the differential protective effects of CNQX and MK-081. (A, E, I) control samples at all three studied levels (cervical, thoracic, lumbar) present large $M N$ populations in the ventral horn after 14 DIV. $(B, F, J)$ The ventral MN population in the all OSC is strongly decreased by addition of glutamate when compared to controls. (C, G, K) MK-801 neuroprotective effects can be only be observed in the thoracic OSC model. (D, H, L) CNQX, on the other hand, exerts its neuroprotective effect in $\mathrm{MN}$ from both cervical and lumbar but not thoracic OSCs (scale bar $=100 \mu \mathrm{m}$ ). 
A

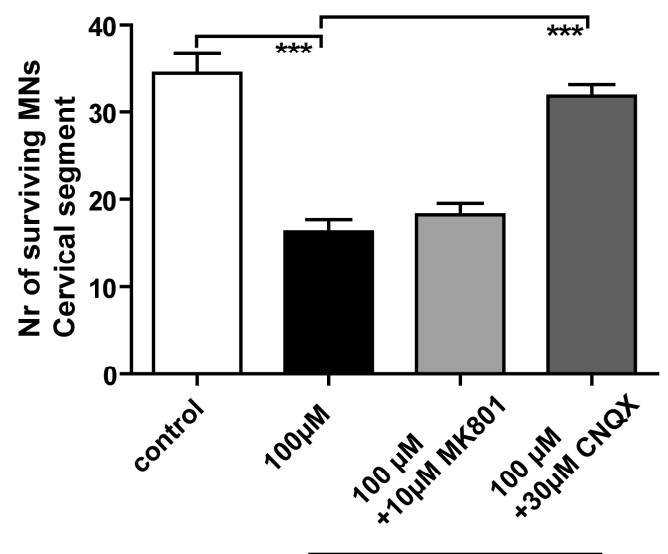

Glutamate

C

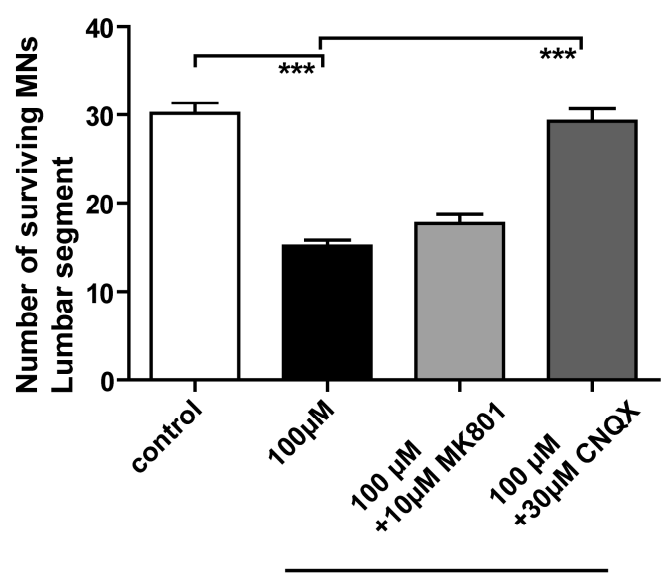

Glutamate
B

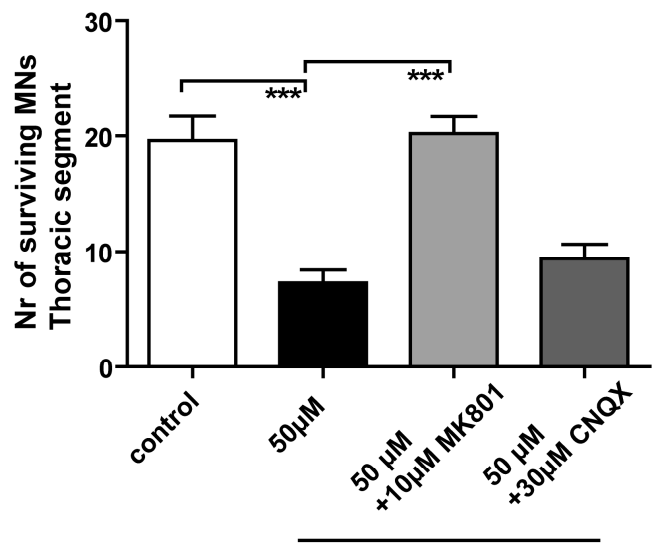

Glutamate

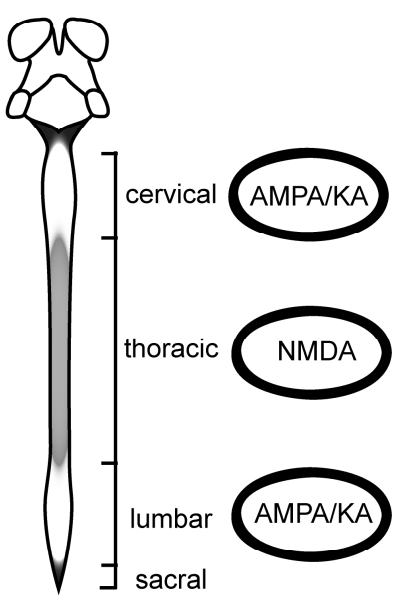

Fig. 4. NMDA and $A M P A / K A$ receptor-mediated $M N$ excitotoxicity in cervical (A), thoracic (B) and lumbar (C) spinal cord OSCS. The involvement of a particular type of glutamate receptor was assessed by evaluating differences in neuroprotection against excitotoxicity. Glutamate induced a significant reduction of MN numbers at all three levels of spinal cord; however the neuroprotective effects of MK-801 or CNQX were strongly dependent on spinal cord level origin of the slice culture. (A, C) While CNQX protected MNs from the excitotoxic shock in cervical and lumbar OSC, (B) MK-801 played the primary neuroprotective role in thoracic slices. (D) Schematic representation of a neonatal rat brain stem and spinal cord summarizing the functional organization of glutamatergic AMPA, NMDA and KA receptors observed in this study (data shows mean values \pm SEM; ***p < 0.001). 


\section{Discussion}

The spinal cord OSC technique provides an advantage over dissociated $\mathrm{MN}$ cell cultures in that it offers a superior $\mathrm{MN}$ survival and a closer resemblance to the in vivo situation (Avossa et al. 2003). This approach also allows for the in vitro investigation of MNs with a greater degree of maturity, since OSCs are derived from early post-natal pups and are often allowed to continue to develop for a number of weeks in vitro (Delfs et al. 1989). Furthermore, it has been reported that MNs from P7-P8 rats show better survival in slice culture conditions in the presence of serum than when they are obtained at prenatal age due to their shift from target-derived growth factor dependency to target-derived growth factor independency (Rakowicz et al. 2002). While the presence of serum seems to be important for the survival of the slice culture, others groups (e.g. Guzmán-Lenis et al., 2009) as well as ours, have been able to successfully achieve viable spinal cord OSC in serum-free media. The presence of serum within the medium exerts a general neuroprotective effect which would clearly obscure the sensitivity or susceptibility of neuronal populations to an excitotoxic insult. It might thus be argued that the serum free OSC is a representative model of some of the pathophysiological events that take place in the CNS and that the model is an excellent screening tool for investigations into excitotoxicity and pharmacological intervention strategies aimed at enhancing $\mathrm{MN}$ preservation.

The spinal cord OSC excitotoxic model is widely used for the evaluation of neuroprotective drugs. By inducing an increase of glutamate in the OSC, either by direct application or indirect clearance inhibition through glutamate transporter blockers in the OSC, MN excitotoxicity can be reproduced in vitro (Rothstein et al. 1993). In both cases, over activation of ionotropic receptors (NMDA, AMPA, KA) leads to a cascade of processes ending in a characteristic functional impairment of the locomotor network (Mazzone et al. 2010) and in worst cases initiates degeneration leading to $M N$ death. The exact mechanism through which the MNs undergo degeneration is still unknown, with both short term necrotic and long term apoptotic morphology/biochemistry being observed in the dying cells (Ribe et al. 2008). While other neural cells have been reported to undergo glutamate mediated toxicity (e.g. oligodendrocytes; (Káradóttir et al. 2005)), it is also not clear whether this apoptotic/necrotic process apply to these cells. Our PI stains suggest general long term OSC cellular damage induced by high concentrations (500 $\mu \mathrm{M})$ of glutamate is observable after $48 \mathrm{~h}$. This long lasting damage to the tissue could reflect apoptotic mechanisms. Lower glutamate concentrations (50 $\mu \mathrm{M}, 100 \mu \mathrm{M})$ however induced basal PI levels in the long term, indicating minimal tissue damage and, probably, a more focused excitotoxic effect on the neuronal population, specifically ventral $\mathrm{MN}$, as observed by the decrease in SMI-32 soma counts. 
The main finding of the present study is the region specific involvement of glutamate receptor sub-types in glutamate-induced excitotoxicity as demonstrated in the present model by using glutamate ionotropic receptor blockers MK-801 and CNQX. Previous studies using either of these receptor blockers have reported improved functional recovery and tissue preservation in excitotoxic models; however, their effects are clearly mediated through the blocking of different receptor sub-types: MK-801 mediated neuroprotection being through its ability to block the NMDA sub-type receptors following activation by glutamate, and CNQX-mediated neuroprotection being through specific inhibition of the AMPA sub-type receptor. Our results suggest that glutamateinduced MN excitotoxicity in the thoracic regions is exerted predominantly via NMDAmediated mechanisms, as demonstrated by the sparing of MN by MK-801. This supports recent observations (Guzmán-Lenis et al. 2009) with the small difference that in our case similar concentrations of glutamate led to a less pronounced MN loss. CNQX on the other hand preserved MNs in the cervical and lumbar preparations. Induction of excessive $\mathrm{Ca2+}$ influx into the cell by over activation of ionotropic glutamate receptors is the main mechanism leading to excitotoxicity (Rothman \& Olney 1995). Traditionally, discrimination was made between the Ca2+-impermeable AMPA/KA receptors and the Ca2+-permeable NMDA receptors and their implications in excitotoxicity. However, extensive studies performing electrophysiological recordings on MN cultures and spinal cord OSC treated with kainic acid have shown that AMPA receptors missing the GluR2 subunit can also be $\mathrm{Ca} 2+$ permeable and thereby be key role players in the excitotoxic process (Van Damme et al. 2002; Isaac et al. 2007; Mazzone et al. 2010).

Comparative studies have indicated that AMPA and NMDA glutamatergic receptors do not contribute equally in excitotoxic spinal $M N$ death. Some lines of evidence have demonstrated that AMPA antagonists exert the highest degree of spinal cord MN preservation in comparison to negligible neuroprotection provided by the NMDA antagonists (Hori et al. 2002; Saroff et al. 2000), whereas others have reported the contrary (Allaoua et al. 1992; Guzmán-Lenis et al. 2009). Though the existing evidence regarding NMDA and AMPA receptors might, at first glance be seen as conflicting, one should keep in mind that the observed effects had not been compared in the same model system. In the reported excitotoxicity studies, behavior of NMDA and AMPA/KA receptors in spinal MNs have not been examined within the context of functional specialization and anatomical rostro-caudal location of MNs within the spinal cord. In fact, many authors assume homogeneity of MN population throughout the spinal cord; hence some even fail to report which level of spinal cord their studies were focused on. Autoradiographic analyses have either focused on glutamate receptor distribution in MNs at one particular spinal level (Kalb et al. 1992; Verhovshek et al. 2005) without comparison to MN at other segmental levels, or have investigated receptor distribution throughout parts or all of spinal cord without matching the receptors to any specific cell phenotype (Akesson et al. 
2000; Henley et al. 1993; Kalb \& Fox 1997; Li et al. 1999; Tomiyama et al. 1994); glutamate receptor sub-types being distributed on a range of cell types including MNs, astrocytes and oligodendrocytes (Matute 2010). This suggests that investigations of regional or segmental glutamate receptor sub-type and density warrant further attention since they may shed more light on the fundamental organizational complexity of the spinal cord.

The expression of glutamate ionotropic receptors during development seems to be, however, a dynamic process extending beyond the first post-natal days. Quantitative NMDA receptor autoradiography has shown that the density of receptors in the ventral horn of the cervical and lumbar segmental levels of spinal cord is high in P7 rats, but is lost from all areas of the gray matter by the second or third postnatal week (Kalb et al. 1992). This was supported by Hori and associates who reported high levels of NMDA receptors in developing rodent MNs at PD2, which was reduced at PD9 and virtually absent at PD14 (Hori et al. 2001). Meanwhile, cervical spinal cord slices from neonatal and adult animals remained sensitive to AMPA/KA. Age-related maturation of motor control and changes in lumbar MN firing properties during the first two postnatal weeks have been linked to the relative increase of non-NMDA receptor-mediated excitatory amino acid neurotransmission (Vinay et al. 2000).

Diversity of MN populations has already been established (for review see (Friese et al. 2009)) with no fewer than seven different categories of MNs being identified on the basis of their target innervation pattern, suggesting a new degree of complexity than had previously been appreciated. This variability in MN populations can be observed and further studied in disorders such as ALS where selective MN degeneration occurs. Studies made on human post mortem samples have indicated that cervical MNs of adult ALS cases and age-matched controls have limited affinity to NMDA antagonists (Krieger et al. 1993). This was recently supported by gene expression experiments comparing oculomotor (normally spared in ALS) and lumbar spinal cord MNs in control human tissue, revealing increased expression of GlutR2 sub-unit in the oculomotor MNs suggesting a more resistant phenotype to excitotoxicity (Brockington et al. 2013). In the same way, autonomic MN (also relatively spared in ALS) show resistance to over activation by NMDA compared to somatic MN in rat thoracic OSC (Annis \& Vaughn 1998). Heterogeneity in the MN pool can be further observed in ALS patients as revealed by disease progression, with distal limb and paraspinal muscles being affected more severely suggesting differential MN susceptibility to degeneration in the spinal cord (Kuncl et al. 1988).

The mechanism(s) underlying segmental variable expression of ionotropic glutamate transporters in the spinal cord remain unclear. It is possible that this is a part of a genetic/evolutionary design to have selective receptor dominance for different $\mathrm{MN}$ pools which in turn innervate different groups of muscle compartments; for instance MNs in the cervical and lumbar enlargements innervate a more substantial fraction of the 
Neuroprotection patterns in the spinal cord

skeletal musculature than the thoracic MNs. Moreover, alpha-MNs, reported to be considerably more sensitive to non-NMDA than to NMDA-mediated toxicity (Saroff et al. 2000), innervate the upper and lower limbs and form large cell columns that contribute to the cervical and lumbar enlargements of the spinal cord (Haines 2004), regions of spinal cord that in our results are linked to increased AMPA/KA receptors activity.

\section{Conclusion}

The present findings strongly suggest that the phenotype of spinal cord MNs might be population-specific and hence play a role in the coordination of the complex neuronal circuits and the control of functionally diverse muscle systems. Nevertheless, it is clear that the results derived from the present study strengthen the understanding of the contribution of receptor sub-types within the scheme of glutamate interactions in the CNS, highlighting the importance of taking into consideration both age and location of the $\mathrm{MN}$ source in the design of drug screening experiments using primary cell culture systems.

\section{Acknowledgements}

This work has been supported by funding from Aachen-Maastricht "Rotationsstelle", the European Master in Translational Neuroscience (EMTN) MSc thesis pilot (Grant: 502677LLP-1-2009-1-NL-ERASMUS-ECDS). This work was supported by the facility "Two-Photon Imaging", a core facility of the Interdisciplinary Center of Clinical Research (IZKF) Aachen within the Faculty of Medicine at RWTH Aachen University. 


\section{References}

Akesson, E., Kjaeldgaard, a, Samuelsson, E.B., Seiger, a \& Sundström, E., 2000. Ionotropic glutamate receptor expression in human spinal cord during first trimester development. Brain research. Developmental brain research, 119(1), pp.55-63.

Allaoua, H., Chaudieu, I., Krieger, C., Boksa, P., Privat, a \& Quirion, R., 1992. Alterations in spinal cord excitatory amino acid receptors in amyotrophic lateral sclerosis patients. Brain research, 579(1), pp.169-72.

Annis, C. \& Vaughn, J., 1998. Differential vulnerability of autonomic and somatic motor neurons to N-methyl-daspartate-induced excitotoxicity. Neuroscience, 83(1), pp.239-249.

Avossa, D., Rosato-Siri, M.D., Mazzarol, F. \& Ballerini, L., 2003. Spinal circuits formation: a study of developmentally regulated markers in organotypic cultures of embryonic mouse spinal cord. Neuroscience, 122(2), pp.391-405.

Van Den Bosch, L., Vandenberghe, W., Klaassen, H., Van Houtte, E. \& Robberecht, W., 2000. Ca(2+)-permeable AMPA receptors and selective vulnerability of motor neurons. Journal of the neurological sciences, 180(12), pp.29-34.

Brockington, A., Ning, K., Heath, P.R., Wood, E., Kirby, J., Fusi, N., Lawrence, N., Wharton, S.B., Ince, P.G. \& Shaw, P.J., 2013. Unravelling the enigma of selective vulnerability in neurodegeneration: motor neurons resistant to degeneration in ALS show distinct gene expression characteristics and decreased susceptibility to excitotoxicity. Acta neuropathologica, 125(1), pp.95-109.

Van Damme, P., Van Den Bosch, L., Van Houtte, E., Callewaert, G. \& Robberecht, W., 2002. GluR2-dependent properties of AMPA receptors determine the selective vulnerability of motor neurons to excitotoxicity. Journal of neurophysiology, 88(3), pp.1279-87.

Delfs, J., Friend, J., Ishimoto, S. \& Saroff, D., 1989. Ventral and dorsal horn acetylcholinesterase neurons are maintained in organotypic cultures of postnatal rat spinal cord explants. Brain research, 488(1-2), pp.3142.

Emerit, J., Edeas, M. \& Bricaire, F., 2004. Neurodegenerative diseases and oxidative stress. Biomedicine \& pharmacotherapy = Biomédecine \& pharmacothérapie, 58(1), pp.39-46.

Foran, E. \& Trotti, D., 2009. Glutamate transporters and the excitotoxic path to motor neuron degeneration in amyotrophic lateral sclerosis. Antioxidants \& redox signaling, 11(7), pp.1587-602.

Friese, A., Kaltschmidt, J. a, Ladle, D.R., Sigrist, M., Jessell, T.M. \& Arber, S., 2009. Gamma and alpha motor neurons distinguished by expression of transcription factor Err3. Proceedings of the National Academy of Sciences of the United States of America, 106(32), pp.13588-93.

Guzmán-Lenis, M.-S., Navarro, X. \& Casas, C., 2009. Drug screening of neuroprotective agents on an organotypicbased model of spinal cord excitotoxic damage. Restorative neurology and neuroscience, 27(4), pp.33549. 


\section{Neuroprotection patterns in the spinal cord}

Haines, D.E., 2004. Neuroanatomy: an atlas of structures, sections, and systems 6th editio., Hagerstown, MD: Lippincott Williams \& Wilkins.

Henley, J.M., Jenkins, R. \& Hunt, S.P., 1993. Localisation of glutamate receptor binding sites and mRNAs to the dorsal horn of the rat spinal cord. Neuropharmacology, 32(1), pp.37-41.

Hori, N., Tan, Y., Strominger, N.L. \& Carpenter, D.O., 2001. Intracellular activity of rat spinal cord motoneurons in slices. Journal of neuroscience methods, 112(2), pp.185-91.

Hori, N., Tan, Y., Strominger, N.L. \& Carpenter, D.O., 2002. Rat motoneuron cell death in development correlates with loss of N-methyl-D-aspartate receptors. Neuroscience letters, 330(2), pp.131-4.

Isaac, J.T.R., Ashby, M.C. \& McBain, C.J., 2007. The role of the GluR2 subunit in AMPA receptor function and synaptic plasticity. Neuron, 54(6), pp.859-71.

Kalb, R.G. \& Fox, a J., 1997. Synchronized overproduction of AMPA, kainate, and NMDA glutamate receptors during human spinal cord development. The Journal of comparative neurology, 384(2), pp.200-10.

Kalb, R.G., Lidow, M.S., Halsted, M.J. \& Hockfield, S., 1992. N-methyl-D-aspartate receptors are transiently expressed in the developing spinal cord ventral horn. Proceedings of the National Academy of Sciences of the United States of America, 89(18), pp.8502-6.

Káradóttir, R., Cavelier, P., Bergersen, L. \& Attwell, D., 2005. NMDA receptors are expressed in oligodendrocytes and activated in ischaemia. Nature, 438(7071), pp.1162-1166.

Krieger, C., Wagey, R. \& Shaw, C., 1993. Amyotrophic lateral sclerosis: quantitative autoradiography of [3H]MK801/NMDA binding sites in spinal cord. Neuroscience letters, 159(1-2), pp.191-4.

Kuncl, R.W., Cornblath, D.R. \& Griffin, J.W., 1988. Assessment of thoracic paraspinal muscles in the diagnosis of ALS. Muscle \& nerve, 11(5), pp.484-92.

Li, N., Young, M.M., Bailey, C.J. \& Smith, M.E., 1999. NMDA and AMPA glutamate receptor subtypes in the thoracic spinal cord in lean and obese-diabetic ob/ob mice. Brain research, 849(1-2), pp.34-44.

Loetscher, P.D., Rossaint, J., Rossaint, R., Weis, J., Fries, M., Fahlenkamp, A., Ryang, Y.-M., Grottke, O. \& Coburn, M., 2009. Argon: neuroprotection in in vitro models of cerebral ischemia and traumatic brain injury. Critical care (London, England), 13(6), p.R206.

Matute, C., 2010. Calcium dyshomeostasis in white matter pathology. Cell calcium, 47(2), pp.150-7.

Mazzone, G.L., Margaryan, G., Kuzhandaivel, A., Nasrabady, S.E., Mladinic, M. \& Nistri, A., 2010. Kainate-induced delayed onset of excitotoxicity with functional loss unrelated to the extent of neuronal damage in the in vitro spinal cord. Neuroscience, 168(2), pp.451-62.

Mehta, A., Prabhakar, M., Kumar, P., Deshmukh, R. \& Sharma, P.L., 2013. Excitotoxicity: bridge to various triggers in neurodegenerative disorders. European journal of pharmacology, 698(1-3), pp.6-18. 


\section{Chapter 5}

Rakowicz, W.P., Staples, C.S., Milbrandt, J., Brunstrom, J.E. \& Johnson, E.M., 2002. Glial cell line-derived neurotrophic factor promotes the survival of early postnatal spinal motor neurons in the lateral and medial motor columns in slice culture. The Journal of neuroscience : the official journal of the Society for Neuroscience, 22(10), pp.3953-62.

Ribe, E.M., Serrano-Saiz, E., Akpan, N. \& Troy, C.M., 2008. Mechanisms of neuronal death in disease: defining the models and the players. The Biochemical journal, 415(2), pp.165-82.

Rothman, S.M. \& Olney, J.W., 1995. Excitotoxicity and the NMDA receptor--still lethal after eight years. Trends in neurosciences, 18(2), pp.57-8.

Rothstein, J.D., Jin, L., Dykes-Hoberg, M. \& Kuncl, R.W., 1993. Chronic inhibition of glutamate uptake produces a model of slow neurotoxicity. Proceedings of the National Academy of Sciences of the United States of America, 90(14), pp.6591-5.

Saroff, D., Delfs, J., Kuznetsov, D. \& Geula, C., 2000. Selective vulnerability of spinal cord motor neurons to nonNMDA toxicity. Neuroreport, 11(5), pp.1117-21.

Stavridis, S.I., Dehghani, F., Korf, H.-W. \& Hailer, N.P., 2005. Characterisation of transverse slice culture preparations of postnatal rat spinal cord: preservation of defined neuronal populations. Histochemistry and cell biology, 123(4-5), pp.377-92.

Tomiyama, M., Kannari, K., Nunomura, J., Oyama, Y., Takebe, K. \& Matsunaga, M., 1994. Quantitative autoradiographic distribution of glutamate receptors in the cervical segment of the spinal cord of the wobbler mouse. Brain research, 650(2), pp.353-7.

Verhovshek, T., Wellman, C.L. \& Sengelaub, D.R., 2005. NMDA receptor binding declines differentially in three spinal motor nuclei during postnatal development. Neuroscience letters, 384(1-2), pp.122-6.

Vinay, L., Brocard, F., Pflieger, J.F., Simeoni-Alias, J. \& Clarac, F., 2000. Perinatal development of lumbar motoneurons and their inputs in the rat. Brain research bulletin, 53(5), pp.635-47. 
Neuroprotection patterns in the spinal cord 


\title{
Chapter 6
}

\section{Characterization of the glutamate uptake capacity of the human fetal stem cell line SPC1 and its neuroprotective capacity in a slice culture model for excitotoxicity}

\author{
Jose Gerardo-Nava ${ }^{1,2,3}$, Ivanna I. Mayorenko ${ }^{1,3}$, Graham Cocks ${ }^{4}$, Stéphanie Goursaud ${ }^{5}$, \\ Jack Price ${ }^{4}$, Harry W.M. Steinbusch ${ }^{2,3}$, Emmanuel Hermans ${ }^{5}$, Joachim Weis ${ }^{1,3}$, Gary A. \\ Brook $^{1,3}$ \\ ${ }^{1}$ Institute of Neuropathology, Medical Faculty, RWTH Aachen University, Aachen, Germany \\ ${ }^{2}$ Department of Translational Neuroscience, Maastricht University Medical Center, \\ Maastricht, The Netherlands \\ ${ }^{3}$ European Graduate School of Neuroscience (EURON), Maastricht University, The \\ Netherlands \\ ${ }^{4}$ Institute of Psychiatry, King's College London, London, United Kingdom \\ ${ }^{5}$ Institute of Neuroscience (IoNS), Université Catholique de Louvain, Brussels, Belgium.
}




\begin{abstract}
Reduced expression levels of excitatory amino acid transporter 2 (EAAT2) and excitatory amino acid transporter 1 (EAAT1) in ALS patients and animal models suggest an unstable astroglial population that contributes directly to an excitotoxic environment that accelerates the motoneuronal degeneration. Replacing the afflicted astrocytic population with cells expressing EAAT transporters has been proposed as a way to reduce glutamate levels in ALS patients. In the present study, a c-Myc conditionally immortalized human foetal spinal cord neural progenitor cell line (SPC-01) has been used to generate large numbers of naïve (undifferentiated) cells as well as immature astrocytes for the evaluation of their glutamate uptake capacity and their ability to protect spinal cord motor neurons in an organotypic model of excitotoxicity. SPC-01 cells were successfully differentiated into an immature astrocytic phenotype by treatment with bone morphogenetic protein 4 (BMP4) and leukaemia inhibitory factor (LIF) as demonstrated by an increased number of cells expressing glial fibrillary acidic protein (GFAP). Results show that naïve SPC-01 cells show higher uptake levels compared to differentiated cells as demonstrated by the aspartate uptake assay. Data also showed EAAT1 to be the major uptake contributor. Application of SPC-01 cells directly onto the slice cultures showed increased motoneuronal survival, suggesting a potential use of these cells as a cell replacement therapy.
\end{abstract}

Keywords: stem cells, excitotoxicity, organotypic slice cultures, neuroprotection 


\section{Introduction}

Amyotrophic lateral sclerosis (ALS) is a neuronal disorder characterized by rapid degeneration of the upper and lower motor neurons (MN) in the CNS, and usually concludes with death by respiratory failure within the 5 years of diagnosis (Bruijn et al. 2004) . The mechanisms leading to motor neuron degeneration in ALS are yet to be fully characterized. Studies have shown that non-neuronal cells are also affected by the disease, contributing directly to neuronal loss (Clement et al. 2003; Yamanaka et al. 2008). Glutamate excitotoxicity has been identified as one of the major contributors to motoneuronal degeneration in ALS (Bogaert et al. 2010). Astrocytes play the central role in glutamate homeostasis in the CNS and reduced excitatory amino acid transporter 2 levels (EAAT2; GLT1 in the rodent), the primary extracellular glutamate regulator, has been reported in rodent models of ALS as well as studies in human tissues (Rothstein et al. 1995). In view of these observations, cell replacement strategies aimed at improving the local environment of MN have focussed on introducing supplementary cells such as stem cells, glial progenitors or immature astrocytes, as a means of compensating the pathological glutamate dysregulation. Rodent glial progenitors as well as human neural progenitors have demonstrated neuroprotective properties in a number of in vitro and in vivo motoneuronal degeneration models (Lepore et al. 2008; Maragakis et al. 2005). However the greatest difficulty in the use of such cell replacement therapies resides in obtaining reliable and reproducible sources of progenitors, as well as generating the large numbers of cells required for transplantation. These challenges must be overcome to exploit the therapeutic potential of such cells.

In the present study, c-Myc conditionally immortalized human foetal spinal cord neural progenitor cell line (SPC-01) has been used to generate large numbers cells. This cell line is capable to enter a high proliferative state only in the presence of the artificial ligand 4-hydroxytamoxifen (OHT). SPC-01 naïve (undifferentiated) cells as well as those induced into an immature astrocytes state by incubation with bone morphogenetic protein 4 (BMP4) and leukaemia inhibitory factor (LIF) were tested to determine their glutamate uptake capacity. The cells with the higher uptake capacity were then tested in their ability to protect spinal cord motoneurons in an organotypic model of excitotoxicity.

\section{Materials and Methods}

\section{Cell Culture}

The conditionally immortalized human cell line SPC-01 was generated from 10-week-old human fetal spinal cord. The anonymous fetal tissue was obtained from Advanced 
Bioscience Resources (Alameda, CA, USA) after normal terminations in accordance with nationally (UK and/or USA) approved ethical and legal guidelines. A single-cell suspension was prepared by mechanical and enzymatic dissociation of the cervical region and the cells conditionally immortalized with a c-myc construct that generates a c-myc protein fused to a mutated estrogen receptor (c-myc-ERTAM) and is transcriptionally active only in the presence of the synthetic ligand 4-hydroxytamoxifen (OHT). SPC-01 cells were cultured in laminin-coated tissue culture flasks (Sigma-Aldrich; $20 \mu \mathrm{g} / \mathrm{ml}$ in DMEM:F12). Growth media comprising DMEM:F12 with 2mM GlutaMAX (Life Technologies) was supplemented with $0.03 \%$ human serum albumin (Baxter Healthcare Ltd.), $100 \mu \mathrm{g} / \mathrm{ml}$ human transferring (Sigma-Aldrich), $16.2 \mu \mathrm{g} / \mathrm{ml}$ putrescine dihydrochloride (Sigma-Aldrich), 5 $\mu \mathrm{g} / \mathrm{ml}$ human insulin (Sigma-Aldrich), $60 \mathrm{ng} / \mathrm{ml}$ progesterone (Sigma-Aldrich), $40 \mathrm{ng} / \mathrm{ml}$ sodium selenite (Sigma-Aldrich), $20 \mathrm{ng} / \mathrm{ml}$ EGF (Cell Comcepts), and $100 \mathrm{nM}$ 4-hydroxytamoxifen (Sigma-Aldrich) and $10 \mathrm{ng} / \mathrm{ml}$ FGF (Cell Concepts) and was changed 2 times per week. When cultures were $70 \%$ - 90\% confluent, the cells were passaged by using $0.25 \%$ TrypZean (Lonza) for 2 minutes at $37^{\circ} \mathrm{C}$ followed by $0.25 \mathrm{mg} / \mathrm{ml}$ soybean trypsin inhibitor (Sigma-Aldrich). SPC-01 cells from passages 27 through 37 were used in all experiments.

\section{Differentiation of SPC1 cells into immature astrocytes}

Differentiation of the human spinal cord progenitors (SPC-01) to an immature astrocytic phenotype (ASPC-01) was performed according to the protocol described by Führmann and colleagues, adapted for its use on monolayer cultures instead of neurospheres (Führmann et al. 2010). Briefly, cells were seeded at a density of $20,000 \mathrm{cells} / \mathrm{cm}^{2}$ and cultured in neural progenitor differentiation medium, composed of growth medium without $\mathrm{OHT}$, but supplemented with $10 \mathrm{ng} / \mathrm{ml}$ human recombinant leukemia inhibitory factor (LIF; Millipore) and $20 \mathrm{ng} / \mathrm{ml}$ human recombinant bone morphogenetic protein (BMP4; R\&D Systems), leading to the generation a highly enriched population of progenitor-derived astrocytes after 2 weeks in culture.

\section{Quantification of astrocytic and stem cell marker expression}

Immunofluorescent staining was performed on SPC-01 and ASPC-01 cells that had been seeded $\left(20,000\right.$ cells $\left./ \mathrm{cm}^{2}\right)$ onto $15 \mathrm{~mm}$ round laminin-coated coverslips $24 \mathrm{~h}$ before fixation with $4 \%$ paraformaldehyde (PFA) for $30 \mathrm{~min}$ at room temperature (RT). Samples were blocked with 0.1M PBS containing 5\% normal goat serum (Sigma Aldrich) and 0.2\% Triton X-100 (Sigma Aldrich) at RT for 1 hour. Primary antibodies for glial fibrillary acidic protein (rabbit anti-GFAP, 1:1000; Dako), nestin (rabbit anti-nestin, 1:1000; Millipore), SOX2 (rabbit anti-SOX2, 1:1000; Millipore), beta-III tubulin- (mouse anti-TUBB3, 1:1000; 
Sigma Aldich) and CD44 (mouse anti-CD44, 1:200; Millipore) were applied overnight at $4^{\circ} \mathrm{C}$ on a shaker. Secondary antibodies, (goat anti-rabbit and goat anti-mouse conjugated to either Alexa 594 or Alexa 488, both Molecular Probes) were applied at a dilution of 1:500 and incubated at RT for 2 hours in the dark. A nuclear counterstain was performed by adding $1 \mu \mathrm{g} / \mathrm{ml}$ diamidino-2-phenylindole (DAPI) to the secondary antibody solutions. Coverslips were mounted using Fluoroprep mounting medium (BioMerieux). Three areas per sample were photographed using the 20x objective and analysed using Axiovision Rel.4.6. to determine the percentage of the of cells expressing the marker of interest. Quantification was obtained from samples of 3 independent differentiation experiments.

\section{Cell proliferation Ki-67 stain}

Proliferation of the SPC-01 and ASPC-01 was assessed by Ki-67 immunostaing of cells $24 \mathrm{~h}$ after seeding onto laminin-coated coverslips $\left(20,000\right.$ cells $\left./ \mathrm{cm}^{2}\right)$. Cells were immunostained using a rabbit anti-Ki64 antibody (1:1000; DAKO) and counterstained using DAPI. After immunolabeling cells were examined using a Zeiss Axiovert 200M inverted fluorescence microscope. Three images per sample were obtained using the 20x objective and analyzed using Axiovision Rel.4.6. to determine the percentage of Ki-67 postive cells.

\section{Aspartate uptake assay}

Uptake assays were performed as previously described (Goursaud et al. 2009) with some modifications. SPC-01 cells and ASPC-01 cells with or without exposure to $150 \mu \mathrm{M}$ dibutiryl cyclic adenosine monophosphat (db-CAMP, Sigma Aldrich; cASPC-01) were used, since astroglia and their progenitors are known to present a strong reduced expression of glutamate transporters in vitro in comparison to in vivo (Schlag et al. 1998), glutamate transporter expression in the ASPC-01 cells was induced by adding db-cAMP (150 $\mu \mathrm{M})$ for 5 days. Cells were grown on laminin-coated 24 -well plates to $90 \%$ confluency. Plates were immediately placed at the surface of a $37{ }^{\circ} \mathrm{C}$ water bath and rinsed twice with pre-warmed Krebs buffer (25 mmol/I HEPES pH 7.4, $4.8 \mathrm{mmol} / \mathrm{I} \mathrm{KCl}, 1.2 \mathrm{mmol} / \mathrm{I} \mathrm{KH}_{2} \mathrm{PO}_{4}, 1.3 \mathrm{mmol} / \mathrm{l}$ $\mathrm{CaCl}_{2}, 1.2 \mathrm{mmol} / \mathrm{l} \mathrm{MgSO}, 6 \mathrm{mmol} / \mathrm{l}$ glucose and $140 \mathrm{mmol} / \mathrm{l} \mathrm{NaCl}$ ). Inhibitors of glutamate transporters were added $6 \mathrm{~min}$ before the addition of the substrate, to final concentrations of $200 \mu \mathrm{mol} / \mathrm{I}$ for L-serine-O-sulphate (L-SOS; Bachem) and $100 \mu \mathrm{mol} / \mathrm{I}$ for DL-threo-beta-hydroxyaspartate (LTHA; Tocris) and dihydrokianic acid (DHK; Tocris), to assess the individual contribution of EAAT1 and EAAT2 to the glutamate uptake. In these experiments, L-glutamate was substituted by aspartate, its transportable analogue which does not interact with glutamate receptors and is not metabolized. D- $\left[{ }^{3} \mathrm{H}\right]$ - aspartate (50 
$\mathrm{nmol} / \mathrm{l})$ was diluted with unlabeled L-aspartate to achieve a final concentration of 100 $\mu \mathrm{mol} / \mathrm{l}$. The uptake was stopped after $6 \mathrm{~min}$ by three rinses with ice-cold sodium-free Krebs buffer in which $\mathrm{NaCl}$ was replaced by choline chloride at the same osmolarity (120 $\mathrm{mmol} / \mathrm{l})$. The cells were lysed with $500 \mu \mathrm{l} 1 \mathrm{~N} \mathrm{NaOH}$ and the radioactivity of the lysate was evaluated by liquid scintillation counting. A fraction of the lysate was also used for protein determination. The specific activity of the glutamate transporters (expressed as the uptake velocity per $\mathrm{mg}$ of protein) was estimated after subtracting the data obtained using the non-selective glutamate transporter inhibitor LTHA. Quantitative analysis was obtained from three independent cultures in quadruplicates.

Neuroprotective effects of SPC-01 in an in vitro model of excitotoxicity

The neuroprotective capacity of the naïve SPC-01 cell line was assessed in a model of glutamate excitotoxicity using lumbar spinal cord organotypic slices as previously described (Gerardo-Nava et al. 2013). Briefly, spinal cord organotypic slice cultures (OSC) were prepared from post-natal day 7-9 (P7-P9) Sprague-Dawley donor rat pups. Rat pups were decapitated in accordance with the local animal ethics regulations and with the European Communities Council Directive 86/609/EEC. The spinal cord was rapidly isolated and the lumbar enlargement sectioned transversely (thickness, 350 $\mu \mathrm{m}$ ) with a Mcllwain tissue chopper (Mickle Laboratory Engineering), after which five slices from the same spinal cord level were transferred to a PTFE culture plate membrane inserts (Millipore Millicell $\mathrm{CM}$ ) and cultured in $35 \mathrm{~mm}$ culture wells (Falcon, Becton Dickinson Labware). The OSC were maintained in serum-free medium [Neurobasal-A medium (Life Technologies) supplemented with B27 (life Technologies), $6.4 \mathrm{mg} / \mathrm{ml}$ D-glucose , $2 \mathrm{mM}$ GlutaMAX (Life Technologies)] with an antibiotic/anti-mycotic solution (penicillin $G \quad 10,000 \mathrm{U} / \mathrm{ml}$ streptomycin sulfate $10 \mathrm{mg} / \mathrm{ml}$ and amphotericin B $25 \mu \mathrm{g} / \mathrm{ml} ; 1: 100 \mathrm{vol} / \mathrm{vol}$, Sigma Aldrich) and incubated at $37^{\circ} \mathrm{C} / 5 \% \mathrm{CO}_{2}$. Culture medium was refreshed after 1 day in-vitro (DIV), then changed twice weekly for the first 14 DIV.

Briefly, SPC-01 cells were applied to spinal cord organotypic slice cultures 2 days before the glutamate insult by carefully pipetting $2 \mu \mathrm{l}$ of cell suspension ( $5000 \mathrm{cells} / \mu \mathrm{l}$ ) to

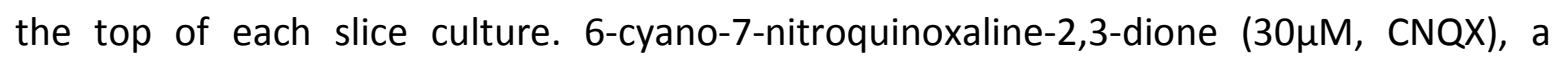
known MN protector was used as a positive control. Glutamate induced toxicity was performed on slice cultures on day 15 as follows: slice culture preparations with or without applied SPC-01 were placed in modified Locke's buffer $(137 \mathrm{mM} \mathrm{NaCl}, 2.5 \mathrm{mM}$ $\mathrm{CaCl}_{2}, 5 \mathrm{mM} \mathrm{KCl}, 5.6 \mathrm{mM}$ D-glucose, $0.3 \mathrm{mM} \mathrm{KH}_{2} \mathrm{PO}_{4}, 4 \mathrm{mM} \mathrm{NaHCO}, 0.3 \mathrm{mM} \mathrm{Na} \mathrm{HPO}_{4}$, $0.01 \mathrm{mM}$ glycine, $10 \mathrm{mM}$ Hepes) in the presence of added glutamate $(100 \mu \mathrm{M})$ and incubated for 30 minutes at $37^{\circ} \mathrm{C}$ in $5 \% \mathrm{CO}_{2}$. Extra control samples were placed in Locke's buffer without the addition of glutamate. The OSC were then washed in glutamate-free 150 
Locke's buffer for 5 minutes, transferred to fresh medium and cultured for an additional 48 hours. For the quantification of MN cell survival, OSC were fixed with PFA for 1 hour at RT followed by 20 minute incubation in ice-cold acetic alcohol (95\% ethanol and $5 \%$ acetic acid) and rinsed in $0.1 \mathrm{M}$ Tris buffered saline (TBS; $0.1 \mathrm{M}$ Tris- $\mathrm{HCl}, 0.15 \mathrm{M} \mathrm{NaCl}$; $\mathrm{pH} 7.4$ ). Free-floating OSC were then processed for immunohistochemistry using antibodies for non-phosphorylated 200kDa neurofilament (mouse anti-SMI-32, 1:1000; Covance) and for human nuclei (mouse anti-HuNu, 1:1000; Millipore). Whole slices were photographed (x20 objective lens) using the automatic image acquisition and mosaic reconstruction feature of the Zeiss AxioVision software. From these images, MN quantification was performed by counting SMI-32-positive profiles per slice that were defined by the following criteria: localization to the ventral gray matter and a soma diameter of greater than $20 \mu \mathrm{m}$. Cultures from at least 3 donor animals were used, for the quantitative analysis 2-3 slices per culture were used.

\section{Statistical analysis}

All data was obtained from at least three independent experiments, unless otherwise mentioned. Using GraphPad Prism Software version 4.0, multiple group comparisons were performed by one-way analysis of variance (ANOVA) followed by the Bonferroni post-hoc test. Differences were considered significant if $p<0.05$.

\section{Results}

Characterization of differentiated SPC-01 cells

The SPC-01 cell line was grown as a monolayer and had the tendency to form clusters. Cells in the middle of the cluster presented a rounded shape with small diameters while those on the periphery extended short processes (Fig. 1A). Upon removal of OHT and addition of BMP4/LIF, cells changed morphology within 72 hours to longer process bearing cells, abandoning the clusters and spreading over the cell culture surface (Fig. 1B). By one week of differentiation some cells still bore processes but the majority had adopted a more flattened, polymorphic morphology and distributed themselves evenly across the culture surface (Fig. 1C). Phenotypically, cells expressed the stem cell markers nestin and SOX2 as well as vimentin and CD44, before and after 2 week of differentiation with BMP4/LIF ( Fig 2). An increase in GFAP expression was observed upon induced differentiation with over $96 \%$ of cells being GFAP+ immunoreactive. Cells that had just been in OHT free media for 7 days showed increased expression of astrocytic (GFAP+) and 
to a lesser degree neuronal marker (TUBB3+) as previously described (Cocks et al. 2013a) (supplementary figure 1).
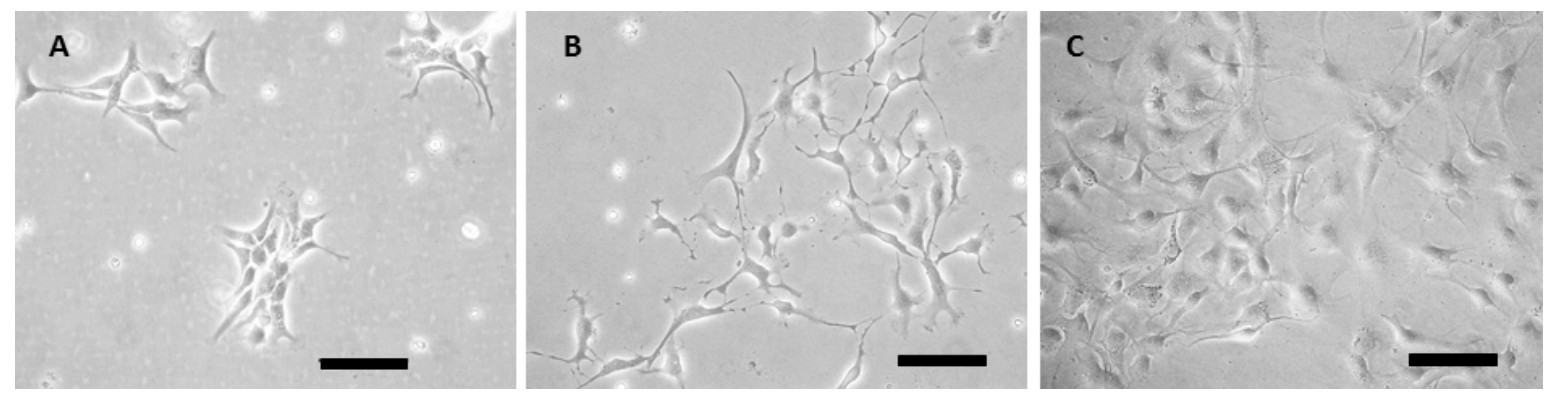

Fig 1. Changes in the morphology of the SPC-01 cells are clearly observed following treatment with BMP4/LIF. A) Undifferentiated SPC-01 cells grew in clusters and presented small diameter. B) Upon OHT removal and treatment with BMP4/LIF cells shifted from a more dispersed phenotype extending short processes by $72 \mathrm{hrs}$. C) 1 week after BMP4/LIF treatment cells adopt a flattened morphology. Scale bars A-C: $100 \mu \mathrm{m}$

The proliferative capacity of the SPC-01 cell line in both its naïve and differentiated states was also investigated. Ki67 immunostains studies revealed that cells that had undergone differentiation following exposure to BMP4/LIF demonstrated reduced proliferation. The percentage of cells expressing Ki67 was strongly reduced from $83.43 \pm 1.7 \%$ in the non-differentiated SPC-01 cells to $12.87 \pm 2.23 \%$ in the differentiated ASPC-01 cells ( $P<0.001$; Fig. 2 C).

\section{Glutamate uptake capacity of SPC-01 cells}

Glutamate transporter function on SPC-01, ASPC-01 and CASPC-01 cells was characterized by means of a tritiated aspartate uptake assay. Total glutamate uptake was greatest in the SPC-01 cell line and was significantly reduced following BMP4/LIF-mediated differentiation to ASPC-01 cells $(4.8 \pm 0.28 \mathrm{pmol} / \mathrm{mg} / \mathrm{min}$ to $1.0 \pm 0.13, \mathrm{pmol} / \mathrm{mg} / \mathrm{min}$ respectively, $\mathrm{p}<$ 0.001). However, the induction of glutamate transporter expression following treatment with cAMP prompted a partial, but still statistically significant recovery of function (from $1.0 \pm 0.13 \mathrm{pmol} / \mathrm{mg} / \mathrm{min}$ to $2.8 \pm 0.15 \mathrm{pmol} / \mathrm{mg} / \mathrm{min}$ respectively, $\mathrm{p}<0.05 ;$ Fig. 4$)$. The use of competitive transporter inhibitors (L-SOS or DHK) allowed the relative contributions of the specific transporters EAAT1 and EAAT2 to be demonstrated (respectively). Incubation with L-SOS induced the greatest reduction of uptake levels in all 3 cell types studied (i.e. SPC01, ASPC-01 and CASPC-01) causing a 81.25\% uptake reduction in SPC-01 cells, a $70 \%$ reduction in ASPC-01 cells and a 77\% reduction in CASPC-01 cells (all $p<0.001$ relative to 
their respective totals, Fig 4). The introduction of DHK induced a much smaller, but still statistically significant, reduction of uptake levels in all cell types: (18.75\% reduction in SPC-01 cells, $23 \%$ reduction in ASPC-01 cells and a 12\% reduction in CASPC-01, $p<0.05$ for SPC-01 and ASPC-1, and $p<0.001$ for CASCP relative to their respective controls, Fig 4).
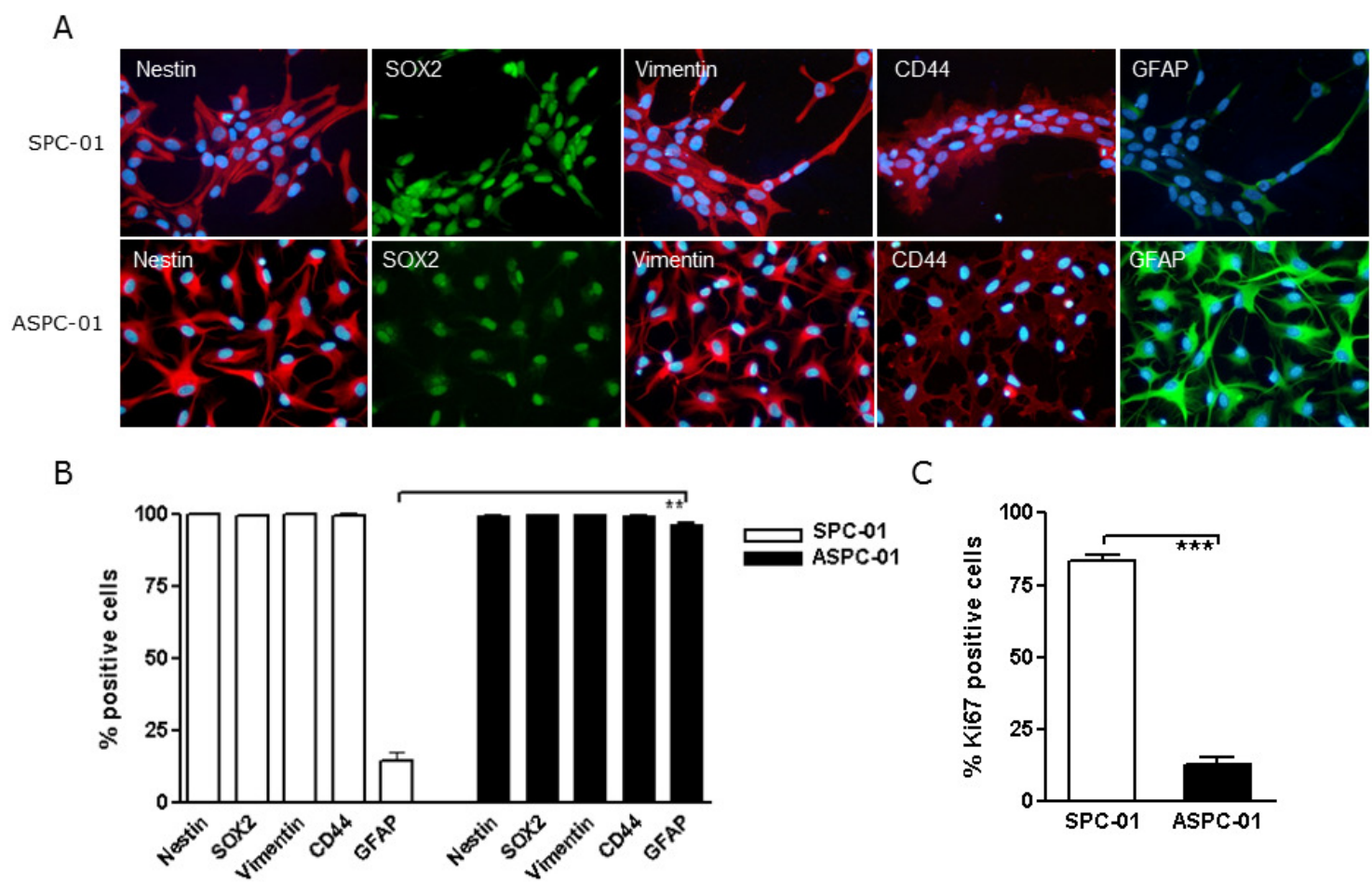

C

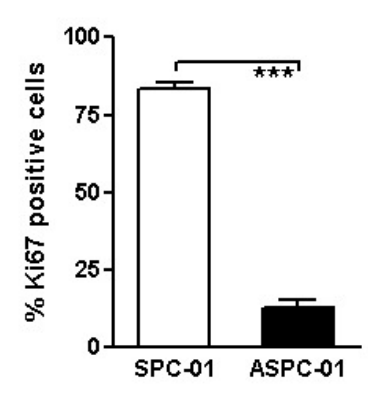

Fig 2. Exposure of SPC-01 cells to BMP4/LIF induce and immature astrocyte phenotype. A) Expression of stem cell markers (nestin and SOX2) as well as astrocytic markers (vimentin, CD44 and GFAP) in naive (top panel) and BMP4/LIF treated cells(bottom panel). B) Quantitative analysis showed that while stem cell and early astrocytic markers are still present after BMP4/LIF treatment, GFAP expression is induced and is expressed in over $98 \%$ of differentiated cells. C) SPC-01 when cultured in 4-OHT containing growth media show high immunoreactivity to the proliferation marker Ki-67, compared to BMP4/LIF treated cells. $(* *=p<0.01, * * *=p<0.010)$

Neuroprotective capacity of the SPC-01 cell line in an organotypic model of excitotoxicity

Since the previous study has clearly showed that the greatest glutamate uptake capacity was demonstrated by the non-differentiated SPC-01 cell line, the organotypic slice culture model was used to evaluate the neuroprotective capacity of these cells. Seeding of the SPC-01 cells onto the slices 48 hourse before exposure to glutamate resulted in many cells bound to the supporting membrane of the transwell, forming a halo of adherent cells around the slices (Fig 5A), while a substantial amount of cells adhered the surface (Fig 5B). Each healthy lumbar organotypic spinal cord slice contained approximately $30 \mathrm{SMI}-32$ immunoreactive ventral horn MN (Fig 4C). Exposure to excess glutamate (100 $\mu \mathrm{M})$ caused 
excitotoxicity and degeneration of ventral horn $M N$ count to a half $(15.1 \pm 0.6 \mathrm{MN} p<$ 0.001 , Fig $5 \mathrm{~A}$ ) when compared to the numbers of $\mathrm{MN}$ surviving in untreated OSCs controls (30.1 $\pm 1.2 \mathrm{MN})$. Whereas exposure to excess glutamate in the presence of CNQX (30 $\mu \mathrm{M})$ lead to a robust protection of $97 \% \mathrm{MN}(29.3 \pm 1.4 \mathrm{MN})$ and was not statistically significantly different from the non-treated controls ( $p>0.05$ ). The effect of the locally seeded SPC-01 cells was also to impart significant neuroprotection with $83 \%$ survival rates $(24.9 \pm 1.32$ $\mathrm{MN}$; relative to the non-treated controls).

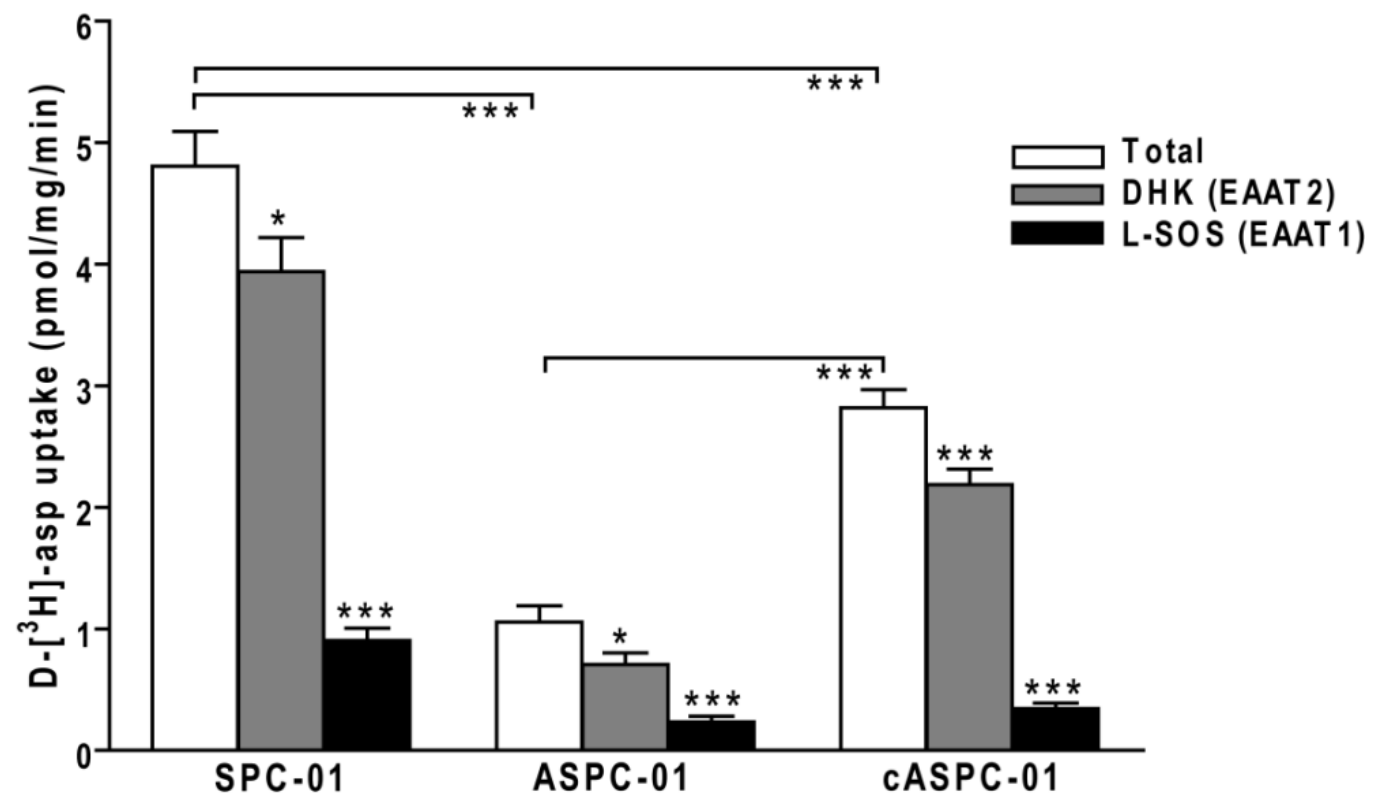

Fig 3. Glutamate transporter activity. The SPC-01 cell line in its naïve state, possess a high glutamate transporter activity that is reduced upon treatment with BPL4/LIF (ASPC-01). Induction of glutamate transporter expression in the ASPC-01 cells through cAMP (CASPC-01) increases significantly transport activity. EAAT1 is in all stages of differentiation the major contributor to glutamate uptake, while EAAT2 contribution although significant, is minimal. $(*=p<0.05, * * *=p<0.001)$

\section{Discussion}

The glutamate transporter EAAT2 is responsible for the bulk clearance of glutamate after synaptic transmission. It is expressed, along with EAAT1, primarily in the perisynaptic astrocytic processes in the CNS (Chaudhry et al. 1995). Increased glutamate levels due to reduced EAAT2 expression in the astrocytic population in ALS patients has been identified as one of the key mechanisms contributing to MN degeneration (Rothstein et al. 1995). 

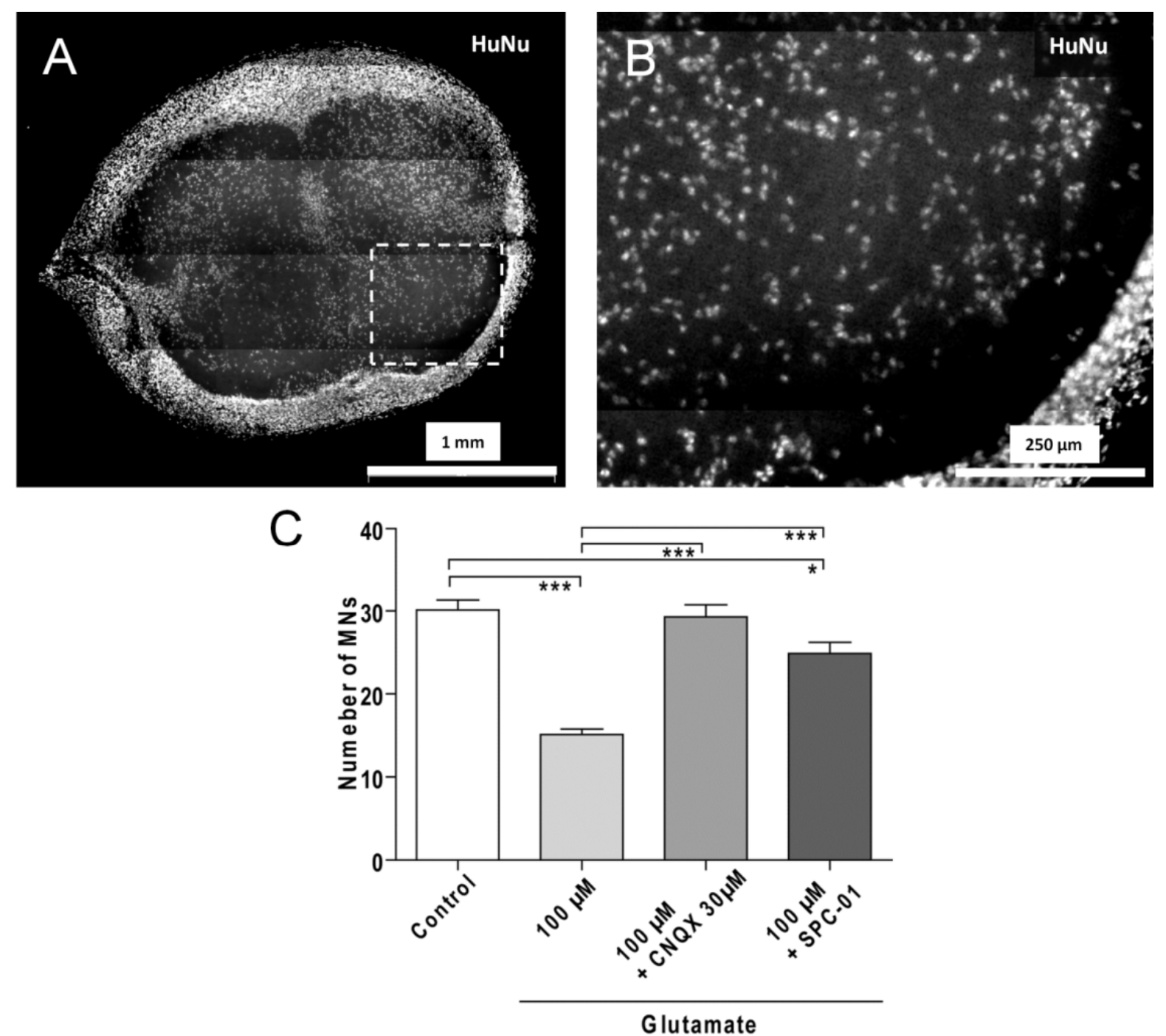

Fig 4. Neuroprotective capacity of the SPC-01 cell line. A) Seeded SPC-01 cells are found primarily surrounding the slice culture. B) HuNu positive cells present in the ventral horn of the OSC. C) Untreated control samples present a high count of surviving $M N$ which decreases to half when presented with a glutamate toxic environment. Samples seeded with SPC-01 cells 48 hours before the glutamate insult led to significant $M N$ sparing, however inferior but not significant compared to OSCs treated with $30 \mu \mathrm{M} \mathrm{CNQX.}\left(^{*}=p<0.05, * * *=p<\right.$ 0.001)

Neural stem cells, glial restricted progenitors and derived astrocytes, especially the latter expected to express high levels of EAAT2, have been long proposed in replacement therapy (Mazzini et al. 2009). Our investigation revealed that the cell line SPC-01 possess a highly active glutamate uptake capacity and is $\mathrm{MN}$ neuroprotective in a spinal cord organotypic in vitro model of glutamate excess. 
The fetal spinal cord SPC-01 was incubated in media containing BMF-4/LIF to induce astroglial differentiation and thereby increase glutamate uptake capacity. During differentiation, cells underwent morphological and phenotypical changes yielding an enriched population of GFAP+ expressing cells within the first two weeks when cultured in monolayer compared with the original 8 week protocol using neurospheres (Führmann et al. 2010; Weible \& Chan-Ling 2007). Cells before and after differentiation expressed the neural stem cell markers SOX2 and nestin, indicating that cells retain their stem cell nature. $\mathrm{CD} 44+$ was also present before and after differentiation. Although the presence of CD44+ suggests a restricted astrocytic lineage (Liu et al. 2004), our results show that the CD44+ SPC-01 cells are multi potent and can differentiate into neurons. CD44 expression in neurospheres obtained from human fetal spinal cord has been previously documented and maintain their multipotency (Weible \& Chan-Ling 2007). The prospect of using these cells for cell transplant therapy requires high levels of proliferation during the expansion phase and reduced proliferative levels during therapy to avoid tumorgenicity. The fetal spinal cord SPC-01 cell line has been designed to enter a high proliferative state when supplemented with the synthetic compound 4-Hydroxytamoxifen (Cocks et al. 2013b). The activation of the CMycER protein up regulates telomerase, allowing cell proliferation without undergoing replicative senescence (Greenberg et al. 1999). This provides a stable cell line capable to generate the high number of cells necessary for transplantation. Under the influence of $\mathrm{OHT}$, the cell line expresses Ki67 in high levels, an indicator of the proliferative capacity of the cells, and decreases upon removal of OHT (Cocks et al. 2013b). Cocks and colleagues had also reported reduced SPC-01 proliferation upon removal of the $\mathrm{OHT}$ and cells transplanted into rodent models of spinal cord injury have shown no teratoma formation. ASPC-01 cells, although retaining stem cell marker expression, also showed low Ki67 levels.

Glutamate transporter uptake studies were carried out in SPC-01, ASPC-01 and CASPC-01 cells. Our study shows that the SPC-01 line provides higher glutamate transport levels compared to those differentiated into an astrocytic lineage (ASPC-01 and CASPC-01). These results contrast with studies performed on human glial restricted progenitor and human astrocyte precursors derived from fetal brain tissue where astrocytic differentiation through BMP4 provided increased uptake capacity (Maragakis et al. 2004). Primary astrocyte and glial restricted progenitors in vitro are known to express EAAT2 and EAAT1 at reduced levels. However, EAAT2 and EAAT1 expression can be induced by incubation with neurons or by db-cAMP (Schlag et al. 1998). Treatment of ASPC-01 with $\mathrm{db}$-CAMP increased the glutamate uptake; however, levels never reached those of SPC-01 cells. Uptake was minimally inhibited by DHK and strongly inhibited by LSOS in all conditions suggesting that EAAT1 and not EAAT2, functions as the main transporter involved in the uptake process in vitro, as previously reported with other cells (Vanhoutte et al. 2004). Expression and location of EAATs is rather complex and strongly dependent 
on neuron-astrocyte interactions (Swanson et al. 1997). SPC-01 cells engrafted onto the organotypic slice cultures showed to be neuroprotective in the slice culture model of excess glutamate, and their effect compares to that of CNQX. However, although the neuroprotective effect of the SPC-01 cells can be attributed to rapid clearance of glutamate, other mechanisms such as neurotrophic factor release driven by stem cell slice culture interactions cannot be overseen as neural stem cells are known to constitutively produce significant levels of neurotrophic factors that increase when cells come in contact with tissue (Lu et al. 2003).

\section{Conclusions}

The high glutamate transporter uptake capacity of the SPC-01 cell line as well as its ability to protect $\mathrm{MN}$ in the spinal cord slice culture model of excitotoxicity demonstrates the potential of these cells as future cell replacement therapy. However, while the neuroprotective effects shown by the SPC-01 cell line point in the right direction and further studies should focus on further assessing the neuroprotective capacity and their safety in vivo.

\section{Acknowledgements}

This work has been supported by funding from Aachen-Maastricht "Rotationsstelle", the European Master in Translational Neuroscience (EMTN) MSc thesis pilot (Grant: $502677-$ LLP-1-2009-1-NL-ERASMUS-ECDS). 


\section{Supplementary data}
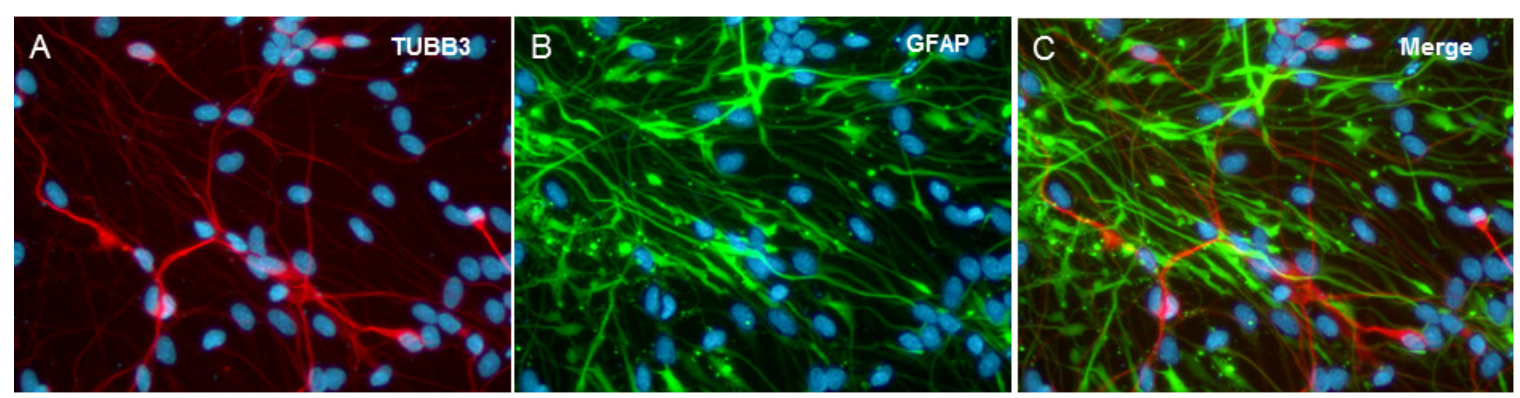

Supplementary Fig. 1 Cells cultured in OHT free media for 7 days showed increased expression of astrocytic $(\mathrm{GFAP+})$ and to a lesser degree neuronal marker (TUBB3+) showing the multipotency of the SPC-01 cells. 


\section{References}

Bogaert, E., D’Ydewalle, C. \& Van Den Bosch, L., 2010. Amyotrophic lateral sclerosis and excitotoxicity: from pathological mechanism to therapeutic target. CNS \& neurological disorders drug targets, 9(3), pp.297304.

Bruijn, L.I., Miller, T.M. \& Cleveland, D.W., 2004. Unraveling the mechanisms involved in motor neuron degeneration in ALS. Annual review of neuroscience, 27, pp.723-49.

Chaudhry, F.A., Lehre, K.P., van Lookeren Campagne, M., Ottersen, O.P., Danbolt, N.C. \& Storm-Mathisen, J., 1995. Glutamate transporters in glial plasma membranes: highly differentiated localizations revealed by quantitative ultrastructural immunocytochemistry. Neuron, 15(3), pp.711-20.

Clement, A.M., Nguyen, M.D., Roberts, E. a, Garcia, M.L., Boillée, S., Rule, M., McMahon, a P., Doucette, W., Siwek, D., Ferrante, R.J., Brown, R.H., Julien, J.-P., Goldstein, L.S.B. \& Cleveland, D.W., 2003. Wild-type nonneuronal cells extend survival of SOD1 mutant motor neurons in ALS mice. Science (New York, N.Y.), 302(5642), pp.113-7.

Cocks, G., Romanyuk, N., Amemori, T., Jendelova, P., Forostyak, O., Jeffries, A.R., Perfect, L., Thuret, S., Dayanithi, G., Sykova, E. \& Price, J., 2013a. Conditionally immortalized stem cell lines from human spinal cord retain regional identity and generate functional V2a interneurons and motorneurons. Stem cell research \& therapy, 4(3), p.69.

Cocks, G., Romanyuk, N., Amemori, T., Jendelova, P., Forostyak, O., Jeffries, A.R., Perfect, L., Thuret, S., Dayanithi, G., Sykova, E. \& Price, J., 2013b. Conditionally immortalized stem cell lines from human spinal cord retain regional identity and generate functional V2a interneurons and motorneurons. Stem cell research \& therapy, 4(3), p.69.

Führmann, T., Hillen, L.M., Montzka, K., Wöltje, M. \& Brook, G.A., 2010. Cell-cell interactions of human neural progenitor-derived astrocytes within a microstructured 3D-scaffold. Biomaterials, 31(30), pp.7705-15.

Gerardo-Nava, J., Mayorenko, I.I., Grehl, T., Steinbusch, H.W.M., Weis, J. \& Brook, G.A., 2013. Differential pattern of neuroprotection in lumbar, cervical and thoracic spinal cord segments in an organotypic rat model of glutamate-induced excitotoxicity. Journal of chemical neuroanatomy, 53, pp.11-17.

Goursaud, S., Kozlova, E.N., Maloteaux, J.-M. \& Hermans, E., 2009. Cultured astrocytes derived from corpus callosum or cortical grey matter show distinct glutamate handling properties. Journal of Neurochemistry, 108(6), pp.1442-1452.

Greenberg, R.A., O’Hagan, R.C., Deng, H., Xiao, Q., Hann, S.R., Adams, R.R., Lichtsteiner, S., Chin, L., Morin, G.B. \& DePinho, R.A., 1999. Telomerase reverse transcriptase gene is a direct target of c-Myc but is not functionally equivalent in cellular transformation. Oncogene, 18(5), pp.1219-26.

Lepore, A.C., Rauck, B., Dejea, C., Pardo, A.C., Rao, M.S., Rothstein, J.D. \& Maragakis, N.J., 2008. Focal transplantation-based astrocyte replacement is neuroprotective in a model of motor neuron disease. Nature neuroscience, 11(11), pp.1294-301. 


\section{Neuroprotective capacity of SPC1 stem cells}

Liu, Y., Han, S.S.W., Wu, Y., Tuohy, T.M.F., Xue, H., Cai, J., Back, S. a, Sherman, L.S., Fischer, I. \& Rao, M.S., 2004. CD44 expression identifies astrocyte-restricted precursor cells. Developmental biology, 276(1), pp.31-46.

Lu, P., Jones, L.L., Snyder, E.Y. \& Tuszynski, M.H., 2003. Neural stem cells constitutively secrete neurotrophic factors and promote extensive host axonal growth after spinal cord injury. Experimental neurology, 181(2), pp.115-29.

Maragakis, N.J., Dietrich, J., Wong, V., Xue, H., Mayer-Proschel, M., Rao, M.S. \& Rothstein, J.D., 2004. Glutamate transporter expression and function in human glial progenitors. Glia, 45(2), pp.133-43.

Maragakis, N.J., Rao, M.S., Llado, J., Wong, V., Xue, H., Pardo, A., Herring, J., Kerr, D., Coccia, C. \& Rothstein, J.D., 2005. Glial restricted precursors protect against chronic glutamate neurotoxicity of motor neurons in vitro. Glia, 50(2), pp.145-59.

Mazzini, L., Vercelli, A., Ferrero, I., Mareschi, K., Boido, M., Servo, S., Oggioni, G.D., Testa, L., Monaco, F. \& Fagioli, F., 2009. Stem cells in amyotrophic lateral sclerosis: state of the art. Expert opinion on biological therapy, 9(10), pp.1245-58.

Rothstein, J.D., Van Kammen, M., Levey, A.I., Martin, L.J. \& Kuncl, R.W., 1995. Selective loss of glial glutamate transporter GLT-1 in amyotrophic lateral sclerosis. Annals of neurology, 38(1), pp.73-84.

Schlag, B.D., Vondrasek, J.R., Munir, M., Kalandadze, a, Zelenaia, O. a, Rothstein, J.D. \& Robinson, M.B., 1998. Regulation of the glial $\mathrm{Na}+$-dependent glutamate transporters by cyclic AMP analogs and neurons. Molecular pharmacology, 53(3), pp.355-69.

Swanson, R. a, Liu, J., Miller, J.W., Rothstein, J.D., Farrell, K., Stein, B. a \& Longuemare, M.C., 1997. Neuronal regulation of glutamate transporter subtype expression in astrocytes. The Journal of neuroscience : the official journal of the Society for Neuroscience, 17(3), pp.932-40.

Vanhoutte, N., de Hemptinne, I., Vermeiren, C., Maloteaux, J.-M. \& Hermans, E., 2004. In vitro differentiated neural stem cells express functional glial glutamate transporters. Neuroscience letters, 370(2-3), pp.2305 .

Weible, M.W. \& Chan-Ling, T., 2007. Phenotypic characterization of neural stem cells from human fetal spinal cord: synergistic effect of LIF and BMP4 to generate astrocytes. Glia, 55(11), pp.1156-68.

Yamanaka, K., Chun, S.J., Boillee, S., Fujimori-Tonou, N., Yamashita, H., Gutmann, D.H., Takahashi, R., Misawa, H. \& Cleveland, D.W., 2008. Astrocytes as determinants of disease progression in inherited amyotrophic lateral sclerosis. Nature neuroscience, 11(3), pp.251-3. 


\section{Chapter 7}

General Discussion 
General Discussion 


\section{General discussion}

Adherence to the principle of the $3 R$ s (Replacement, Reduction and Refinement) for the use of animals in experimentation has been driven by the increasing concern about the welfare of laboratory animals and is reflected by the endorsement by regulatory authorities in Directive 2010/63/EU which explicitly includes a reference to the 3Rs principle. This has led to stricter requirements for the authorization of in vivo procedures designed to evaluate new therapies. In this context, new therapies need to show substantial beneficial effects, e.g. in vitro, to be admissible for animal experimentation. For this reason great emphasis has been placed on developing in vitro models capable of better characterizing new therapies by assessing their effects as well as their mechanisms of action and demonstrating their worthiness for further development. In the field of neuroregeneration and neuroprotection, cell and tissue culture models have long been explored and are commonly used to establish the potential for development of new therapy strategies. However as the field of bioengineering promotes faster discoveries, improvement of the selection process through first level in vitro models is necessary. This thesis sought to establish and refine in vitro assays used for the characterization of cell substrate interactions as well as the evaluation of new donor cell tissue. For this, a series of questions were proposed in the introduction of the thesis and will be answered in the following sections.

- Can deposition of low density nanofibers allow for the evaluation of individual cell - single nanofiber interactions?

- Do human astrocytoma cell lines respond to topographical and molecular cues? Do these responses reflect those of primary human neural progenitor-derived astrocytes?

- $\quad$ Are the axons from MN present in the slice culture, able to respond to physical cues presented by 3D micropatterned and non-micropatterned substrates?

- Can the MN population in the in vitro organotypic slice culture model of excitotoxicity be further characterized?

- Is the in vitro organotypic slice culture model of excitotoxicity capable of demonstrating the neuroprotective properties of the primary human spinal cord progenitor stem cells (SPC-01)?

Individual cell-substrate interactions in 2D cell culture systems

In order to determine the extent to which individual nanofibers have the power to promote directed axonal growth and glial cell orientation, in Chapter 3, we presented a 
way to collect nanofibers at low densities and to immobilize them onto glass coverslips using the SPEG technology. This experimental design enabled the study of the interactions of single axon/cells with single nanofibers in a relatively simple 2D in vitro system. Using this set up we could observe that SH-SY5Y cells and their neurites, showed poor attachment to single PCL and C/PCL nanofibers. This observation agrees with other studies showing that neuroblastoma cell lines of the N-type, neuroblastic in appearance such as SH-SY5Y, are poorly adherent (Ross et al. 2003; Voigt et al. 2000). However, neurites still showed direct interaction with the nanofibers and grew along their axis, suggesting that the main guiding property was through topographical cues. We also observed that single nanofibers ( $\mathrm{PCL}$ and $\mathrm{C} / \mathrm{PCL}$ ), were capable of supporting the migration and orientation of large numbers of astroglia. Cellular and axonal guidance by fibers has been of great interest as these can be readily suspended within a gel or housed in a nerve guide in order to simulate natural ECM cues (Ngo et al. 2003; Yoshii et al. 2003). Studies in vivo using microfibers have shown that improved regeneration was observed in nerve guides that contained the least number of microfibers (Ngo et al. 2003). The notion that less topographical cues present better regenerative properties has been further supported by recent in vivo studies showing that conduits containing a single sheet of nanofibers presented better axonal growth and conduction velocity, than those with multiple sheets of nanofibers (Clements et al. 2009). These results suggest that only a minimal number of fibers may be required to be present in order to support oriented tissue repair in a 3D scaffold. In addition, studies using silk based microfibers suggests that 200 of these fibers provided optimal functional recovery, comparable to autologous controls, in a $11-13 \mathrm{~mm}$ gap in the sciatic nerve (Huang et al. 2012). However, the ideal number of nanofibers required for successful functional regeneration remains unknown. The ability of nanofibers to modify astrocytic morphology and support migration suggests they may be capable of improving graft-host astroglial integration rather than astroglial scarring, thereby creating a more inviting environment for directed axonal growth. However, caution needs to be exercised to avoid over interpretation of results when applying purified cell suspensions - rather than following cell migration out of a well organised tissue. This becomes evident when comparing these in vitro data with recent in vivo studies using collagen scaffolds presenting orientated micropores, as the good astrocytic migration shown in vitro was not observed in $\mathrm{SCl}$ in vivo models, where only minimal astrocytic migration into the implanted scaffold could be observed (Cholas et al. 2012; Führmann et al. 2010; Altinova - personal communication). These observations in vivo could be explained by the migration of other cell types into the implant e.g. meningeal fibroblasts and Schwann cells - which in large numbers are known to be mutually repulsive to astrocyte migration (Abnet et al. 1991; Afshari \& Fawcett 2012).

In vitro studies aimed at dissecting the response of specific cell populations to molecular and physical cues are commonly based on the use of primary cells or cell lines. 
While the use of these cells, especially cell lines, allow for highly reproducible results, there is still the question whether these observations are representative of the behavior of cells to be used in emergent therapies, such neural stem cell and their derivates. As previously mentioned, the morphology and alignment of processes of U373 astrocytoma cells, as well as hNP-ACs, were strikingly influenced by orientated nanofibers. However, migration by U373 astrocytoma and hNP-ACs on functionalized and non-functionalized nanofibers is a clear example in which the cell line behaved differently from the progenitor-derived astrocytes. The U373 astrocytoma cells showed equally extensive migration on both PCL and C/PCL nanofibers. While migration distances of hNP-ACs on PCL nanofibers and PLL-positive-control substrates were similar, the presence of type I collagen promoted a significant increase in migration, albeit still significantly less than that of the U373 cells. Focal adhesions-points are macromolecular complexes that physically link the ECM to the contractile actin cytoskeleton of the cells and are required for cell adhesion and migration (Wang et al. 1993). Integrins are the most important molecular receptors for ECM binding and interact directly with collagen (Leitinger \& Hohenester 2007). It has been shown that indirect binding between collagen and integrin receptors may also be mediated by fibronectin (Geiger et al. 2001). It is possible that the presence of fibronectin in our serum-containing medium may have influenced cell behavior, not only on C/PCL fibers, but it could also have been adsorbed onto the PCL fibers adding functional groups to their surface. ECM-integrin interactions are known to activate a variety of intracellular signal cascades that result in potential synergistic effects between growth factor and integrin signaling (Geiger et al. 2001). This suggests that an increased migratory behavior of cells on electrospun fibers might be achieved by incorporating other ECM molecules, such as laminin or fibronectin, or a combination of these, with soluble factors acting synergistically on integrin-activated pathways (e.g., FGF-2, TGF- $\beta$ or PDGF) (Dalton \& Mey 2009; French-Constant \& Colognato 2004). The reduced proliferative capacity of hNP-ACs shown on either PCL or C/PCL nanofibers compared to the largely unaffected U373 cell proliferation when associated with either nanofiber type is another example of the difference between both cell types. Increased proliferation of rat astrocytes has been reported when grown on laminin and fibronectin, although no such effect could be seen when these cells were grown on type I collagen compared to tissue culture plastic controls (Nagano et al. 1993). It is possible that hNP-AC cells are affected by collagen type I, thereby showing characteristics typical of those of primary cells, while the U373 cells show strong proliferating rates commonly observed with any tumor cell line. The different responses (particularly the migratory responses) presented by the human U373 astrocytoma cells and hNP-ACs while cultured on the same substrate, revealed the limited predictive value of using cell lines for their use in cell-substrate interactions. These observations suggest caution should be exercised when using cell lines to study cellsubstrate interactions. 
Development of the OSC nerve regeneration model for the in vitro evaluation of motor axon responses to 3D scaffolds

A clear understanding of how regenerating motor axons, as well as glial and nonglial cells, may interact with the topographical cues presented by 3D growth-promoting substrates is important in the development of bridges or scaffolds for nerve regeneration. To date, the evaluation of tissue-nerve scaffold interactions in vitro has been primarily limited to the use of DRG cultures (Bozkurt et al. 2007; Corey et al. 2007; Schnell et al. 2007). The multiple cellular components of the DRG (satellite cells, Schwann cells, fibroblasts, endothelial cells, macrophages) as well as the axons from sensory neurons help to provide information of the ability of the construct to facilitate cell migration and sensory axon growth.

The organotypic slice presented in Chapter 4 represents a new tool that allows for the specific evaluation of axonal growth from MNs and tissue-3D scaffold interactions. Our study focused on exploiting the axonal processes from ventral horn $\mathrm{MN}$ and the glial and non-glial cell population of the OSC, as a tool to study their responses to topographical cues presented by different 3D substrates. The results presented in this thesis show that the OSC system proved to be a reliable source for $\mathrm{MN}$, useful to demonstrate motor axonal growth and cell migration within a microstructured collagen $3 \mathrm{D}$ substrates. Similar organotypic models have been developed for the evaluation of axonal growth using cortical tissue, entorhinal cortex, whole spinal cord segments, and parasagital or transversal slices of spinal cord (Ishihara et al. 2011; Prang et al. 2006; Shichinohe et al. 2008; Vyas et al. 2010; Weightman et al. 2014). An organotypic model using entorhino-hippocampal slices was first proposed by Prang and colleagues to assess the capacity of orientated alginate-based micopatterned scaffolds to direct axonal growth in the CNS (Prang et al. 2006); In this model, by cleaving the entorhino-dentate pathway, the neurons that originate in the entorhinal cortex are separated from their targets within the outer layer of the dentate gyrus of the hippocampus, thereby establishing a model of targeted re-innervation. Ishihara and colleagues on the other hand, used a cortical slice culture model to evaluate axonal growth from cortical neurons into 3D Matrigel blocks without any topographical cues (Ishihara et al. 2011). More recently, Weightman's in vitro spinal cord lesion model has been used to study the influence of topographical cues, in the form of suspended orientated nanofibers, on axonal growth from spinal neurons and cell migration (Weightman et al. 2014). Although cellular migration as well as axonal growth from the gray matter onto the nanofibers is observed, specific information on which populations of neurons were contributing to this effect are not described. Further development of biomaterials or scaffolds, especially those designed to improve targeted axon regeneration, requires the use of models that provide information about specifically 
populations of neurons/axons. In this work we show regeneration of $\mathrm{MN}$ axons - a welldefined and delineated system to complement the existent DRG models.

In our model, we showed motor axon regeneration and all stages of maturing Schwann cell-axon interactions within the longitudinally orientated micro-porous framework of a 3D collagen scaffold. These observations mirror those occurring in an in vivo model of sciatic nerve transection using a similar collagen scaffold (Bozkurt et al. 2012). In addition, the interactions of astrocytes, Schwann cells and microglial cells when in contact with the 3D collagen scaffold are also similar to those observed in in vivo experiments, including limited astrocyte migration into the scaffold as well as axonal growth and myelination into the scaffold, thereby adding to the validity of the OSC in vitro model (Bozkurt et al. 2012). While this investigation demonstrated the potential of the OSC-model as a tool for the evaluation of interactions between nervous tissue and 3D microstructured scaffolds, with strong emphasis on the response of regenerating motor axons, it is clear that this model has the potential to be expanded to allow other types of investigations. For example, the degree of myelination of the motor axons suggests that it could complement the set of in vitro techniques currently existing focusing on myelination, demyelination, and remyelination studies ( for review see Jarjour et al. 2012). By adopting this refined technique it could be possible to help reduce the number of animals used to test motor and tissue responses to bridging materials.

\section{Refinement of the OSC glutamate-induced excitotoxicity model}

Organotypic slice cultures from CNS tissue, primarily the hippocampus, have been routinely used in the laboratory as a tool to study cellular and molecular mechanisms of neuronal cell death, neuroprotection as well as synaptic plasticity (Gähwiler et al. 1997; Peña 2010). However, organotypic slice cultures from the spinal cord have recently regained popularity and are being used to evaluate the effects of drugs upon motoneuronal populations, particularly in models of excitotoxicity. The glutamate induced excitotoxicity OSC model, for example, evaluates the neuroprotective capacity of new drugs primarily by studying how these agents prevent high Ca2+ influx, by modulating the activation of NMDA and AMPA/KA receptors in spinal MNs. Nevertheless, in these studies, homogeneity of MN populations throughout the spinal cord is frequently assumed and tissue slices are often obtained from different spinal cord levels (Guzmán-Lenis et al. 2009; Kalb et al. 1992; Verhovshek et al. 2005). Other studies investigate the role of glutamate receptors in the excitotoxicity process and focus upon specific regions of the spinal cord, without indication as to the phenotype of the cells under study (Akesson et al. 2000; Henley et al. 1993; Kalb \& Fox 1997; Li et al. 1999; Tomiyama et al. 1994). Since glutamate receptor sub-types have been shown to be expressed on a range of cell types including 
MNs, astrocytes and oligodendrocytes, this can obscure the information obtained in these studies (Matute 2010). The results presented in Chapter 5 show that in the cervical and lumbar regions, the AMPA receptors are the main contributors to MN excitotoxicity, whereas in the thoracic region, NMDA receptors are the main contributors. These findings strongly suggest that the phenotype of spinal cord MNs in regard to ionotropic glutamate receptor expression is region-specific. The expression of glutamate ionotropic receptors during development is also a dynamic process extending beyond the first post-natal days. NMDA receptor density in the ventral horn of the cervical and lumbar segmental levels of spinal cord is high in $\mathrm{P} 7$ rats, but is lost from all areas of the gray matter by the second or third postnatal week (Hori et al. 2001; Kalb et al. 1992). Meanwhile, cervical spinal cord slices from neonatal and adult animals remained sensitive to AMPA/KA (Vinay et al. 2000). These observations can be used for the improvement of the OSC excitotoxicity model by allowing the use of different spinal cord regions for the evaluation of specific MN neuronal populations. This highlights the importance of taking into consideration parameters such as age and location of the MN source when designing new drug screening experiments using these culture systems.

The acute OSC glutamate-induced excitotoxicity model to study MN protection in cellular therapies

The glutamate induced excitotoxicity OSC model was primarily designed to assess the ability of molecular agents to provide protection to $\mathrm{MN}$ through direct modulation of glutamate release, glutamate receptors or glutamate transporters. Novel cellular therapies present a new challenge and their evaluation using already established in vitro models of glutamate excitotoxicity need to be adapted to deal with the multiple mechanisms (e.g. glutamate clearance, neurotrophic factor release, etc.) through which these agents provide their protection. Assessment of the neuroprotective capacity of stem cells and their astrocytic derivatives against glutamate excitotoxicity in in vitro models have previously been studied in a well-established, chronic excitotoxicity slice culture model (Maragakis et al. 2005; Rothstein et al. 1993). In this model high glutamate levels within the slice culture are achieved by applying competitive glutamate transporter inhibitors (e.g. THA, TBOA) to EAAT1 and EAAT2. While this model has proved effective in achieving chronic, high glutamate levels in the slice culture, pharmacologically tampering with the glutamate machinery in order to achieve high glutamate levels prevents their use as a tool for the evaluation of cell therapies (such as those focused on introducing astrocyte-like cells to compensate for the excess glutamate in the tissue). The OSC in vitro model of glutamate-induced excitotoxicity on the other hand, provides a short, transient increase in glutamate that selectively triggers $\mathrm{MN}$ neurodegeneration without interfering 
with the normal glutamate pathways. In Chapter 6 we showed how this model was capable of showing that the human foetal neural stem cell line, SPC-01, provided neuroprotection to MN. However, as previously mentioned, this model could not be used to dissect the mechanism through which this neuroprotection was provided. Therefore, complementary testing of the donor cells with the aspartate uptake assay was performed to try to further understand the potential mechanisms involved in this process. Nevertheless, we cannot disregard the contribution of other mechanisms such as the release of neurotrophic factors or receptor modulation to the neuroprotective process. These questions however can be addressed by slightly modifying the OSC technique; for example, by seeding the cells in the lower chamber, released factors from these cells and their effects on the MN population of the slice culture can be studied. However, while this model mimics an acute insult similar to that observed during trauma, the need for an improved in vitro organotypic method of chronic glutamate excitotoxicity capable of simulating the glutamate damage observed in diseases such as ALS is still needed.

\section{Final remarks}

The full response complex organisms have to a newly developed therapy can only be studied in in vivo experimental models. Therefore, existent in vitro culture models cannot currently be used as a complete replacement of investigations in vivo. However, in vitro models may allow a higher screening throughput, by identifying important characteristics present in new candidate therapies, thereby facilitating their initial development and identification. For this, it is important that improvement and refinement of in vitro assays are to take place in order to increase their screening abilities, thereby helping to reduce the number of animals used for in vivo investigations, particularly for the development of new nerve regeneration and neuroprotection strategies. In the spinal cord OSC technique, the possibility to obtain up to 12 transverse slices from each spinal cord region (cervical, thoracic and lumbar) permits the evaluation of more than one condition per animal, allowing for the evaluation of MN/axon responses to pharmacological agents or to bioengineered materials on a large scale. The relevance of any in vitro models, especially the OSC, can only be maintained by performing continuous characterization of the tissue in order to better identify the different cellular components and how they interact with each other, thereby allowing for a better understanding of tissue response to given stimuli. Therefore, a more extensive studies of these models need to be carried out to establish to what extent the events occurring in vivo can be reproduced in vitro. The ability to work on serum free and serum containing environments also affords the OSC model a greater versatility in neuroprotection studies (Gerardo-Nava et al. 2013; Gerardo-Nava et al. 2014; Guzmán-Lenis et al. 2009; Rothstein et al. 1993). However, limitations to the OSC 


\section{General Discussion}

models exist, including the lack of any functioning vasculature, an incomplete immune system, and the absence of appropriate end organ targets for the regenerating motor axons. Further development of the nerve regeneration OSC model would address these issues and, for example, the addition of specific muscle targets, allowing for histological and electrophysiological re-innervation studies, is in progress. In addition, our observations regarding the advanced stages of Schwann cell-axon in the nerve regeneration model suggest the possibility of expanding the use of the model for studies focusing on MN myelination and demyelination. The adoption of these approaches in neuroscience will ultimately help accelerate the rate of discovery of new therapeutic agents. 


\section{References}

Abnet, K., Fawcett, J.W. \& Dunnett, S.B., 1991. Interactions between meningeal cells and astrocytes in vivo and in vitro. Brain research. Developmental brain research, 59(2), pp.187-96.

Afshari, F.T. \& Fawcett, J.W., 2012. Astrocyte-Schwann-cell coculture systems. Methods in molecular biology (Clifton, N.J.), 814, pp.381-91.

Akesson, E., Kjaeldgaard, a, Samuelsson, E.B., Seiger, a \& Sundström, E., 2000. Ionotropic glutamate receptor expression in human spinal cord during first trimester development. Brain research. Developmental brain research, 119(1), pp.55-63.

Bareyre, F.M., Kerschensteiner, M., Raineteau, O., Mettenleiter, T.C., Weinmann, O. \& Schwab, M.E., 2004. The injured spinal cord spontaneously forms a new intraspinal circuit in adult rats. Nature neuroscience, $7(3)$, pp.269-77.

Bozkurt, A., Brook, G.A., Moellers, S., Lassner, F., Sellhaus, B., Weis, J., Woeltje, M., Tank, J., Beckmann, C., Fuchs, P., Damink, L.O., Schügner, F., Heschel, I. \& Pallua, N., 2007. In vitro assessment of axonal growth using dorsal root ganglia explants in a novel three-dimensional collagen matrix. Tissue engineering, 13(12), pp.2971-9.

Bozkurt, A., Lassner, F., O’Dey, D., Deumens, R., Böcker, A., Schwendt, T., Janzen, C., Suschek, C. V, Tolba, R., Kobayashi, E., Sellhaus, B., Tholl, S., Eummelen, L., Schügner, F., Damink, L.O., Weis, J., Brook, G.A. \& Pallua, N., 2012. The role of microstructured and interconnected pore channels in a collagen-based nerve guide on axonal regeneration in peripheral nerves. Biomaterials, 33(5), pp.1363-75.

Cholas, R., Hsu, H.-P. \& Spector, M., 2012. Collagen scaffolds incorporating select therapeutic agents to facilitate a reparative response in a standardized hemiresection defect in the rat spinal cord. Tissue engineering. Part A, 18(19-20), pp.2158-72.

Clements, I.P., Kim, Y., English, A.W., Lu, X., Chung, A. \& Bellamkonda, R. V, 2009. Thin-film enhanced nerve guidance channels for peripheral nerve repair. Biomaterials, 30(23-24), pp.3834-46.

Corey, J.M., Lin, D.Y., Mycek, K.B., Chen, Q., Samuel, S., Feldman, E.L. \& Martin, D.C., 2007. Aligned electrospun nanofibers specify the direction of dorsal root ganglia neurite growth. Journal of biomedical materials research. Part A, 83(3), pp.636-45.

Dalton, P.D. \& Mey, J., 2009. Neural interactions with materials. Frontiers in bioscience (Landmark edition), 14, pp.769-95.

French-Constant, C. \& Colognato, H., 2004. Integrins: versatile integrators of extracellular signals. Trends in cell biology, 14(12), pp.678-86.

Führmann, T., Hillen, L.M., Montzka, K., Wöltje, M. \& Brook, G.A., 2010. Cell-cell interactions of human neural progenitor-derived astrocytes within a microstructured 3D-scaffold. Biomaterials, 31(30), pp.7705-15. 


\section{General Discussion}

Gähwiler, B.H., Capogna, M., Debanne, D., McKinney, R. a \& Thompson, S.M., 1997. Organotypic slice cultures: a technique has come of age. Trends in neurosciences, 20(10), pp.471-7.

Geiger, B., Bershadsky, A., Pankov, R. \& Yamada, K.M., 2001. Transmembrane crosstalk between the extracellular matrix--cytoskeleton crosstalk. Nature reviews. Molecular cell biology, 2(11), pp.793-805.

Gerardo-Nava, J., Hodde, D., Katona, I., Bozkurt, A., Grehl, T., Steinbusch, H.W.M., Weis, J. \& Brook, G.A., 2014. Spinal cord organotypic slice cultures for the study of regenerating motor axon interactions with 3D scaffolds. Biomaterials.

Gerardo-Nava, J., Mayorenko, I.I., Grehl, T., Steinbusch, H.W.M., Weis, J. \& Brook, G.A., 2013. Differential pattern of neuroprotection in lumbar, cervical and thoracic spinal cord segments in an organotypic rat model of glutamate-induced excitotoxicity. Journal of chemical neuroanatomy, 53, pp.11-17.

Guzmán-Lenis, M.-S., Navarro, X. \& Casas, C., 2009. Drug screening of neuroprotective agents on an organotypicbased model of spinal cord excitotoxic damage. Restorative neurology and neuroscience, 27(4), pp.33549.

Henley, J.M., Jenkins, R. \& Hunt, S.P., 1993. Localisation of glutamate receptor binding sites and mRNAs to the dorsal horn of the rat spinal cord. Neuropharmacology, 32(1), pp.37-41.

Hori, N., Tan, Y., Strominger, N.L. \& Carpenter, D.O., 2001. Intracellular activity of rat spinal cord motoneurons in slices. Journal of neuroscience methods, 112(2), pp.185-91.

Huang, W., Begum, R., Barber, T., Ibba, V., Tee, N.C.H., Hussain, M., Arastoo, M., Yang, Q., Robson, L.G., Lesage, S., Gheysens, T., Skaer, N.J. V, Knight, D.P. \& Priestley, J. V, 2012. Regenerative potential of silk conduits in repair of peripheral nerve injury in adult rats. Biomaterials, 33(1), pp.59-71.

Ishihara, M., Mochizuki-Oda, N., Iwatsuki, K., Kishima, H., Iwamoto, Y., Ohnishi, Y., Umegaki, M. \& Yoshimine, T., 2011. A new three-dimensional axonal outgrowth assay for central nervous system regeneration. Journal of neuroscience methods, 198(2), pp.181-6.

Jarjour, A.A., Zhang, H., Bauer, N., Ffrench-Constant, C. \& Williams, A., 2012. In vitro modeling of central nervous system myelination and remyelination. Glia, 60(1), pp.1-12.

Kalb, R.G. \& Fox, a J., 1997. Synchronized overproduction of AMPA, kainate, and NMDA glutamate receptors during human spinal cord development. The Journal of comparative neurology, 384(2), pp.200-10.

Kalb, R.G., Lidow, M.S., Halsted, M.J. \& Hockfield, S., 1992. N-methyl-D-aspartate receptors are transiently expressed in the developing spinal cord ventral horn. Proceedings of the National Academy of Sciences of the United States of America, 89(18), pp.8502-6.

Leitinger, B. \& Hohenester, E., 2007. Mammalian collagen receptors. Matrix biology : journal of the International Society for Matrix Biology, 26(3), pp.146-55.

Li, N., Young, M.M., Bailey, C.J. \& Smith, M.E., 1999. NMDA and AMPA glutamate receptor subtypes in the thoracic spinal cord in lean and obese-diabetic ob/ob mice. Brain research, 849(1-2), pp.34-44. 
Maragakis, N.J., Rao, M.S., Llado, J., Wong, V., Xue, H., Pardo, A., Herring, J., Kerr, D., Coccia, C. \& Rothstein, J.D., 2005. Glial restricted precursors protect against chronic glutamate neurotoxicity of motor neurons in vitro. Glia, 50(2), pp.145-59.

Matute, C., 2010. Calcium dyshomeostasis in white matter pathology. Cell calcium, 47(2), pp.150-7.

Nagano, N., Aoyagi, M. \& Hirakawa, K., 1993. Extracellular matrix modulates the proliferation of rat astrocytes in serum-free culture. Glia, 8(2), pp.71-6.

Ngo, T.-T.B., Waggoner, P.J., Romero, A.A., Nelson, K.D., Eberhart, R.C. \& Smith, G.M., 2003. Poly(L-Lactide) microfilaments enhance peripheral nerve regeneration across extended nerve lesions. Journal of neuroscience research, 72(2), pp.227-38.

Peña, F., 2010. Organotypic cultures as tool to test long-term effects of chemicals on the nervous system. Current medicinal chemistry, 17(10), pp.987-1001.

Prang, P., Müller, R., Eljaouhari, A., Heckmann, K., Kunz, W., Weber, T., Faber, C., Vroemen, M., Bogdahn, U. \& Weidner, N., 2006. The promotion of oriented axonal regrowth in the injured spinal cord by alginatebased anisotropic capillary hydrogels. Biomaterials, 27(19), pp.3560-9.

Ross, R.A., Biedler, J.L. \& Spengler, B.A., 2003. A role for distinct cell types in determining malignancy in human neuroblastoma cell lines and tumors. Cancer letters, 197(1-2), pp.35-9.

Rothstein, J.D., Jin, L., Dykes-Hoberg, M. \& Kuncl, R.W., 1993. Chronic inhibition of glutamate uptake produces a model of slow neurotoxicity. Proceedings of the National Academy of Sciences of the United States of America, 90(14), pp.6591-5.

Schnell, E., Klinkhammer, K., Balzer, S., Brook, G., Klee, D., Dalton, P. \& Mey, J., 2007. Guidance of glial cell migration and axonal growth on electrospun nanofibers of poly-epsilon-caprolactone and a collagen/polyepsilon-caprolactone blend. Biomaterials, 28(19), pp.3012-25.

Shichinohe, H., Kuroda, S., Tsuji, S., Yamaguchi, S., Yano, S., Lee, J.-B., Kobayashi, H., Kikuchi, S., Hida, K. \& Iwasaki, Y., 2008. Bone marrow stromal cells promote neurite extension in organotypic spinal cord slice: significance for cell transplantation therapy. Neurorehabilitation and neural repair, 22(5), pp.447-57.

Tomiyama, M., Kannari, K., Nunomura, J., Oyama, Y., Takebe, K. \& Matsunaga, M., 1994. Quantitative autoradiographic distribution of glutamate receptors in the cervical segment of the spinal cord of the wobbler mouse. Brain research, 650(2), pp.353-7.

Verhovshek, T., Wellman, C.L. \& Sengelaub, D.R., 2005. NMDA receptor binding declines differentially in three spinal motor nuclei during postnatal development. Neuroscience letters, 384(1-2), pp.122-6.

Vinay, L., Brocard, F., Pflieger, J.F., Simeoni-Alias, J. \& Clarac, F., 2000. Perinatal development of lumbar motoneurons and their inputs in the rat. Brain research bulletin, 53(5), pp.635-47.

Voigt, A., Hartmann, P. \& Zintl, F., 2000. Differentiation, proliferation and adhesion of human neuroblastoma cells after treatment with retinoic acid. Cell adhesion and communication, 7(5), pp.423-40. 


\section{General Discussion}

Vyas, A., Li, Z., Aspalter, M., Feiner, J., Hoke, A., Zhou, C., O’Daly, A., Abdullah, M., Rohde, C. \& Brushart, T.M., 2010. An in vitro model of adult mammalian nerve repair. Experimental neurology, 223(1), pp.112-8.

Wang, N., Butler, J.P. \& Ingber, D.E., 1993. Mechanotransduction across the cell surface and through the cytoskeleton. Science (New York, N.Y.), 260(5111), pp.1124-7.

Weightman, A.P., Pickard, M.R., Yang, Y. \& Chari, D.M., 2014. An in vitro spinal cord injury model to screen neuroregenerative materials. Biomaterials, 35(12), pp.3756-65.

Yoshii, S., Oka, M., Shima, M., Akagi, M. \& Taniguchi, A., 2003. Bridging a spinal cord defect using collagen filament. Spine, 28(20), pp.2346-51. 


\section{Valorisation}

A new approach being observed in universities is the evaluation of the economic and or the social value gained from research. Whether derived from direct development of products and or services from scientific discoveries, or by direct cooperation with industry or government, establishing potential valorization paths during project planning, offers great benefits to both society and the researcher. On one hand it allows scientists to better focus their goals; on the other hand, pre visualization of the potential applications of scientific discoveries, accelerate the development of new products and services reaching the general public. While in some cases valorization is not readably evident or research is not immediately translatable, it is important to still take the time to establish the role that our research would play in a larger valuable scheme. Parts of this thesis already discuss the value of this research; a small summary of it is presented below.

Affections of the nervous system, whether originated by trauma or disease, represent a great burden not only to the patient, but also to their families, especially those impairing motor function. Strategies aiming to reinstate motor function are varied and depend on the source and extent of the damage, and range from simple drugs to complex bioengineered devices. During the development of such strategies, it is necessary to evaluate their suitability for clinical use. For this, all medical strategies undergo a thorough screening process to secure their safety and effectiveness both in the laboratory and with patients in what is called preclinical and clinical studies. Clinical studies in humans as well as animals are demanding, time consuming and very expensive in comparison to in vitro culture systems. However, while it is true that the results obtained from in vitro systems are hard to translate into solutions readably applicable to patients, they often represent a great pre-screening tool during the development stages of drugs and medical devices. These in vitro models also help us to better understand the mechanisms of action of new developed drugs and devices, improving thereby the chances of success on future discoveries.

In this thesis, we sought to evaluate and to a certain degree, improve in vitro models that had been established for the evaluation of potential therapeutic strategies in the field of neuroprotection and nerve regeneration, with a strong focus on assays targeting the motoneuronal population. Studies in vitro aimed at studying $\mathrm{MN}$ have been limited, primarily due to the challenges that the in vitro culture of single cell MN present. Short survival times and the elevated number of supplements, as well as their associated costs, needed to maintain MN cells alive for long periods of time, often interfere with the drug screening studies. The solution so far, has been the use of in vivo models. However, 
the tight regulations imposed on the use of animals for experimentation, along with the associated high costs, and especially the burden to the well-being of the animals, serve as fuel to the development of alternative methods. We therefore, looked into the use of the organotypic slice culture model as a way to replace the use of in vivo models.

In chapter 4 we presented a novel use of the organotypic slice culture as a tool to study $\mathrm{MN}$ axon/glial cell -substrate interactions. The results of this chapter reveal that the regenerative events occurring in vitro closely resemble those observed in vivo. As mentioned before in this work, the potential of the model can go beyond the investigation of tissue-substrate interactions in the biomaterials field, but could also be expanded to investigate other mechanisms such as myelination/demyelination, important for diseases such as multiple sclerosis and Guillain-Barre Syndrome, CNS/PNS barrier formation, among others.

However, the organotypic slice culture can also be used for the purpose of studying $\mathrm{MN}$ as entities within their native environment. The ability of MN to survive for long periods of time in serum free media makes them a good candidate for the evaluation of drugs targeted to protect MN from degenerative processes such as excitotoxicity. AMPA and NMDA receptors are activated by glutamate and mediate synaptic transmission in the CNS. Over activation of glutamate receptors lead to $\mathrm{MN}$ death via excitotoxicity. In chapter 5, differential activation of AMPA and NMDA receptors was described in terms of their spatial distribution in the spinal cord. These findings helped complement the organotypic slice culture excitotoxicity model and strengthen the understanding of the contribution of receptor sub-types within the scheme of glutamate interactions in the CNS. It also stresses the importance that factors such as age and location of the MN population play in the design of experiments.

Motor neurons are highly dependent on the cells surrounding them for their survival. A good example of this is the role astrocytes play on glutamate regulation during synapse transmission. Through their glutamate transporter machinery, astrocytes regulate glutamate homeostasis thereby prevent excitotoxicity. In chapter 6 we evaluate the human fetal stem cell line SPC1 and its ability to serve as glutamate uptake surrogates. Glutamate mediated excitotoxicity plays a key role in diseases such as amyotrophic laterals sclerosis/motoneuronal disease. The results of this investigation revealed that SPC1 cells have natively strong glutamate uptake machinery and that their predifferentiation into astrocytes is not necessary. These findings open a new door for the treatment of ALS/MND. However, it should be pointed out that more preclinical studies need to take place before the jump into clinical application can be made.

New policies adopted by governments around the world focusing on the reduction of animals for experimentation has been a major game changer in scientific 176 
research. These new regulations help scientists plan their experiments better and also serves as a stimulant for the development of new screening methods. In view of the increased rate at which new medical discoveries are made, the demand for better established and efficient pre-screening methods capable of singling out those with higher chances to be translated into bed side applications also increase. The models presented in this thesis, while they do not completely do away with use of animals, they certainly comply with the reduction of animal use. Revisiting old models, and updating them with new knowledge, can accelerate the development of new in vitro techniques. 


\section{Abbreviations}

\section{A}

aFGF: acidic fibroblast growth factor

ALS: amyotrophic lateral sclerosis

AMPA: a-amino-3-hydroxy-5-methyl-4-isoxazole

propionate

ANOVA: analysis of variance

ASPC-01: immature SPC-01 astrocytes

\section{B}

BBB: Basso, Beattie, Bresnahan Locomotor Rating

Scale

BDNF: brain-derived neurotrophic factor

BMP4: bone morphogenetic protein 4

C

C: cervical

C/PCL: collagen type I/Poly caprolactone

CASPC: db-cAMP Immature SPC-01 Astrocytes

CGRP: calcitonin gene-related peptide

ChAT: choline acetyl transferase

CNQX: 6-cyano-7-nitroquinoxaline-2,3-dione

CNS: central nervous system

CSPG: chondrotin sulphate proteoglycan

\section{D}

DAPI: 4,6-diamidino-2-phenylindole dihydrochloride db-cAMP: di-butiryl cyclic adenosine mono phosphate DHK: di-hydrokianic acid

DIV: days in vitro

DNA: deoxyribonucleic acid

DRG: dorsal root ganglia

\section{E}

EAAT1: excitatory aminoacid transporter 1

EAAT2: excitatory aminoacid transporter 2

MK-801: (+)-5-methyl-10,11-dihydro-5H-

dibenzo[a,d]cyclohepten-5,10-imine

ECM : extracellular matrix

EDC : 1-ethyl-3(3-dimethylaminopropyl)

carbodiimide

EGF : endothelial growth factor

EPO : erythropoietin

$\mathbf{F}$

FGF : fibroblast growth factor

FN : fibronectin

G

GABA : gamma-aminobutyric acid

GDNF: glial cell derived neurotrophic factor
GFAP: glial fibrillary acidic protein

GLAST: glutamate aspartate transporter

GLT1: glutamate transporter 1

GTP: guanosine Triphosphate

\section{H}

HA: hyaluronic acid

HAMC: hyaluronan-methylcellulose

hNP-AC: human neural progenitor-derived astrocytes

K

KA: kainate

kGy: kilo grey

L

L: lumbar

L-SOS: L-serine-O-sulphate

LIF: leukaemia inhibitory factor

LTHA: DL-threo-beta-hydroxyaspartate

$M$

MAG: myelin-associated glycoprotein

MgSO4: magnesium sulphate

$\mathrm{MN}$ : motor neurons

MSC: mesenchymal stromal cells

mTOR: mammalian target of rapamycin

N

NeuN: neuronal nuclei antigen

NF: neurofilament

NGF: nerve growth factor

NgR: nogo receptor

NMDA: N-methyl-d-aspartate

NT-3: neurotrophin 3

SPC-01: human foetal spinal cord neural progenitor cells sPEG: star PEG

0

OEC: olfactory ensheathing cells

OHT: 4-hydroxytamoxifen

OmgP: oligodendrocyte myelin glycoprotein

OSC: organotypic slice culture

$\mathbf{P}$

PAN/PVC: poly(-acrylonitrile-co-vinilchloride)

PBS: phosphate buffered saline

PCL: poly caprolactone

PDLA: poly-d-lactic acid

PEG: poly-ethylene glycol

PELAPDLLA: poly(ethylene oxide)-block poly(d,I-lactic acid) 
PFA: paraformaldehyde

PGA: poly-glycolic acid

PHB: poly-b-hydroxybutyrate

PHEMA: poly-hyrdoxyethyl methacrylate

PHEMAMMA: poly(2-hydroxyethyl methacrylate-

comethyl methacrylate

PHPMA: poly[ $N$-(2-hydroxypropyl)methacrylamide]

PI: propidium lodide

PirB: paired immunoglobulin-like receptor B

PLGA: poly-I-glycolic acid

PLL: poly-I-lysine

PSN: propriospinal neurons

PTEN: phosphatase and tensin homolog

PTFE: polytetrafluoroethylene

PVC: poly-vinylcholride

PLA-b-PEGb-PLA: poly(lactic acid)-b-poly (ethylene

glycol)-b-(poly lactic acid)

PLLA: poly-I-lactic acid

PNS: peripheral nervous system

R

RhoA: Ras homologue A

SEM: scanning electron microscope

$\mathrm{SCl}$ : spinal cord injury

$\mathbf{T}$

T: thoracic

TBS: Tris buffered saline

TEM: transmission electron microscope

TUBB3: Beta-3 tubulin 


\section{Summary}

The aim of this thesis was to analyze and improve in vitro assays systems used for the characterization of cell-substrate interactions as well as for donor cell-tissue interactions in the development of strategies in neuroregenerative medicine and neuroprotection.

Chapter 2 briefly reviews the pathophysiology of $\mathrm{SCl}$. It further explains approaches taken on the development of biomaterials and tissue engineering strategies intended to promote axon regeneration following traumatic injury. While this section focuses primarily on injury to the CNS, the basic principles explained extend to the PNS.

Chapter 3 evaluates the interactions of single nanofibers with single cells/neurites. For this, an in vitro assay which takes advantage of the collection of orientated electrospun nanofibers onto glass coverslips at low densities was used. Neurite-nanofiber interactions were studied using the cell line SH-SY5Y after differentiation with BDNF and RA into neurite bearing cells. The U373 astrocytic cell line and primary astrocytes derived from neural stem cells, helped reveal the differences on the behavior of cell lines versus primary cells. Results showed that topographical cues play an important role on guiding neurite and process extension as demonstrated by the ability of a single nanofiber to support morphological changes on multiple cells. Furthermore, the poor response of the U373 cell line to the substrate functionalization contrasted with that of the neural derived astrocyte progenitors and indicated the poor value cell lines have for the evaluation of bioengineered substrates.

Chapter 4 shifts the focus of this research from 2D in vitro assays to more complex 3D in vitro assays. Regeneration of motor axons originating from organotypic spinal cord slice preparations into explanted spinal nerve roots as well as by 3D bioengineered scaffolds is evaluated. The validity of the nerve root reconstruction model in vitro and the correlation of in vivo events associated with Wallerian degeneration, axon regeneration and re-myelination is explored in the first part of this chapter. The model was then used to assess axonal growth and cell migration into 3D bioengineered constructs. Confronting the slice cultures on its ventral side with a microstructured collagen scaffold and a fibrin hydrogel block, showed the response axons and cells from the OSC had to the different materials and topographies. Axonal growth and cell migration through the microstructure collagens scaffold indicated the importance topographical cues have for the development of bioengineered scaffolds. Using transmission electron microscopy we further showed the complex cell-cell, cell-axon and cell-biomaterial interactions occurring within the collagen scaffold. 
Chapter 5 moves the focus from neuroregeneration to neuroprotection. We use the organotypic spinal cord slice preparation to investigate aspects of motoneuronal excitotoxicity in complex 3D tissues. The excess glutamate slice culture model of motor neuronal degeneration was subsequently established using tissue from different levels of the spinal cord (cervical, thoracic and lumbar). The observation that $\mathrm{MN}$ in the different levels were protected from excitotoxicity by different neuroprotective agents targeting either NMDA or AMPA/KA receptors, shed a light on the differential rostro-caudal localization of specific sub-populations of motor neurons within the spinal cord. These observations are valuable for the refinement of the organotypic slice culture model of excess glutamate.

Chapter 6 focuses on the characterization of an immortalized human fetal spinal cord stem cell line SPC-01; its ability to induce astrocytic differentiation by treatment with $\mathrm{BMP} 4 / \mathrm{LIF}$, and their potential to provide neuroprotection to $\mathrm{MN}$ in the of organotypic spinal cord slice excitotoxicity model. We showed that the cell line SPC-01 in its undifferentiated state possesses powerful glutamate uptake machinery compared to those differentiated into an astrocytic phenotype. We also demonstrate that the OSC excitotoxicity model is a strong tool capable of detecting the neuroprotective effects of cells, as demonstrated by the increased MN survival provided by the SPC-01 line.

Chapter 7 discusses the findings from the preceding chapters in regard to the refinement and development of new in vitro models that would aid the scientist in the field of neurosciences.

Adapting the principles of "reduction, replacement and refinement" in science signifies a shift in the way we make research. Laboratory pre-screening will require improved in vitro models capable of better characterizing the potential new therapies have for further development. To accelerate this process, it is necessary for old methods to be revised and updated, and new methods to be developed. To succeed in this endeavor, dynamic renewal mechanisms should be put in place, such as the continuous assimilation of new discoveries and their effects on the in vitro models, in order to maintain the validity of the developed methods. 


\section{Acknowledgements}

To close this thesis, I would like to reserve some pages to thank everyone who directly and indirectly took part in the realization of this work.

To Prof. Weis, thank you very much for supporting my research and my candidacy to the Aachen-Maastricht Rotation Program, and for letting me be a part of this new experiment. I appreciate your guidance during the elaboration of this work and your support throughout all the zig-zags this project has taken. I've always appreciated your good humor and your positive attitude.

Prof. Steinbusch, Thank you also for supporting my candidacy to the Aachen-Maastricht Rotation Program. I appreciate the trust you put in me to carry out the Aachen-Maastricht link. Thank you also for our talks, that although sporadic, were none the less long and insightful and provided good advice to help me with my future career in science.

Dr. Brook my Co-Supervisor, Gary, I will always be grateful to you for introducing me to the field of nerve regeneration. Thank you for teaching me the Bio side which complements my Biomedical Engineering education. And foremost, thank you for believing in me and our project. This work went through many unexpected turns and you were always there to help me control the steering wheel on the hardest of the curves. I have learned from you the passion for research, and the importance of doing it well. Thanks for being a good friend.

To my partner in crime Doro, thank you for being there for me all these years, I always enjoyed our spontaneous brainstorming sessions trying to build something new, the long hours in the lab; the motivation to go on even when it felt like there was no way ahead; thanks for being my friend. To my other partner in crime, Tobi, thank you for being the biologist I could come to and ask things when I started working in the lab; you left too quickly. To Ivanna, thank you for your hard work, I am glad I could guide you during your master thesis.

I would also like to thank Prof. Emmanuel Hermans for allowing me to work in his lab at the Universite catolique the Louvain in Brussels. You are a great guy and a big inspiration to me, one of the best professors I have had the chance to work with. A big thank you to the team at UCL, especially, Stephanie and Amelie for their help with my experiments. To the girls in the Lab: Claudia, Aurelie, Marie, Laetitia it was fun to work with you. A very special thanks to my dear friend Sabrina, I came to Brussels thanks to you; you will always be Scientific Buddy. 
To my colleagues in London Dr. Price and Graham Cocks as well as my colleagues here in Germany, Dr. Bozkurt, Dr. Mey, Dr. Klee, Dr. Klinkhammer, Andreas Krebel and Dr. Grehl, thank you for a great collaboration throughout the years.

Katrin Pech, you taught me everything when I first stepped into a biology lab. Thank you. Martina Tape and Beate Kratz, thank you for your support in the IZKF Lab. You taught me how to work in the cell culture lab, which is the basis of this whole story.

To my Uniklinik friends, Agi, Kay, Tina, Sabien, Romy, Haktan and Ron, thank you for your support. You filled my days with nice conversations so that lunch in the cafeteria and work in the lab were always pleasant and amusing. Thanks for your friendship and for your support.

Big thanks to all the diagnostics team, scientific staff and administrative personnel at the Institute of Neuropathology, especially to Doris and Heidi for helping with the administrative work needed for me to be there, thanks for making things work smoothly. Frau Knischewski, Frau Mader, Frau Wiederholt, Frau Krude, Frau Beck and Evi, you have the expertise I needed and were always there to help and teach me. Eva, Andy, Istvan, Anand and Stephen, you are the people I went to when I needed to learn new techniques, thank you guys for your help. Dr. Sellhaus, Dr. Nikolin you know how to make the after lunch conversation interesting, it has helped my German so much.

Marie-Therese and Nicole, thanks for your help with all the administrative work needed in Maastricht. You have always helped me navigate the complicated Dutch bureaucracy. I'm very grateful.

Very special thanks to Prof. Horst Fischer, and his team at the ZWBF. Horst, you showed me the engineering face of biomaterial research and I will always be thankful for that; I have learned a lot from you. I really appreciate you giving me the opportunity to join your young team. And to you guys, Daniela, Armin, Anne, Karolina, Andreas, Jessi, Miriam, Frederik, Stefan, Christian, Mandy, Markus, Roswita, Ines, Mr. Jungwirth, Michael and all the HiWis and Students working in the Lab, thank you for being there for me, I appreciate your friendship very much, you are the best.

To my Aachen family, Ata, Susanna, David and Jonas, I thank you for being there for me, your friendship means a lot to me.

To all of my family, friends and those who have always kept up with my work and keep asking about it. I am finally done, thanks for your support.

A mi Mamá mala, muchas gracias por tu apoyo incondicional, por tu cariño y tu amor. Por recordarme cada vez que la vida sigue y es para vivirse. A mi Papá, aunque ya no estés 184 
aquí, sé que me sigues cuidando y guiando. A los dos les agradezco mucho, por dejarme volar tan lejos tratando de perseguir mi sueño. Zoa, César, Gavin, Nancy, Sofia, Noah, Alana, Ximena y los que vienen, ustedes son mi mayor inspiración y sé que este no es solo mi triunfo, pero el de ustedes también, los quiero mucho. Mia, Pancho, Erik, mi familia aquí en Europa, gracias por estar siempre a mi lado, por su amor y poner siempre una sonrisa en mi rostro al escuchar sus voces. Geri and Maribeth, thanks for always being there for me with your cheers and positive energy, I love you very much.

And to my husband, Rob, thank you for being there for me no matter what, for letting me live my dream, for taking all my rants like a punching bag, for your unconditional support, for your love, for your care. I would've never reached this end without you. 


\section{Curriculum Vitae}

Jose Luis Gerardo Nava was born on 19 of November 1978 in Ciudad Obregón (Mexico). In 1996 he graduated High School with a technical degree in Electronics. Upon a cultural exchange year in Germany, he returned to Mexico to start his university studies at Instituto Tecnologico de Sonora, and was awarded in 2002 the degree of Engineering in Control Electronics. In 2003 he worked at Centro de Investigaciones Biologicas del Noroeste S.C. as part of the laboratory equipment development team. In 2004 he was awarded a CONACYT-DAAD scholarship to pursue his Master's degree in Biomedical Engineering at Aachen University, Germany. After graduating in 2007, he formed part of the scientific team in the Institute of Neuropathology. A year later he was awarded a grant from the Rotation Programme Aachen-Maastricht and started his PhD at the Department of Translational Neurosciences at the University of Maastricht and the Institute of Neuropathology at the University Hospital in Aachen. The results of his PhD project are described in this thesis. 


\section{List of publications}

\section{Journal Articles:}

1. Möllers S, Heschel I, Olde Damink LHH, Schügner F, Deumens R, Müller B, Bozkurt A, Gerardo Nava J, Noth J, Brook GA. Cytocompatibility of a Novel, Longitudinally Microstructured Collagen Scaffold Intended for Nerve Tissue Repair. Tissue Engineering Part A. 2008.

2. Klinkhammer K, Seiler N, Grafahrend D, Gerardo-Nava J, Mey J, Brook GA, Möller M, Dalton P, Klee D. Deposition of electrospun fibers on reactive substrates for in vitro investigations. Tissue Engineering Part C. 2008.

3. Gerardo-Nava J, Führmann J, Klinkhammer K, Seiler N, Klee D, Mey J, Dalton P, Möller M, Brook GA. Neural and glial interactions with electrospun nanofibers in vitro. Nanomedicine. 2009.

4. Gerardo-Nava J, Mayorenko II, Grehl T, Steinbusch HWM, Weis J, Brook GA. Differential pattern of neuroprotection in lumbar, cervical and thoracic spinal cord segments in an organotypic rat model of glutamate-induced excitotoxicity. Journal of Chemical Neuroanatomy. 2013.

5. Grerardo-Nava J, Hodde D, Katona I, Bozkurt A, Grehl T, Steinbusch HWM, Weis J, Brook GA. Spinal cord organotypic slice cultures for the study of regenerating motor axon interactions with 3D scaffolds. Biomaterials. 2014.

6. Dreier A, Lüscher B, Piroth M, Nolte K, Gerardo-Nava J, Goswami A, Eble M, Clusmann H, Weinandy A, Weis J. Cetuximab induces Eme1-mediated DNA repair: A novel mechanism for cetuximab resistance. Neoplasia. 2014.

7. Schickle K, Gerardo-Nava J, Puidokas S, Samadian Anavar S, Bergmann C, Gingter P, Schickle B, Bobzin $\mathrm{K}$, Fischer $\mathrm{H}$. Preparation of spherical calcium phosphate granulates suitable for the biofunctionalization of active brazed titanium alloy coatings. Biomedical Engineering/Biomedizinische Technik. Accepted 2014

8. Gerardo-Nava J, Mayorenko II, Grehl T, Cocks G, Price J, Goursaurd S, Hermanns E, Steinbusch HWM , Weis J, Brook GA. Characterization of the human fetal stem cell line SPC1 and its neuroprotective capacity in an slice culture model for excitotoxicity. In preparation

9. Hodde D, Gerardo-Nava J, Wolke VV, Krebel A, Mey J, Weis J, Brook GA. Directional growth of Schwann cells within nanofibre-containing fibrin hydrogels. In preparation.

10. Duarte Campos DF, Broeckmann M, Blaeser A, Jahr H, Jäkel J, Gerardo-Nava JL, Rath B and Fischer H. Platelet derived- and transforming growth factor induced migration behavior of articular chondrocytes and mesenchymal stem cells in three-dimensionally-printed hydrogels. In preparation.

\section{Book Chapters:}

1. Führmann T, Gerardo-Nava J, Brook GA. Central Nervous System. In: Tissue Engineering. Pallua N, Suschek C Eds. Springer Verlag, London, Heidelberg. In press. 2010

2. Hodde D, Gerardo-Nava JL, Deumens R, Mey J, Brook GA. Electrospinning of Nanofibres for Repair of the Injured Peripheral Nervous System. In: Nanomedicine and the Nervous System. Ed. Preedy VR. Science Publishers, New Hampshire USA. 2012 


\section{Oral Presentations:}

1. Gliotoxicity in a slice culture model for motoneuronal degeneration. 15th Euron PhD Meeting, October 2010, Hasselt, Belgium.

2. Spinal cord organotypic slice culture: a cost effective, versatile and simple in vitro model to study motoneurons and their axons in health or following insult. 3rd Joint Meeting - Belgian-Dutch Neuromuscular Study Club and German Reference Center for Neuromuscular Diseases of the DGNN, May 2014, Vaals, The Netherlands.

\section{Poster Presentations:}

1. Gerardo-Nava J, Führmann J, Klinkhammer K, Seiler N, Klee D, Mey J, Dalton P, Möller M, Brook GA. Investigation of the cytocompatibility of electrospun nanofibres using human neuronal and nonneuronal cell lines. 6. Überregionaler ACRC Workshop, March 2007, Kerkerade, Netherlands

2. Gerardo-Nava J, Grehl T, Cocks G, Price J, Steinbusch HWM , Weis J, Brook GA. Generation of highly enriched populations of immature astrocytes from human foetal neural progenitors. 54th Annual Meeting o the German Society for Neuropathology and Neuroanatomy (DGNN), September 2009, Düsseldorf, Germany

3. Gerardo-Nava J, Grehl T, Cocks G, Price J, Steinbusch HWM, Weis J, Brook GA. Differentiation of rapid proliferating human foetal neural progenitors into immature astrocytes: a potential candidate in astrocyte-replacement strategies. NeuroVisionen 5, September 2009, Bochum, Germany

4. Gerardo-Nava J, Grehl T, Cocks G, Price J, Steinbusch HWM , Weis J, Brook GA. Characterization of immature astrocytes derived from rapid proliferating human foetal neural progenitors: A potential candidate in astrocyte replacement strategies. 14th Euron PhD Meeting, October 2009, Nejmegen, The Netherlands

5. Gerardo-Nava J, Grehl T, Cocks G, Price J, Steinbusch HWM, Weis J, Brook GA. Investigation of a human stem cell-based intervention strategy in an experimental model of amyotrophic lateral sclerosis. 7th International Stem Cell School in Regenerative Medicine, November 2009, Prague, Checz Republic

6. Gerardo-Nava J, Grehl T, Steinbusch HWM, Weis J, Brook GA. Investigations into a slice culture model for motoneuronal degeneration. Neurowoche 2010, September 2010, Mannheim, Germany

7. Grerardo-Nava J, Hodde D, GrehI T, Steinbusch HWM, Weis J, Brook GA. Development of an in vitro system for the assessment of axon growth promoting properties of bioengineered scaffolds. 16th Euron PhD Meeting 2011 Bonn

8. Grerardo-Nava J, Hodde D, Grehl T, Steinbusch HWM, Weis J, Brook GA. Establishment of an in vitro system for the evaluation of axon growth promoting properties of 3D bioengineered scaffolds. NeuroVisionen 7, October 2011, Essen, Germany

9. Grerardo-Nava J, Hodde D, Grehl T, Steinbusch HWM, Weis J, Brook GA. Evaluation of axonal growth in 3D bioengineered constructs using spinal cord organotypic slice cultures. NeuroVisionen 8 , October 2012, Aachen, Germany 